INSTITUTO DE PESQUISAS ENERGÉTICAS E NUCLEARES

Autarquia associada à Universidade de São Paulo

\title{
AVALIAÇÃO DE DISPOSITIVOS DE PROTEÇÃO INDIVIDUAL UTILIZADOS EM RADIOLOGIA DIAGNÓSTICA
}

\section{FERNANDA CRISTINA SALVADOR SOARES}

Dissertação apresentada como parte dos requisitos para obtenção do Grau de Mestre em Ciências na Área de Tecnologia Nuclear - Aplicações

Orientadora:

Dra. Linda V. E. Caldas

São Paulo 


\section{DEDICATÓRIA}

À estrela da minha vida, Patrick, por tanto amor, carinho e compreensão. 


\section{Agradecimentos}

À Dra. Linda V. E. Caldas, pela orientação e carinho na conduta deste trabalho.

Ao amigo Dr. Paulo Costa, pela amizade e co-orientação no desenvolvimento deste trabalho.

À amiga Dra. Denise Nersissian, pela amizade e auxílio durante o desenvolvimento de todas as etapas deste trabalho.

Ao amigo Márcio Bottaro, pela amizade e auxílio na avaliação das incertezas e solução do método do somatório de exponenciais.

Ao Dr. Maurício Moralles, pelo auxílio indireto na solução do método do somatório de exponenciais.

À amiga Dra. Tânia Furquim, pelo incentivo, pela amizade e pelos cafezinhos matinais que me davam mais força para concluir este trabalho.

À amiga Rosana Storel, pelos momentos de risadas e descontração.

Ao amigo Leandro Donizeti, pelo auxílio nos cálculos das derivadas.

A todos os amigos da STADI, em especial Tânia Furquim, Ricardo Saito, Givaldo dos Reis, Leonardo Severo e Leandro Donizeti, pela amizade, apoio e, principalmente, por compensar a minha ausência nas saídas a campo.

A todos os amigos do STAMH do Instituto de Eletrotécnica e Energia da USP, em especial, Edson Barbosa e Camila Mandelli, modelos das fotos deste trabalho.

A todos os amigos do Instituto de Pesquisas Energéticas e Nucleares (IPEN) que me auxiliaram na primeira etapa deste trabalho, em especial, Ana Carolina Bessa e Ana Figueiredo Maia pelos constantes favores.

À minha família, Salvador \& Soares, pelo constante incentivo.

Ao meu marido Patrick, pelo constante carinho, compreensão e incentivo, essenciais para a continuidade deste trabalho.

Ao IPEN, pela oportunidade para o desenvolvimento deste trabalho.

A todos os fabricantes que cederam as amostras, essenciais para o desenvolvimento deste trabalho.

A Deus, pelo dom da vida. 


\title{
AVALIAÇÃO DE DISPOSITIVOS DE PROTEÇÃO INDIVIDUAL UTILIZADOS EM RADIOLOGIA DIAGNÓSTICA
}

\section{FERNANDA CRISTINA SALVADOR SOARES}

\begin{abstract}
Resumo
Neste trabalho foram avaliados aventais de proteção e blindagens de ovário de cinco fabricantes segundo as normas NBR / IEC 61331-1 e NBR / IEC 61331-3 de 2004. Para a determinação da espessura equivalente de atenuação foram aplicadas três metodologias diferentes (interpolação linear, modelo de Archer e somatório de exponenciais), uma vez que a norma não indica como este valor deve ser obtido. Além disso, foram estimadas as incertezas associadas a cada método e a influência do número de medições na incerteza combinada. As características de confecção avaliadas foram: documento acompanhante, projeto, materiais, dimensões e marcação da etiqueta. Para esta avaliação foi elaborado um formulário que contemplava todas as exigências da NBR / IEC 61331-3. Os resultados mostraram uma grande diferença entre os valores de espessura equivalente de atenuação declarados e medidos. A comparação dos resultados das três metodologias aplicadas mostrou que há pouca variação entre os valores obtidos e entre as incertezas associadas nas diferentes metodologias. Foi possível observar também que o número de medições não contribui significativamente para o aumento da incerteza nas três metodologias. A metodologia que melhor se adequou à rotina do laboratório foi a metodologia da interpolação linear com cinco medições da taxa de kerma no ar. A discrepância entre os resultados apresentados neste trabalho e as exigências das normas estudadas mostra a necessidade de tornar compulsória a certificação dos dispositivos de proteção, contribuindo assim para o aumento da proteção radiológica do usuário.
\end{abstract}




\title{
EVALUATION OF PERSONAL PROTECTIVE DEVICES USED IN DIAGNOSTIC RADIOLOGY
}

\section{FERNANDA CRISTINA SALVADOR SOARES}

\begin{abstract}
In this work protective devices of five manufacturers were evaluated according to the NBR/IEC 61331-1 and NBR/IEC 61331-3 standards. Three different methodologies (linear interpolation, Archer model and sum of exponentials) were applied for the determination of the attenuation equivalent, since the standard does not indicate how it must be determined. Moreover, the uncertainties associated to each method, and the influence of the number of measurements in the combined uncertainty were estimated. The evaluated manufacture characteristics were: accompanying document, design, materials, dimensions and label marking. For this evaluation a check list about the requirements of the NBR/IEC 61331-3 standard was elaborated. The results showed a great difference between nominal and measured attenuation equivalent values. The comparison of the results using the three methodologies showed small variations among the obtained values and among the associated uncertainties in the different methodologies. It was possible to observe that the number of measurements does not contribute significantly for the increase of the uncertainty in all three methodologies. The best methodology for the laboratory routine is the linear interpolation methodology, with five measurements for each air kerma rate value. The discrepancy between the results obtained in this work and the requirements of the applied standards show the need to adopt a compulsory certification process for protective devices, thus contributing for the increase of the radiation protection of the users.
\end{abstract}




\section{SUMÁRIO}

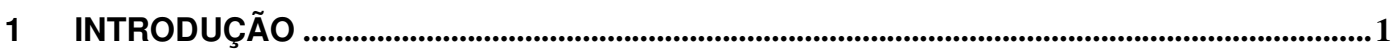

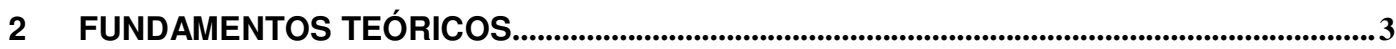

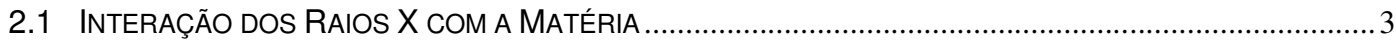

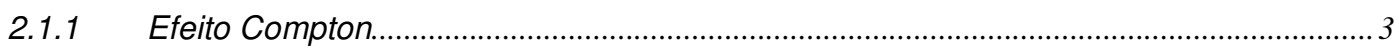

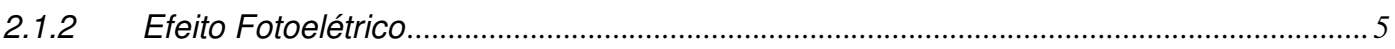

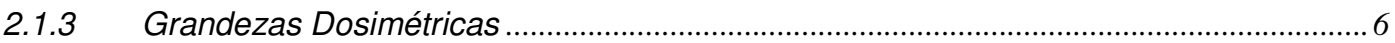

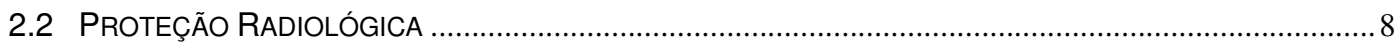

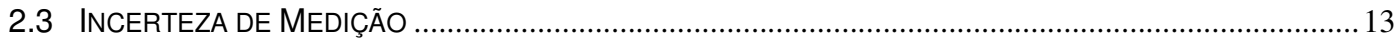

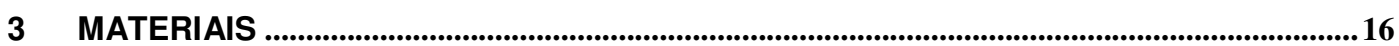

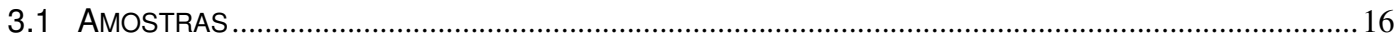

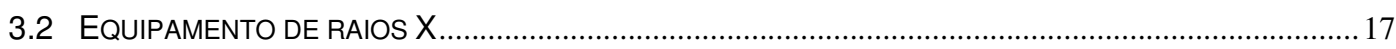

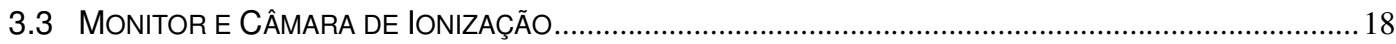

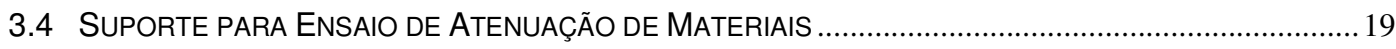

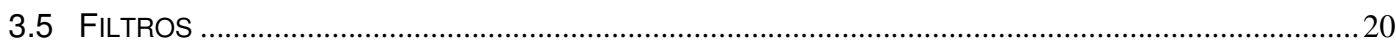

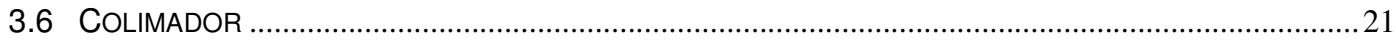

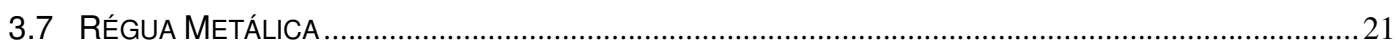

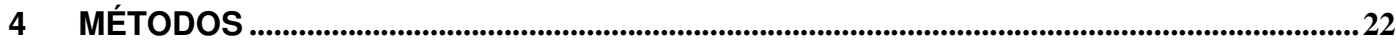

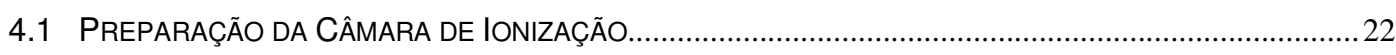

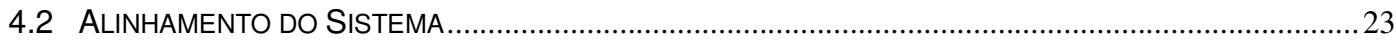

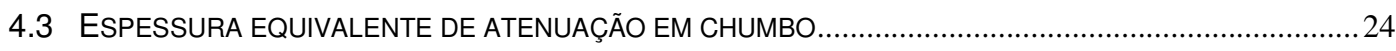

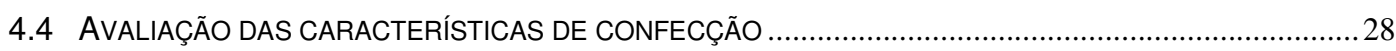

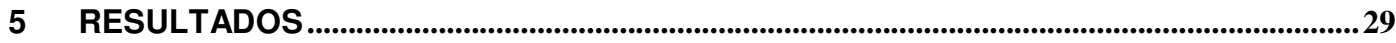

5.1 COMERCIALIZAÇÃO DE ACESSÓRIOS DE PROTEÇÃO RADIOLÓGICA NO BRASIL..................................29

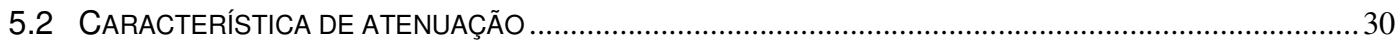

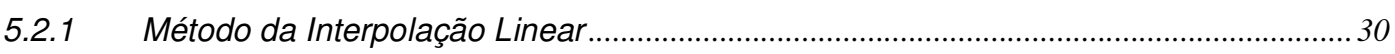

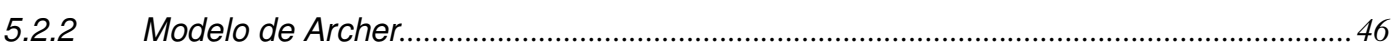

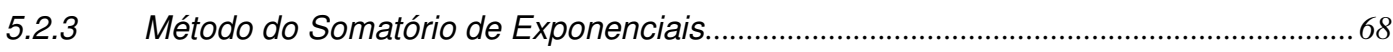

5.2.4 Re-avaliação da Espessura Equivalente de Atenuação dos Aventais Modificados pelo

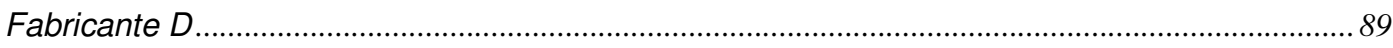

5.2.5 Comparação entre as três Metodologias Avaliadas para Determinação da Espessura

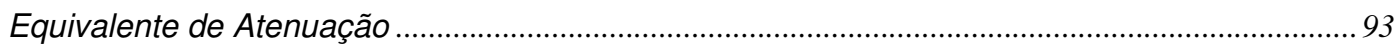

5.2.6 Avaliação da Reprodutibilidade da Espessura Equivalente de Atenuação .................... 94

5.2.7 Avaliação do Percentual de Transmissão Para os Dispositivos de Proteção

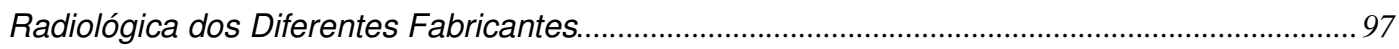




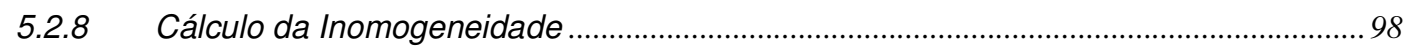

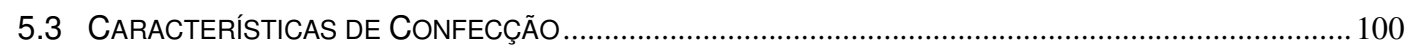

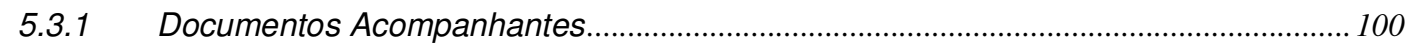

5.3.2 Prescrições Gerais na Marcação, Projeto e Materiais...................................................... 102

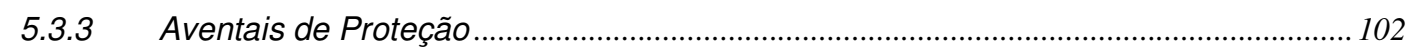

5.3.4 Re-avaliação da Espessura Equivalente de Atenuação dos Aventais Modificados pelo

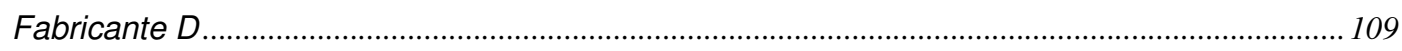

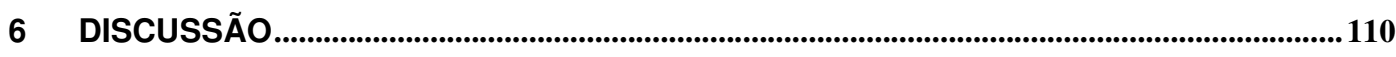

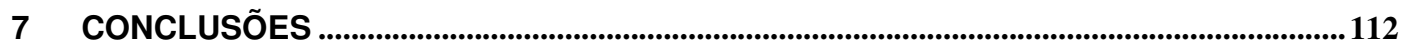

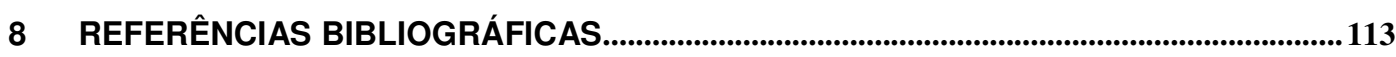




\section{ÍNDICE DE FIGURAS}

Figura 1 - Representação do efeito Compton durante um procedimento radiográfico ${ }^{19}{ }^{19}$

Figura 2 - Interação dos fótons de raios X com o átomo por meio do espalhamento Compton ${ }^{19} 4$

Figura 3 - Interação dos fótons de raios X com o átomo por meio da absorção fotoelétrica ${ }^{19}{ }^{6}$

Figura 4 - llustração da lei do inverso do quadrado da distância 10

Figura 5 - Requisitos de proteção radiológica durante um procedimento em medicina veterinária 11

Figura 6 - Requisitos de proteção radiológica em medicina veterinária quando não há barreiras fixas $^{24}$ 12

Figura 7 - Defeitos no material atenuador: (a) fissura na região torácica de um avental protetor; (b) rasgo na região posterior dos ombros de um avental protetor; (c) luvas de proteção aparentemente em bom estado e sua imagem radiográfica (d) mostrando uma grande falha no material atenuador.

Figura 8 - Exemplo de amostras recebidas: (a) avental de proteção leve; (b) avental de proteção fechado leve; (c) avental de proteção fechado leve - costas; (d) blindagem de ovário

Figura 9 - (a) Equipamento de raios X Philips MG325 utilizado nos testes; (b) Painel de comando do equipamento 18

Figura 10 - Câmara de ionização $6 \mathrm{~cm}^{3}$ Radcal Corporation e Monitor 9015 Radcal Corporation utilizados nos testes. 19

Figura 11 - Suporte para ensaio de atenuação de materiais desenvolvido pelo IEE/USP. Em destaque: diafragma utilizado para geometria de feixe estreito e anel redutor, utilizado para determinação da inomogeneidade do material atenuador 20

Figura 12 - Filtros utilizados nos testes: (a) filtros de cobre e (b) filtros de chumbo padrão _ 20

Figura 13 - (a) Colimador utilizado e (b) suas principais dimensões 21

Figura 14 - Monitoração da taxa de kerma no ar remotamente: uma câmera de vídeo foi utilizada para transmitir os dados via Internet 22

Figura 15 - Alinhamento do suporte de materiais com o tubo de raios $X$ : (a) posicionamento do écran no suporte de materiais; (b) alinhamento do feixe de raios $X$ com o écran, monitorado via câmera de vídeo

Figura 16 - Alinhamento da câmara de ionização com o tubo de raios $X$ e o suporte de materiais: (a) écran fixado na câmara de ionização; (b) alinhamento da câmara de ionização com o feixe de raios $X$, monitorado via câmera de vídeo 
Figura 17 - Geometria de feixe estreito segundo a norma NBR / IEC 61331-1 $1^{13}$

Figura 18 - Posicionamento dos filtros de chumbo padrão para a obtenção da curva de atenuação 26

Figura 19 - Exemplo do posicionamento da amostra para a determinação da espessura equivalente de atenuação

Figura 20 - Resultado da pesquisa com relação ao número de empresas que comercializam acessórios de proteção radiológica 29

Figura 21 - Obtenção da espessura equivalente de atenuação em chumbo por meio da interpolação linear 30

Figura 22 - Determinação da espessura equivalente de atenuação e incerteza combinada do método segundo o modelo de Archer: as setas azuis representam a primeira etapa enquanto que as setas laranjas representam a segunda etapa 48

Figura 23 - Verificação da reprodutibilidade do equivalente de atenuação dos dispositivos com equivalência nominal igual a 0,25 mmPb e 0,50 mmPb, para as tensões de $80 \mathrm{kV}, 100 \mathrm{kV}$ e $150 \mathrm{kV}$

Figura 24 - Avaliação do percentual de transmissão dos dispositivos com equivalência igual a $0,25 \mathrm{mmPb}$ e $0,50 \mathrm{mmPb}$ pertencentes aos diferentes fabricantes ( $A, B, C, D, E$ e $D$ re-teste) na faixa de tensão utilizada em radiodiagnóstico

Figura 25 - Resultado da avaliação dos documentos acompanhantes dos aventais de proteção e das blindagens de ovário 101

Figura 26 - Resultado da classificação por categoria dos aventais de proteção avaliados _ 105

Figura 27 - Resultado da verificação se os aventais de proteção cobrem a parte anterior do corpo, da garganta, todo o esterno e os ombros, descendo pelo menos até o joelho 105

Figura 28 - (a) Medição do comprimento e (b) da largura dos aventais de proteção 106

Figura 29 - Resultados da classificação dos aventais de proteção por tamanho padronizado 106 Figura 30 - Requisitos de confecção dos aventais de confecção: (a) a largura do material atenuador nos ombros deve ser maior que $11 \mathrm{~cm}$; (b) deve haver pelo menos $15 \mathrm{~cm}$ de material atenuador na região posterior dos ombros 107

Figura 31 - Resultado da avaliação dos aventais de proteção com relação à presença de material atenuador na região posterior dos ombros. 


\section{ÍNDICE DE TABELAS}

Tabela 1 - Quantidade de aventais de proteção e de blindagens de ovário cedida pelos fabricantes 17

Tabela 2 - Composição química dos filtros de chumbo utilizados como material de referência 21 Tabela 3 - Qualidades de radiação descritas pela NBR/IEC 61331-1 e utilizadas nos testes_ 26

Tabela 4 - Resultados da determinação da espessura equivalente de atenuação em chumbo, incerteza e diferença percentual entre o valor calculado e o valor nominal, para os aventais de proteção e blindagens de ovário do Fabricante A, em 80 kV. Método: interpolação linear 35

Tabela 5 - Resultados da determinação da espessura equivalente de atenuação em chumbo, incerteza e diferença percentual entre o valor calculado e o valor nominal, para os aventais de proteção e blindagens de ovário Fabricante A, em 100 kV. Método: interpolação linear 36

Tabela 6 - Resultados da determinação da espessura equivalente de atenuação em chumbo, incerteza e diferença percentual entre o valor calculado e o valor nominal, para os aventais de proteção e blindagens de ovário do Fabricante A, em 150 kV. Método: interpolação linear __ 37

Tabela 7 - Resultados da determinação da espessura equivalente de atenuação em chumbo, incerteza e diferença percentual entre o valor calculado e o valor nominal, para os aventais de proteção e blindagens de ovário do Fabricante B, em 80 kV. Método: interpolação linear 38

Tabela 8 - Resultados da determinação da espessura equivalente de atenuação em chumbo, incerteza e diferença percentual entre o valor calculado e o valor nominal, para os aventais de proteção e blindagens de ovário do Fabricante B, em 100 kV. Método: interpolação linear 38

Tabela 9 - Resultados da determinação da espessura equivalente de atenuação em chumbo, incerteza e diferença percentual entre o valor calculado e o valor nominal, para os aventais de proteção e blindagens de ovário do Fabricante B, em 150 kV. Método: interpolação linear _ 39 Tabela 10 - Resultados da determinação da espessura equivalente de atenuação em chumbo, incerteza e diferença percentual entre o valor calculado e o valor nominal, para os aventais de proteção do Fabricante $C$, em 80 kV. Método: interpolação linear

Tabela 11 - Resultados da determinação da espessura equivalente de atenuação em chumbo, incerteza e diferença percentual entre o valor calculado e o valor nominal, para os aventais de proteção do Fabricante C, em 100 kV. Método: interpolação linear 40

Tabela 12 - Resultados da determinação da espessura equivalente de atenuação em chumbo, incerteza e diferença percentual entre o valor calculado e o valor nominal, para os aventais de proteção do Fabricante C em 150 kV. Método: interpolação linear 40

Tabela 13 - Resultados da determinação da espessura equivalente de atenuação em chumbo, incerteza e diferença percentual entre o valor calculado e o valor nominal, para os aventais de proteção do Fabricante D em 80 kV. Método: interpolação linear 
Tabela 14 - Resultados da determinação da espessura equivalente de atenuação em chumbo, incerteza e diferença percentual entre o valor calculado e o valor nominal, para os aventais de proteção do Fabricante $D$ em 100 kV. Método: interpolação linear 42

Tabela 15 - Resultados da determinação da espessura equivalente de atenuação em chumbo, incerteza e diferença percentual entre o valor calculado e o valor nominal, para os aventais de proteção do Fabricante D, em 150 kV. Método: interpolação linear

Tabela 16 - Resultados da determinação da espessura equivalente de atenuação em chumbo, incerteza e diferença percentual entre o valor calculado e o valor nominal, para os aventais de proteção do Fabricante E, em 80 kV. Método: interpolação linear 44

Tabela 17 - Resultados da determinação da espessura equivalente de atenuação em chumbo, incerteza e diferença percentual entre o valor calculado e o valor nominal, para os aventais de proteção do Fabricante E, em 100 kV. Método: interpolação linear 44

Tabela 18 - Resultados da determinação da espessura equivalente de atenuação em chumbo, incerteza e diferença percentual entre o valor calculado e o valor nominal, para os aventais de proteção do Fabricante E, em 150 kV. Método: interpolação linear 45

Tabela 19 - Parâmetros de ajustes iniciais em $80 \mathrm{kV}\left(\alpha, \beta, \gamma, y_{0}, \chi_{\text {red }}^{2}\right.$ e v) para a função do modelo de Archer 49

Tabela 20 - Parâmetros de ajustes iniciais em $100 \mathrm{kV}\left(\alpha, \beta, \gamma, y_{0}, \chi_{\text {red }}^{2}\right.$ e v) para a função do modelo de Archer

Tabela 21 - Parâmetros de ajustes iniciais em $150 \mathrm{kV}\left(\alpha, \beta, \gamma, y_{0}, \chi_{\text {red }}^{2}\right.$ e v) para a função do modelo de Archer

Tabela 22 - Parâmetros de ajustes finais em $80 \mathrm{kV}\left(\alpha, \beta, \gamma, y_{0}, \chi^{2}\right.$ red $\left.e v\right)$ para a função do modelo de Archer 52

Tabela 23 - Parâmetros de ajustes finais em $100 \mathrm{kV}\left(\alpha, \beta, \gamma, y_{0}, \chi_{\text {red }}^{2}\right.$ e v) para a função do modelo de Archer 53

Tabela 24 - Parâmetros de ajustes finais em $150 \mathrm{kV}\left(\alpha, \beta, \gamma, y_{0}, \chi_{\text {red }}^{2}\right.$ e v) para a função do modelo de Archer 54

Tabela 25 - Resultados da determinação da espessura equivalente de atenuação em chumbo, incerteza e diferença percentual entre o valor calculado e o valor nominal, para as amostras do Fabricante A, em 80 kV. Método: modelo de Archer 56

Tabela 26 - Resultados da determinação da espessura equivalente de atenuação em chumbo, incerteza e diferença percentual entre o valor calculado e o valor nominal, para as amostras do Fabricante A, em 100 kV. Método: modelo de Archer 57 
Tabela 27 - Resultados da determinação da espessura equivalente de atenuação em chumbo, incerteza e diferença percentual entre o valor calculado e o valor nominal, para as amostras do Fabricante A, em 150 kV. Método: modelo de Archer 58

Tabela 28 - Resultados da determinação da espessura equivalente de atenuação em chumbo, incerteza e diferença percentual entre o valor calculado e o valor nominal, para as amostras do Fabricante B, em 80 kV. Método: modelo de Archer 59

Tabela 29 - Resultados da determinação da espessura equivalente de atenuação em chumbo, incerteza e diferença percentual entre o valor calculado e o valor nominal, para as amostras do Fabricante B, em 100 kV. Método: modelo de Archer 60

Tabela 30 - Resultados da determinação da espessura equivalente de atenuação em chumbo, incerteza e diferença percentual entre o valor calculado e o valor nominal, para as amostras do Fabricante B, em 150 kV. Método: modelo de Archer 61

Tabela 31 - Resultados da determinação da espessura equivalente de atenuação em chumbo, incerteza e diferença percentual entre o valor calculado e o valor nominal, para as amostras do Fabricante C, em 80 kV. Método: modelo de Archer 61

Tabela 32 - Resultados da determinação da espessura equivalente de atenuação em chumbo, incerteza e diferença percentual entre o valor calculado e o valor nominal, para as amostras do Fabricante C, em 100 kV. Método: modelo de Archer 62

Tabela 33 - Resultados da determinação da espessura equivalente de atenuação em chumbo, incerteza e diferença percentual entre o valor calculado e o valor nominal, para as amostras do Fabricante C, em 150 kV. Método: modelo de Archer 62

Tabela 34 - Resultados da determinação da espessura equivalente de atenuação em chumbo, incerteza e diferença percentual entre o valor calculado e o valor nominal, para as amostras do Fabricante D, em $80 \mathrm{kV}$. Método: modelo de Archer 63

Tabela 35 - Resultados da determinação da espessura equivalente de atenuação em chumbo, incerteza e diferença percentual entre o valor calculado e o valor nominal, para as amostras do Fabricante D, em $100 \mathrm{kV}$. Método: modelo de Archer 64

Tabela 36 - Resultados da determinação da espessura equivalente de atenuação em chumbo, incerteza e diferença percentual entre o valor calculado e o valor nominal, para as amostras do Fabricante D, em 150 kV. Método: modelo de Archer 65

Tabela 37 - Resultados da determinação da espessura equivalente de atenuação em chumbo, incerteza e diferença percentual entre o valor calculado e o valor nominal, para as amostras do Fabricante E, em 80 kV. Método: modelo de Archer 66

Tabela 38 - Resultados da determinação da espessura equivalente de atenuação em chumbo, incerteza e diferença percentual entre o valor calculado e o valor nominal, para as amostras do Fabricante E, em 100 kV. Método: modelo de Archer 66 
Tabela 39 - Resultados da determinação da espessura equivalente de atenuação em chumbo, incerteza e diferença percentual entre o valor calculado e o valor nominal, para as amostras do Fabricante E, em 150 kV. Método: modelo de Archer 67

Tabela 40 - Parâmetros de ajustes iniciais em $80 \mathrm{kV}\left(A_{1}, t_{1}, A_{2}, t_{2}, \chi_{\text {red }}^{2}\right.$ e v) para a função do somatório de exponenciais

Tabela 41 - Parâmetros de ajustes iniciais em $100 \mathrm{kV}\left(A_{1}, t_{1}, A_{2}, t_{2}, \chi^{2}\right.$ red e v) para a função do somatório de exponenciais

Tabela 42 - Parâmetros de ajustes iniciais em $150 \mathrm{kV}\left(A_{1}, t_{1}, A_{2}, t_{2}, \chi_{\text {red }}^{2}\right.$ e v) para a função do somatório de exponenciais

Tabela 43 - Parâmetros de ajustes finais em $80 \mathrm{kV}\left(A_{1}, t_{1}, A_{2}, t_{2}, \chi_{\text {red }}^{2}\right.$ e v) para a função do somatório de exponenciais 74

Tabela 44 - Parâmetros de ajustes finais em $100 \mathrm{kV}\left(A_{1}, t_{1}, A_{2}, t_{2}, \chi_{\text {red }}^{2}\right.$ e $\left.v\right)$ para a função do somatório de exponenciais 75

Tabela 45 - Parâmetros de ajustes finais em $150 \mathrm{kV}\left(A_{1}, t_{1}, A_{2}, t_{2}, \chi_{\text {red }}^{2}\right.$ e $\left.v\right)$ para a função do somatório de exponenciais

Tabela 46 - Resultados da determinação da espessura equivalente de atenuação em chumbo, incerteza e diferença percentual entre o valor calculado e o valor nominal, para as amostras do Fabricante A, em 80 kV. Método: somatório de exponenciais 78

Tabela 47 - Resultados da determinação da espessura equivalente de atenuação em chumbo, incerteza e diferença percentual entre o valor calculado e o valor nominal, para as amostras do Fabricante A, em 100 kV. Método: somatório de exponenciais 79

Tabela 48 - Resultados da determinação da espessura equivalente de atenuação em chumbo, incerteza e diferença percentual entre o valor calculado e o valor nominal, para as amostras do Fabricante A, em $150 \mathrm{kV}$. Método: somatório de exponenciais 80

Tabela 49 - Resultados da determinação da espessura equivalente de atenuação em chumbo, incerteza e diferença percentual entre o valor calculado e o valor nominal, para as amostras do Fabricante $B$, em $80 \mathrm{kV}$. Método: somatório de exponenciais 81

Tabela 50 - Resultados da determinação da espessura equivalente de atenuação em chumbo, incerteza e diferença percentual entre o valor calculado e o valor nominal, para as amostras do Fabricante B, em $100 \mathrm{kV}$. Método: somatório de exponenciais 81 Tabela 51 - Resultados da determinação da espessura equivalente de atenuação em chumbo, incerteza e diferença percentual entre o valor calculado e o valor nominal, para as amostras do Fabricante B, em 150 kV. Método: somatório de exponenciais 82 
Tabela 52 - Resultados da determinação da espessura equivalente de atenuação em chumbo, incerteza e diferença percentual entre o valor calculado e o valor nominal, para as amostras do Fabricante C, em 80 kV. Método: somatório de exponenciais 82

Tabela 53 - Resultados da determinação da espessura equivalente de atenuação em chumbo, incerteza e diferença percentual entre o valor calculado e o valor nominal, para as amostras do Fabricante C, em 100 kV. Método: somatório de exponenciais 83

Tabela 54 - Resultados da determinação da espessura equivalente de atenuação em chumbo, incerteza e diferença percentual entre o valor calculado e o valor nominal, para as amostras do Fabricante C, em $150 \mathrm{kV}$. Método: somatório de exponenciais_ 83

Tabela 55 - Resultados da determinação da espessura equivalente de atenuação em chumbo, incerteza e diferença percentual entre o valor calculado e o valor nominal, para as amostras do Fabricante $D$, em $80 \mathrm{kV}$. Método: somatório de exponenciais 84

Tabela 56 - Resultados da determinação da espessura equivalente de atenuação em chumbo, incerteza e diferença percentual entre o valor calculado e o valor nominal, para as amostras do Fabricante D, em $100 \mathrm{kV}$. Método: somatório de exponenciais 85

Tabela 57 - Resultados da determinação da espessura equivalente de atenuação em chumbo, incerteza e diferença percentual entre o valor calculado e o valor nominal, para as amostras do Fabricante D, em $150 \mathrm{kV}$. Método: somatório de exponenciais 86

Tabela 58 - Resultados da determinação da espessura equivalente de atenuação em chumbo, incerteza e diferença percentual entre o valor calculado e o valor nominal, para as amostras do Fabricante E, em 80 kV. Método: somatório de exponenciais 87

Tabela 59 - Resultados da determinação da espessura equivalente de atenuação em chumbo, incerteza e diferença percentual entre o valor calculado e o valor nominal, para as amostras do Fabricante E, em 100 kV. Método: somatório de exponenciais 87

Tabela 60 - Resultados da determinação da espessura equivalente de atenuação em chumbo, incerteza e diferença percentual entre o valor calculado e o valor nominal, para as amostras do Fabricante E, em 150 kV. Método: somatório de exponenciais 88

Tabela 61 - Resultados da re-avaliação dos aventais de proteção do Fabricante D. Método: interpolação linear 90

Tabela 62 - Resultados da re-avaliação dos aventais de proteção do Fabricante D. Método: modelo de Archer 91

Tabela 63 - Resultados da re-avaliação dos aventais de proteção do Fabricante D. Método: somatório de exponenciais 92

Tabela 64 - Comparação dos resultados utilizando as três metodologias avaliadas na tensão de $100 \mathrm{kV}$ entre todos os fabricantes. 94 
Tabela 65 - Intervalo de variação do percentual de transmissão dos dispositivos de proteção com equivalência igual a 0,25 mmPb e 0,50 mmPb, em $100 \mathrm{kV}$

Tabela 66 - Inomogeneidade do material atenuador dos dispositivos de proteção em $100 \mathrm{kV} 99$ Tabela 67 - Tamanhos padronizados de aventais de proteção segundo a NBR / IEC 61331-3 $3^{15}$ de 2004 104 


\section{INTRODUÇÃO}

A qualidade de dispositivos de proteção individual contra os efeitos da radiação ionizante tem sido alvo de pesquisas tanto com referência à avaliação crítica da qualidade e da aplicação de dispositivos de proteção individual ${ }^{1-4}$, quanto na detecção de defeitos que possam aparecer devido a seu uso continuado ${ }^{5,6}$.

Um estudo realizado por Christodoulou et al $^{7}$ apresentou resultados da avaliação de aventais de proteção utilizados em departamentos de radiologia utilizando medições da transmissão da radiação ionizante. Os aventais avaliados eram provenientes de oito diferentes fornecedores que atuam nos Estados Unidos e seus resultados mostraram algumas discrepâncias entre os valores de equivalência em chumbo declarados e as medições realizadas pelos autores. Finnerty e Brennam ${ }^{8}$ também encontraram diferenças entre os valores da espessura equivalente de atenuação declarada e calculada, e os resultados apontaram a importância da vistoria de defeitos e a necessidade de se verificar as informações descritas pelos fabricantes de modo a garantir que os aventais de proteção promovam o nível de proteção que é esperado.

Diversos autores ${ }^{9-12}$ também vêm estudando as propriedades de atenuação e as metodologias de aplicação de dispositivos de proteção coletiva. Estes materiais, apresentados geralmente como dispositivos estruturais instalados no ambiente onde a radiação é emitida, não fazem parte do escopo do presente trabalho. Contudo, algumas metodologias experimentais a serem utilizadas neste trabalho têm grande semelhança com as adotadas por estes autores.

No segundo semestre de 2004, foi publicada no Brasil pela Associação Brasileira de Normas Técnicas (ABNT) uma série de normas NBR / IEC 61331 13 -15. Destas normas, a NBR / IEC $61331-1^{13}$ define os parâmetros físicos a serem utilizados e as geometrias que devem ser adotadas nos experimentos para a caracterização de materiais de radioproteção. Esta norma se aplica tanto a materiais estruturais (argamassas baritadas, lençóis de chumbo, visores plumbíferos, etc.) quanto à matéria prima utilizada em dispositivos de proteção individual (aventais, blindagens de ovário etc.). A norma NBR / IEC $61331-2^{14}$ determina as características construtivas que devem ter os visores plumbíferos para serem adotados em portas, paredes ou biombos de salas radiológicas. Estes dispositivos não serão avaliados no presente projeto. Por fim, a norma NBR / IEC $61331-3^{15}$ define as propriedades de confecção que devem ser adotadas pelos fabricantes de forma a garantir a adequada proteção dos usuários de vestimentas desta natureza. 
Nestas normas são definidos parâmetros que permitem a caracterização destes materiais em termos de atenuação à radiação ionizante. Estes parâmetros são a razão de atenuação, o fator de crescimento, a inomogeneidade e a espessura equivalente de atenuação, indicando o chumbo como referência. Tais parâmetros devem ser adequadamente determinados para que seja possível calcular as espessuras necessárias dos materiais a serem instalados em paredes, portas ou visores ou das vestimentas protetoras a serem utilizadas por profissionais ocupacionalmente expostos ou por acompanhantes ${ }^{16}$.

Tendo em vista a importância destes dispositivos para proteção radiológica, este trabalho tem como objetivo a avaliação de aventais de proteção e blindagens de ovário, disponíveis comercialmente, quanto à adequação de seus padrões de confecção e das propriedades de atenuação. As propriedades de atenuação estudadas serão a espessura equivalente de atenuação e a inomogeneidade.

Além disso, o trabalho tem ainda como objetivo comparar três metodologias de ajuste da curva de atenuação do chumbo padrão e o número de medições necessárias para a determinação da taxa de kerma no ar, por meio do cálculo de incertezas destes métodos. A norma NBR / IEC $61331-1^{13}$ descreve a geometria e as qualidades de radiação que devem ser utilizadas nesta determinação, porém não especifica qual é a metodologia de ajuste da curva de atenuação do chumbo padrão que deve ser utilizada. 


\section{FUNDAMENTOS TEÓRICOS}

\subsection{INTERAÇÃo dos RAIOS X COM A MATÉRIA}

Os fótons de raios $X$ são gerados por meio da interação dos elétrons em alta velocidade com 0 alvo. Esses fótons de raios $X$ ao passarem através de um objeto, podem interagir pelos processos de absorção e espalhamento, ou ainda passar através dele sem sofrer nenhuma alteração ${ }^{17,18}$.

No processo de absorção, toda a energia do fóton é cedida para o meio, enquanto que no processo de espalhamento, somente uma parte da energia é perdida. Ambos os processos caracterizam o processo de atenuação, uma vez que a atenuação é a redução do número de fótons que passam através da matéria.

É impossível saber com certeza o que irá acontecer com um único fóton que passa através de um tecido biológico, pois os processos de interação com a matéria são aleatórios. Porém, quando se trata de um grande número de fótons, é possível saber o que irá acontecer na média. Os cinco possíveis tipos de interação dos fótons de raios $X$ com a matéria são: espalhamento coerente, efeito Compton, efeito fotoelétrico, produção de pares e fotodesintegração. Destes, os importantes na faixa de energia de radiodiagnóstico são: o efeito Compton e o efeito fotoelétrico ${ }^{19}$.

\subsubsection{Efeito Compton}

O efeito Compton, também conhecido como espalhamento incoerente, é responsável pela maior parte da radiação espalhada que é produzida durante um procedimento radiográfico, como mostra a Figura 1.

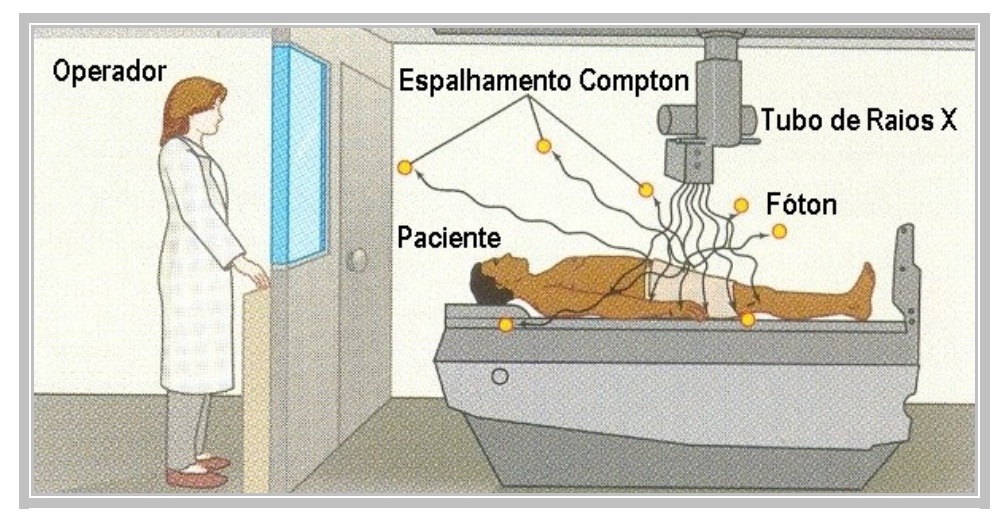

Figura 1 - Representação do efeito Compton durante um procedimento radiográfico ${ }^{19}$ 
Neste processo, ilustrado na Figura 2, o fóton de raios $X$ interage com um elétron de uma camada externa do átomo do objeto irradiado. Ao interagir com 0 elétron, o fóton incidente cede parte da sua energia para o elétron, que é ejetado para fora do átomo, e o novo fóton (com energia diferente) continua o seu trajeto, porém agora em uma nova direção.

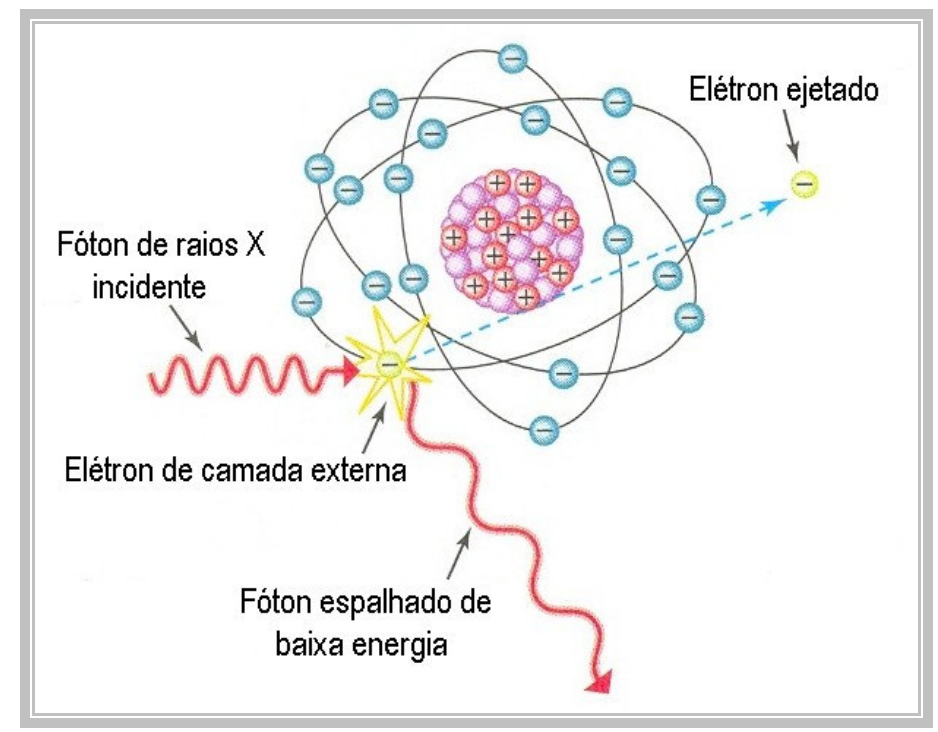

\section{Figura 2 - Interação dos fótons de raios $\mathrm{X}$ com o átomo por meio do espalhamento Compton ${ }^{19}$}

O elétron que foi ejetado possui um excesso de energia cinética e é capaz de ionizar átomos. Ele perde esse excesso de energia por meio de uma série de interações com átomos vizinhos e depois se recombina com um átomo que precisa de um elétron.

O fóton espalhado pode sofrer novas interações, pelos processos do efeito fotoelétrico ou efeito Compton, ou ainda pode emergir do paciente, contribuindo assim para a radiação secundária na sala de exames.

A probabilidade de ocorrer uma interação por meio do processo do efeito Compton aumenta com o aumento da energia. 


\subsubsection{Efeito Fotoelétrico}

A interação dos fótons de raios $X$ com a matéria pelo efeito fotoelétrico é muito importante na faixa de energia de radiodiagnóstico (incluindo a faixa de mamografia), de 23 a $150 \mathrm{kV}$. Este processo ocorre através da interação dos fótons de raios $\mathrm{X}$ com elétrons das camadas mais internas do átomo, em geral na camada $\mathrm{K}$.

No efeito fotoelétrico, representado na Figura 3, o fóton de raios $X$ ao interagir com o elétron cede toda a sua energia para ele, ejetando-o do átomo (chamado de fotoelétron) e criando uma vacância. Esta vacância é preenchida por um elétron de uma camada mais externa do átomo que libera o seu excesso de energia em forma de um outro fóton (chamado de fóton característico). A vacância criada na camada mais externa também será preenchida por um elétron proveniente de uma camada superior, que também liberará seu excesso de energia por meio da emissão de um fóton característico. Este processo cessa quando o átomo atinge o seu equilíbrio eletrônico.

O fotoelétron possui energia igual ao do fóton incidente menos a energia de ligação do elétron à camada do átomo. Ele pode interagir com outros átomos causando excitação ou ionização até que toda a sua energia seja cedida para o meio.

Assim, os produtos do efeito fotoelétrico são os fotoelétrons e os fótons característicos e quando as energias dos produtos são absorvidas localmente no tecido humano, a dose no paciente e o potencial para risco biológico aumentam.

A probabilidade de ocorrência do efeito fotoelétrico depende da energia do fóton incidente e do número atômico dos átomos que compõem o objeto irradiado. Ela aumenta acentuadamente quando a energia do fóton incidente diminui e o número atômico do objeto irradiado aumenta. 


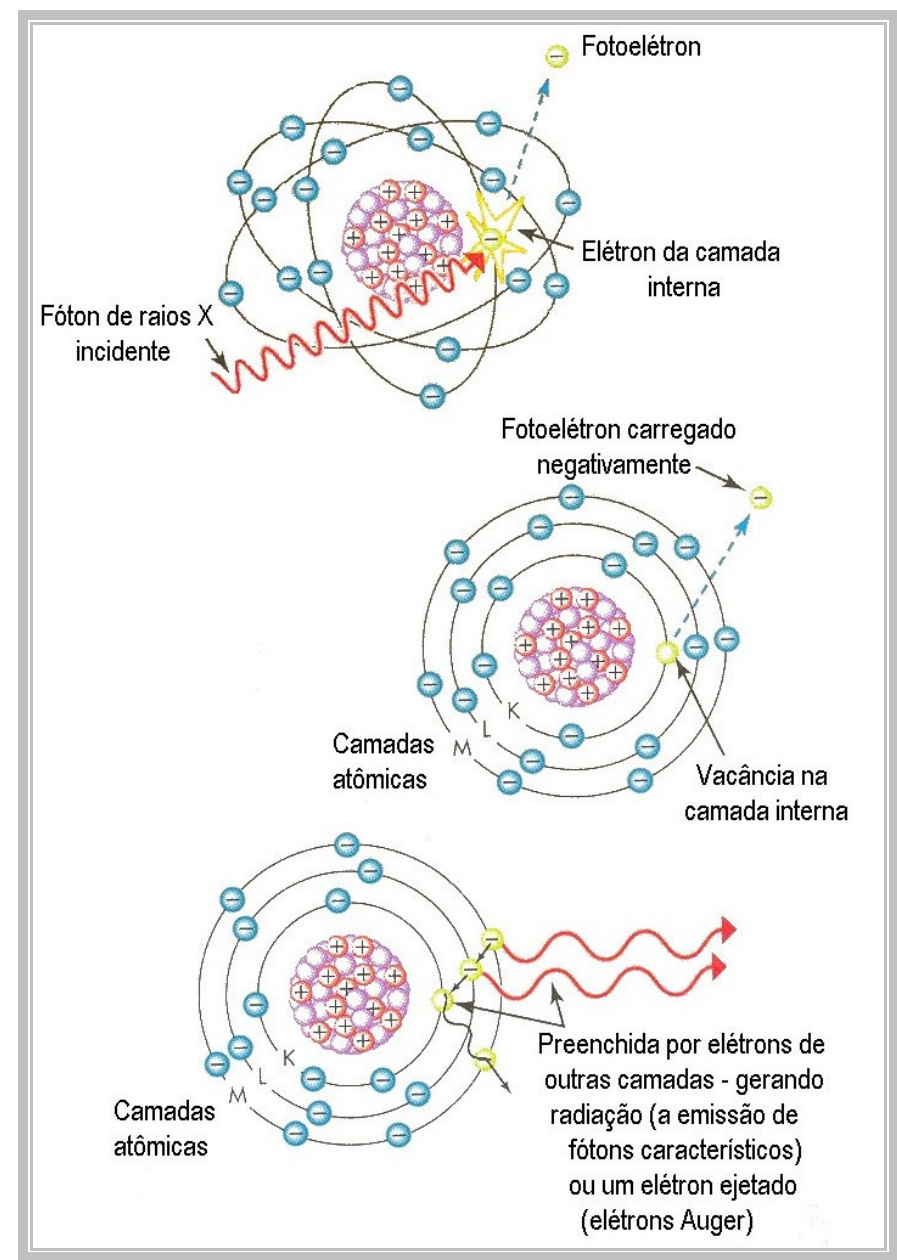

Figura 3 - Interação dos fótons de raios $X$ com o átomo por meio da absorção fotoelétrica ${ }^{19}$

\subsubsection{Grandezas Dosimétricas}

Os efeitos da radiação na matéria dependem de fatores como tipo da radiação e das interações da radiação com a matéria. As grandezas dosimétricas correlacionam as medidas físicas com os efeitos reais ou efetivos e são, em essência, produtos de grandezas radiométricas e coeficientes de interação ${ }^{20}$.

As grandezas dosimétricas apresentadas a seguir estão descritas no relatório da ICRU Report $60^{20}$.

\section{$\operatorname{Kerma}(K)$}

A grandeza kerma (kinetic energy released per unit mass) é o quociente de $d E_{t r}$ por $d m$, onde $d E_{t r}$ é a soma da energia cinética inicial de todas as partículas 
carregadas liberadas por partículas não carregadas em uma massa $d m$ de material, como mostra a Equação 1. A unidade do kerma é J.kg-1 e o nome especial para esta unidade é gray (Gy). É necessário definir o meio para a expressão do valor de kerma, normalmente o ar ou a água

$$
K=\frac{d E_{t r}}{d m}
$$

Equação 1

A taxa de kerma, $\dot{K}$, é o quociente de $d K$ por $d t$, onde $d K$ é o incremento do kerma no intervalo de tempo $d t$, como mostra a Equação 2. A unidade da taxa de kerma é $\mathrm{J}^{\mathrm{kg}}{ }^{-1} \cdot \mathrm{s}^{-1}$ e se o nome especial gray está sendo utilizado, a unidade é gray por segundo $\left(G y \cdot s^{-1}\right)$.

$$
\dot{K}=\frac{d K}{d t}
$$

Equação 2

\section{Exposição $(X)$}

A grandeza exposição é o quociente de $d Q$ por $d m$, onde $d Q$ é o valor absoluto da carga total de íons de um sinal produzido no ar quando todos os elétrons e pósitrons liberados ou criados pelos fótons no ar de massa $d m$ são completamente freados no ar, como mostra a Equação 3. A unidade da grandeza exposição é o C.kg ${ }^{-1}$.

$$
X=\frac{d Q}{d m}
$$

Equação 3

A taxa de exposição, $\dot{X}$, é o quociente de $d X$ por $d t$, onde $d X$ é o incremento da exposição no intervalo de tempo $d t$, como mostra a Equação 4. A unidade da taxa de exposição é $\mathrm{C} \cdot \mathrm{kg}^{-1} \cdot \mathrm{s}^{-1}$.

$$
\dot{X}=\frac{d X}{d t}
$$

Equação 4

\section{Dose Absorvida (D)}

A grandeza dose absorvida é o quociente de $d \bar{\varepsilon}$ por $d m$, onde $d \bar{\varepsilon}$ é a energia média depositada na matéria de massa dm, como mostra a Equação 5. A unidade 
desta grandeza é $\mathrm{J} \mathrm{kg}^{-1}$ e o nome especial para a unidade de dose absorvida é o gray (Gy).

$$
D=\frac{d \bar{\varepsilon}}{d m}
$$

Equação 5

A taxa de dose absorvida, $\dot{D}$, é o quociente de $d D$ por $d t$, onde $d D$ é o incremento da dose absorvida no intervalo de tempo $d$, como mostra a Equação 6 . A unidade para a taxa de dose absorvida é o $\mathrm{J}_{\mathrm{kg}} \mathrm{kg}^{-1} \cdot \mathrm{s}^{-1}$. Quando for utilizado o nome especial para unidade, gray, a unidade da taxa de dose absorvida é gray por segundo $\left(\mathrm{Gy} \cdot \mathrm{s}^{-1}\right)$.

$$
\dot{D}=\frac{d D}{d t}
$$

\section{Equação 6}

\subsection{Proteção Radiológica}

Proteção radiológica pode ser definida como um conjunto de ações para proteger trabalhadores ocupacionalmente expostos, pacientes e público em geral, da exposição desnecessária à radiação ionizante. A exposição desnecessária é qualquer exposição à radiação ionizante que não traz benefício ao paciente em termos de informação diagnóstica obtida, ou qualquer exposição à radiação que não aumente a qualidade do estudo ${ }^{19}$.

Em junho de 1998 foi publicada no Brasil a Portaria SVS-MS $453^{21}$ que estabelece as diretrizes básicas de proteção radiológica em radiodiagnóstico médico e odontológico. Ela é regida por quatro princípios básicos de proteção radiológica. São eles:

1. Justificação da prática e das exposições médicas individuais;

2. Otimização da proteção radiológica;

3. Limitação de doses individuais;

4. Prevenção de acidentes. 
O primeiro princípio estabelece que nenhuma prática deve ser autorizada a menos que produza benefício suficiente para o indivíduo exposto ou para a sociedade, de modo a compensar o detrimento que possa ser causado.

Este princípio deve ser aplicado considerando-se que a totalidade dos benefícios potenciais em matéria de diagnóstico ou terapêutica que decorram da exposição médica é maior que o detrimento que possa ser causado pela radiação ao indivíduo. Além disso, deve-se considerar a eficácia, os benefícios e os riscos de técnicas alternativas disponíveis com o mesmo objetivo, mas que envolvam menos ou nenhuma exposição a radiações ionizantes.

O segundo princípio da proteção radiológica é o da otimização. Tal princípio estabelece que as instalações e as práticas devem ser planejadas, implantadas e executadas de modo que a magnitude das doses individuais, o número de pessoas expostas e a probabilidade de exposições acidentais sejam tão baixos quanto razoavelmente exeqüíveis (Princípio ALARA - as low as reasonably achievable), levando-se em conta fatores sociais e econômicos, além das restrições de dose aplicáveis.

O princípio da limitação de doses individuais estabelece que os limites de dose, tanto para trabalhadores com radiação quanto para indivíduos do público, devem ser respeitados. Estes limites são valores de dose efetiva ou de dose equivalente, estabelecidos para exposição ocupacional e exposição do público, decorrentes de práticas controladas, cujas magnitudes não devem ser excedidas.

No quarto e último princípio, prevenção de acidentes, as instalações e os equipamentos devem ser projetados de tal forma a minimizar a probabilidade de ocorrência de acidentes (exposições potenciais). Além disso, deve-se desenvolver os meios e implementar as ações necessárias para minimizar a contribuição de erros humanos que levem à ocorrência de exposições acidentais.

A minimização da exposição desnecessária pode ser obtida fazendo-se uso de três fatores principais: tempo, distância e blindagem. O tempo e a dose são diretamente proporcionais, ou seja, quanto mais o trabalhador ocupacionalmente exposto e o paciente ficarem expostos a uma fonte de radiação ionizante, maior será a dose.

A distância é o fator de proteção radiológica mais eficiente. Neste caso, quando a distância entre a fonte de radiação e o indivíduo aumenta, a dose diminui pelo quadrado da razão da distância inicial pela nova distância da fonte (lei do inverso do quadrado da distância, apresentada na Figura 4). 


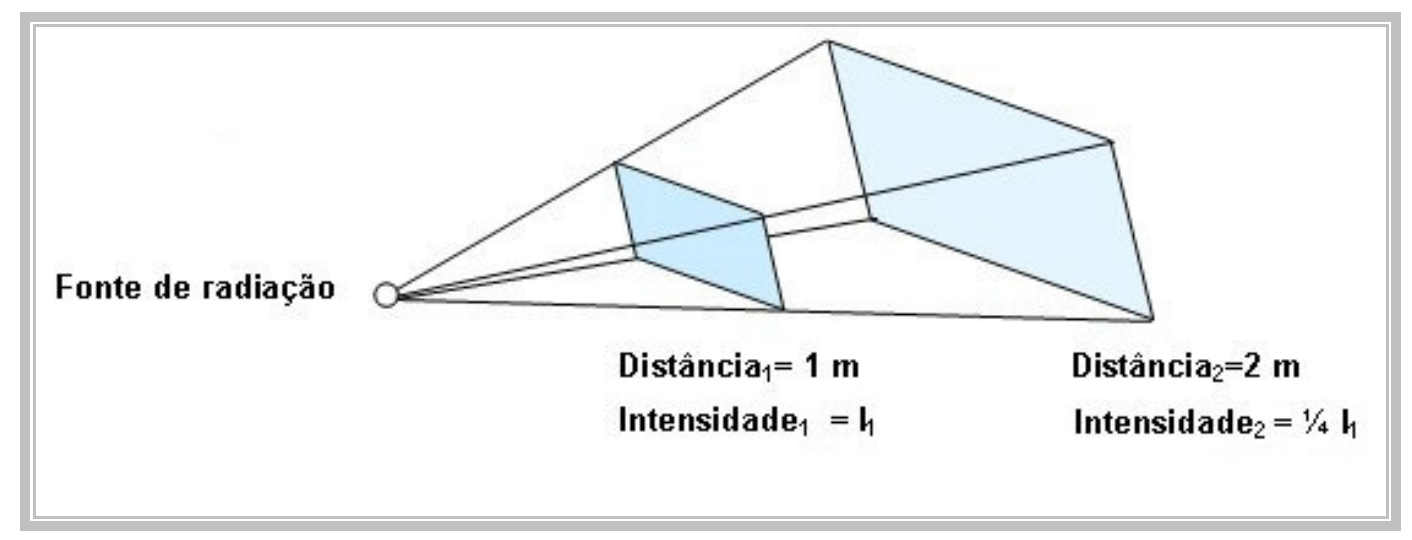

Figura 4 - llustração da lei do inverso do quadrado da distância

O terceiro fator utilizado para minimizar a dose é a blindagem. As blindagens consistem em materiais estruturais, como portas e visores plumbíferos, ou dispositivos como barreiras móveis, aventais de proteção, óculos e blindagens de ovário, confeccionados com material radio-opaco.

As blindagens são confeccionadas com materiais compostos por elementos de alto número atômico. Na proteção radiológica o chumbo é o material de referência, pois o seu alto número atômico $(Z=82)$ garante a absorção de grande parte dos fótons espalhados ${ }^{18}$.

\section{Avental de Proteção e Blindagem de Ovário}

Em geral, os aventais de proteção e as blindagens de ovário são confeccionados com borracha flexível composta por chumbo, entre outros elementos.

O uso de dispositivos de proteção é necessário, pois durante os procedimentos radiográficos, órgãos e tecidos sensíveis do paciente são expostos à radiação ionizante.

Além disso, o paciente comporta-se como uma fonte de radiação espalhada resultante dos processos de interações Compton, provocando o aumento do potencial da exposição ocupacional para operadores, radiologistas ou para o corpo de enfermagem, no caso de cirurgias radio-assistidas. Acompanhantes que, eventualmente, necessitem dar assistência para imobilização ou conforto do paciente examinado nas salas de exame também estarão submetidos à radiação espalhada resultante do procedimento clínico.

Desta forma, o uso de dispositivos de proteção radiológica é muito importante em procedimentos intervencionistas, uma vez que o radiologista e a equipe clínica ficam submetidos à radiação espalhada por um longo período de tempo. Em 2003, 
Theocharopoulos et al ${ }^{22}$ realizaram um estudo a fim de verificar a exposição ocupacional em procedimentos ortopédicos guiados por fluoroscopia. Neste estudo foi verificado que o uso do avental de proteção reduz a dose por um fator de 16 nas projeções anterior-posterior e posterior-anterior.

O uso de dispositivos de proteção radiológica também é importante na radiologia veterinária. Segundo o Safety Code $28^{23}$, o animal a ser examinado deve estar sedado ou deve-se utilizar dispositivos para imobilização sempre que possível. Na prática, porém, isto nem sempre é possível sendo necessária a imobilização do animal por uma ou mais pessoas. Neste caso, todas as pessoas que estiverem dentro da sala de exames devem estar paramentadas adequadamente, como é apresentado na Figura 5.

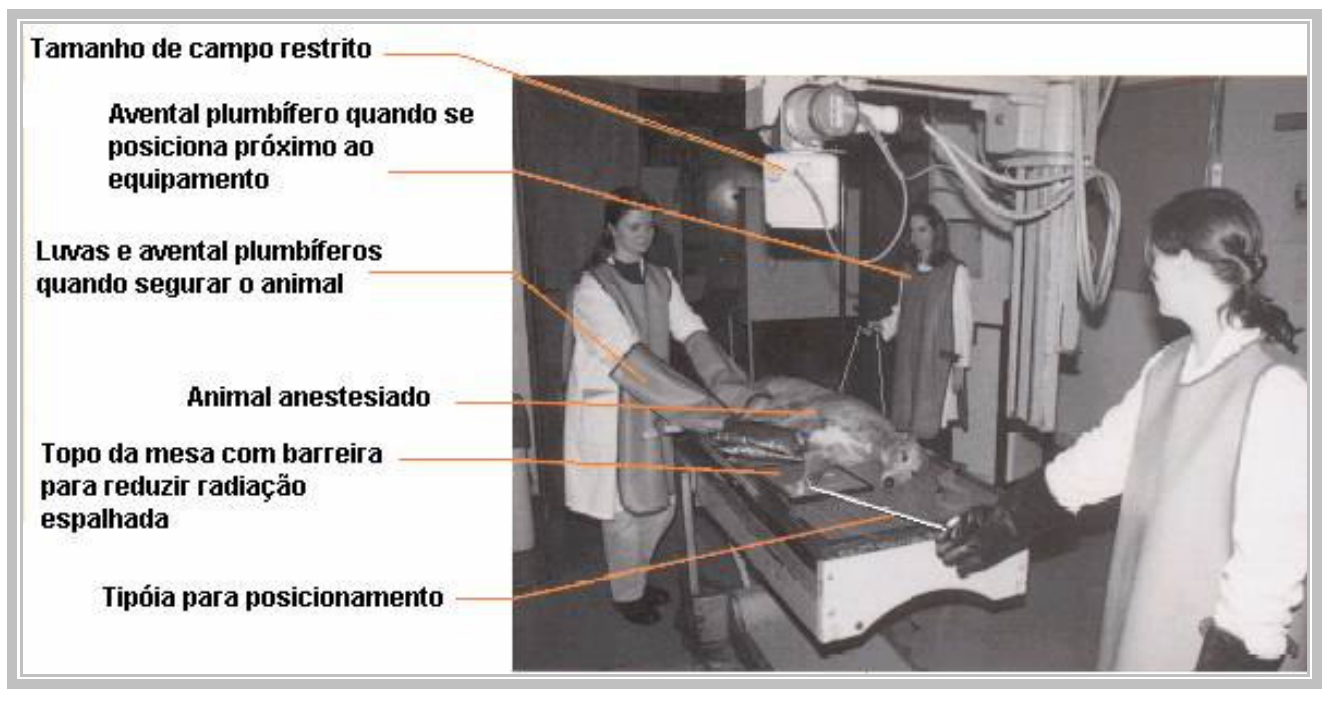

Figura 5 - Requisitos de proteção radiológica durante um procedimento em medicina veterinária $^{24}$

Outra situação da aplicação das vestimentas de radioproteção em veterinária é quando não há condições de transportar o animal de grande porte, por exemplo, para uma sala de exames com blindagem adequada. Neste caso, não há barreiras de proteção radiológica e o veterinário deve estar necessariamente utilizando todas as ferramentas e vestimentas de proteção radiológica, como mostra a Figura 6. 


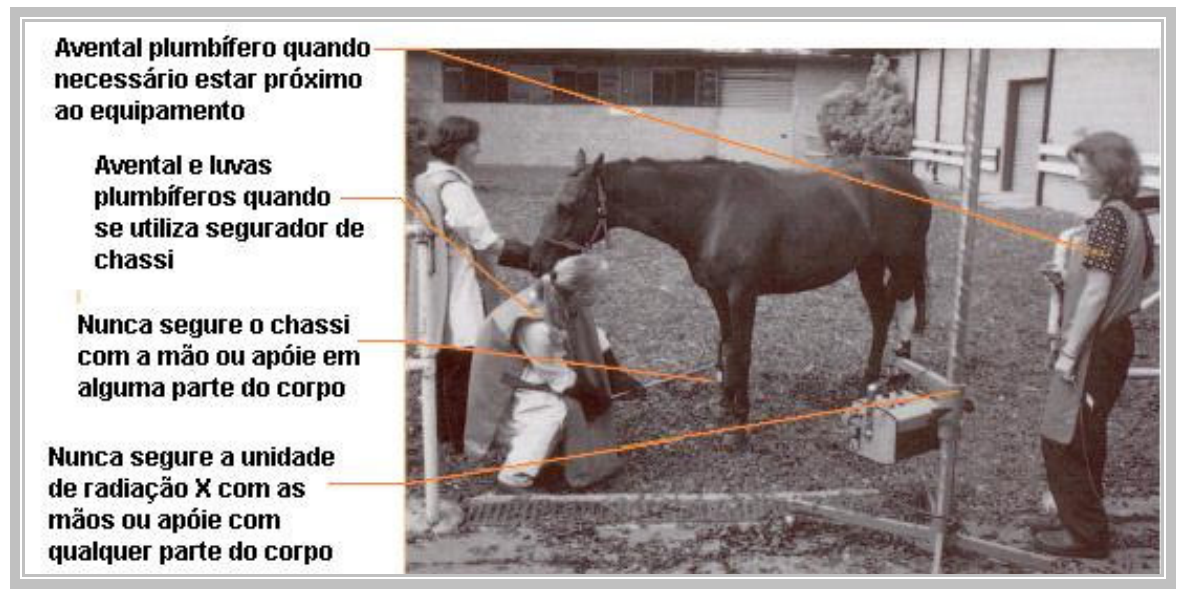

Figura 6 - Requisitos de proteção radiológica em medicina veterinária quando não há barreiras fixas $^{24}$

Estes dispositivos devem ser avaliados periodicamente a fim de verificar se 0 material atenuador possui trincas ou furos que possam minimizar as suas propriedades de proteção e consequentemente inutilizarem o uso destes dispositivos. Segundo a Portaria $453^{21}$, o controle de qualidade, com o objetivo de se verificar a integridade de acessórios e vestimentas de proteção individual, deve ser realizado pelo menos uma vez ao ano. Na Figura 7 são apresentados exemplos de defeitos no material atenuador de dispositivos de proteção encontrados na rotina do controle de qualidade.

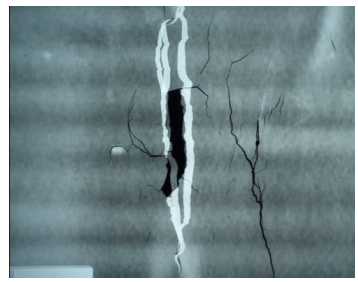

(a)

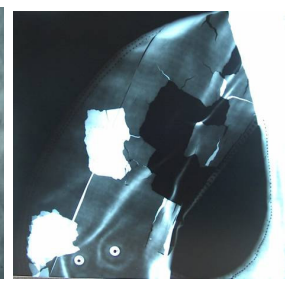

(b)

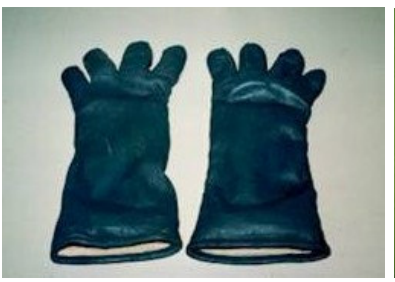

(c)

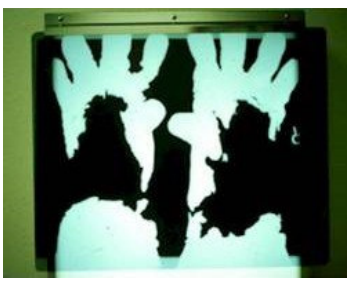

(d)

Figura 7 - Defeitos no material atenuador: (a) fissura na região torácica de um avental protetor; (b) rasgo na região posterior dos ombros de um avental protetor; (c) luvas de proteção aparentemente em bom estado e sua imagem radiográfica (d) mostrando uma grande falha no material atenuador. 


\subsection{INCERTEZA DE MEDIÇÃo}

Quando se relata o resultado de medição de uma grandeza física, é obrigatório que seja dada alguma indicação quantitativa da qualidade do resultado, de forma tal que aqueles que o utilizam possam avaliar sua confiabilidade. Sem essa indicação, resultados de medição não podem ser comparados, seja entre eles ou com valores de referência fornecidos numa especificação ou numa norma. É, portanto, necessário que haja um procedimento prontamente implementado, facilmente compreendido e de aceitação geral para caracterizar a qualidade de um resultado de uma medição, isto é, para avaliar e expressar sua incerteza ${ }^{25}$.

De acordo com o Guia para a Expressão da Incerteza de Medição (GUM) ${ }^{25}$, incerteza de medição é um "parâmetro, associado ao resultado de uma medição, que caracteriza a dispersão dos valores que podem ser razoavelmente atribuídos ao mensurando".

Em outras palavras, o termo incerteza de medição significa que, para um dado mensurando e um dado resultado, não há um único valor, mas sim, um infinito número de valores dispersos em torno do resultado, que são consistentes com todas as observações e dados e conhecimentos sobre o mundo físico, e que podem ter diferentes graus de credibilidade atribuídos ao mensurando.

Embora as incertezas avaliadas sejam pequenas, não se pode afirmar que 0 erro no resultado da medição é pequeno, uma vez que ao se determinar uma correção, por exemplo, um efeito sistemático pode ter passado despercebido, por não ser reconhecido ${ }^{25}$.

Os componentes da incerteza são agrupados em duas categorias baseadas no seu método de avaliação: A e B. A primeira categoria (incerteza do tipo A, representada por $u_{A}$ ) está relacionada com métodos de avaliação da incerteza pela análise estatística de séries de observações, enquanto que a segunda (incerteza do tipo $\mathrm{B}$, representada por $u_{B}$ ) está relacionada a métodos de avaliação da incerteza por outros meios que não a análise estatística de série de observações, ou seja, informações contidas nos certificados de calibração, especificação dos instrumentos e padrões, dados técnicos dos fabricantes, livros e manuais técnicos e estimativas baseadas na experiência ${ }^{25,26}$.

Sendo a incerteza padrão $(u)$ a incerteza do resultado de uma medição expressa como um desvio padrão, a incerteza padrão combinada é a incerteza padrão do resultado de uma medição, quando este resultado é obtido por meio de valores de várias outras grandezas. Ela é igual à raiz quadrada positiva de uma soma de termos, 
que constituem as variâncias ou covariâncias destas outras grandezas, ponderadas de acordo com quanto o resultado da medição varia com mudanças nestas grandezas ${ }^{25}$.

A incerteza padrão combinada, representada por $u_{c}$, para grandezas não correlacionadas é obtida pela Equação 7.

$$
u_{C}^{2}(y)=\sum_{i=1}^{N}\left[\frac{\partial f}{\partial x_{i}}\right]^{2} \cdot u^{2}\left(x_{i}\right)
$$

onde: $u\left(x_{i}\right)$ é a incerteza padrão

$$
\left[\frac{\partial f}{\partial x_{i}}\right] \text { é o coeficiente de sensibilidade }
$$

Quando as grandezas apresentam dependência entre si, diz-se que há uma correlação entre elas; a correlação pode aumentar ou diminuir o valor da incerteza associada a esta grandeza. No caso de um mesmo instrumento utilizado para a medição de dois ou mais parâmetros, a correlação é gerada devido ao efeito sistemático intrínseco a este instrumento de medição ${ }^{27}$. Assim, a incerteza padrão combinada para grandezas correlacionadas é dada pela Equação 8.

$u_{C}^{2}(y)=\sum_{i=1}^{N}\left[\frac{\partial f}{\partial x_{i}}\right]^{2} \cdot u^{2}\left(x_{i}\right)+2 \sum_{i=1}^{N-1} \sum_{j=i+1}^{N} \frac{\partial f}{\partial x_{i}} \frac{\partial f}{\partial x_{j}} \cdot u\left(x_{i}\right) \cdot u\left(x_{j}\right) \cdot r\left(x_{i}, x_{j}\right)$

Equação 8

onde: $u\left(x_{i}\right), \mathrm{u}\left(x_{j}\right)$ são as incertezas padrão das grandezas $x_{i}$ e $x_{j}$;

$$
\begin{aligned}
& {\left[\frac{\partial f}{\partial x_{i}}\right] \text { e }\left[\frac{\partial f}{\partial x_{j}}\right] \text { são os coeficientes de sensibilidade; }} \\
& r\left(x_{i}, x_{j}\right) \text { é o coeficiente de correlação } \Rightarrow-1<r\left(x_{i}, x_{j}\right) \leq+1
\end{aligned}
$$

A incerteza expandida, representada por $U_{95}$, é a grandeza que define um intervalo em torno do resultado de uma medição com o qual se espera abranger uma grande fração da distribuição dos valores que possam ser razoavelmente atribuídos ao mensurando. Ela é obtida por meio da Equação 9, onde $k$ é o fator de abrangência. $O$ fator de abrangência $k$ é um fator numérico que, tipicamente, está na faixa de 2 a $3^{25}$. 
$U_{95}=u_{C} \cdot k$

Equação 9

A metodologia utilizada para o cálculo das incertezas na determinação da espessura equivalente de atenuação deste trabalho foi a proposta pelo GUM ${ }^{25}$.

No procedimento para a avaliação e a expressão da incerteza proposto inicialmente deve-se equacionar as fontes de incerteza modelando a medição. Em seguida, devem ser obtidas as incertezas do tipo B por meio das informações apresentadas nos certificados de calibração e nos manuais dos equipamentos utilizados durante a medição.

Então, as incertezas do tipo A e B são dispostas juntas, geralmente utilizandose uma planilha de cálculo, de forma que os coeficientes de sensibilidade e a incerteza padrão possam ser avaliados e a incerteza combinada seja calculada.

Com esses resultados, calcula-se o número de graus de liberdade efetivo $\left(v_{\text {eff }}\right)$ definido por Welch-Satterthwaite de acordo com a Equação 10.

$$
v_{e f f}=\frac{u_{C}^{4}}{\sum_{i}^{n} \frac{u_{i}^{4}}{v_{i}}}
$$

\section{Equação 10}

onde: $u_{C}$ é a incerteza padrão combinada

$u_{i}$ é a incerteza padrão

$v_{i}$ é o número de graus de liberdade

Após a determinação do $v_{\text {eff, }}$ procura-se numa tabela de coeficientes de Student, o coeficiente que será adotado como fator de abrangência $(k)$ correspondente a um nível de confiança de $95,45 \%$. Finalmente, multiplica-se o valor de $k$ por $u_{C}$ obtendo-se a incerteza expandida $\left(U_{C}\right)$. 


\section{MATERIAIS}

\subsection{AmOStRAS}

As amostras dos aventais de proteção e das blindagens de ovários utilizadas neste trabalho, mostradas na Figura 8, foram cedidas por cinco fabricantes que serão tratados como Fabricantes A, B, C, D e E. As amostras enviadas pelos fabricantes estão mostradas na Tabela 1. Foram avaliadas um total de 60 amostras, sendo 54 modelos de aventais de proteção e 6 modelos de blindagem de ovário.

Alguns aventais de proteção, tais como os do tipo ondontológico e pediátrico, foram considerados não aplicáveis à norma NBR / IEC 61331-3 ${ }^{15}$, uma vez que para estes não há exigências nos padrões de confecção. Dentre as amostras de aventais de proteção avaliadas, 14 modelos não eram aplicáveis à norma NBR / IEC 61331-3 ${ }^{15}$, sendo que cinco pertenciam ao Fabricante $B$, três pertenciam ao Fabricante $D$ e seis pertenciam ao Fabricante $D$ no re-teste. Para esses aventais de proteção foram realizadas apenas as medições de equivalência de atenuação em chumbo.

O resultado da espessura equivalente de atenuação dos aventais de proteção não aplicáveis à parte 3 da norma foi utilizado apenas na avaliação da porcentagem de transmissão dos dispositivos de proteção e na avaliação da reprodutibilidade da espessura equivalente de atenuação apresentada pelos fabricantes.

As amostras de aventais de proteção foram identificadas como AV seguido por um número que não tinha nenhuma correlação com o modelo do fabricante, apenas com a ordem em que foram feitas as medições. Do mesmo modo, as amostras de blindagens de ovário foram classificadas como BO seguido por um número referente à ordem em que foram testadas.

Os testes foram realizados na Seção Técnica de Desenvolvimento em Tecnologia em Saúde (STDTS) do Instituto de Eletrotécnica e Energia (IEE) da Universidade de São Paulo (USP). Os instrumentos e equipamentos utilizados nos testes estão descritos a seguir.

Após todos os testes, foi elaborado um relatório para cada fabricante que especificava todas as conformidades e não conformidades de suas amostras segundo as normas NBR / IEC 61331-1 $1^{13}$ e NBR / IEC 61331-3 ${ }^{15}$. O Fabricante D, após o recebimento do relatório, fez algumas modificações com o objetivo de adequar as suas amostras e re-enviou novas amostras para teste. Os testes foram realizados nas novas amostras e foi denomimado neste trabalho como Fabricante D (re-teste). 


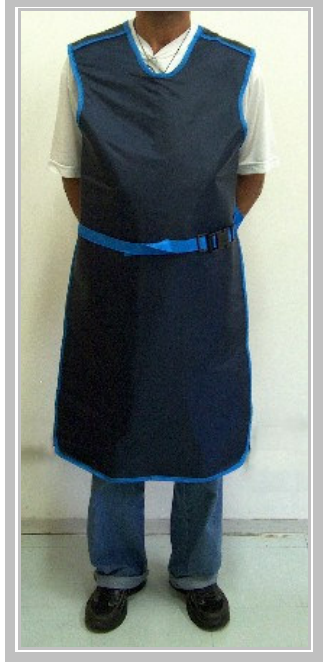

(a)

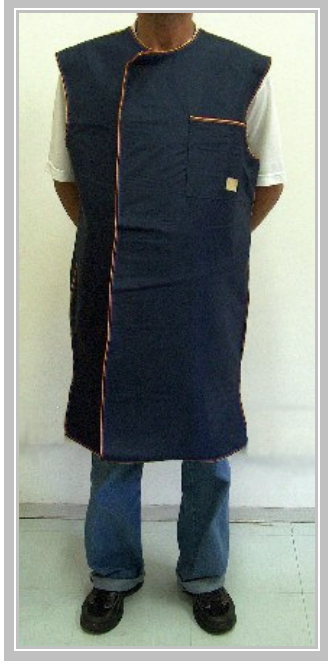

(b)

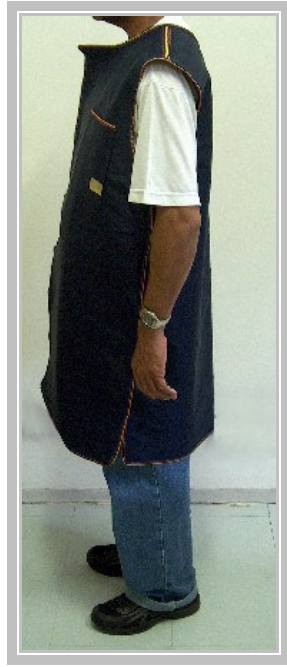

(c)

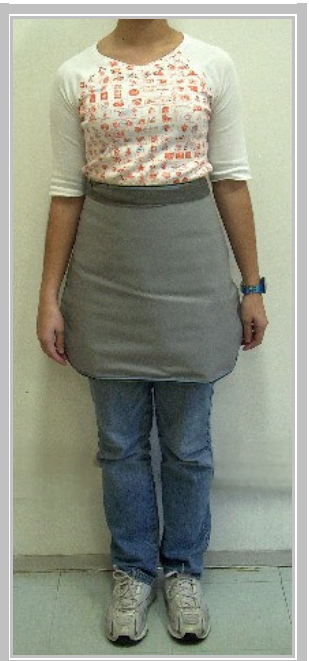

(d)

Figura 8 - Exemplo de amostras recebidas: (a) avental de proteção leve; (b) avental de proteção fechado leve; (c) avental de proteção fechado leve - costas; (d) blindagem de ovário

Tabela 1 - Quantidade de aventais de proteção e de blindagens de ovário cedida pelos fabricantes

\begin{tabular}{c|c|c}
\hline \multirow{2}{*}{ Fabricante } & \multicolumn{2}{|c}{ Quantidade enviada } \\
\cline { 2 - 3 } & Avental de proteção & Blindagem de Ovário \\
\hline A & 10 & 03 \\
\hline B & 09 & 03 \\
\hline C & 02 & - \\
\hline D & 17 & - \\
\hline E & 04 & - \\
\hline D (re-teste) & 12 & - \\
\hline Total & 54 & 06 \\
\hline Total aplicável à norma & $\mathbf{4 0}$ & $\mathbf{0 6}$ \\
\hline \hline
\end{tabular}

\subsection{Equipamento de RaIOS $X$}

Para os ensaios de determinação da espessura equivalente de atenuação, foi utilizado um equipamento de raios $X$ industrial da marca Philips, modelo MCN 323. Esse equipamento é do tipo potencial constante com faixa de tensão de 15 a $320 \mathrm{kV}$, corrente de 0,5 a $45 \mathrm{~mA}$ e tempo de exposição de $2 \mathrm{~s}$ a 99 min e $50 \mathrm{~s}$. 
O painel de comando deste equipamento está localizado na ante-sala do equipamento de raios X. A Figura 9-a ilustra o tubo de raios X e a Figura 9-b, o painel de comando do equipamento.

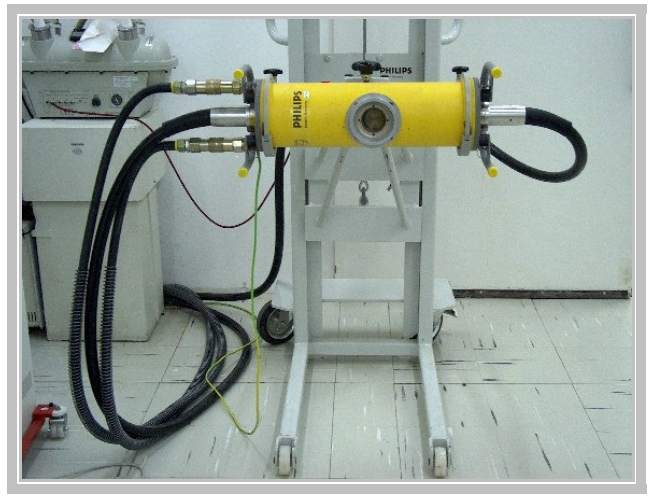

(a)

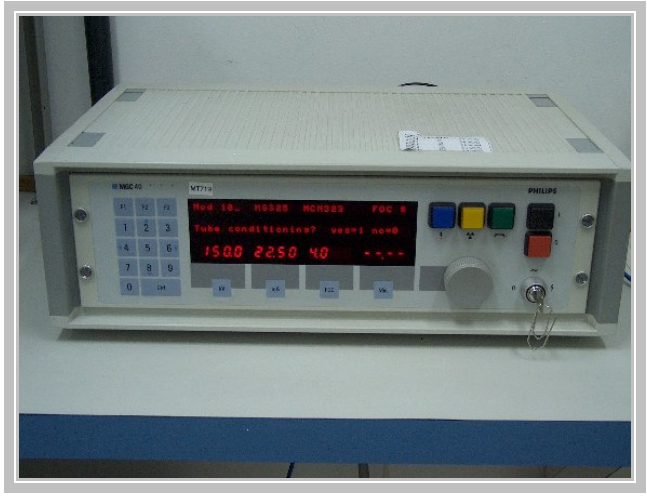

(b)

Figura 9 - (a) Equipamento de raios X Philips MG325 utilizado nos testes; (b) Painel de comando do equipamento

\subsection{Monitor E CÂmara de IONIZAÇÃo}

Foi utilizada uma câmara de ionização de $6 \mathrm{~cm}^{3}$, mostrada na Figura 10-a, marca Radcal Corporation, modelo 10x5-6, no de série 15896. Esta câmara de ionização possui dependência energética de $\pm 5 \%$ na faixa de $20 \mathrm{keV}$ a 1,33 MeV (com capa de build-up) e dependência pela taxa de dose de $\pm 5 \%$ na faixa de $3,5 \mu \mathrm{Gy} / \mathrm{s}$ a $0,7 \mathrm{~Gy} / \mathrm{s}$ e abaixo de $4,4 \mathrm{~Gy} / \mathrm{s}$ para pulsos de $50 \mu \mathrm{s}^{28}$.

A câmara de ionização foi utilizada juntamente com um monitor para câmara de ionização, Figura 10-b, modelo 9015, marca Radcal Corporation, oํ de série 91-0448. Este monitor possui exatidão de $\pm 4 \%$ da leitura, \pm 1 dígito.

Este conjunto foi calibrado no Laboratório de Calibração de Instrumentos (LCI) do Instituto de Pesquisas Energéticas e Nucleares (IPEN). 


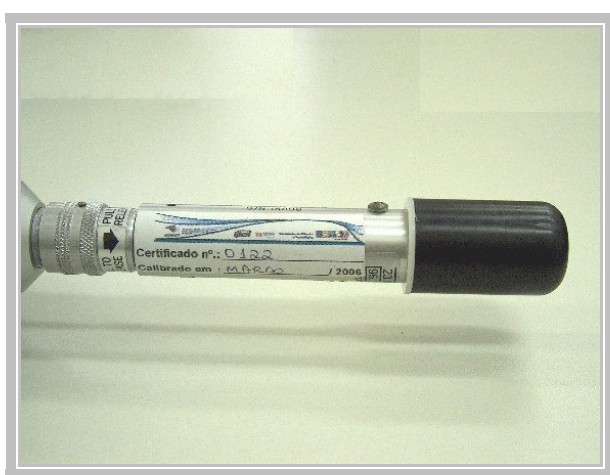

(a)

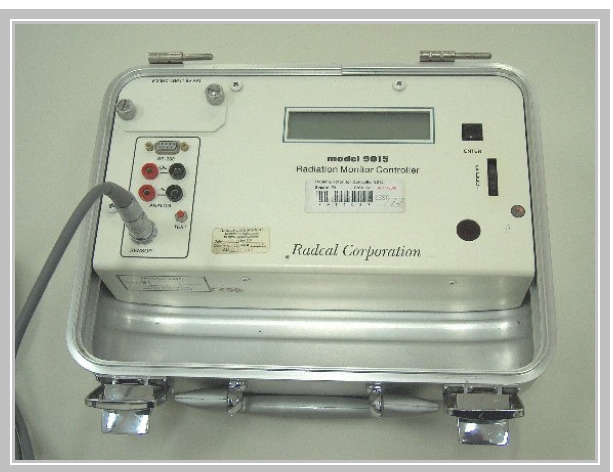

(b)

Figura 10 - Câmara de ionização $6 \mathrm{~cm}^{3}$ Radcal Corporation e Monitor 9015 Radcal Corporation utilizados nos testes.

\subsection{Suporte para Ensaio de Atenuação de Materiais}

O suporte para ensaio de atenuação de materiais utilizado nos testes foi desenvolvido no Instituto de Eletrotécnica e Energia da USP.

Ele foi projetado de modo a atender às especificações da NBR / IEC 61331-1 ${ }^{13}$ tanto para condições de feixe largo, quanto para condições de feixe estreito. Segundo esta norma, no arranjo para medições no feixe estreito o feixe de radiação deve ter um diâmetro de $(20 \pm 1) \mathrm{mm}$ no lado distal do corpo de prova, e nas medições feitas para determinar a homogeneidade o feixe estreito deve ser limitado a um diâmetro inferior a $10 \mathrm{~mm}$ no lado distal do corpo-de-prova.

Assim, quando o suporte para ensaio de materiais é utilizado para atender às especificações de feixe estreito, um colimador de chumbo (diafragma) de $3 \mathrm{~mm}$ de chumbo e diâmetro de 17,4 mm é posicionado a $200 \mathrm{~mm}$ à frente do suporte. Além disso, nas medições feitas para se determinar a inomogeneidade da amostra, um redutor de abertura de diafragma de $8,5 \mathrm{~mm}$ de diâmetro é colocado no diafragma, como mostra a Figura 11. 


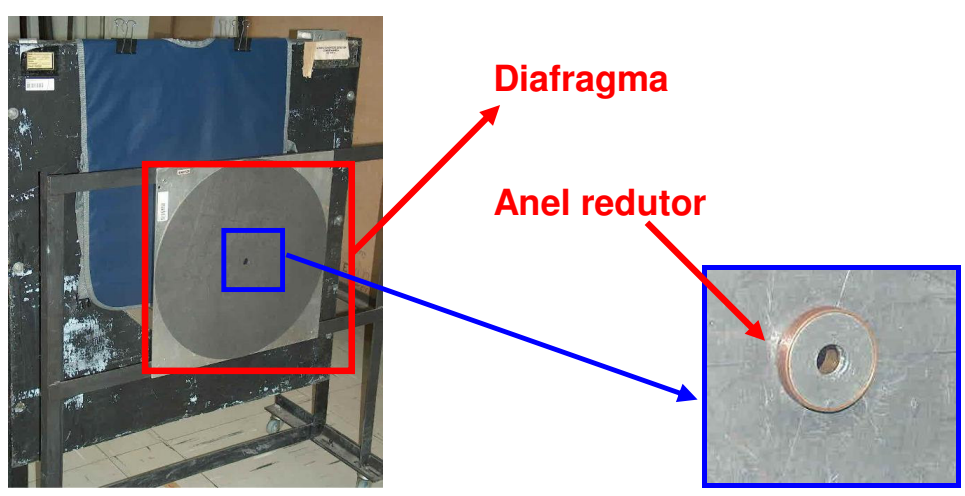

Figura 11 - Suporte para ensaio de atenuação de materiais desenvolvido pelo IEE/USP. Em destaque: diafragma utilizado para geometria de feixe estreito e anel redutor, utilizado para determinação da inomogeneidade do material atenuador

\subsection{FILTROS}

Foram utilizados dois conjuntos de filtros: um de cobre e o outro de chumbo. Os filtros de cobre (Figura 12-a) foram utilizados na saída do tubo de raios $\mathrm{X}$, a fim de produzir as qualidades de feixe indicadas pela norma NBR / IEC 61331-1 ${ }^{13}$. Como não se trata de um conjunto de filtros adquirido recentemente, não foi possível rastrear o fabricante e porcentagem de pureza desses filtros.

Os filtros de chumbo (Figura 12-b) foram utilizados na determinação da espessura equivalente de atenuação como material de referência. O material possui certificado de análise espectrométrica* e sua composição química está apresentada na Tabela 2. O conjunto é composto por 12 filtros de chumbo, que foram enumerados de $1 \mathrm{a} 12$, e a espessura de cada filtro é de $(0,12 \pm 0,01) \mathrm{mm}$.

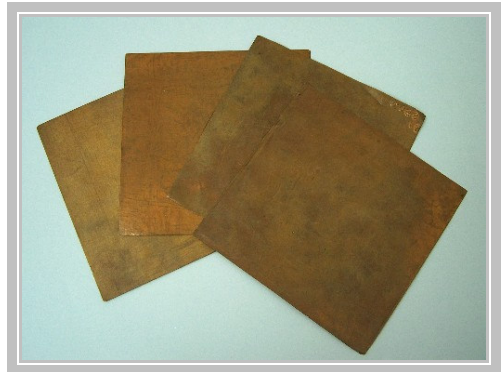

(a)

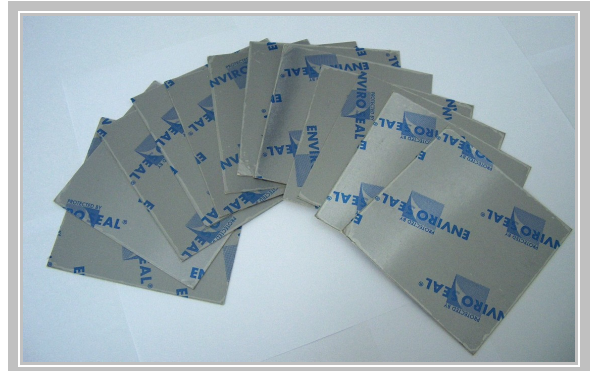

(b)

Figura 12 - Filtros utilizados nos testes: (a) filtros de cobre e (b) filtros de chumbo padrão

* HCG Equipamentos Ltda. Certificado de análise espectrométrica no 0238/05. São Bernardo do Campo, 28/03/05. 
Tabela 2 - Composição química dos filtros de chumbo utilizados como material de referência

\begin{tabular}{c|c}
\hline \hline Elemento & Resultado (\%) \\
\hline \hline $\mathrm{Pb}$ & 96,33 \\
\hline $\mathrm{Fe}$ & 0,29 \\
\hline $\mathrm{Sn}$ & 1,36 \\
\hline $\mathrm{Bi}$ & 1,33 \\
\hline $\mathrm{Cu}$ & 0,11 \\
\hline \hline
\end{tabular}

\subsection{Colimador}

Foi utilizado nos ensaios um colimador na saída do tubo de raios X. Este colimador possui o diâmetro interno de $24 \mathrm{~mm}$ e a espessura do chumbo igual a $15 \mathrm{~mm}$. O colimador utilizado está mostrado na Figura 13-a. A Figura 13-b mostra as principais dimensões deste colimador.

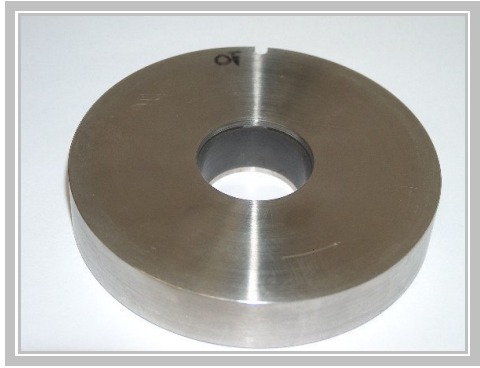

(a)

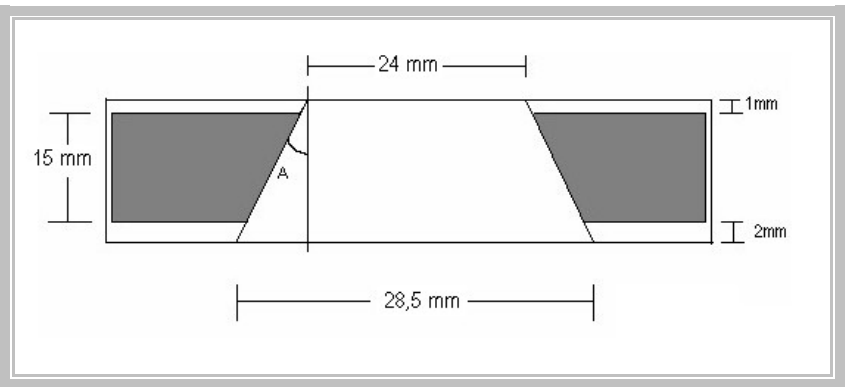

(b)

Figura 13 - (a) Colimador utilizado e (b) suas principais dimensões

\subsection{RÉGua Metálica}

Nos testes para avaliação das propriedades de confecção dos dispositivos de proteção, foi utilizada uma régua metálica calibrada, da marca Stanley, para as medições da largura, comprimento e cintura (para aventais do tipo fechado). 


\section{MÉTODOS}

\subsection{Preparação da Câmara de lonização}

Antes de iniciar cada conjunto de medições, a câmara de ionização foi irradiada por 10 minutos para estabilização elétrica do conjunto monitor-câmara de ionização. Durante o intervalo de tempo de 10 minutos, a taxa de kerma no ar foi monitorada com o objetivo de verificar se ela se mantinha constante.

Além disso, o monitor da câmara de ionização foi mantido dentro do laboratório, junto com a câmara de ionização, uma vez que o sensor de temperatura do conjunto fica no monitor. Foi necessário, então, o uso de uma câmera de vídeo que transmite a imagem do monitor da câmera de ionização via Internet, sendo possível, desta forma, a monitoração da taxa de kerma no ar remotamente, como ilustra a Figura 14.

As medições foram realizadas no modo taxa de dose e a unidade de medição foi $\mathrm{mGy} / \mathrm{min}$.

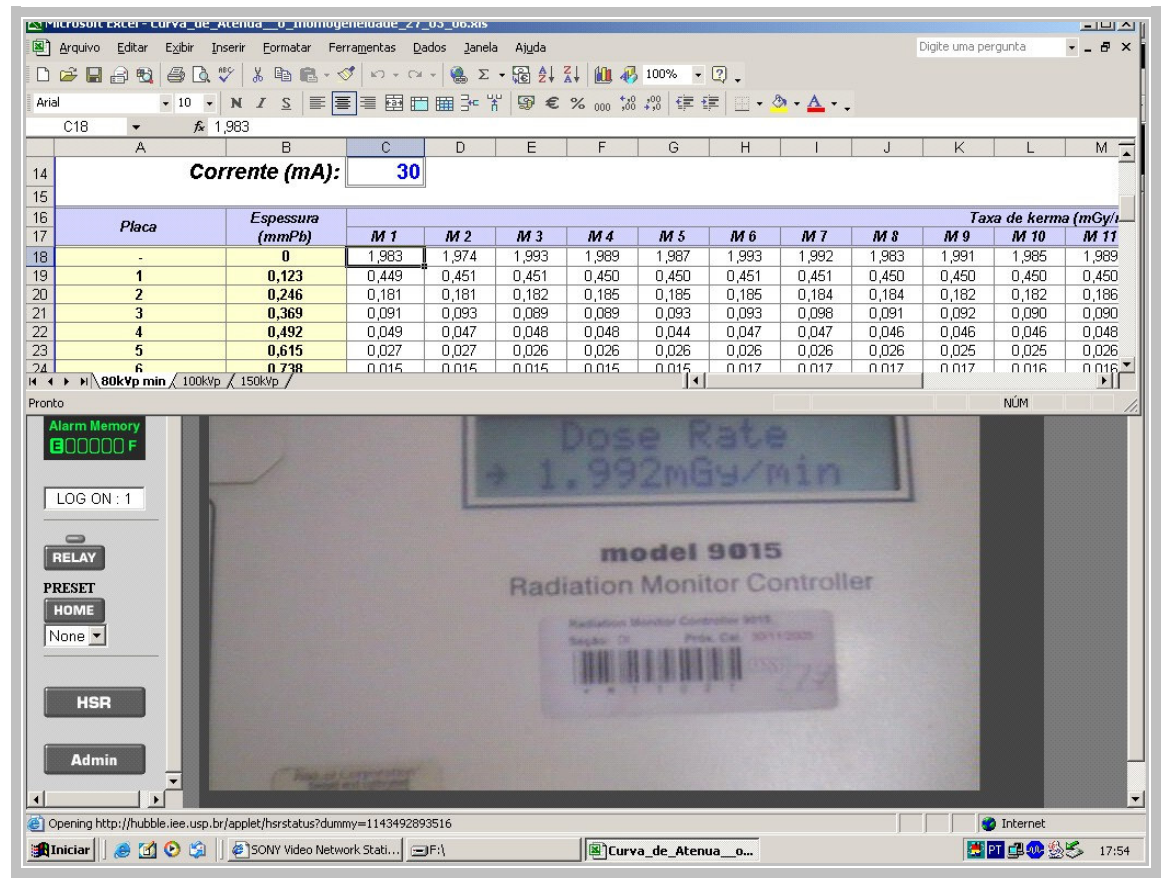

Figura 14 - Monitoração da taxa de kerma no ar remotamente: uma câmera de vídeo foi utilizada para transmitir os dados via Internet 


\subsection{Alinhamento do Sistema}

Antes de cada procedimento para obtenção da curva de atenuação do chumbo padrão e taxa de kerma no ar transmitida pelas amostras, foi necessário alinhar o sistema: tubo de raios $\mathrm{X}$, suporte para ensaio de materiais e câmara de ionização.

O alinhamento do sistema foi feito utilizando-se um sistema de laser e écran. $\mathrm{O}$ sistema de laser foi utilizado para alinhar o tubo vertical e horizontalmente, a $1 \mathrm{~m}$ do piso. Após o alinhamento do tubo vertical e horizontalmente, foi necessário posicionar o tubo de raios $X$ a uma altura de $78,5 \mathrm{~cm}$, uma vez que esta é a altura do suporte para ensaio de materiais. O suporte para ensaio de atenuação de materiais foi posicionado à distância de $1,5 \mathrm{~m}$ do ponto focal do tubo de raios $\mathrm{X}$.

Foi colocado na saída do tubo de raios $X$ um colimador de $3,4 \mathrm{~mm}$ de diâmetro interno, que foi utilizado apenas no alinhamento do sistema. Um écran foi alinhado com o suporte de materiais, como mostra a Figura 15-a. As luzes do laboratório foram apagadas, o écran foi irradiado, e o alinhamento do feixe de raios $X$ com o écran foi monitorado por meio de uma câmera de vídeo, Figura 15-b. Foram feitos os ajustes necessários de forma que o suporte para ensaio de materiais ficasse alinhado com o tubo de raios $X$.

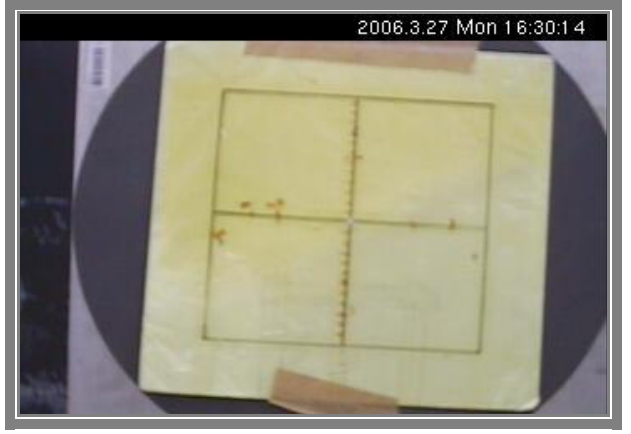

(a)

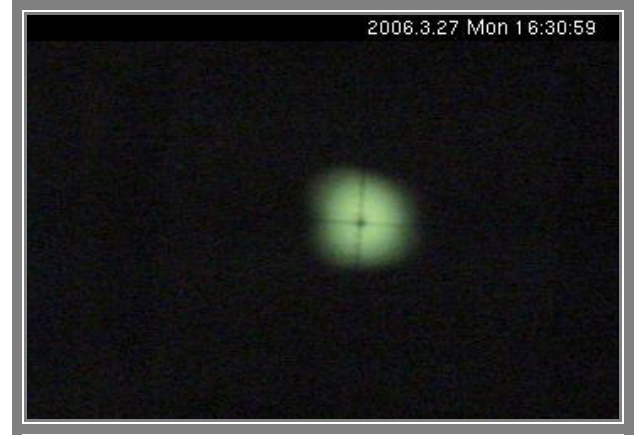

(b)

Figura 15 - Alinhamento do suporte de materiais com o tubo de raios $\mathrm{X}$ : (a) posicionamento do écran no suporte de materiais; (b) alinhamento do feixe de raios $X$ com o écran, monitorado via câmera de vídeo

Por fim, o écran foi retirado do suporte de materiais e um outro écran foi fixado na câmara de ionização, como mostra a Figura 16-a, de maneira a alinhar a câmara de ionização com o tubo de raios $\mathrm{X}$ e com o suporte de materiais, Figura 16-b. 


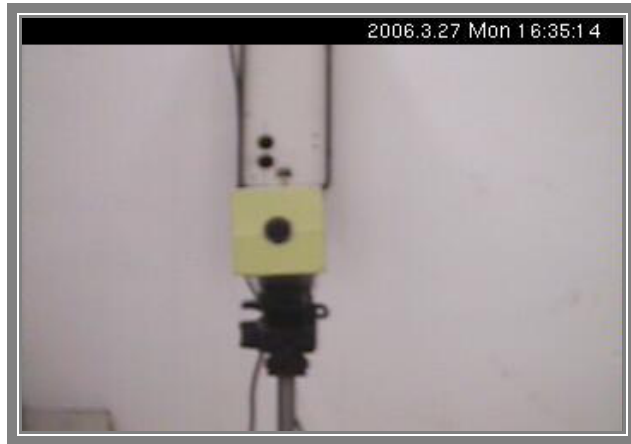

(a)

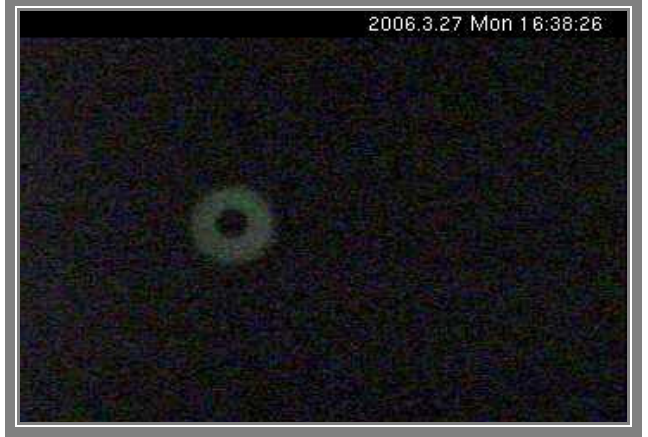

(b)

Figura 16 - Alinhamento da câmara de ionização com o tubo de raios $X$ e o suporte de materiais: (a) écran fixado na câmara de ionização; (b) alinhamento da câmara de ionização com o feixe de raios $X$, monitorado via câmera de vídeo

\subsection{ESPESSURA EQUIVALENTE DE ATENUAÇÃO EM CHUMBO}

De acordo com a publicação Terminologia, ABNT, de $1995^{16}$, espessura equivalente de atenuação é a espessura de uma camada de material de referência que, substituindo o material considerado, fornece o mesmo grau de atenuação num feixe com condições geométricas e qualidade de radiação especificada. A espessura equivalente de atenuação é expressa em submúltiplos adequados ao metro, juntamente com a indicação do material de referência e da qualidade de radiação do feixe incidente.

Por definição, a espessura equivalente de atenuação em chumbo, ou simplesmente, equivalente em chumbo, é a espessura equivalente de atenuação expressa em espessura de chumbo, que é utilizado como material de referência ${ }^{16}$.

Os testes para determinação da espessura equivalente em chumbo das amostras foram realizados utilizando-se a geometria de feixe estreito. Por definição, feixe estreito é o feixe de radiação compreendido num ângulo sólido tão reduzido quanto possível, de modo tal que, na medição de uma grandeza associada à radiação, fica minimizada a contribuição da radiação espalhada e assegurado, se necessário, o equilíbrio eletrônico lateral ${ }^{16}$.

A geometria de feixe estreito, de acordo com a norma NBR / IEC 61331- ${ }^{13}$, é apresentada na Figura 17, onde a dimensão a é a distância do lado distal do corpo-deprova até o ponto de referência da câmara de ionização no centro do feixe estreito, e a dimensão w é a distância entre o ponto de referência do detector de radiação e qualquer objeto adjacente ou parede do lado distal da fonte de radiação. 
O suporte para ensaio de materiais foi posicionado a $1,5 \mathrm{~m}$ do ponto focal do tubo de raios $X$ e a câmara de ionização foi posicionada a $4,0 \mathrm{~m}$ do suporte ( $\dot{K}=2,532 \mathrm{mGy} / \mathrm{min}$ a $100 \mathrm{kV}$ com filtração adicional de 0,25 mmCu).

A norma NBR / IEC $61331-1^{13}$ também padroniza as qualidades de radiação que devem ser utilizadas na determinação da espessura equivalente de atenuação. Qualidade de radiação é uma característica da radiação ionizante determinada pela distribuição espectral de uma grandeza relacionada com a radiação, em função da energia de radiação. Ela pode ser expressa em termos de valores de variáveis, como por exemplo: alta tensão com sua ondulação percentual e a filtração total ${ }^{16}$.

As três qualidades de radiação utilizadas para a realização dos testes, descritas na Tabela 3, foram escolhidas dentre as padronizadas pela norma, pois compreendem a faixa de energia mais utilizada em radiodiagnóstico.

Para cada conjunto tensão-filtração adicional foram obtidas 20 medições da taxa de kerma no ar sem nenhum material atenuador entre o ponto focal e a câmara de ionização.

O filtro do chumbo padrão $n^{\circ} 1$ foi colocado no suporte para ensaio de atenuação de materiais, como mostra a Figura 18, entre o ponto focal e a câmara de ionização, mostrado na Figura 17. Novamente foram realizadas 20 medições da taxa de kerma no ar. O procedimento foi repetido para cada filtro de chumbo adicionado.

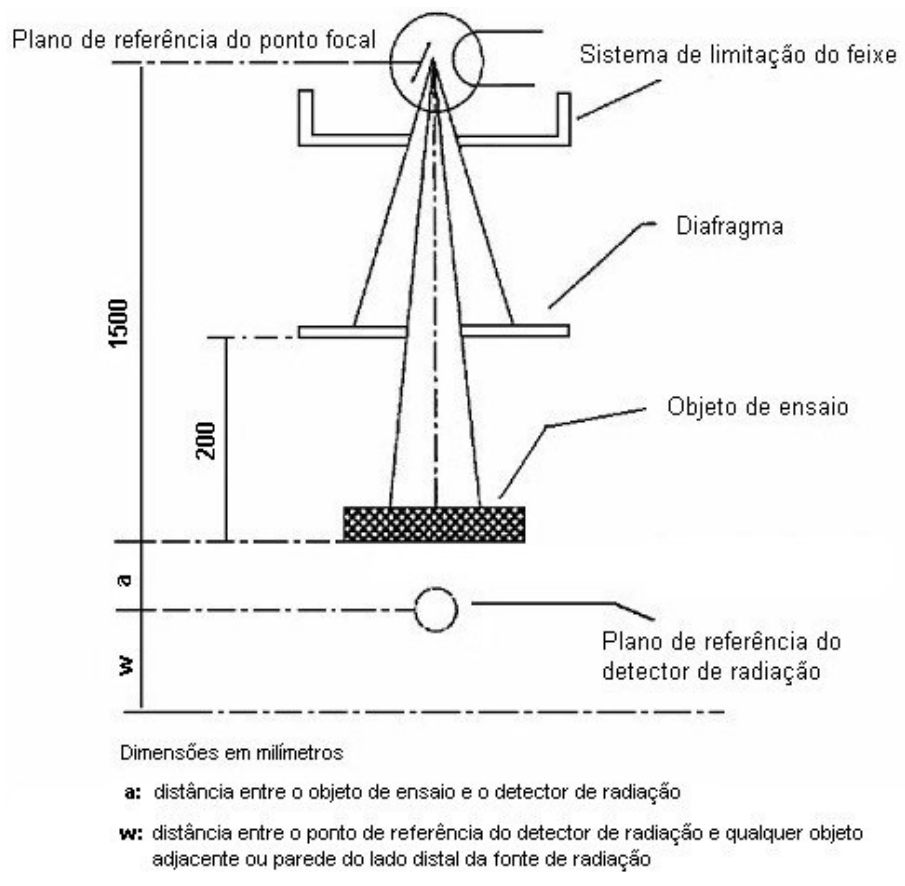

Figura 17 - Geometria de feixe estreito segundo a norma NBR / IEC $61331-1^{13}$ 
Tabela 3 - Qualidades de radiação descritas pela NBR/IEC 61331-1 e utilizadas nos testes

\begin{tabular}{c|c|c}
\hline $\begin{array}{c}\text { Tensão } \\
(\mathbf{k V})\end{array}$ & $\begin{array}{c}\text { Filtração Adicional }(\mathbf{m m C u}) \\
\text { NBR/IEC 61331-1 }\end{array}$ & $\begin{array}{c}\text { Filtração Adicional (mmCu) } \\
\text { utilizada }\end{array}$ \\
\hline \hline 80 & 0,15 & $0,16 \pm 0,01$ \\
\hline 100 & 0,25 & $0,25 \pm 0,01$ \\
\hline 150 & 0,70 & $0,73 \pm 0,02$ \\
\hline \hline
\end{tabular}

* com uma ondulação percentual nunca maior que 4.

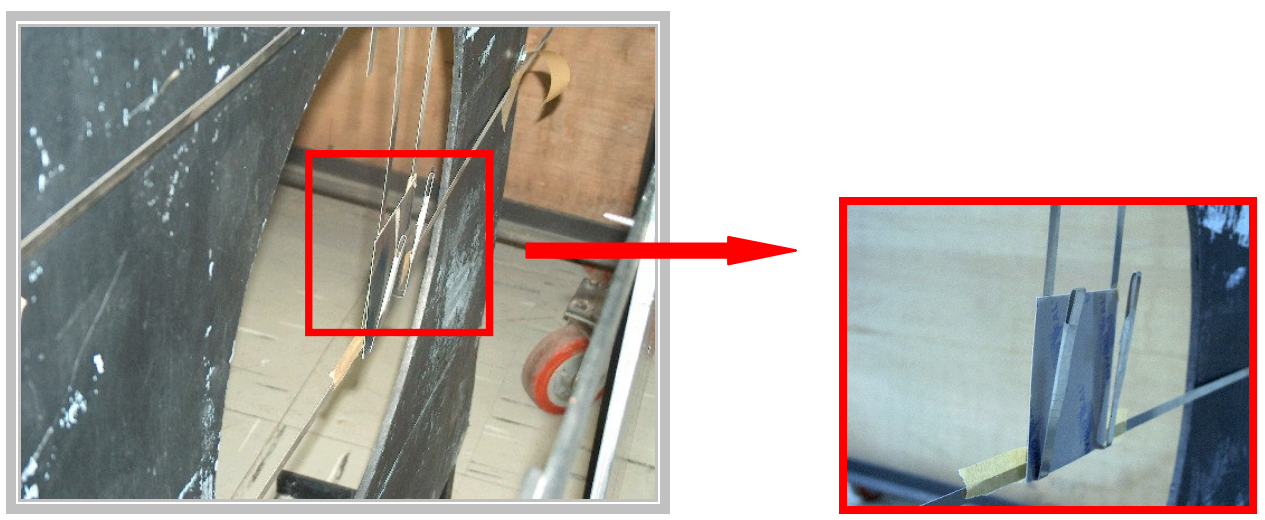

Figura 18 - Posicionamento dos filtros de chumbo padrão para a obtenção da curva de atenuação

Para a obtenção da espessura equivalente de atenuação em chumbo, as amostras (aventais de proteção e blindagens de ovário) foram penduradas no suporte para ensaio de atenuação de materiais na mesma posição que os filtros de chumbo, Figura 19, e os valores da taxa de kerma no ar transmitida foram medidos 20 vezes. 


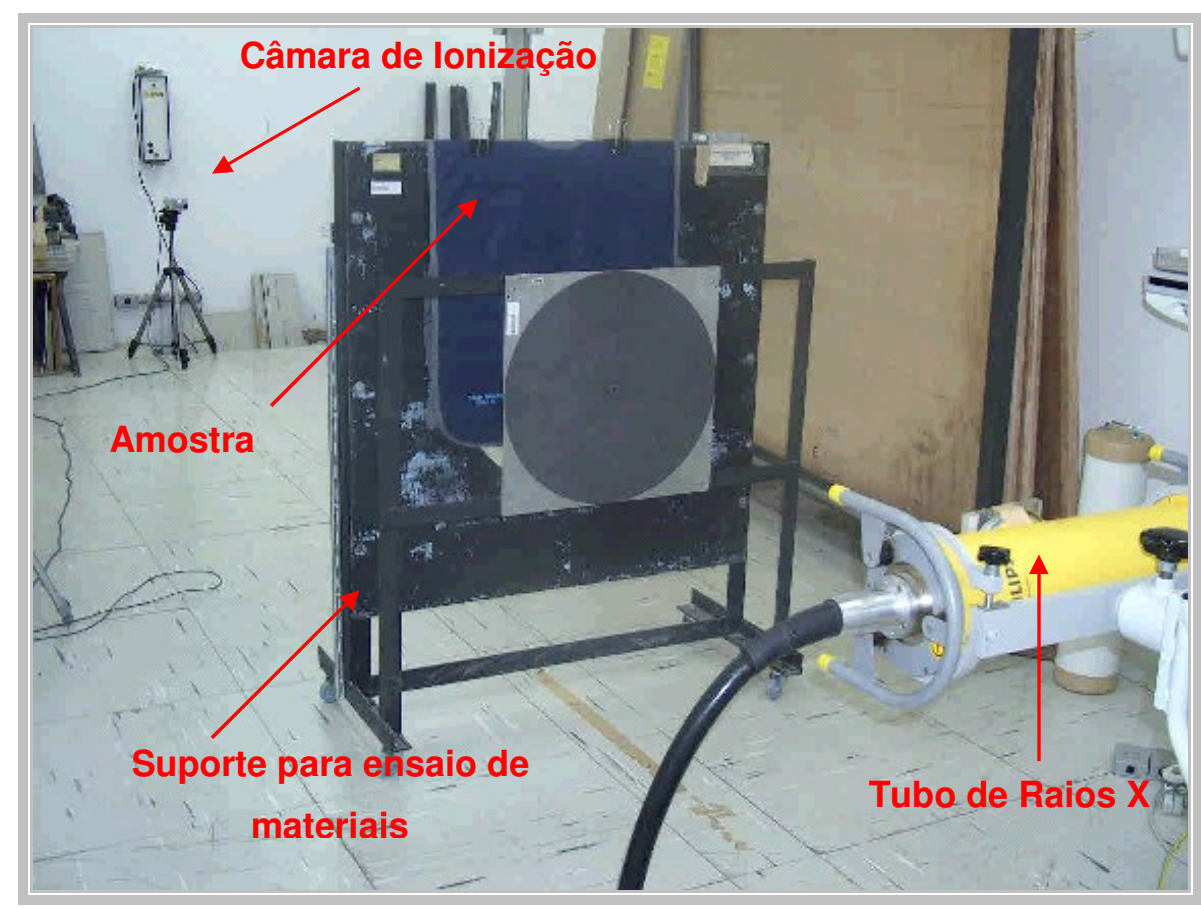

Figura 19 - Exemplo do posicionamento da amostra para a determinação da espessura equivalente de atenuação

Para se obter a espessura equivalente de atenuação em chumbo, os valores da taxa de kerma no ar obtidos (atenuados pelas amostras) foram comparados com a curva de atenuação do chumbo padrão, de maneira a encontrar a espessura de chumbo que fornecia o mesmo grau de atenuação.

Como era praticamente impossível encontrar exatamente a mesma taxa de kerma no ar (atenuada pela amostra) na curva de atenuação do chumbo padrão, foi necessário fazer o uso de métodos de ajuste da curva de atenuação do chumbo padrão, com a finalidade de se obter os valores intermediários. Para fins de comparação, os ajustes foram feitos utilizando-se três metodologias: interpolação linear, ajuste do somatório de exponenciais e o modelo empírico proposto por Archer et al $^{9}$. A descrição de cada método será apresentada no Capítulo 5.

Segundo a norma NBR / IEC 61331-1 ${ }^{13}$ a inomogeneidade ( $V$ ) do material de proteção é determinada como o maior desvio de um único valor de espessura equivalente de atenuação $\delta_{\mathrm{i}}$ em relação ao valor médio da espessura equivalente de atenuação $\delta$ (Equação 11), conforme é apresentado na Equação 12, onde $n$ é o número de localizações representativas sobre a superfície do dispositivo de proteção.

$$
\delta=\frac{1}{n} \sum_{i=1}^{n} \delta_{i}
$$




$$
V=\left|\delta-\delta_{i}\right|_{\text {máx }}
$$

Para a determinação da inomogeneidade (V) do material atenuador, o anel redutor foi encaixado no diafragma do suporte para ensaio de materiais e a taxa de kerma no ar foi determinada em cinco pontos diferentes (localizações representativas) do dispositivo de proteção.

\subsection{Avaliação das CARACterísticas de CONFECÇÃo}

Os testes para avaliação das características de confecção das amostras foram realizados segundo a norma NBR / IEC 61331-3 ${ }^{15}$. Foi elaborado um procedimento em forma de questionário que contemplava todos os itens requeridos pela norma. Dentre as características de confecção foram analisados os documentos acompanhantes, as prescrições gerais na marcação, o projeto, os materiais de atenuação e de revestimento, as dimensões e a marcação das etiquetas.

A avaliação dos documentos acompanhantes foi a mesma tanto para os aventais de proteção quanto para as blindagens de ovário, uma vez que a norma NBR / IEC 61331-3 ${ }^{15}$ trata este item como generalidade, ou seja, o item é uma exigência para todos os dispositivos de proteção aplicáveis à norma. Os documentos acompanhantes foram avaliados, por exemplo, quanto à presença de informações de limpeza, armazenamento, e método recomendado e freqüência da inspeção periódica pelo usuário.

A avaliação do projeto dos dispositivos foi feita conferindo-se se havia alguma superfície do material atenuador exposta e se o material atenuador possuía certificação segundo a NBR / IEC 61331-1 ${ }^{13}$.

Outras características de confecção, como por exemplo dimensões mínimas da largura, comprimento, dimensão do material atenuador nos ombros e nas costas também foram verificadas.

Os formulários desenvolvidos para estas verificações estão apresentados no Anexo 1. 


\section{RESULTADOS}

\subsection{ComercializaçÃo de ACEssórios de PRoteçÃo Radiológica No BRASIL}

Foi realizada uma pesquisa na internet, com o objetivo de verificar a quantidade de fabricantes e revendedores de equipamentos ou acessórios de proteção radiológica (avental de proteção, blindagem de ovário, luvas etc.) presentes no mercado brasileiro.

Nesta pesquisa, foram localizadas 24 empresas. Para cada empresa localizada, foi feito um contato telefônico que tinha como objetivo principal identificar o que a empresa comercializava e se ela era fabricante ou apenas revendedor.

Das 24 empresas localizadas foi possível identificar que 12 empresas comercializam acessórios de proteção radiológica, tais como aventais de proteção e blindagens de ovário, sendo que em 3 das 12 empresas não foi possível saber se ela fabricava ou apenas revendia. Isto se deve ao fato que em cada contato telefônico solicitava-se falar com o responsável pela empresa, porém nem sempre se obtinha um retorno por parte do responsável. A Figura 20 mostra o resultado da pesquisa.

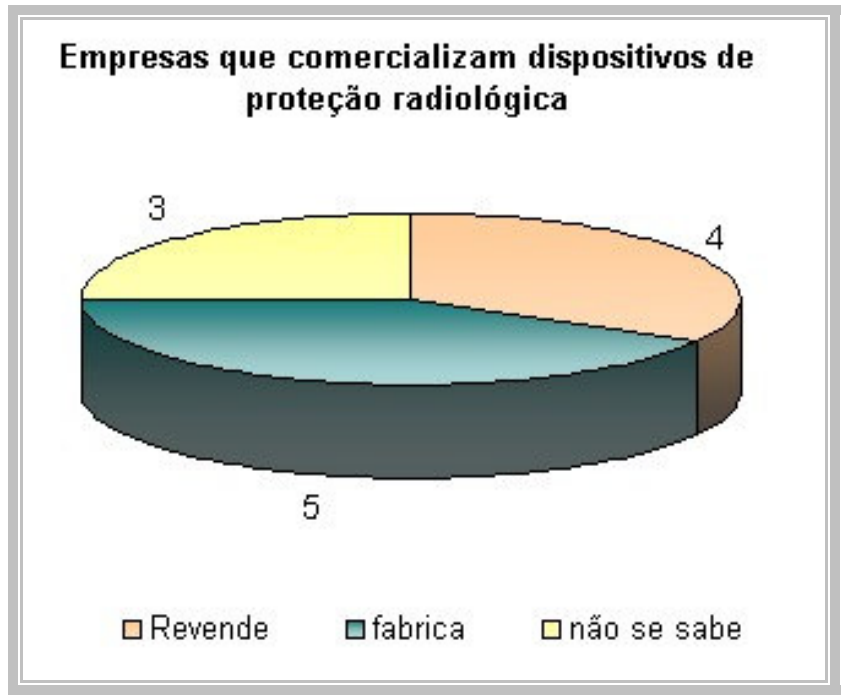
Figura 20 - Resultado da pesquisa com relação ao número de empresas que
comercializam acessórios de proteção radiológica

As empresas identificadas como fabricantes foram convidadas a participar deste trabalho, cedendo alguns dos modelos de acessórios de proteção radiológica 
fabricados. Como retorno, a empresa receberia um relatório não oficial relacionando as não conformidades dos modelos cedidos com a norma NBR/IEC 61331- $3^{15}$.

As 5 empresas aceitaram o convite e enviaram alguns de seus modelos, os quais já foram apresentados na Tabela 1.

\subsection{Característica de atenuação}

Para a determinação da espessura equivalente de atenuação dos aventais de proteção e das blindagens de ovário foram escolhidos três métodos: interpolação linear, modelo empírico proposto por Archer et $\mathrm{al}^{9} \mathrm{e}$ ajuste do somatório de exponenciais. Para os três métodos foram também avaliadas as incertezas que foram calculadas seguindo o procedimento proposto pelo GUM ${ }^{25}$.

\subsubsection{Método da Interpolação Linear}

O primeiro método utilizado para se determinar a espessura equivalente de atenuação das amostras avaliadas foi o método da interpolação linear.

Este método consistiu em se ajustar uma reta a dois pontos conhecidos na curva de atenuação do chumbo padrão, como mostra a Figura 21.

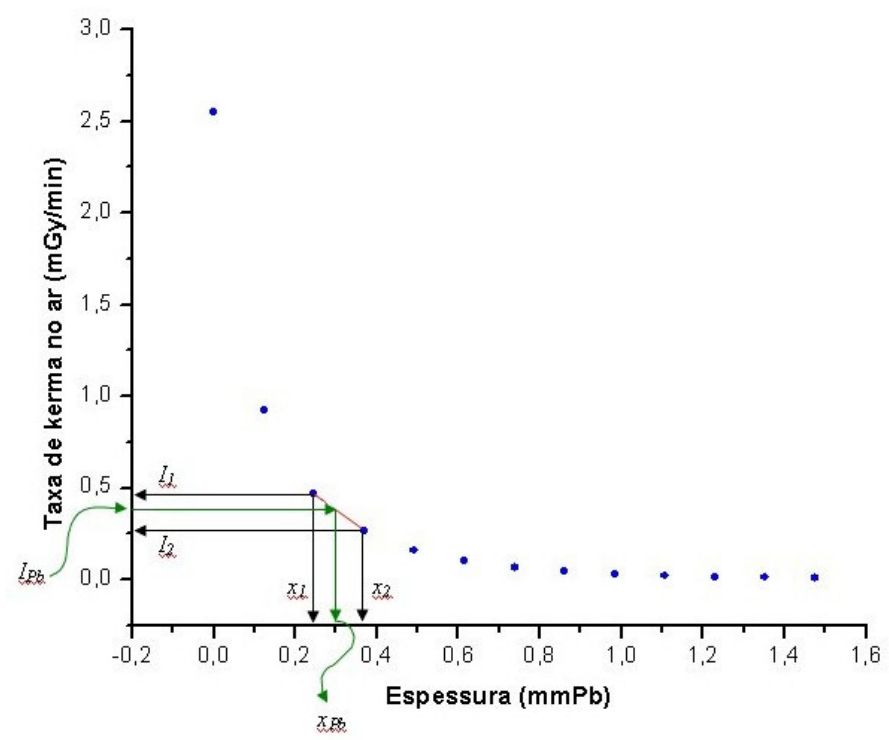

Figura 21 - Obtenção da espessura equivalente de atenuação em chumbo por meio da interpolação linear 
Para cada qualidade de radiação foi obtida uma curva de atenuação do chumbo padrão. Em seguida, media-se a taxa de kerma no ar transmitida em cada amostra, que foi denominado $\dot{K}_{P b}$.

Então, procurava-se entre os pontos experimentais da curva de atenuação do chumbo padrão um valor da taxa de kerma no ar imediatamente acima do valor de $\dot{K}_{P b}$, denominado $\dot{K}_{I_{1}}$ e um valor da taxa de kerma no ar imediatamente abaixo do valor de $\dot{K}_{P b}$, denominado $\dot{K}_{I_{2}}$.

Os valores das espessuras dos filtros de chumbo padrão que resultavam nas taxas de kerma no ar igual a $\dot{K}_{I_{1}}$ e $\dot{K}_{I_{2}}$ eram denominados $x_{1}$ e $x_{2}$, respectivamente. A partir desses dados, a Equação 13 era utilizada para se determinar a espessura equivalente de atenuação da amostra $\left(x_{P b}\right)$.

$$
x_{P b}=x_{2}+\left[\left(x_{1}-x_{2}\right) \cdot\left(\frac{\dot{K_{P b}}-\dot{K_{I_{2}}}}{\dot{K_{I_{1}}-\dot{K}_{I_{2}}}}\right)\right]
$$

\section{Equação 13}

Os valores de $\dot{K}_{I_{1}}, \dot{K}_{I_{2}}$ e $\dot{K}_{P b}$ foram obtidos por meio da média aritmética dos valores medidos da taxa de kerma no ar. Como já dito anteriormente, foram feitas 20 medições em cada ponto da determinação da curva de atenuação em chumbo e 20 medições da taxa de kerma no ar transmitida.

Com o objetivo de otimizar o procedimento para determinação da espessura equivalente de atenuação, foi necessário investigar se o número de medições em cada ponto influenciava no resultado final e contribuía significativamente para o aumento da incerteza do método. Desta forma, os valores de $\dot{K}_{I_{1}}, \dot{K}_{I_{2}}$ e $\dot{K}_{P b}$ também foram obtidos por meio da média aritmética dos dez e dos cinco primeiros valores da taxa de kerma no ar.

Buscando a otimização na determinação dos valores de $\dot{K}_{I_{1}}, \dot{K}_{I_{2}}, x_{1}$ e $x_{2}$, foram utilizadas as funções "ÍNDICE" e "CORRESP" do Microsoft Excel ${ }^{\circledR}$.

Os resultados obtidos para a espessura equivalente de atenuação dos aventais de proteção e blindagens de ovário pelo método da interpolação linear serão apresentados no item 5.2.1.2. 


\subsubsection{Avaliação das incertezas associadas à determinação da espessura equivalente de atenuação pelo método da interpolação linear}

Para o estudo das incertezas associadas à determinação da espessura equivalente de atenuação pelo método da interpolação linear, inicialmente foram pesquisadas as fontes de incerteza de cada parâmetro utilizado na Equação 13.

As condições atmosféricas do laboratório foram monitoradas durante os testes e observou-se flutuações não significativas na temperatura, pressão e umidade relativa. Além disso, Gregory et al ${ }^{29}$ relataram que as variações na resposta da câmara de ionização devido às flutuações das condições atmosféricas não influenciam as medições que são realizadas em um curto período de tempo.

Desta forma, apesar da resposta da câmara de ionização variar, dependendo das flutuações da temperatura, pressão e umidade relativa, neste estudo não foram consideradas tais fontes de incerteza, dado que cada conjunto de medições relativas foi realizado sempre em no máximo trinta minutos.

A incerteza combinada na determinação da espessura equivalente de atenuação $\left(u x_{P b i}\right)$ foi calculada utilizando-se a Equação 14:

$u x_{P b i}=\sqrt{\left(\frac{\partial \dot{K}_{P b}}{\partial x_{P b}}\right)^{2} \cdot u I_{P b}{ }^{2}+\left(\frac{\partial \dot{K}_{I_{1}}}{\partial x_{P b}}\right)^{2} \cdot u I_{1}{ }^{2}+\left(\frac{\partial \dot{K}_{I_{2}}}{\partial x_{P b}}\right)^{2} \cdot u I_{2}{ }^{2}+\left(\frac{\partial x_{1}}{\partial x_{P b}}\right)^{2} \cdot u x_{1}{ }^{2}+\left(\frac{\partial x_{2}}{\partial x_{P b}}\right)^{2} \cdot u x_{2}{ }^{2}}$

Equação 14

onde:

$u I_{P b}$ e $\frac{\partial \dot{K}_{P b}}{\partial x_{P b}}$ são a incerteza padrão na determinação de $\dot{K}_{P b}$ e o respectivo coeficiente de sensibilidade, em $\mathrm{mmPb} /(\mathrm{mGy} / \mathrm{min})$

$u I_{1}$ e $\frac{\partial \dot{K}_{I_{1}}}{\partial x_{P b}}$ são a incerteza padrão na determinação de $\dot{K}_{I_{1}}$ e o respectivo coeficiente de sensibilidade, em $\mathrm{mmPb} /(\mathrm{mGy} / \mathrm{min})$

$u I_{2}$ e $\frac{\partial \dot{K}_{I_{2}}}{\partial x_{P b}}$ são a incerteza padrão na determinação de $\dot{K}_{I_{2}}$ e o respectivo coeficiente de sensibilidade, em $\mathrm{mmPb} /(\mathrm{mGy} / \mathrm{min})$

$u x_{1}$ e $\frac{\partial x_{1}}{\partial x_{P b}}$ são a incerteza padrão na determinação de $x_{1}$ e o respectivo coeficiente de sensibilidade 


$$
\begin{gathered}
u x_{2} \text { e } \frac{\partial x_{2}}{\partial x_{P b}} \text { são a incerteza padrão na determinação de } x_{2} \text { e o respectivo } \\
\text { coeficiente de sensibilidade }
\end{gathered}
$$

A incerteza associada à determinação da espessura de uma lâmina de chumbo padrão foi obtida no procedimento da qualidade interno do Instituto de Eletrotécnica e Energia da USP nº 2005LG01PR010Y. A espessura de cada lâmina de chumbo, de acordo com este procedimento, é de $(0,123+0,003) \mathrm{mmPb}$ com nível de confiança de $68 \%$.

Desta forma, a incerteza padrão de $x_{1}$ foi calculada de acordo com a Equação 15 , onde $\sigma x$ é a incerteza combinada de uma lâmina de chumbo $(0,003 \mathrm{mmPb})$ e $n_{L}$ é o número de lâminas que resultam nas espessuras $x_{1}$. Sabendo que o valor da espessura de $x_{2}$ é o valor imediatamente acima da espessura de $x_{1}$, a incerteza padrão de $x_{2}$ foi calculada utilizando-se a Equação 16.

$$
\begin{aligned}
& u x_{1}=\sqrt{\sigma x^{2} \cdot n_{L}} \\
& u x_{2}=\sqrt{\sigma x^{2} \cdot\left(n_{L}+1\right)}
\end{aligned}
$$

Equação 16

A incerteza associada à determinação das taxas de kerma no ar, $\dot{K}_{I_{1}}, \dot{K}_{I_{2}}$ e $\dot{K}_{P b}$, foi estimada considerando-se como fonte do tipo A o desvio padrão experimental da média, determinado pela Equação 17; e como fontes do tipo $\mathrm{B}$ a resolução (Equação 18) e exatidão do monitor da câmara de ionização (Equação 19), do manual de instruções e especificados no item 3.3 deste trabalho.

$$
u_{A}=\frac{s(x)}{\sqrt{n}}
$$

Equação 17

onde $s(x)$ é o desvio padrão experimental

$n$ é o número de medições consideradas

$$
u_{\text {res }}=\frac{r e s}{\sqrt{3}} \cdot c=\frac{0,5}{\sqrt{3}} \cdot 0,001 \Rightarrow u_{\text {res }}=2,89 \times 10^{-4}
$$

onde res é a resolução do monitor da câmara de ionização ${ }^{28}$

$c$ é o coeficiente de sensibilidade em (mGy/min)/( $\mu \mathrm{Gy} / \mathrm{min})$ 


$$
u_{\text {exat }}=\dot{K}_{i} \cdot \text { exat }
$$

Equação 19

onde $\dot{K}_{i}$ é o valor de $\dot{K}_{I_{1}}, \dot{K}_{I_{2}}$ ou $\dot{K}_{P b}$

exat é a exatidão do monitor da câmara de ionização $=4 \%{ }^{28}$

A incerteza combinada destes três parâmetros foi determinada utilizando-se a Equação 20.

$$
u I_{i}=\sqrt{u_{A}^{2}+u_{\text {res }}^{2}+u_{\text {exat }}^{2}}
$$

\section{Equação 20}

Os coeficientes de sensibilidade, determinados a partir da derivada parcial de cada parâmetro com relação a $x_{P b}$, foram calculados com o auxílio do software Mathcad 2000 Professional ${ }^{\circledR}$. Nesse software também foi desenvolvida uma rotina em que, ao se inserir os valores de $\dot{K}_{I_{1}}, \dot{K}_{I_{2}}, \dot{K}_{P b}, x_{1}, x_{2}, \sigma I_{P}, \sigma I_{l}$ e $\sigma I_{2}$, obtinha-se os valores da espessura equivalente de atenuação e incerteza combinada automaticamente.

\subsubsection{Resultados das Espessuras Equivalente de Atenuação e Incertezas Associadas Obtidas pelo Método da Interpolação Linear}

Os resultados obtidos para a espessura equivalente de atenuação (equivalência calculada) em chumbo para os aventais $(A V)$ e blindagens de ovário (BO) do Fabricante A para as qualidades de 80 kV, 100 kV e 150 kV estão apresentados nas Tabelas 4 a 6 , respectivamente. Os resultados obtidos referentes ao Fabricante B para 80 kV, 100 kV e 150 kV estão apresentados nas Tabelas 7 a 9 , respectivamente. Do mesmo modo, os resultados do Fabricante $\mathrm{C}$ estão mostrados nas Tabelas 10 a 12, os resultados do Fabricante $D$ estão mostrados nas Tabelas 13 a 15 e os resultados do Fabricante E estão mostrados nas Tabelas 16 a 18.

Nessas tabelas também estão os resultados das incertezas calculadas e a diferença percentual entre os valores calculados e os valores declarados da espessura equivalente de atenuação em chumbo. 
Tabela 4 - Resultados da determinação da espessura equivalente de atenuação em chumbo, incerteza e diferença percentual entre o valor calculado e o valor nominal, para os aventais de proteção e blindagens de ovário do Fabricante A, em 80 kV. Método: interpolação linear

\begin{tabular}{|c|c|c|c|c|c|}
\hline Dispositivo & $\begin{array}{c}\text { Equivalência } \\
\text { Nominal (mmPb) }\end{array}$ & $\begin{array}{c}\text { № } \\
\text { Medições }\end{array}$ & $\begin{array}{c}\text { Equivalência } \\
\text { Calculada (mmPb) }\end{array}$ & $\begin{array}{c}\text { Incerteza } \\
(\mathrm{mmPb})\end{array}$ & $\begin{array}{c}\text { Diferença } \\
(\%)\end{array}$ \\
\hline \multirow{3}{*}{ AV1 } & \multirow{3}{*}{0,5} & 20 & 0,463 & 0,008 & $-8,0$ \\
\hline & & 10 & 0,463 & 0,007 & $-8,1$ \\
\hline & & 5 & 0,463 & 0,008 & $-7,9$ \\
\hline \multirow{3}{*}{ AV1 - costas } & \multirow{3}{*}{0,25} & 20 & 0,231 & 0,005 & $-8,4$ \\
\hline & & 10 & 0,230 & 0,005 & $-8,7$ \\
\hline & & 5 & 0,230 & 0,005 & $-8,7$ \\
\hline \multirow{3}{*}{$\mathrm{AV} 2$} & \multirow{3}{*}{0,5} & 20 & 0,447 & 0,007 & $-12,0$ \\
\hline & & 10 & 0,445 & 0,008 & $-12,4$ \\
\hline & & 5 & 0,443 & 0,008 & $-12,8$ \\
\hline \multirow{3}{*}{ AV2 - costas } & \multirow{3}{*}{0,25} & 20 & 0,232 & 0,005 & $-7,6$ \\
\hline & & 10 & 0,232 & 0,005 & $-8,0$ \\
\hline & & 5 & 0,232 & 0,005 & $-7,9$ \\
\hline \multirow{3}{*}{$\mathrm{AV} 3$} & \multirow{3}{*}{0,25} & 20 & 0,230 & 0,005 & $-8,9$ \\
\hline & & 10 & 0,229 & 0,005 & $-9,1$ \\
\hline & & 5 & 0,229 & 0,005 & $-9,0$ \\
\hline \multirow{3}{*}{ AV4 } & \multirow{3}{*}{0,25} & 20 & 0,231 & 0,005 & $-8,1$ \\
\hline & & 10 & 0,231 & 0,005 & $-8,4$ \\
\hline & & 5 & 0,231 & 0,005 & $-8,3$ \\
\hline \multirow{3}{*}{ AV5 } & \multirow{3}{*}{0,25} & 20 & 0,233 & 0,005 & $-7,5$ \\
\hline & & 10 & 0,232 & 0,005 & $-7,6$ \\
\hline & & 5 & 0,232 & 0,005 & $-7,7$ \\
\hline \multirow{3}{*}{ AV6 } & \multirow{3}{*}{0,5} & 20 & 0,452 & 0,007 & $-10,7$ \\
\hline & & 10 & 0,451 & 0,007 & $-10,8$ \\
\hline & & 5 & 0,450 & 0,009 & $-11,0$ \\
\hline \multirow{3}{*}{ AV7 } & \multirow{3}{*}{0,5} & 20 & 0,457 & 0,007 & $-9,5$ \\
\hline & & 10 & 0,455 & 0,008 & $-9,9$ \\
\hline & & 5 & 0,457 & 0,009 & $-9,4$ \\
\hline \multirow{3}{*}{ AV8 } & \multirow{3}{*}{0,5} & 20 & 0,463 & 0,008 & $-8,0$ \\
\hline & & 10 & 0,461 & 0,007 & $-8,5$ \\
\hline & & 5 & 0,461 & 0,008 & $-8,4$ \\
\hline \multirow{3}{*}{ AV9 } & \multirow{3}{*}{0,25} & 20 & 0,238 & 0,005 & $-4,8$ \\
\hline & & 10 & 0,238 & 0,005 & $-5,2$ \\
\hline & & 5 & 0,237 & 0,005 & $-5,4$ \\
\hline \multirow{3}{*}{ AV10 } & & 20 & 0,234 & 0,005 & $-6,8$ \\
\hline & 0,25 & 10 & 0,234 & 0,005 & $-7,0$ \\
\hline & & 5 & 0,233 & 0,005 & $-7,2$ \\
\hline & & 20 & 0,459 & 0,008 & $-8,9$ \\
\hline BO1 & 0,5 & 10 & 0,459 & 0,008 & $-8,9$ \\
\hline & & 5 & 0,459 & 0,010 & $-8,8$ \\
\hline & & 20 & 0,463 & 0,008 & $-8,1$ \\
\hline BO2 & 0,5 & 10 & 0,460 & 0,008 & $-8,7$ \\
\hline & & 5 & 0,461 & 0,009 & $-8,4$ \\
\hline & & 20 & 0,459 & 0,008 & $-8,9$ \\
\hline BO3 & 0,5 & 10 & 0,458 & 0,008 & $-9,1$ \\
\hline & & 5 & 0,458 & 0,009 & $-9,1$ \\
\hline
\end{tabular}


Tabela 5 - Resultados da determinação da espessura equivalente de atenuação em chumbo, incerteza e diferença percentual entre o valor calculado e o valor nominal, para os aventais de proteção e blindagens de ovário Fabricante A, em 100 kV.

Método: interpolação linear

\begin{tabular}{|c|c|c|c|c|c|}
\hline $\begin{array}{l}\text { Dispositivo } \\
\text { de proteção }\end{array}$ & $\begin{array}{c}\text { Equivalência } \\
\text { Nominal (mmPb) }\end{array}$ & $\begin{array}{c}\text { № } \\
\text { Medições }\end{array}$ & $\begin{array}{c}\text { Equivalência } \\
\text { Calculada (mmPb) }\end{array}$ & $\begin{array}{c}\text { Incerteza } \\
(\mathrm{mmPb})\end{array}$ & $\begin{array}{l}\text { Diferença } \\
(\%)\end{array}$ \\
\hline \multirow{3}{*}{ AV1 } & \multirow{3}{*}{0,5} & 20 & 0,454 & 0,008 & $-10,0$ \\
\hline & & 10 & 0,455 & 0,008 & $-9,9$ \\
\hline & & 5 & 0,455 & 0,008 & $-10,0$ \\
\hline \multirow{3}{*}{ AV1 - costas } & \multirow{3}{*}{0,25} & 20 & 0,228 & 0,006 & $-9,5$ \\
\hline & & 10 & 0,229 & 0,006 & $-9,2$ \\
\hline & & 5 & 0,229 & 0,006 & $-9,4$ \\
\hline \multirow{3}{*}{ AV2 } & \multirow{3}{*}{0,5} & 20 & 0,451 & 0,008 & $-10,9$ \\
\hline & & 10 & 0,451 & 0,008 & $-10,9$ \\
\hline & & 5 & 0,450 & 0,008 & $-11,1$ \\
\hline \multirow{3}{*}{ AV2 - costas } & \multirow{3}{*}{0,25} & 20 & 0,233 & 0,006 & $-7,4$ \\
\hline & & 10 & 0,233 & 0,006 & $-7,4$ \\
\hline & & 5 & 0,233 & 0,006 & $-7,5$ \\
\hline \multirow{3}{*}{$\mathrm{AV} 3$} & \multirow{3}{*}{0,25} & 20 & 0,228 & 0,006 & $-9,4$ \\
\hline & & 10 & 0,229 & 0,006 & $-9,3$ \\
\hline & & 5 & 0,228 & 0,006 & $-9,6$ \\
\hline \multirow{3}{*}{ AV4 } & \multirow{3}{*}{0,25} & 20 & 0,232 & 0,006 & $-7,6$ \\
\hline & & 10 & 0,233 & 0,006 & $-7,5$ \\
\hline & & 5 & 0,232 & 0,006 & $-7,6$ \\
\hline \multirow{3}{*}{ AV5 } & \multirow{3}{*}{0,25} & 20 & 0,231 & 0,006 & $-8,1$ \\
\hline & & 10 & 0,232 & 0,006 & $-7,9$ \\
\hline & & 5 & 0,231 & 0,006 & $-8,1$ \\
\hline \multirow{3}{*}{ AV6 } & \multirow{3}{*}{0,5} & 20 & 0,450 & 0,008 & $-11,1$ \\
\hline & & 10 & 0,450 & 0,008 & $-11,2$ \\
\hline & & 5 & 0,448 & 0,008 & $-11,5$ \\
\hline \multirow{3}{*}{ AV7 } & \multirow{3}{*}{0,5} & 20 & 0,458 & 0,008 & $-9,1$ \\
\hline & & 10 & 0,458 & 0,008 & $-9,1$ \\
\hline & & 5 & 0,459 & 0,009 & $-9,0$ \\
\hline \multirow{3}{*}{ AV8 } & \multirow{3}{*}{0,5} & 20 & 0,432 & 0,008 & $-15,9$ \\
\hline & & 10 & 0,431 & 0,008 & $-15,9$ \\
\hline & & 5 & 0,430 & 0,008 & $-16,4$ \\
\hline \multirow{3}{*}{ AV9 } & \multirow{3}{*}{0,25} & 20 & 0,233 & 0,006 & $-7,3$ \\
\hline & & 10 & 0,233 & 0,006 & $-7,1$ \\
\hline & & 5 & 0,233 & 0,006 & $-7,5$ \\
\hline \multirow{3}{*}{ AV10 } & & 20 & 0,235 & 0,006 & $-6,3$ \\
\hline & 0,25 & 10 & 0,235 & 0,006 & $-6,2$ \\
\hline & & 5 & 0,235 & 0,006 & $-6,5$ \\
\hline & & 20 & 0,458 & 0,008 & $-9,2$ \\
\hline BO1 & 0,5 & 10 & 0,457 & 0,008 & $-9,3$ \\
\hline & & 5 & 0,455 & 0,008 & $-9,8$ \\
\hline & & 20 & 0,461 & 0,008 & $-8,5$ \\
\hline BO2 & 0,5 & 10 & 0,460 & 0,008 & $-8,7$ \\
\hline & & 5 & 0,458 & 0,008 & $-9,3$ \\
\hline & & 20 & 0,459 & 0,008 & $-8,9$ \\
\hline BO3 & 0,5 & 10 & 0,458 & 0,008 & $-9,1$ \\
\hline & & 5 & 0,457 & 0,008 & $-9,4$ \\
\hline
\end{tabular}


Tabela 6 - Resultados da determinação da espessura equivalente de atenuação em chumbo, incerteza e diferença percentual entre o valor calculado e o valor nominal, para os aventais de proteção e blindagens de ovário do Fabricante A, em 150 kV. Método: interpolação linear

\begin{tabular}{|c|c|c|c|c|c|}
\hline Dispositivo & $\begin{array}{c}\text { Equivalência } \\
\text { Nominal (mmPb) }\end{array}$ & $\begin{array}{c}\text { № } \\
\text { Medições }\end{array}$ & $\begin{array}{c}\text { Equivalência } \\
\text { Calculada (mmPb) }\end{array}$ & $\begin{array}{c}\text { Incerteza } \\
(\mathrm{mmPb})\end{array}$ & $\begin{array}{c}\text { Diferença } \\
\text { (\%) }\end{array}$ \\
\hline \multirow{3}{*}{ AV1 } & \multirow{3}{*}{0,5} & 20 & 0,457 & 0,009 & $-9,5$ \\
\hline & & 10 & 0,457 & 0,009 & $-9,4$ \\
\hline & & 5 & 0,458 & 0,009 & $-9,3$ \\
\hline \multirow{3}{*}{ AV1 - costas } & \multirow{3}{*}{0,25} & 20 & 0,228 & 0,007 & $-9,7$ \\
\hline & & 10 & 0,228 & 0,007 & $-9,8$ \\
\hline & & 5 & 0,228 & 0,007 & $-9,7$ \\
\hline \multirow{3}{*}{ AV2 } & \multirow{3}{*}{0,5} & 20 & 0,457 & 0,009 & $-9,4$ \\
\hline & & 10 & 0,457 & 0,009 & $-9,4$ \\
\hline & & 5 & 0,459 & 0,009 & $-8,9$ \\
\hline \multirow{3}{*}{ AV2 - costas } & \multirow{3}{*}{0,5} & 20 & 0,228 & 0,007 & $-9,5$ \\
\hline & & 10 & 0,228 & 0,007 & $-9,6$ \\
\hline & & 5 & 0,228 & 0,007 & $-9,6$ \\
\hline \multirow{3}{*}{$\mathrm{AV} 3$} & \multirow{3}{*}{0,25} & 20 & 0,228 & 0,007 & $-9,6$ \\
\hline & & 10 & 0,228 & 0,007 & $-9,8$ \\
\hline & & 5 & 0,228 & 0,007 & $-9,7$ \\
\hline \multirow{3}{*}{ AV4 } & \multirow{3}{*}{0,25} & 20 & 0,232 & 0,007 & $-7,6$ \\
\hline & & 10 & 0,232 & 0,007 & $-7,7$ \\
\hline & & 5 & 0,232 & 0,007 & $-7,6$ \\
\hline \multirow{3}{*}{ AV5 } & \multirow{3}{*}{0,25} & 20 & 0,233 & 0,007 & $-7,3$ \\
\hline & & 10 & 0,233 & 0,007 & $-7,4$ \\
\hline & & 5 & 0,233 & 0,007 & $-7,3$ \\
\hline \multirow{3}{*}{ AV6 } & \multirow{3}{*}{0,25} & 20 & 0,458 & 0,009 & $-9,3$ \\
\hline & & 10 & 0,459 & 0,009 & $-9,0$ \\
\hline & & 5 & 0,459 & 0,009 & $-9,0$ \\
\hline \multirow{3}{*}{ AV7 } & \multirow{3}{*}{0,5} & 20 & 0,463 & 0,009 & $-8,0$ \\
\hline & & 10 & 0,463 & 0,009 & $-7,9$ \\
\hline & & 5 & 0,464 & 0,009 & $-7,8$ \\
\hline \multirow{3}{*}{ AV8 } & \multirow{3}{*}{0,5} & 20 & 0,471 & 0,009 & $-6,2$ \\
\hline & & 10 & 0,471 & 0,009 & $-6,2$ \\
\hline & & 5 & 0,471 & 0,009 & $-6,1$ \\
\hline \multirow{3}{*}{ AV9 } & \multirow{3}{*}{0,5} & 20 & 0,232 & 0,007 & $-7,5$ \\
\hline & & 10 & 0,232 & 0,007 & $-7,6$ \\
\hline & & 5 & 0,233 & 0,007 & $-7,4$ \\
\hline \multirow{3}{*}{ AV10 } & & 20 & 0,236 & 0,007 & $-6,0$ \\
\hline & 0,25 & 10 & 0,235 & 0,007 & $-6,2$ \\
\hline & & 5 & 0,236 & 0,007 & $-6,0$ \\
\hline & & 20 & 0,472 & 0,009 & $-6,0$ \\
\hline BO1 & 0,25 & 10 & 0,473 & 0,009 & $-5,8$ \\
\hline & & 5 & 0,474 & 0,009 & $-5,6$ \\
\hline & & 20 & 0,458 & 0,009 & $-9,3$ \\
\hline BO2 & 0,5 & 10 & 0,456 & 0,009 & $-9,6$ \\
\hline & & 5 & 0,458 & 0,009 & $-9,2$ \\
\hline & & 20 & 0,465 & 0,009 & $-7,6$ \\
\hline BO3 & 0,5 & 10 & 0,464 & 0,009 & $-7,7$ \\
\hline & & 5 & 0,465 & 0,009 & $-7,6$ \\
\hline
\end{tabular}


Tabela 7 - Resultados da determinação da espessura equivalente de atenuação em chumbo, incerteza e diferença percentual entre o valor calculado e o valor nominal, para os aventais de proteção e blindagens de ovário do Fabricante $\mathrm{B}, \mathrm{em} 80 \mathrm{kV}$. Método: interpolação linear

\begin{tabular}{|c|c|c|c|c|c|}
\hline $\begin{array}{l}\text { Dispositivo } \\
\text { de proteção }\end{array}$ & $\begin{array}{c}\text { Equivalência } \\
\text { Nominal (mmPb) }\end{array}$ & $\begin{array}{c}\text { № } \\
\text { Medições }\end{array}$ & $\begin{array}{c}\text { Equivalência } \\
\text { Calculada (mmPb) }\end{array}$ & $\begin{array}{c}\text { Incerteza } \\
(\mathrm{mmPb})\end{array}$ & $\begin{array}{c}\text { Diferença } \\
(\%)\end{array}$ \\
\hline \multirow{3}{*}{$\mathrm{AV} 1$} & \multirow{3}{*}{0,25} & 20 & 0,240 & 0,005 & $-4,1$ \\
\hline & & 10 & 0,240 & 0,005 & $-4,3$ \\
\hline & & 5 & 0,240 & 0,005 & $-4,4$ \\
\hline \multirow{3}{*}{ AV2 } & \multirow{3}{*}{0,25} & 20 & 0,244 & 0,005 & $-2,3$ \\
\hline & & 10 & 0,244 & 0,005 & $-2,5$ \\
\hline & & 5 & 0,244 & 0,005 & $-2,5$ \\
\hline \multirow{3}{*}{$\mathrm{AV} 3$} & \multirow{3}{*}{0,25} & 20 & 0,272 & 0,008 & 8,3 \\
\hline & & 10 & 0,272 & 0,008 & 8,1 \\
\hline & & 5 & 0,271 & 0,008 & 7,9 \\
\hline \multirow{3}{*}{$\mathrm{AV} 4$} & \multirow{3}{*}{0,25} & 20 & 0,244 & 0,005 & $-2,3$ \\
\hline & & 10 & 0,244 & 0,005 & $-2,4$ \\
\hline & & 5 & 0,243 & 0,005 & $-2,7$ \\
\hline \multirow{3}{*}{ BO1 } & \multirow{3}{*}{0,5} & 20 & 0,473 & 0,008 & $-5,7$ \\
\hline & & 10 & 0,472 & 0,008 & $-5,9$ \\
\hline & & 5 & 0,472 & 0,009 & $-5,9$ \\
\hline \multirow{3}{*}{ BO2 } & \multirow{3}{*}{0,5} & 20 & 0,492 & 0,009 & $-1,6$ \\
\hline & & 10 & 0,490 & 0,008 & $-2,0$ \\
\hline & & 5 & 0,491 & 0,010 & $-1,7$ \\
\hline \multirow{3}{*}{$\mathrm{BO} 3$} & \multirow{3}{*}{0,5} & 20 & 0,470 & 0,008 & $-6,4$ \\
\hline & & 10 & 0,468 & 0,008 & $-6,8$ \\
\hline & & 5 & 0,468 & 0,008 & $-6,7$ \\
\hline
\end{tabular}

Tabela 8 - Resultados da determinação da espessura equivalente de atenuação em chumbo, incerteza e diferença percentual entre o valor calculado e o valor nominal, para os aventais de proteção e blindagens de ovário do Fabricante $\mathrm{B}$, em $100 \mathrm{kV}$.

Método: interpolação linear

\begin{tabular}{|c|c|c|c|c|c|}
\hline $\begin{array}{l}\text { Dispositivo } \\
\text { de proteção }\end{array}$ & $\begin{array}{c}\text { Equivalência } \\
\text { Nominal (mmPb) }\end{array}$ & $\begin{array}{c}\text { № } \\
\text { Medições }\end{array}$ & $\begin{array}{c}\text { Equivalência } \\
\text { Calculada (mmPb) }\end{array}$ & $\begin{array}{l}\text { Incerteza } \\
(\mathrm{mmPb})\end{array}$ & $\begin{array}{l}\text { Diferença } \\
\text { (\%) }\end{array}$ \\
\hline \multirow{3}{*}{$\mathrm{AV} 1$} & \multirow{3}{*}{0,25} & 20 & 0,240 & 0,006 & $-4,3$ \\
\hline & & 10 & 0,240 & 0,006 & $-4,0$ \\
\hline & & 5 & 0,240 & 0,006 & $-4,1$ \\
\hline \multirow{3}{*}{ AV2 } & \multirow{3}{*}{0,25} & 20 & 0,243 & 0,006 & $-2,9$ \\
\hline & & 10 & 0,243 & 0,006 & $-2,7$ \\
\hline & & 5 & 0,243 & 0,006 & $-3,0$ \\
\hline \multirow{3}{*}{$\mathrm{AV} 3$} & \multirow{3}{*}{0,25} & 20 & 0,282 & 0,008 & 11,5 \\
\hline & & 10 & 0,283 & 0,008 & 11,7 \\
\hline & & 5 & 0,282 & 0,008 & 11,3 \\
\hline \multirow{3}{*}{ AV4 } & \multirow{3}{*}{0,25} & 20 & 0,244 & 0,006 & $-2,3$ \\
\hline & & 10 & 0,245 & 0,006 & $-2,1$ \\
\hline & & 5 & 0,244 & 0,006 & $-2,3$ \\
\hline \multirow{3}{*}{ BO1 } & \multirow{3}{*}{0,5} & 20 & 0,474 & 0,008 & $-5,5$ \\
\hline & & 10 & 0,474 & 0,008 & $-5,6$ \\
\hline & & 5 & 0,473 & 0,009 & $-5,8$ \\
\hline \multirow{3}{*}{ BO2 } & \multirow{3}{*}{0,5} & 20 & 0,490 & 0,009 & $-2,1$ \\
\hline & & 10 & 0,489 & 0,009 & $-2,2$ \\
\hline & & 5 & 0,488 & 0,009 & $-2,4$ \\
\hline \multirow{3}{*}{$\mathrm{BO} 3$} & \multirow{3}{*}{0,5} & 20 & 0,469 & 0,008 & $-6,6$ \\
\hline & & 10 & 0,469 & 0,009 & $-6,5$ \\
\hline & & 5 & 0,471 & 0,009 & $-6,2$ \\
\hline
\end{tabular}


Tabela 9 - Resultados da determinação da espessura equivalente de atenuação em chumbo, incerteza e diferença percentual entre o valor calculado e o valor nominal, para os aventais de proteção e blindagens de ovário do Fabricante B, em 150 kV. Método: interpolação linear

\begin{tabular}{|c|c|c|c|c|c|}
\hline $\begin{array}{l}\text { Dispositivo } \\
\text { de proteção }\end{array}$ & $\begin{array}{c}\text { Equivalência } \\
\text { Nominal (mmPb) }\end{array}$ & $\begin{array}{c}\text { № } \\
\text { Medições }\end{array}$ & $\begin{array}{c}\text { Equivalência } \\
\text { Calculada (mmPb) }\end{array}$ & $\begin{array}{c}\text { Incerteza } \\
\text { (mmPb) }\end{array}$ & $\begin{array}{c}\text { Diferença } \\
(\%)\end{array}$ \\
\hline \multirow{3}{*}{ AV1 } & \multirow[t]{3}{*}{ 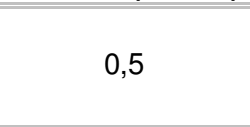 } & 20 & 0,240 & 0,007 & $-4,0$ \\
\hline & & 10 & 0,241 & 0,007 & $-3,9$ \\
\hline & & 5 & 0,241 & 0,007 & $-3,8$ \\
\hline \multirow{3}{*}{ AV2 } & \multirow{3}{*}{0,25} & 20 & 0,246 & 0,011 & $-1,4$ \\
\hline & & 10 & 0,246 & 0,011 & $-1,5$ \\
\hline & & 5 & 0,247 & 0,011 & $-1,1$ \\
\hline \multirow{3}{*}{ AV3 } & \multirow{3}{*}{0,25} & 20 & 0,281 & 0,009 & 10,9 \\
\hline & & 10 & 0,281 & 0,009 & 10,9 \\
\hline & & 5 & 0,281 & 0,009 & 11,1 \\
\hline \multirow{3}{*}{ AV4 } & \multirow{3}{*}{0,25} & 20 & 0,252 & 0,011 & 0,9 \\
\hline & & 10 & 0,252 & 0,011 & 0,8 \\
\hline & & 5 & 0,253 & 0,011 & 1,1 \\
\hline \multirow{3}{*}{ BO1 } & \multirow{3}{*}{0,25} & 20 & 0,491 & 0,013 & $-1,8$ \\
\hline & & 10 & 0,496 & 0,013 & $-0,9$ \\
\hline & & 5 & 0,497 & 0,013 & $-0,5$ \\
\hline \multirow{3}{*}{ BO2 } & \multirow{3}{*}{0,5} & 20 & 0,491 & 0,009 & $-1,9$ \\
\hline & & 10 & 0,490 & 0,009 & $-2,0$ \\
\hline & & 5 & 0,491 & 0,009 & $-1,8$ \\
\hline \multirow{3}{*}{$\mathrm{BO} 3$} & \multirow{3}{*}{0,5} & 20 & 0,479 & 0,009 & $-4,4$ \\
\hline & & 10 & 0,479 & 0,009 & $-4,4$ \\
\hline & & 5 & 0,479 & 0,009 & $-4,5$ \\
\hline
\end{tabular}

Tabela 10 - Resultados da determinação da espessura equivalente de atenuação em chumbo, incerteza e diferença percentual entre o valor calculado e o valor nominal, para os aventais de proteção do Fabricante C, em 80 kV. Método: interpolação linear

\begin{tabular}{cccccc}
\hline \hline $\begin{array}{c}\text { Dispositivo } \\
\text { de proteção }\end{array}$ & $\begin{array}{c}\text { Equivalência } \\
\text { Nominal (mmPb) }\end{array}$ & $\begin{array}{c}\text { No } \\
\text { Medições }\end{array}$ & $\begin{array}{c}\text { Equivalência } \\
\text { Calculada (mmPb) }\end{array}$ & $\begin{array}{c}\text { Incerteza } \\
(\mathbf{m m P b})\end{array}$ & $\begin{array}{c}\text { Diferença } \\
(\%)\end{array}$ \\
\hline \hline \multirow{2}{*}{ AV1 } & \multirow{2}{*}{0,5} & 20 & 0,521 & 0,011 & 4,1 \\
& & 10 & 0,521 & 0,012 & 3,9 \\
\hline \hline \multirow{2}{*}{ AV2 } & \multirow{2}{*}{0,25} & 5 & 0,523 & 0,012 & 4,3 \\
\hline \hline & & 10 & 0,289 & 0,007 & 13,4 \\
& & 5 & 0,288 & 0,007 & 13,2 \\
\hline \hline
\end{tabular}


Tabela 11 - Resultados da determinação da espessura equivalente de atenuação em chumbo, incerteza e diferença percentual entre o valor calculado e o valor nominal, para os aventais de proteção do Fabricante C, em 100 kV. Método: interpolação linear

\begin{tabular}{cccccc}
\hline \hline $\begin{array}{c}\text { Dispositivo } \\
\text { de proteção }\end{array}$ & $\begin{array}{c}\text { Equivalência } \\
\text { Nominal (mmPb) }\end{array}$ & $\begin{array}{c}\text { No } \\
\text { Medições }\end{array}$ & $\begin{array}{c}\text { Equivalência } \\
\text { Calculada (mmPb) }\end{array}$ & $\begin{array}{c}\text { Incerteza } \\
(\mathbf{m m P b})\end{array}$ & $\begin{array}{c}\text { Diferença } \\
(\%)\end{array}$ \\
\hline \hline \multirow{2}{*}{ AV1 } & \multirow{2}{*}{0,5} & 20 & 0,567 & 0,009 & 11,8 \\
& & 10 & 0,565 & 0,009 & 11,5 \\
\cline { 3 - 6 } & \multirow{2}{*}{0,25} & 5 & 0,565 & 0,009 & 11,5 \\
\hline \hline \multirow{2}{*}{ AV2 } & 20 & 0,271 & 0,009 & 7,6 \\
& & 10 & 0,270 & 0,009 & 7,5 \\
\hline \hline
\end{tabular}

Tabela 12 - Resultados da determinação da espessura equivalente de atenuação em chumbo, incerteza e diferença percentual entre o valor calculado e o valor nominal, para os aventais de proteção do Fabricante C em 150 kV. Método: interpolação linear

\begin{tabular}{cccccc}
\hline \hline $\begin{array}{c}\text { Dispositivo de } \\
\text { proteção }\end{array}$ & $\begin{array}{c}\text { Equivalência Nominal } \\
(\mathbf{m m P b})\end{array}$ & $\begin{array}{c}\text { No } \\
\text { Medições }\end{array}$ & $\begin{array}{c}\text { Equivalência } \\
\text { Calculada (mmPb) }\end{array}$ & $\begin{array}{c}\text { Incerteza } \\
(\mathbf{m m P b})\end{array}$ & $\begin{array}{c}\text { Diferença } \\
(\%)\end{array}$ \\
\hline \hline \multirow{2}{*}{ AV1 } & \multirow{2}{*}{0,5} & 20 & 0,572 & 0,010 & 12,5 \\
& & 10 & 0,570 & 0,012 & 12,4 \\
\hline \hline \multirow{3}{*}{ AV2 } & 5 & 0,567 & 0,017 & 11,9 \\
\hline \multirow{2}{*}{0,5} & 20 & 0,278 & 0,009 & 10,2 \\
\hline & & 10 & 0,278 & 0,009 & 10,2 \\
\hline
\end{tabular}


Tabela 13 - Resultados da determinação da espessura equivalente de atenuação em chumbo, incerteza e diferença percentual entre o valor calculado e o valor nominal, para os aventais de proteção do Fabricante D em 80 kV. Método: interpolação linear

\begin{tabular}{|c|c|c|c|c|c|}
\hline $\begin{array}{l}\text { Dispositivo } \\
\text { de proteção }\end{array}$ & $\begin{array}{c}\text { Equivalência } \\
\text { Nominal (mmPb) }\end{array}$ & $\begin{array}{c}\text { № } \\
\text { Medições } \\
\end{array}$ & $\begin{array}{c}\text { Equivalência } \\
\text { Calculada }(\mathrm{mmPb})\end{array}$ & $\begin{array}{c}\text { Incerteza } \\
(\mathrm{mmPb})\end{array}$ & $\begin{array}{c}\text { Diferença } \\
(\%)\end{array}$ \\
\hline \multirow{3}{*}{$\mathrm{AV} 1$} & \multirow{3}{*}{0,25} & 20 & 0,210 & 0,005 & $-19,2$ \\
\hline & & 10 & 0,209 & 0,005 & $-19,7$ \\
\hline & & 5 & 0,209 & 0,005 & $-19,8$ \\
\hline \multirow{3}{*}{ AV2 } & \multirow{3}{*}{0,5} & 20 & 0,565 & 0,009 & 11,5 \\
\hline & & 10 & 0,563 & 0,009 & 11,2 \\
\hline & & 5 & 0,568 & 0,009 & 11,9 \\
\hline \multirow{3}{*}{ AV3 } & \multirow{3}{*}{0,25} & 20 & 0,292 & 0,007 & 14,4 \\
\hline & & 10 & 0,292 & 0,007 & 14,2 \\
\hline & & 5 & 0,289 & 0,007 & 13,5 \\
\hline \multirow{3}{*}{ AV4 } & \multirow{3}{*}{0,25} & 20 & 0,261 & 0,008 & 4,4 \\
\hline & & 10 & 0,260 & 0,008 & 4,0 \\
\hline & & 5 & 0,258 & 0,008 & 3,2 \\
\hline \multirow{3}{*}{ AV5 } & \multirow{3}{*}{0,25} & 20 & 0,227 & 0,005 & $-10,2$ \\
\hline & & 10 & 0,227 & 0,005 & $-10,1$ \\
\hline & & 5 & 0,226 & 0,005 & $-10,6$ \\
\hline \multirow{3}{*}{ AV6 } & \multirow{3}{*}{0,5} & 20 & 0,399 & 0,009 & $-25,2$ \\
\hline & & 10 & 0,400 & 0,010 & $-25,0$ \\
\hline & & 5 & 0,398 & 0,011 & $-25,7$ \\
\hline \multirow{3}{*}{ AV7 } & \multirow{3}{*}{0,5} & 20 & 0,483 & 0,008 & $-3,5$ \\
\hline & & 10 & 0,486 & 0,009 & $-3,0$ \\
\hline & & 5 & 0,488 & 0,009 & $-2,4$ \\
\hline \multirow{3}{*}{ AV8 } & \multirow{3}{*}{0,25} & 20 & 0,230 & 0,005 & $-8,9$ \\
\hline & & 10 & 0,230 & 0,005 & $-8,8$ \\
\hline & & 5 & 0,230 & 0,005 & $-8,7$ \\
\hline \multirow{3}{*}{ AV9 } & \multirow{3}{*}{0,25} & 20 & 0,317 & 0,006 & 21,2 \\
\hline & & 10 & 0,317 & 0,006 & 21,1 \\
\hline & & 5 & 0,315 & 0,006 & 20,6 \\
\hline \multirow{3}{*}{ AV10 } & \multirow{3}{*}{0,5} & 20 & 0,605 & 0,010 & 17,3 \\
\hline & & 10 & 0,605 & 0,010 & 17,4 \\
\hline & & 5 & 0,607 & 0,010 & 17,7 \\
\hline \multirow{3}{*}{ AV11 } & \multirow{3}{*}{0,5} & 20 & 0,457 & 0,008 & $-9,4$ \\
\hline & & 10 & 0,456 & 0,008 & $-9,5$ \\
\hline & & 5 & 0,456 & 0,008 & $-9,6$ \\
\hline \multirow{3}{*}{ AV12 } & \multirow{3}{*}{0,5} & 20 & 0,557 & 0,009 & 10,2 \\
\hline & & 10 & 0,558 & 0,010 & 10,4 \\
\hline & & 5 & 0,563 & 0,009 & 11,3 \\
\hline \multirow{3}{*}{ AV13 } & & 20 & 0,240 & 0,005 & $-4,1$ \\
\hline & 0,25 & 10 & 0,240 & 0,005 & $-4,1$ \\
\hline & & 5 & 0,240 & 0,005 & $-4,3$ \\
\hline & & 20 & 0,522 & 0,011 & 4,3 \\
\hline AV14 & 0,5 & 10 & 0,521 & 0,012 & 4,1 \\
\hline & & 5 & 0,528 & 0,011 & 5,4 \\
\hline
\end{tabular}


Tabela 14 - Resultados da determinação da espessura equivalente de atenuação em chumbo, incerteza e diferença percentual entre o valor calculado e o valor nominal, para os aventais de proteção do Fabricante D em 100 kV. Método: interpolação linear

\begin{tabular}{|c|c|c|c|c|c|}
\hline $\begin{array}{l}\text { Dispositivo } \\
\text { de proteção }\end{array}$ & $\begin{array}{c}\text { Equivalência } \\
\text { Nominal (mmPb) }\end{array}$ & $\begin{array}{c}\text { № } \\
\text { Medições }\end{array}$ & $\begin{array}{c}\text { Equivalência } \\
\text { Calculada }(\mathrm{mmPb})\end{array}$ & $\begin{array}{c}\text { Incerteza } \\
(\mathrm{mmPb})\end{array}$ & $\begin{array}{c}\text { Diferença } \\
(\%)\end{array}$ \\
\hline \multirow{3}{*}{ AV1 } & \multirow{3}{*}{0,25} & 20 & 0,207 & 0,006 & $-20,8$ \\
\hline & & 10 & 0,207 & 0,006 & $-21,0$ \\
\hline & & 5 & 0,206 & 0,006 & $-21,3$ \\
\hline \multirow{3}{*}{ AV2 } & \multirow{3}{*}{0,5} & 20 & 0,559 & 0,009 & 10,6 \\
\hline & & 10 & 0,558 & 0,010 & 10,3 \\
\hline & & 5 & 0,558 & 0,011 & 10,4 \\
\hline \multirow{3}{*}{ AV3 } & \multirow{3}{*}{0,25} & 20 & 0,315 & 0,007 & 20,7 \\
\hline & & 10 & 0,315 & 0,007 & 20,7 \\
\hline & & 5 & 0,315 & 0,007 & 20,7 \\
\hline \multirow{3}{*}{ AV4 } & \multirow{3}{*}{0,25} & 20 & 0,260 & 0,010 & 4,0 \\
\hline & & 10 & 0,261 & 0,010 & 4,0 \\
\hline & & 5 & 0,260 & 0,010 & 3,9 \\
\hline \multirow{3}{*}{ AV5 } & \multirow{3}{*}{0,25} & 20 & 0,229 & 0,006 & $-9,4$ \\
\hline & & 10 & 0,228 & 0,006 & $-9,5$ \\
\hline & & 5 & 0,228 & 0,006 & $-9,8$ \\
\hline \multirow{3}{*}{ AV6 } & \multirow{3}{*}{0,5} & 20 & 0,411 & 0,009 & $-21,8$ \\
\hline & & 10 & 0,410 & 0,009 & $-22,1$ \\
\hline & & 5 & 0,408 & 0,009 & $-22,5$ \\
\hline \multirow{3}{*}{ AV7 } & \multirow{3}{*}{0,5} & 20 & 0,482 & 0,009 & $-3,7$ \\
\hline & & 10 & 0,481 & 0,009 & $-3,9$ \\
\hline & & 5 & 0,481 & 0,010 & $-4,0$ \\
\hline \multirow{3}{*}{ AV8 } & \multirow{3}{*}{0,25} & 20 & 0,226 & 0,006 & $-10,6$ \\
\hline & & 10 & 0,226 & 0,006 & $-10,5$ \\
\hline & & 5 & 0,226 & 0,006 & $-10,7$ \\
\hline \multirow{3}{*}{ AV9 } & \multirow{3}{*}{0,25} & 20 & 0,319 & 0,007 & 21,7 \\
\hline & & 10 & 0,320 & 0,007 & 21,8 \\
\hline & & 5 & 0,319 & 0,007 & 21,7 \\
\hline \multirow{3}{*}{ AV10 } & \multirow{3}{*}{0,5} & 20 & 0,590 & 0,009 & 15,2 \\
\hline & & 10 & 0,590 & 0,010 & 15,2 \\
\hline & & 5 & 0,588 & 0,010 & 15,0 \\
\hline \multirow{3}{*}{ AV11 } & \multirow{3}{*}{0,5} & 20 & 0,458 & 0,008 & $-9,2$ \\
\hline & & 10 & 0,457 & 0,008 & $-9,4$ \\
\hline & & 5 & 0,457 & 0,009 & $-9,3$ \\
\hline \multirow{3}{*}{ AV12 } & \multirow{3}{*}{0,5} & 20 & 0,555 & 0,009 & 9,9 \\
\hline & & 10 & 0,553 & 0,010 & 9,6 \\
\hline & & 5 & 0,554 & 0,011 & 9,7 \\
\hline \multirow{3}{*}{ AV13 } & & 20 & 0,237 & 0,006 & $-5,4$ \\
\hline & 0,25 & 10 & 0,237 & 0,006 & $-5,5$ \\
\hline & & 5 & 0,236 & 0,006 & $-5,8$ \\
\hline & & 20 & 0,505 & 0,012 & 1,0 \\
\hline AV14 & 0,5 & 10 & 0,504 & 0,013 & 0,9 \\
\hline & & 5 & 0,506 & 0,015 & 1,2 \\
\hline
\end{tabular}


Tabela 15 - Resultados da determinação da espessura equivalente de atenuação em chumbo, incerteza e diferença percentual entre o valor calculado e o valor nominal, para os aventais de proteção do Fabricante D, em 150 kV. Método: interpolação linear

\begin{tabular}{|c|c|c|c|c|c|}
\hline $\begin{array}{l}\text { Dispositivo } \\
\text { de proteção }\end{array}$ & $\begin{array}{c}\text { Equivalência } \\
\text { Nominal }(\mathrm{mmPb})\end{array}$ & $\begin{array}{c}\text { № } \\
\text { Medições }\end{array}$ & $\begin{array}{c}\text { Equivalência } \\
\text { Calculada (mmPb) }\end{array}$ & $\begin{array}{c}\text { Incerteza } \\
(\mathrm{mmPb})\end{array}$ & $\begin{array}{c}\text { Diferença } \\
(\%)\end{array}$ \\
\hline \multirow{3}{*}{$\mathrm{AV} 1$} & \multirow{3}{*}{0,25} & 20 & 0,203 & 0,011 & $-23,2$ \\
\hline & & 10 & 0,203 & 0,007 & $-23,4$ \\
\hline & & 5 & 0,203 & 0,007 & $-23,4$ \\
\hline \multirow{3}{*}{ AV2 } & \multirow{3}{*}{0,5} & 20 & 0,565 & 0,018 & 11,4 \\
\hline & & 10 & 0,564 & 0,009 & 11,4 \\
\hline & & 5 & 0,563 & 0,010 & 11,2 \\
\hline \multirow{3}{*}{ AV3 } & \multirow{3}{*}{0,25} & 20 & 0,294 & 0,012 & 14,9 \\
\hline & & 10 & 0,293 & 0,009 & 14,8 \\
\hline & & 5 & 0,293 & 0,009 & 14,8 \\
\hline \multirow{3}{*}{ AV4 } & \multirow{3}{*}{0,25} & 20 & 0,258 & 0,013 & 3,2 \\
\hline & & 10 & 0,258 & 0,010 & 3,1 \\
\hline & & 5 & 0,258 & 0,010 & 3,1 \\
\hline \multirow{3}{*}{ AV5 } & \multirow{3}{*}{0,25} & 20 & 0,228 & 0,011 & $-9,8$ \\
\hline & & 10 & 0,227 & 0,007 & $-9,9$ \\
\hline & & 5 & 0,228 & 0,007 & $-9,8$ \\
\hline \multirow{3}{*}{ AV6 } & \multirow{3}{*}{0,5} & 20 & 0,421 & 0,015 & $-18,8$ \\
\hline & & 10 & 0,421 & 0,009 & $-18,8$ \\
\hline & & 5 & 0,421 & 0,009 & $-18,7$ \\
\hline \multirow{3}{*}{ AV7 } & \multirow{3}{*}{0,5} & 20 & 0,487 & 0,014 & $-2,6$ \\
\hline & & 10 & 0,488 & 0,010 & $-2,4$ \\
\hline & & 5 & 0,488 & 0,009 & $-2,4$ \\
\hline \multirow{3}{*}{ AV8 } & \multirow{3}{*}{0,25} & 20 & 0,229 & 0,007 & $-9,0$ \\
\hline & & 10 & 0,229 & 0,007 & $-9,1$ \\
\hline & & 5 & 0,229 & 0,007 & $-9,1$ \\
\hline \multirow{3}{*}{ AV9 } & \multirow{3}{*}{0,25} & 20 & 0,328 & 0,008 & 23,7 \\
\hline & & 10 & 0,327 & 0,008 & 23,6 \\
\hline & & 5 & 0,327 & 0,008 & 23,5 \\
\hline \multirow{3}{*}{ AV10 } & \multirow{3}{*}{0,5} & 20 & 0,590 & 0,009 & 15,2 \\
\hline & & 10 & 0,589 & 0,010 & 15,2 \\
\hline & & 5 & 0,588 & 0,010 & 15,0 \\
\hline \multirow{3}{*}{ AV11 } & \multirow{3}{*}{0,5} & 20 & 0,465 & 0,009 & $-7,5$ \\
\hline & & 10 & 0,465 & 0,009 & $-7,4$ \\
\hline & & 5 & 0,465 & 0,009 & $-7,6$ \\
\hline \multirow{3}{*}{ AV12 } & \multirow{3}{*}{0,5} & 20 & 0,593 & 0,010 & 15,6 \\
\hline & & 10 & 0,593 & 0,010 & 15,6 \\
\hline & & 5 & 0,593 & 0,010 & 15,6 \\
\hline \multirow{3}{*}{ AV13 } & & 20 & 0,271 & 0,010 & 7,8 \\
\hline & 0,25 & 10 & 0,270 & 0,010 & 7,5 \\
\hline & & 5 & 0,270 & 0,010 & 7,4 \\
\hline & & 20 & 0,516 & 0,012 & 3,1 \\
\hline AV14 & 0,5 & 10 & 0,517 & 0,012 & 3,2 \\
\hline & & 5 & 0,514 & 0,012 & 2,8 \\
\hline
\end{tabular}


Tabela 16 - Resultados da determinação da espessura equivalente de atenuação em chumbo, incerteza e diferença percentual entre o valor calculado e o valor nominal, para os aventais de proteção do Fabricante E, em 80 kV. Método: interpolação linear

\begin{tabular}{|c|c|c|c|c|c|}
\hline $\begin{array}{l}\text { Dispositivo } \\
\text { de proteção }\end{array}$ & $\begin{array}{c}\text { Equivalência } \\
\text { Nominal (mmPb) }\end{array}$ & $\begin{array}{c}\text { № } \\
\text { Medições }\end{array}$ & $\begin{array}{c}\text { Equivalência } \\
\text { Calculada }(\mathrm{mmPb})\end{array}$ & $\begin{array}{c}\text { Incerteza } \\
(\mathrm{mmPb})\end{array}$ & $\begin{array}{c}\text { Diferença } \\
(\%)\end{array}$ \\
\hline \multirow{3}{*}{$\mathrm{AV} 1$} & \multirow{3}{*}{0,5} & 20 & 0,447 & 0,008 & $-11,7$ \\
\hline & & 10 & 0,449 & 0,008 & $-11,3$ \\
\hline & & 5 & 0,451 & 0,009 & $-10,8$ \\
\hline \multirow{3}{*}{ AV2 } & \multirow{3}{*}{0,5} & 20 & 0,543 & 0,010 & 7,9 \\
\hline & & 10 & 0,545 & 0,010 & 8,2 \\
\hline & & 5 & 0,545 & 0,011 & 8,2 \\
\hline \multirow{3}{*}{ AV3 } & \multirow{3}{*}{0,5} & 20 & 0,485 & 0,008 & $-3,0$ \\
\hline & & 10 & 0,486 & 0,008 & $-2,9$ \\
\hline & & 5 & 0,485 & 0,009 & $-3,1$ \\
\hline \multirow{3}{*}{ AV4 } & \multirow{3}{*}{0,5} & 20 & 0,574 & 0,009 & 12,8 \\
\hline & & 10 & 0,574 & 0,010 & 12,9 \\
\hline & & 5 & 0,574 & 0,011 & 12,9 \\
\hline
\end{tabular}

Tabela 17 - Resultados da determinação da espessura equivalente de atenuação em chumbo, incerteza e diferença percentual entre o valor calculado e o valor nominal, para os aventais de proteção do Fabricante E, em 100 kV. Método: interpolação linear

\begin{tabular}{|c|c|c|c|c|c|}
\hline $\begin{array}{l}\text { Dispositivo } \\
\text { de proteção }\end{array}$ & $\begin{array}{c}\text { Equivalência } \\
\text { Nominal (mmPb) }\end{array}$ & $\begin{array}{c}\text { № } \\
\text { Medições }\end{array}$ & $\begin{array}{c}\text { Equivalência } \\
\text { Calculada (mmPb) }\end{array}$ & $\begin{array}{l}\text { Incerteza } \\
\text { (mmPb) }\end{array}$ & $\begin{array}{c}\text { Diferença } \\
(\%)\end{array}$ \\
\hline \multirow{3}{*}{ AV1 } & \multirow{3}{*}{0,5} & 20 & 0,449 & 0,008 & $-11,2$ \\
\hline & & 10 & 0,450 & 0,008 & $-11,2$ \\
\hline & & 5 & 0,448 & 0,008 & $-11,5$ \\
\hline \multirow{3}{*}{ AV2 } & \multirow{3}{*}{0,5} & 20 & 0,579 & 0,009 & 13,6 \\
\hline & & 10 & 0,579 & 0,009 & 13,6 \\
\hline & & 5 & 0,578 & 0,009 & 13,5 \\
\hline \multirow{3}{*}{ AV3 } & \multirow{3}{*}{0,5} & 20 & 0,495 & 0,013 & $-1,0$ \\
\hline & & 10 & 0,497 & 0,013 & $-0,6$ \\
\hline & & 5 & 0,498 & 0,013 & $-0,4$ \\
\hline \multirow{3}{*}{ AV4 } & \multirow{3}{*}{0,5} & 20 & 0,577 & 0,009 & 13,3 \\
\hline & & 10 & 0,577 & 0,009 & 13,3 \\
\hline & & 5 & 0,578 & 0,009 & 13,5 \\
\hline
\end{tabular}


Tabela 18 - Resultados da determinação da espessura equivalente de atenuação em chumbo, incerteza e diferença percentual entre o valor calculado e o valor nominal, para os aventais de proteção do Fabricante E, em 150 kV. Método: interpolação linear

\begin{tabular}{|c|c|c|c|c|c|}
\hline $\begin{array}{l}\text { Dispositivo } \\
\text { de proteção }\end{array}$ & $\begin{array}{c}\text { Equivalência } \\
\text { Nominal (mmPb) }\end{array}$ & $\begin{array}{c}\text { № } \\
\text { Medições }\end{array}$ & $\begin{array}{c}\text { Equivalência } \\
\text { Calculada }(\mathrm{mmPb})\end{array}$ & $\begin{array}{c}\text { Incerteza } \\
(\mathrm{mmPb})\end{array}$ & $\begin{array}{c}\text { Diferença } \\
(\%)\end{array}$ \\
\hline \multirow{3}{*}{1} & \multirow{3}{*}{0,5} & 20 & 0,443 & 0,009 & $-12,9$ \\
\hline & & 10 & 0,443 & 0,009 & $-12,9$ \\
\hline & & 5 & 0,443 & 0,010 & $-13,0$ \\
\hline \multirow{3}{*}{2} & \multirow{3}{*}{0,5} & 20 & 0,566 & 0,009 & 11,6 \\
\hline & & 10 & 0,566 & 0,010 & 11,6 \\
\hline & & 5 & 0,564 & 0,010 & 11,4 \\
\hline \multirow{3}{*}{3} & \multirow{3}{*}{0,5} & 20 & 0,501 & 0,013 & 0,2 \\
\hline & & 10 & 0,501 & 0,013 & 0,2 \\
\hline & & 5 & 0,500 & 0,014 & 0,1 \\
\hline \multirow{3}{*}{4} & \multirow{3}{*}{0,5} & 20 & 0,573 & 0,009 & 12,7 \\
\hline & & 10 & 0,573 & 0,009 & 12,8 \\
\hline & & 5 & 0,573 & 0,010 & 12,8 \\
\hline
\end{tabular}

Analisando-se os resultados obtidos das diferenças percentuais entre os valores declarados e medidos da espessura equivalente de atenuação em chumbo é possível observar que dos cinco fabricantes, apenas o Fabricante $\mathrm{C}$ apresentou todos os resultados da diferença percentual positivos. Os valores calculados estavam entre 4,1\%, para os aventais de proteção com equivalência declarada igual a $0,50 \mathrm{mmPb}$, a $13,4 \%$, para aventais com equivalência de $0,25 \mathrm{mmPb}$, acima dos valores declarados na tensão de $80 \mathrm{kV}$, por exemplo. Por outro lado, deve-se levar em consideração que foi avaliada apenas uma amostra de cada equivalência nominal do Fabricante $\mathrm{C}$.

Os dispositivos de proteção radiológica pertencentes ao Fabricante $A$ apresentaram todos os valores de espessura equivalente de atenuação abaixo dos valores declarados. A diferença percentual máxima entre o valor medido e o valor declarado foi de $16 \%$ para menos.

Os fabricantes $B, D$ e $E$ apresentaram valores de espessura equivalente de atenuação tanto acima quanto abaixo do valor declarado. No caso do Fabricante B, pôde-se perceber diferenças percentuais entre $-4,1$ \% a 11,5 \% para aventais de $0,25 \mathrm{mmPb}$ na tensão de $100 \mathrm{kV}$. O Fabricante $\mathrm{E}$ apresentou diferenças percentuais entre $-11,3 \%$ a 13,6 \% na tensão de 100 kV.

As amostras enviadas pelo Fabricante $D$ foram as menos uniformes, ou seja, a diferença percentual entre os valores declarados e os valores medidos variaram mais que $44 \%$, uma vez que algumas amostras apresentaram variação de 22,5\% para menos, enquanto que outras apresentaram uma variação de $21,8 \%$ para mais. 
Analisando-se os valores obtidos das espessuras equivalentes de atenuação para os diferentes números de medições realizados, pode-se observar que os resultados obtidos para 5, 10 e 20 medições são da mesma ordem de grandeza. Além disso, pode-se observar que o número de medições não contribui significativamente para o aumento da incerteza associada ao método.

\subsubsection{Modelo de Archer}

O segundo método utilizado para calcular o equivalente de atenuação foi a função empírica proposta por Archer et $\mathrm{al}^{9}$, denominado doravante modelo de Archer. Este modelo tem sido utilizado por diversos autores na investigação das propriedades de atenuação de diversos materiais ${ }^{30,31}$. Além disso, ele é amplamente utilizado no cálculo de barreiras e é recomendado pelo NCRP ํㅜ $147^{32}$. A função proposta está descrita na Equação 21.

$$
\dot{K}=y_{0} \cdot\left[\left(1+\frac{\beta}{\alpha}\right) \cdot e^{\alpha \cdot \gamma \cdot x}-\frac{\beta}{\alpha}\right]^{-\frac{1}{\gamma}}
$$

onde $x$ é o valor da espessura do material atenuador; $\dot{K}$ é o valor da taxa de kerma no ar sem material atenuador; $\alpha, \beta$, $\gamma$ e $y_{0}$ são os parâmetros de ajuste obtidos pelo método dos mínimos quadrados.

A solução algébrica para esta função é apresentada na Equação 22:

$$
x=\frac{1}{\alpha \cdot \gamma} \cdot \ln \left[\frac{\left(\frac{y_{o}}{\dot{K}}\right)^{\gamma}+\frac{\beta}{\alpha}}{1+\frac{\beta}{\alpha}}\right]
$$

Equação 22

No presente trabalho, como já dito anteriormente, o material atenuador é o chumbo. Assim, a espessura equivalente de atenuação foi calculada utilizando-se a Equação 22. Os parâmetros $\alpha, \beta$, $\gamma$ e $y_{0}$ utilizados foram obtidos no ajuste da segunda etapa, que será detalhada a seguir. 


\subsubsection{Avaliação das Incertezas Associadas à Determinação da Espessura Equivalente de Atenuação pelo Modelo de Archer}

Para a avaliação das incertezas associadas à determinação da espessura equivalente de atenuação pelo modelo de Archer, o processo foi dividido em duas etapas, pois foi necessário transferir as incertezas das espessuras dos filtros de chumbo padrão para a taxa de kerma no ar.

Foi feito um primeiro ajuste pelo método dos mínimos quadrados não-linear da Equação 21 na curva de atenuação do chumbo padrão. Este ajuste foi feito utilizando-se o aplicativo GnuPlot versão 4.0. Este software apresenta os parâmetros de ajuste da função e as suas respectivas incertezas; além disso, ele apresenta a matriz de correlação.

Para este ajuste inicial, foi considerada a incerteza da taxa de kerma no ar em cada ponto da curva de atenuação do chumbo padrão, que foi estimada considerando-se as mesmas fontes de incertezas do tipo $A$ e $B$ consideradas no método da interpolação linear. Desta forma, como fonte de incerteza do tipo A foi considerado o desvio padrão experimental da média, determinado pela Equação 17, e como fontes do tipo $\mathrm{B}$, a resolução (Equação 18) e a exatidão do monitor da câmara de ionização (Equação 19).

Desta forma, a incerteza combinada da taxa de kerma no ar da primeira etapa foi estimada utilizando-se a Equação 20.

Os parâmetros de ajuste (iniciais) obtidos e o $\chi_{\text {red }}^{2}\left(\chi^{2}\right.$ reduzido) para cada tensão e curva estão apresentados nas Tabelas 19 a 21.

A partir desse ajuste prévio, foi determinada para cada ponto uma nova incerteza $\left(\sigma_{i}\right)$, de acordo com a Equação $23^{33}$ :

$$
\sigma_{i}^{2}=\sigma_{\dot{K}}^{2}+\sigma_{x i}^{2} \cdot\left(\frac{d \dot{K}(x)}{d x}\right)^{2}
$$

Equação 23

onde $\sigma_{K}$. é a incerteza no valor da taxa de kerma no ar; $\sigma_{x i}$ é a incerteza na espessura dos filtros de chumbo; $d \dot{K}(x) / d x$ é a derivada da função do modelo de Archer com relação a $x$. 
Na segunda etapa foi feito novamente um ajuste pelo método dos mínimos quadrados não-linear, utilizando-se o aplicativo GnuPlot, que gerou novos parâmetros de ajuste $\left(\alpha, \beta\right.$, re $\left.y_{0}\right)$. Os parâmetros de ajuste (agora denominados finais) obtidos e o $\chi^{2}$ red para cada tensão e curva estão apresentados nas Tabelas 22 a 24.

Finalmente, com esses novos parâmetros pode-se então calcular a espessura equivalente de atenuação dos aventais de proteção e das blindagens de ovário e estimar a incerteza associada ao método.

A estimativa da incerteza associada a este método foi determinada segundo a Equação 8 para cálculo da incerteza padrão combinada para grandezas correlacionadas. Os coeficientes de correlação entre os parâmetros foram obtidos da matriz de correlação apresentada pelo aplicativo GnuPlot.

A Figura 22 apresenta um resumo do processo para obtenção da espessura equivalente de atenuação e da estimativa da incerteza associada ao método.

Esse procedimento foi repetido para cada curva de atenuação do chumbo padrão obtida, uma vez que as medições para os diferentes fabricantes foram realizadas em dias diferentes. Essas curvas diferentes, serão tratadas como Curvas 1, 2, 3 e 4.

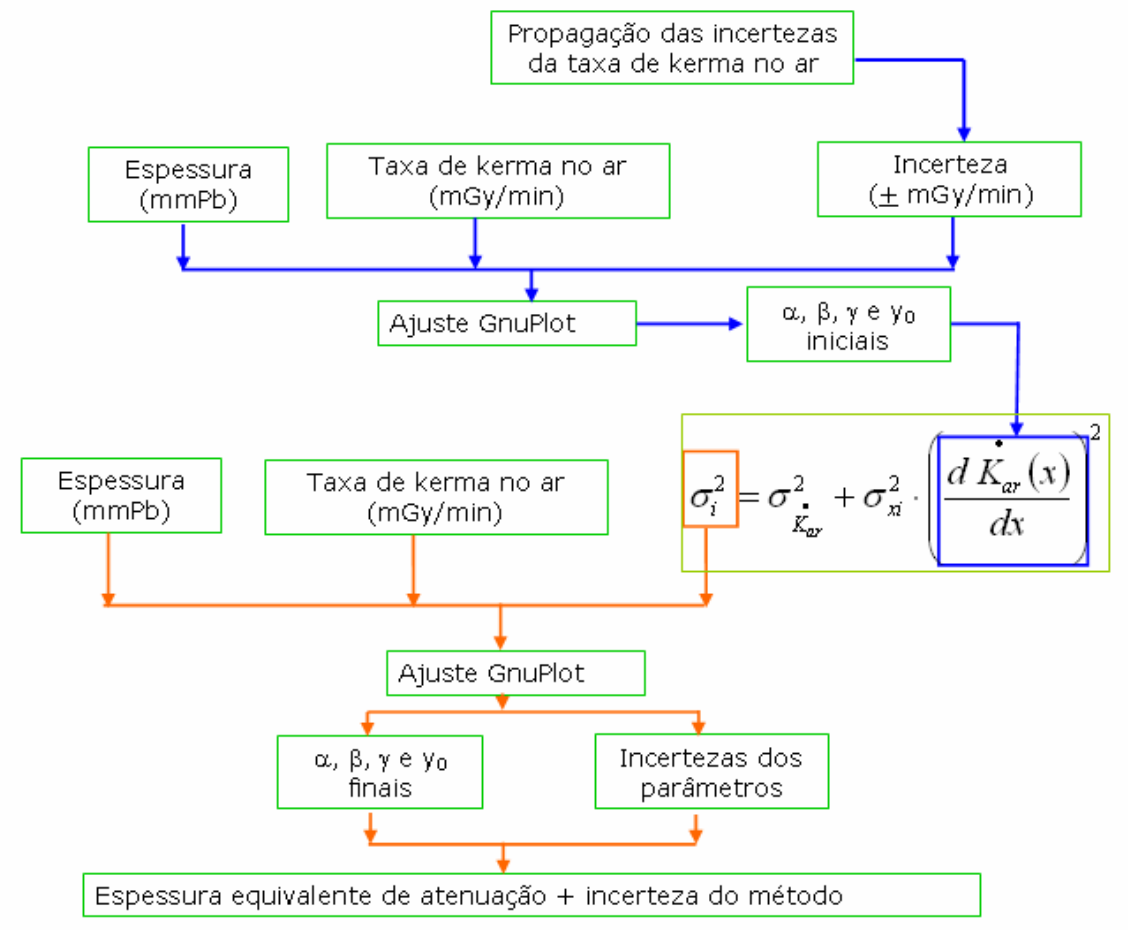

Figura 22 - Determinação da espessura equivalente de atenuação e incerteza combinada do método segundo o modelo de Archer: as setas azuis representam a primeira etapa enquanto que as setas laranjas representam a segunda etapa 
Tabela 19 - Parâmetros de ajustes iniciais em $80 \mathrm{kV}\left(\alpha, \beta, \gamma, y_{0}, \chi_{\text {red }}^{2}\right.$ e v) para a função do modelo de Archer

\begin{tabular}{|c|c|c|c|c|c|c|c|c|c|c|c|}
\hline \multirow{2}{*}{$\begin{array}{l}\text { Curva Chumbo } \\
\text { Padrão }\end{array}$} & \multirow{2}{*}{$\begin{array}{c}\text { № de } \\
\text { medições }\end{array}$} & \multicolumn{2}{|c|}{$\alpha\left(\mathrm{mm}^{-1}\right)$} & \multicolumn{2}{|c|}{$\beta\left(\mathrm{mm}^{-1}\right)$} & \multicolumn{2}{|c|}{$\gamma$} & \multicolumn{2}{|c|}{$\mathrm{y}_{0}$} & \multirow{2}{*}{$\chi_{\text {red }}^{2}$} & \multirow[b]{2}{*}{$v$} \\
\hline & & Valor & $\begin{array}{c}\text { Incerteza } \\
(+/-)\end{array}$ & Valor & $\begin{array}{c}\text { Incerteza } \\
(+/-)\end{array}$ & Valor & $\begin{array}{c}\text { Incerteza } \\
(+/-)\end{array}$ & Valor & $\begin{array}{c}\text { Incerteza } \\
(+/-)\end{array}$ & & \\
\hline \multirow{3}{*}{1} & 20 & 4,631 & 0,363 & 16,628 & 4,446 & 0,987 & 0,252 & 2,045 & 0,128 & 1,831 & 6 \\
\hline & 10 & 4,636 & 0,331 & 16,542 & 3,833 & 0,983 & 0,223 & 2,047 & 0,110 & 1,346 & 6 \\
\hline & 5 & 4,567 & 0,309 & 16,523 & 3,205 & 0,966 & 0,191 & 2,048 & 0,093 & 0,963 & 6 \\
\hline \multirow{3}{*}{2} & 20 & 4,132 & 0,359 & 14,860 & 2,455 & 0,812 & 0,159 & 1,987 & 0,098 & 1,141 & 6 \\
\hline & 10 & 3,917 & 0,316 & 14,246 & 1,642 & 0,736 & 0,114 & 1,987 & 0,077 & 0,699 & 6 \\
\hline & 5 & 3,609 & 0,303 & 13,596 & 1,015 & 0,651 & 0,081 & 1,979 & 0,057 & 0,386 & 6 \\
\hline \multirow{3}{*}{3} & 20 & 4,589 & 0,504 & 15,935 & 4,202 & 0,951 & 0,283 & 1,987 & 0,118 & 1,647 & 5 \\
\hline & 10 & 4,065 & 0,107 & 14,403 & 0,486 & 0,765 & 0,038 & 1,982 & 0,020 & 0,048 & 4 \\
\hline & 5 & 3,890 & 0,233 & 14,392 & 0,919 & 0,732 & 0,073 & 1,983 & 0,040 & 0,193 & 4 \\
\hline \multirow{3}{*}{4} & 20 & 3,964 & 0,135 & 14,324 & 0,571 & 0,735 & 0,044 & 2,072 & 0,026 & 0,076 & 4 \\
\hline & 10 & 3,982 & 0,138 & 14,337 & 0,570 & 0,740 & 0,045 & 2,071 & 0,026 & 0,073 & 4 \\
\hline & 5 & 3,945 & 0,095 & 14,437 & 0,383 & 0,740 & 0,030 & 2,073 & 0,017 & 0,032 & 4 \\
\hline
\end{tabular}


Tabela 20 - Parâmetros de ajustes iniciais em $100 \mathrm{kV}\left(\alpha, \beta, \gamma, y_{0}, \chi_{\text {red }}^{2} \mathrm{e} v\right)$ para a função do modelo de Archer

\begin{tabular}{|c|c|c|c|c|c|c|c|c|c|c|c|}
\hline \multirow{2}{*}{$\begin{array}{l}\text { Curva Chumbo } \\
\text { Padrão }\end{array}$} & \multirow{2}{*}{$\begin{array}{c}\text { № de } \\
\text { medições }\end{array}$} & \multicolumn{2}{|c|}{$\alpha\left(\mathrm{mm}^{-1}\right)$} & \multicolumn{2}{|c|}{$\beta\left(\mathrm{mm}^{-1}\right)$} & \multicolumn{2}{|c|}{$\gamma$} & \multicolumn{2}{|c|}{$\mathrm{y}_{0}$} & \multirow{2}{*}{$\chi_{\text {red }}^{2}$} & \multirow[b]{2}{*}{$v$} \\
\hline & & Valor & $\begin{array}{c}\text { Incerteza } \\
(+/-)\end{array}$ & Valor & $\begin{array}{c}\text { Incerteza } \\
(+/-)\end{array}$ & Valor & $\begin{array}{c}\text { Incerteza } \\
(+/-)\end{array}$ & Valor & $\begin{array}{c}\text { Incerteza } \\
(+/-)\end{array}$ & & \\
\hline \multirow{3}{*}{1} & 20 & 2,839 & 0,050 & 7,808 & 0,233 & 0,724 & 0,029 & 2,596 & 0,028 & 0,054 & 9 \\
\hline & 10 & 2,911 & 0,063 & 7,938 & 0,315 & 0,759 & 0,040 & 2,602 & 0,035 & 0,086 & 9 \\
\hline & 5 & 2,936 & 0,050 & 7,963 & 0,242 & 0,768 & 0,031 & 2,603 & 0,026 & 0,048 & 9 \\
\hline \multirow{3}{*}{2} & 20 & 2,760 & 0,039 & 7,636 & 0,170 & 0,712 & 0,022 & 2,543 & 0,020 & 0,030 & 9 \\
\hline & 10 & 2,728 & 0,118 & 7,700 & 0,467 & 0,698 & 0,062 & 2,542 & 0,057 & 0,241 & 9 \\
\hline & 5 & 2,522 & 0,140 & 7,566 & 0,372 & 0,624 & 0,056 & 2,535 & 0,052 & 0,203 & 9 \\
\hline \multirow{3}{*}{3} & 20 & 2,871 & 0,053 & 7,641 & 0,236 & 0,721 & 0,031 & 2,536 & 0,028 & 0,057 & 9 \\
\hline & 10 & 2,762 & 0,074 & 7,547 & 0,270 & 0,678 & 0,038 & 2,532 & 0,034 & 0,086 & 9 \\
\hline & 5 & 2,765 & 0,088 & 7,542 & 0,295 & 0,978 & 0,043 & 2,529 & 0,037 & 0,101 & 9 \\
\hline \multirow{3}{*}{4} & 20 & 2,764 & 0,035 & 7,835 & 0,160 & 0,706 & 0,020 & 2,639 & 0,020 & 0,027 & 9 \\
\hline & 10 & 2,808 & 0,035 & 7,818 & 0,156 & 0,718 & 0,020 & 2,641 & 0,019 & 0,024 & 9 \\
\hline & 5 & 2,828 & 0,055 & 7,872 & 0,239 & 0,732 & 0,031 & 2,642 & 0,028 & 0,053 & 9 \\
\hline
\end{tabular}


Tabela 21 - Parâmetros de ajustes iniciais em $150 \mathrm{kV}\left(\alpha, \beta, \gamma, y_{0}, \chi_{\text {red }}^{2}\right.$ e v) para a função do modelo de Archer

\begin{tabular}{|c|c|c|c|c|c|c|c|c|c|c|c|}
\hline \multirow{2}{*}{$\begin{array}{c}\text { Curva Chumbo } \\
\text { Padrão }\end{array}$} & \multirow{2}{*}{$\begin{array}{c}\text { № de } \\
\text { medições }\end{array}$} & \multicolumn{2}{|c|}{$\alpha\left(\mathrm{mm}^{-1}\right)$} & \multicolumn{2}{|c|}{$\beta\left(\mathrm{mm}^{-1}\right)$} & \multicolumn{2}{|c|}{$\gamma$} & \multicolumn{2}{|c|}{$y_{0}$} & \multirow{2}{*}{$\chi_{\text {red }}^{2}$} & \multirow[b]{2}{*}{$v$} \\
\hline & & Valor & $\begin{array}{c}\text { Incerteza } \\
(+/-)\end{array}$ & Valor & $\begin{array}{c}\text { Incerteza } \\
(+/-)\end{array}$ & Valor & $\begin{array}{c}\text { Incerteza } \\
(+/-)\end{array}$ & Valor & $\begin{array}{c}\text { Incerteza } \\
(+/-)\end{array}$ & & \\
\hline \multirow{3}{*}{1} & 20 & 2,002 & 0,195 & 3,255 & 0,133 & 0,309 & 0,040 & 2,974 & 0,024 & 0,036 & 9 \\
\hline & 10 & 1,903 & 0,194 & 3,348 & 0,137 & 0,295 & 0,036 & 2,976 & 0,022 & 0,030 & 9 \\
\hline & 5 & 1,922 & 0,283 & 3,338 & 0,201 & 0,299 & 0,053 & 2,978 & 0,032 & 0,060 & 9 \\
\hline \multirow{3}{*}{2} & 20 & 2,038 & 0,197 & 2,340 & 0,130 & 0,320 & 0,043 & 2,944 & 0,027 & 0,044 & 9 \\
\hline & 10 & 2,054 & 0,204 & 3,230 & 0,135 & 0,323 & 0,046 & 2,946 & 0,027 & 0,046 & 9 \\
\hline & 5 & 2,078 & 0,271 & 3,206 & 0,177 & 0,327 & 0,063 & 2,949 & 0,038 & 0,086 & 9 \\
\hline \multirow{3}{*}{3} & 20 & 2,329 & 0,081 & 3,008 & 0,048 & 0,374 & 0,025 & 2,911 & 0,014 & 0,013 & 9 \\
\hline & 10 & 1,970 & 0,145 & 3,286 & 0,100 & 0,300 & 0,028 & 2,905 & 0,017 & 0,018 & 9 \\
\hline & 5 & 1,979 & 0,116 & 3,291 & 0,080 & 0,304 & 0,023 & 2,907 & 0,014 & 0,012 & 9 \\
\hline \multirow{3}{*}{4} & 20 & 2,149 & 0,096 & 3,196 & 0,060 & 0,347 & 0,025 & 3,041 & 0,016 & 0,014 & 9 \\
\hline & 10 & 2,194 & 0,071 & 3,164 & 0,044 & 0,357 & 0,019 & 3,046 & 0,012 & 0,008 & 9 \\
\hline & 5 & 2,067 & 0,099 & 3,265 & 0,066 & 0,331 & 0,023 & 3,046 & 0,014 & 0,011 & 9 \\
\hline
\end{tabular}


Tabela 22 - Parâmetros de ajustes finais em $80 k V\left(\alpha, \beta, \gamma, y_{0}, \chi_{\text {red }}^{2}\right.$ e v) para a função do modelo de Archer

\begin{tabular}{|c|c|c|c|c|c|c|c|c|c|c|c|}
\hline \multirow{2}{*}{$\begin{array}{l}\text { Curva Chumbo } \\
\text { Padrão }\end{array}$} & \multirow{2}{*}{$\begin{array}{c}\text { № de } \\
\text { medições }\end{array}$} & \multicolumn{2}{|c|}{$\alpha\left(\mathrm{mm}^{-1}\right)$} & \multicolumn{2}{|c|}{$\beta\left(\mathrm{mm}^{-1}\right)$} & \multicolumn{2}{|c|}{$\gamma$} & \multicolumn{2}{|c|}{$y_{0}$} & \multirow{2}{*}{$\chi_{\text {red }}^{2}$} & \multirow[b]{2}{*}{$v$} \\
\hline & & Valor & $\begin{array}{c}\text { Incerteza } \\
(+/-)\end{array}$ & Valor & $\begin{array}{c}\text { Incerteza } \\
(+/-)\end{array}$ & Valor & $\begin{array}{c}\text { Incerteza } \\
(+/-)\end{array}$ & Valor & $\begin{array}{c}\text { Incerteza } \\
(+/-)\end{array}$ & & \\
\hline \multirow{3}{*}{1} & 20 & 4,783 & 0,405 & 17,701 & 6,644 & 1,080 & 0,367 & 2,043 & 0,115 & 1,487 & 6 \\
\hline & 10 & 4,784 & 0,380 & 17,595 & 5,987 & 1,074 & 0,336 & 2,046 & 0,104 & 1,220 & 6 \\
\hline & 5 & 4,703 & 0,348 & 17,404 & 4,780 & 1,044 & 0,275 & 2,047 & 0,087 & 0,831 & 6 \\
\hline \multirow{3}{*}{2} & 20 & 4,285 & 0,389 & 15,526 & 3,572 & 0,878 & 0,222 & 1,987 & 0,090 & 0,959 & 6 \\
\hline & 10 & 4,041 & 0,319 & 14,676 & 2,083 & 0,781 & 0,141 & 1,988 & 0,065 & 0,492 & 6 \\
\hline & 5 & 3,609 & 0,303 & 13,596 & 1,015 & 0,651 & 0,081 & 1,979 & 0,057 & 0,386 & 6 \\
\hline \multirow{3}{*}{3} & 20 & 3,976 & 0,245 & 14,237 & 0,758 & 0,739 & 0,074 & 1,984 & 0,023 & 0,063 & 4 \\
\hline & 10 & 4,050 & 0,101 & 14,376 & 0,437 & 0,760 & 0,036 & 1,983 & 0,013 & 0,020 & 4 \\
\hline & 5 & 3,851 & 0,233 & 14,336 & 0,866 & 0,722 & 0,073 & 1,984 & 0,028 & 0,093 & 4 \\
\hline \multirow{3}{*}{4} & 20 & 3,923 & 0,139 & 14,284 & 0,542 & 0,725 & 0,045 & 2,073 & 0,018 & 0,037 & 4 \\
\hline & 10 & 3,939 & 0,141 & 14,287 & 0,546 & 0,729 & 0,046 & 2,072 & 0,018 & 0,036 & 4 \\
\hline & 5 & 3,924 & 0,090 & 14,413 & 0,354 & 0,735 & 0,029 & 2,074 & 0,012 & 0,015 & 4 \\
\hline
\end{tabular}


Tabela 23 - Parâmetros de ajustes finais em $\operatorname{100kV}\left(\alpha, \beta, \gamma, y_{0}, \chi_{\text {red }}^{2}\right.$ e v) para a função do modelo de Archer

\begin{tabular}{|c|c|c|c|c|c|c|c|c|c|c|c|}
\hline \multirow{2}{*}{$\begin{array}{l}\text { Curva Chumbo } \\
\text { Padrão }\end{array}$} & \multirow{2}{*}{$\begin{array}{c}\text { № de } \\
\text { medições }\end{array}$} & \multicolumn{2}{|c|}{$\alpha\left(\mathrm{mm}^{-1}\right)$} & \multicolumn{2}{|c|}{$\beta\left(\mathrm{mm}^{-1}\right)$} & \multicolumn{2}{|c|}{$\gamma$} & \multicolumn{2}{|c|}{$\mathrm{y}_{0}$} & \multirow{2}{*}{$\chi_{\text {red }}^{2}$} & \multirow[b]{2}{*}{$v$} \\
\hline & & Valor & $\begin{array}{c}\text { Incerteza } \\
(+/-)\end{array}$ & Valor & $\begin{array}{c}\text { Incerteza } \\
(+/-)\end{array}$ & Valor & $\begin{array}{c}\text { Incerteza } \\
(+/-)\end{array}$ & Valor & $\begin{array}{c}\text { Incerteza } \\
(+/-)\end{array}$ & & \\
\hline \multirow{3}{*}{1} & 20 & 2,845 & 0,048 & 7,853 & 0,209 & 0,729 & 0,029 & 2,600 & 0,020 & 0,029 & 9 \\
\hline & 10 & 2,927 & 0,063 & 7,985 & 0,300 & 0,768 & 0,041 & 2,604 & 0,027 & 0,052 & 9 \\
\hline & 5 & 2,944 & 0,046 & 7,992 & 0,213 & 0,773 & 0,030 & 2,605 & 0,019 & 0,025 & 9 \\
\hline \multirow{3}{*}{2} & 20 & 2,768 & 0,036 & 7,798 & 0,151 & 0,717 & 0,021 & 2,546 & 0,015 & 0,016 & 9 \\
\hline & 10 & 2,719 & 0,119 & 7,707 & 0,434 & 0,694 & 0,063 & 2,545 & 0,045 & 0,148 & 9 \\
\hline & 5 & 2,522 & 0,140 & 7,566 & 0,372 & 0,624 & 0,056 & 2,535 & 0,052 & 0,203 & 9 \\
\hline \multirow{3}{*}{3} & 20 & 2,864 & 0,054 & 7,673 & 0,220 & 0,720 & 0,032 & 2,540 & 0,022 & 0,034 & 9 \\
\hline & 10 & 2,770 & 0,071 & 7,602 & 0,239 & 0,684 & 0,036 & 2,538 & 0,025 & 0,046 & 9 \\
\hline & 5 & 2,746 & 0,089 & 7,573 & 0,272 & 0,673 & 0,043 & 2,535 & 0,029 & 0,061 & 9 \\
\hline \multirow{3}{*}{4} & 20 & 2,765 & 0,033 & 7,876 & 0,140 & 0,709 & 0,019 & 2,643 & 0,014 & 0,014 & 9 \\
\hline & 10 & 2,811 & 0,032 & 7,852 & 0,134 & 0,721 & 0,019 & 2,644 & 0,014 & 0,012 & 9 \\
\hline & 5 & 2,830 & 0,055 & 7,883 & 0,230 & 0,733 & 0,033 & 2,643 & 0,023 & 0,034 & 9 \\
\hline
\end{tabular}


Tabela 24 - Parâmetros de ajustes finais em $150 \mathrm{kV}\left(\alpha, \beta, \gamma, y_{0}, \chi_{\text {red }}^{2} \mathrm{e} v\right)$ para a função do modelo de Archer

\begin{tabular}{|c|c|c|c|c|c|c|c|c|c|c|c|}
\hline \multirow{2}{*}{$\begin{array}{l}\text { Curva Chumbo } \\
\text { Padrão }\end{array}$} & \multirow{2}{*}{$\begin{array}{c}\text { № de } \\
\text { medições }\end{array}$} & \multicolumn{2}{|c|}{$\alpha\left(\mathrm{mm}^{-1}\right)$} & \multicolumn{2}{|c|}{$\beta\left(\mathrm{mm}^{-1}\right)$} & \multicolumn{2}{|c|}{$\gamma$} & \multicolumn{2}{|c|}{$y_{0}$} & \multirow{2}{*}{$\chi_{\text {red }}^{2}$} & \multirow[b]{2}{*}{$v$} \\
\hline & & Valor & $\begin{array}{c}\text { Incerteza } \\
(+/-)\end{array}$ & Valor & $\begin{array}{c}\text { Incerteza } \\
(+/-)\end{array}$ & Valor & $\begin{array}{c}\text { Incerteza } \\
(+/-)\end{array}$ & Valor & $\begin{array}{c}\text { Incerteza } \\
(+/-)\end{array}$ & & \\
\hline \multirow{3}{*}{1} & 20 & 1,954 & 0,216 & 3,296 & 0,151 & 0,300 & 0,042 & 2,977 & 0,023 & 0,030 & 9 \\
\hline & 10 & 1,928 & 0,176 & 3,339 & 0,128 & 0,301 & 0,033 & 2,980 & 0,016 & 0,015 & 9 \\
\hline & 5 & 1,932 & 0,264 & 3,344 & 0,191 & 0,302 & 0,050 & 2,983 & 0,024 & 0,033 & 9 \\
\hline \multirow{3}{*}{2} & 20 & 2,074 & 0,178 & 3,221 & 0,121 & 0,328 & 0,040 & 2,947 & 0,019 & 0,022 & 9 \\
\hline & 10 & 2,095 & 0,179 & 3,209 & 0,121 & 0,333 & 0,042 & 2,950 & 0,020 & 0,023 & 9 \\
\hline & 5 & 2,078 & 0,271 & 3,206 & 0,177 & 0,327 & 0,063 & 2,949 & 0,038 & 0,086 & 9 \\
\hline \multirow{3}{*}{3} & 20 & 2,332 & 0,072 & 3,008 & 0,045 & 0,374 & 0,022 & 2,912 & 0,010 & 0,006 & 9 \\
\hline & 10 & 2,005 & 0,135 & 3,270 & 0,096 & 0,308 & 0,027 & 2,909 & 0,013 & 0,010 & 9 \\
\hline & 5 & 2,017 & 0,104 & 3,271 & 0,073 & 0,312 & 0,021 & 2,910 & 0,010 & 0,006 & 9 \\
\hline \multirow{3}{*}{4} & 20 & 2,164 & 0,089 & 3,188 & 0,058 & 0,351 & 0,023 & 3,042 & 0,011 & 0,007 & 9 \\
\hline & 10 & 2,197 & 0,064 & 3,166 & 0,041 & 0,358 & 0,017 & 3,047 & 0,008 & 0,004 & 9 \\
\hline & 5 & 2,067 & 0,095 & 3,271 & 0,065 & 0,331 & 0,021 & 3,048 & 0,011 & 0,006 & 9 \\
\hline
\end{tabular}




\subsubsection{Resultados das espessuras equivalente de atenuação e incertezas associadas} obtidas pelo modelo de Archer

Os resultados das espessuras equivalente de atenuação e das incertezas associadas obtidas pelo modelo de Archer para as amostras do Fabricante A em 80 kV, 100 kV e 150 kV estão apresentadas nas Tabelas 25 a 27, respectivamente.

As Tabelas 28 a 30 mostram os resultados obtidos referente às amostras do Fabricante B nas tensões de $80 \mathrm{kV}, 100 \mathrm{kV}$ e $150 \mathrm{kV}$, respectivamente. Os resultados das amostras dos fabricantes $C, D$ e $E$ nas três tensões avaliadas são apresentados nas Tabelas 31 a 33, Tabelas 34 a 36 e Tabelas 37 a 39, respectivamente. 
Tabela 25 - Resultados da determinação da espessura equivalente de atenuação em chumbo, incerteza e diferença percentual entre o valor calculado e o valor nominal, para as amostras do Fabricante A, em 80 kV. Método: modelo de Archer

\begin{tabular}{|c|c|c|c|c|c|c|}
\hline Curva & $\begin{array}{l}\text { Dispositivo } \\
\text { de proteção }\end{array}$ & $\begin{array}{c}\text { Equivalência } \\
\text { Nominal (mmPb) }\end{array}$ & $\begin{array}{c}\text { № } \\
\text { Medições }\end{array}$ & $\begin{array}{c}\text { Equivalência } \\
\text { Calculada (mmPb) }\end{array}$ & $\begin{array}{c}\text { Incerteza } \\
\text { (mmPb) }\end{array}$ & $\begin{array}{l}\text { Diferença } \\
\text { (\%) }\end{array}$ \\
\hline \multirow{3}{*}{2} & \multirow{3}{*}{$\mathrm{AV} 1$} & \multirow{3}{*}{0,5} & 20 & 0,457 & 0,013 & $-9,4$ \\
\hline & & & 10 & 0,454 & 0,012 & $-10,1$ \\
\hline & & & 5 & 0,452 & 0,011 & $-10,6$ \\
\hline \multirow{3}{*}{2} & \multirow{3}{*}{ AV1 - costa } & \multirow{3}{*}{0,25} & 20 & 0,220 & 0,010 & $-13,6$ \\
\hline & & & 10 & 0,219 & 0,008 & $-14,2$ \\
\hline & & & 5 & 0,219 & 0,007 & $-14,2$ \\
\hline \multirow{3}{*}{2} & \multirow{3}{*}{ AV2 } & \multirow{3}{*}{0,5} & 20 & 0,438 & 0,012 & $-14,2$ \\
\hline & & & 10 & 0,435 & 0,011 & $-14,9$ \\
\hline & & & 5 & 0,428 & 0,010 & $-16,8$ \\
\hline \multirow{3}{*}{2} & \multirow{3}{*}{ AV2 - costa } & \multirow{3}{*}{0,25} & 20 & 0,223 & 0,010 & $-12,1$ \\
\hline & & & 10 & 0,221 & 0,008 & $-13,1$ \\
\hline & & & 5 & 0,221 & 0,007 & $-13,1$ \\
\hline \multirow{3}{*}{2} & \multirow{3}{*}{ AV3 } & \multirow{3}{*}{0,25} & 20 & 0,219 & 0,010 & $-14,2$ \\
\hline & & & 10 & 0,218 & 0,008 & $-14,7$ \\
\hline & & & 5 & 0,218 & 0,007 & $-14,7$ \\
\hline \multirow{3}{*}{2} & \multirow{3}{*}{ AV4 } & \multirow{3}{*}{0,25} & 20 & 0,221 & 0,010 & $-13,1$ \\
\hline & & & 10 & 0,220 & 0,008 & $-13,6$ \\
\hline & & & 5 & 0,220 & 0,007 & $-13,6$ \\
\hline \multirow{3}{*}{2} & \multirow{3}{*}{ AV5 } & \multirow{3}{*}{0,25} & 20 & 0,224 & 0,010 & $-11,6$ \\
\hline & & & 10 & 0,223 & 0,008 & $-12,1$ \\
\hline & & & 5 & 0,222 & 0,007 & $-12,6$ \\
\hline \multirow{3}{*}{2} & \multirow{3}{*}{ AV6 } & & 20 & 0,444 & 0,013 & $-12,6$ \\
\hline & & 0,5 & 10 & 0,442 & 0,011 & $-13,1$ \\
\hline & & & 5 & 0,436 & 0,011 & $-14,7$ \\
\hline & & & 20 & 0,450 & 0,013 & $-11,1$ \\
\hline 2 & AV7 & 0,5 & 10 & 0,446 & 0,012 & $-12,1$ \\
\hline & & & 5 & 0,444 & 0,011 & $-12,6$ \\
\hline & & & 20 & 0,457 & 0,013 & $-9,4$ \\
\hline 2 & AV8 & 0,5 & 10 & 0,453 & 0,011 & $-10,4$ \\
\hline & & & 5 & 0,449 & 0,010 & $-11,4$ \\
\hline & & & 20 & 0,233 & 0,010 & $-7,3$ \\
\hline 2 & AV9 & 0,25 & 10 & 0,231 & 0,009 & $-8,2$ \\
\hline & & & 5 & 0,230 & 0,008 & $-8,7$ \\
\hline & & & 20 & 0,226 & 0,010 & $-10,6$ \\
\hline 2 & AV10 & 0,25 & 10 & 0,225 & 0,008 & $-11,1$ \\
\hline & & & 5 & 0,224 & 0,007 & $-11,6$ \\
\hline & & & 20 & 0,453 & 0,013 & $-10,4$ \\
\hline 2 & BO1 & 0,5 & 10 & 0,452 & 0,016 & $-10,6$ \\
\hline & & & 5 & 0,447 & 0,012 & $-11,9$ \\
\hline & & & 20 & 0,457 & 0,013 & $-9,4$ \\
\hline 2 & BO2 & 0,5 & 10 & 0,453 & 0,011 & $-10,4$ \\
\hline & & & 5 & 0,449 & 0,011 & $-11,4$ \\
\hline & & & 20 & 0,453 & 0,013 & $-10,4$ \\
\hline 2 & BO3 & 0,5 & 10 & 0,450 & 0,012 & $-11,1$ \\
\hline & & & 5 & 0,446 & 0,011 & $-12,1$ \\
\hline
\end{tabular}


Tabela 26 - Resultados da determinação da espessura equivalente de atenuação em chumbo, incerteza e diferença percentual entre o valor calculado e o valor nominal, para as amostras do Fabricante A, em 100 kV. Método: modelo de Archer

\begin{tabular}{|c|c|c|c|c|c|c|}
\hline Curva & $\begin{array}{l}\text { Dispositivo } \\
\text { de proteção }\end{array}$ & $\begin{array}{l}\text { Equivalência } \\
\text { Nominal (mmPb) }\end{array}$ & $\begin{array}{c}\text { № } \\
\text { Medições }\end{array}$ & $\begin{array}{c}\text { Equivalência } \\
\text { Calculada (mmPb) }\end{array}$ & $\begin{array}{c}\text { Incerteza } \\
\text { (mmPb) }\end{array}$ & $\begin{array}{c}\text { Diferença } \\
(\%)\end{array}$ \\
\hline \multirow{3}{*}{2} & \multirow{3}{*}{ AV1 } & \multirow{3}{*}{0,5} & 20 & 0,444 & 0,012 & $-12,6$ \\
\hline & & & 10 & 0,446 & 0,012 & $-12,1$ \\
\hline & & & 5 & 0,443 & 0,012 & $-12,9$ \\
\hline \multirow{3}{*}{2} & \multirow{3}{*}{ AV1 - costa } & \multirow{3}{*}{0,25} & 20 & 0,219 & 0,009 & $-14,2$ \\
\hline & & & 10 & 0,220 & 0,009 & $-13,6$ \\
\hline & & & 5 & 0,220 & 0,009 & $-13,6$ \\
\hline \multirow{3}{*}{2} & \multirow{3}{*}{ AV2 } & \multirow{3}{*}{0,5} & 20 & 0,441 & 0,012 & $-13,4$ \\
\hline & & & 10 & 0,440 & 0,012 & $-13,6$ \\
\hline & & & 5 & 0,438 & 0,012 & $-14,2$ \\
\hline \multirow{3}{*}{2} & \multirow{3}{*}{ AV2 - costa } & \multirow{3}{*}{0,25} & 20 & 0,225 & 0,009 & $-11,1$ \\
\hline & & & 10 & 0,225 & 0,010 & $-11,1$ \\
\hline & & & 5 & 0,226 & 0,009 & $-10,6$ \\
\hline \multirow{3}{*}{2} & \multirow{3}{*}{ AV3 } & \multirow{3}{*}{0,25} & 20 & 0,219 & 0,009 & $-14,2$ \\
\hline & & & 10 & 0,220 & 0,010 & $-13,6$ \\
\hline & & & 5 & 0,220 & 0,009 & $-13,6$ \\
\hline \multirow{3}{*}{2} & \multirow{3}{*}{ AV4 } & \multirow{3}{*}{0,25} & 20 & 0,225 & 0,009 & $-11,1$ \\
\hline & & & 10 & 0,225 & 0,009 & $-11,1$ \\
\hline & & & 5 & 0,225 & 0,009 & $-11,1$ \\
\hline \multirow{3}{*}{2} & \multirow{3}{*}{ AV5 } & \multirow{3}{*}{0,25} & 20 & 0,223 & 0,009 & $-12,1$ \\
\hline & & & 10 & 0,224 & 0,009 & $-11,6$ \\
\hline & & & 5 & 0,224 & 0,009 & $-11,6$ \\
\hline \multirow{3}{*}{2} & \multirow{3}{*}{ AV6 } & & 20 & 0,439 & 0,012 & $-13,9$ \\
\hline & & 0,5 & 10 & 0,439 & 0,012 & $-13,9$ \\
\hline & & & 5 & 0,436 & 0,012 & $-14,7$ \\
\hline & & & 20 & 0,450 & 0,013 & $-11,1$ \\
\hline 2 & AV7 & 0,5 & 10 & 0,455 & 0,012 & $-9,9$ \\
\hline & & & 5 & 0,448 & 0,004 & $-11,6$ \\
\hline & & & 20 & 0,426 & 0,017 & $-17,4$ \\
\hline 2 & AV8 & 0,5 & 10 & 0,432 & 0,029 & $-15,7$ \\
\hline & & & 5 & 0,417 & 0,012 & $-19,9$ \\
\hline & & & 20 & 0,226 & 0,009 & $-10,6$ \\
\hline 2 & AV9 & 0,25 & 10 & 0,226 & 0,010 & $-10,6$ \\
\hline & & & 5 & 0,226 & 0,009 & $-10,6$ \\
\hline & & & 20 & 0,228 & 0,009 & $-9,6$ \\
\hline 2 & AV10 & 0,25 & 10 & 0,229 & 0,010 & $-9,2$ \\
\hline & & & 5 & 0,229 & 0,009 & $-9,2$ \\
\hline & & & 20 & 0,448 & 0,012 & $-11,6$ \\
\hline 2 & BO1 & 0,5 & 10 & 0,448 & 0,012 & $-11,6$ \\
\hline & & & 5 & 0,444 & 0,012 & $-12,6$ \\
\hline & & & 20 & 0,452 & 0,012 & $-10,6$ \\
\hline 2 & BO2 & 0,5 & 10 & 0,451 & 0,012 & $-10,9$ \\
\hline & & & 5 & 0,447 & 0,012 & $-11,9$ \\
\hline & & & 20 & 0,450 & 0,012 & $-11,1$ \\
\hline 2 & $\mathrm{BO} 3$ & 0,5 & 10 & 0,449 & 0,012 & $-11,4$ \\
\hline & & & 5 & 0,446 & 0,012 & $-12,1$ \\
\hline
\end{tabular}


Tabela 27 - Resultados da determinação da espessura equivalente de atenuação em chumbo, incerteza e diferença percentual entre o valor calculado e o valor nominal, para as amostras do Fabricante A, em $150 \mathrm{kV}$. Método: modelo de Archer

\begin{tabular}{|c|c|c|c|c|c|c|}
\hline Curva & $\begin{array}{l}\text { Dispositivo } \\
\text { de proteção }\end{array}$ & $\begin{array}{c}\text { Equivalência } \\
\text { Nominal (mmPb) }\end{array}$ & $\begin{array}{c}\text { № } \\
\text { Medições }\end{array}$ & $\begin{array}{c}\text { Equivalência } \\
\text { Calculada (mmPb) }\end{array}$ & $\begin{array}{c}\text { Incerteza } \\
\text { (mmPb) }\end{array}$ & $\begin{array}{l}\text { Diferença } \\
\text { (\%) }\end{array}$ \\
\hline \multirow{3}{*}{2} & \multirow{3}{*}{$\mathrm{AV} 1$} & \multirow{3}{*}{0,5} & 20 & 0,448 & 0,012 & $-11,6$ \\
\hline & & & 10 & 0,449 & 0,012 & $-11,4$ \\
\hline & & & 5 & 0,449 & 0,012 & $-11,4$ \\
\hline \multirow{3}{*}{2} & \multirow{3}{*}{ AV1 - costa } & \multirow{3}{*}{0,25} & 20 & 0,223 & 0,011 & $-12,1$ \\
\hline & & & 10 & 0,223 & 0,011 & $-12,1$ \\
\hline & & & 5 & 0,223 & 0,011 & $-12,1$ \\
\hline \multirow{3}{*}{2} & \multirow{3}{*}{ AV2 } & \multirow{3}{*}{0,5} & 20 & 0,449 & 0,012 & $-11,4$ \\
\hline & & & 10 & 0,449 & 0,012 & $-11,4$ \\
\hline & & & 5 & 0,450 & 0,012 & $-11,1$ \\
\hline \multirow{3}{*}{2} & \multirow{3}{*}{ AV2 - costa } & \multirow{3}{*}{0,25} & 20 & 0,223 & 0,011 & $-12,1$ \\
\hline & & & 10 & 0,223 & 0,011 & $-12,1$ \\
\hline & & & 5 & 0,223 & 0,011 & $-12,1$ \\
\hline \multirow{3}{*}{2} & \multirow{3}{*}{ AV3 } & \multirow{3}{*}{0,25} & 20 & 0,223 & 0,011 & $-12,1$ \\
\hline & & & 10 & 0,223 & 0,011 & $-12,1$ \\
\hline & & & 5 & 0,223 & 0,011 & $-12,1$ \\
\hline \multirow{3}{*}{2} & \multirow{3}{*}{ AV4 } & \multirow{3}{*}{0,25} & 20 & 0,229 & 0,011 & $-9,2$ \\
\hline & & & 10 & 0,228 & 0,011 & $-9,6$ \\
\hline & & & 5 & 0,229 & 0,011 & $-9,2$ \\
\hline \multirow{3}{*}{2} & \multirow{3}{*}{ AV5 } & \multirow{3}{*}{0,25} & 20 & 0,229 & 0,011 & $-9,2$ \\
\hline & & & 10 & 0,229 & 0,011 & $-9,2$ \\
\hline & & & 5 & 0,230 & 0,011 & $-8,7$ \\
\hline \multirow{3}{*}{2} & \multirow{3}{*}{ AV6 } & & 20 & 0,449 & 0,012 & $-11,4$ \\
\hline & & 0,5 & 10 & 0,450 & 0,012 & $-11,1$ \\
\hline & & & 5 & 0,450 & 0,012 & $-11,1$ \\
\hline & & & 20 & 0,455 & 0,012 & $-9,9$ \\
\hline 2 & AV7 & 0,5 & 10 & 0,455 & 0,012 & $-9,9$ \\
\hline & & & 5 & 0,456 & 0,013 & $-9,6$ \\
\hline & & & 20 & 0,464 & 0,012 & $-7,8$ \\
\hline 2 & AV8 & 0,5 & 10 & 0,464 & 0,013 & $-7,8$ \\
\hline & & & 5 & 0,464 & 0,013 & $-7,8$ \\
\hline & & & 20 & 0,229 & 0,011 & $-9,2$ \\
\hline 2 & AV9 & 0,25 & 10 & 0,229 & 0,011 & $-9,2$ \\
\hline & & & 5 & 0,229 & 0,011 & $-9,2$ \\
\hline & & & 20 & 0,233 & 0,011 & $-7,3$ \\
\hline 2 & AV10 & 0,25 & 10 & 0,233 & 0,011 & $-7,3$ \\
\hline & & & 5 & 0,223 & 0,011 & $-12,1$ \\
\hline & & & 20 & 0,465 & 0,012 & $-7,5$ \\
\hline 2 & BO1 & 0,5 & 10 & 0,466 & 0,013 & $-7,3$ \\
\hline & & & 5 & 0,467 & 0,013 & $-7,1$ \\
\hline & & & 20 & 0,449 & 0,012 & $-11,4$ \\
\hline 2 & BO2 & 0,5 & 10 & 0,447 & 0,012 & $-11,9$ \\
\hline & & & 5 & 0,449 & 0,012 & $-11,4$ \\
\hline & & & 20 & 0,457 & 0,012 & $-9,4$ \\
\hline 2 & BO3 & 0,5 & 10 & 0,457 & 0,012 & $-9,4$ \\
\hline & & & 5 & 0,457 & 0,012 & $-9,4$ \\
\hline
\end{tabular}


Tabela 28 - Resultados da determinação da espessura equivalente de atenuação em chumbo, incerteza e diferença percentual entre o valor calculado e o valor nominal, para as amostras do Fabricante B, em 80 kV. Método: modelo de Archer

\begin{tabular}{|c|c|c|c|c|c|c|}
\hline Curva & $\begin{array}{l}\text { Dispositivo de } \\
\text { proteção }\end{array}$ & $\begin{array}{c}\text { Equivalência } \\
\text { Nominal (mmPb) }\end{array}$ & $\begin{array}{c}\text { № } \\
\text { Medições }\end{array}$ & $\begin{array}{c}\text { Equivalência } \\
\text { Calculada (mmPb) }\end{array}$ & $\begin{array}{l}\text { Incerteza } \\
(\mathrm{mmPb})\end{array}$ & $\begin{array}{c}\text { Diferença } \\
\text { (\%) }\end{array}$ \\
\hline \multirow{3}{*}{2} & \multirow{3}{*}{$\mathrm{AV} 1$} & \multirow{3}{*}{0,25} & 20 & 0,236 & 0,010 & $-5,9$ \\
\hline & & & 10 & 0,235 & 0,008 & $-6,4$ \\
\hline & & & 5 & 0,234 & 0,007 & $-6,8$ \\
\hline \multirow{3}{*}{2} & \multirow{3}{*}{ AV2 } & \multirow{3}{*}{0,25} & 20 & 0,244 & 0,010 & $-2,5$ \\
\hline & & & 10 & 0,242 & 0,009 & $-3,3$ \\
\hline & & & 5 & 0,241 & 0,008 & $-3,7$ \\
\hline \multirow{3}{*}{2} & \multirow{3}{*}{ AV3 } & \multirow{3}{*}{0,25} & 20 & 0,265 & 0,010 & 5,7 \\
\hline & & & 10 & 0,264 & 0,009 & 5,3 \\
\hline & & & 5 & 0,262 & 0,008 & 4,6 \\
\hline \multirow{3}{*}{2} & \multirow{3}{*}{ AV4 } & \multirow{3}{*}{0,25} & 20 & 0,244 & 0,010 & $-2,5$ \\
\hline & & & 10 & 0,243 & 0,009 & $-2,9$ \\
\hline & & & 5 & 0,241 & 0,008 & $-3,7$ \\
\hline \multirow{3}{*}{2} & \multirow{3}{*}{ BO1 } & \multirow{3}{*}{0,5} & 20 & 0,470 & 0,013 & $-6,4$ \\
\hline & & & 10 & 0,469 & 0,012 & $-6,6$ \\
\hline & & & 5 & 0,463 & 0,011 & $-8,0$ \\
\hline \multirow{3}{*}{2} & \multirow{3}{*}{ BO2 } & \multirow{3}{*}{0,5} & 20 & 0,496 & 0,013 & $-0,8$ \\
\hline & & & 10 & 0,495 & 0,012 & $-1,0$ \\
\hline & & & 5 & 0,491 & 0,012 & $-1,8$ \\
\hline \multirow{3}{*}{2} & \multirow{3}{*}{$\mathrm{BO} 3$} & \multirow{3}{*}{0,5} & 20 & 0,466 & 0,013 & $-7,3$ \\
\hline & & & 10 & 0,463 & 0,012 & $-8,0$ \\
\hline & & & 5 & 0,458 & 0,011 & $-9,2$ \\
\hline
\end{tabular}


Tabela 29 - Resultados da determinação da espessura equivalente de atenuação em chumbo, incerteza e diferença percentual entre o valor calculado e o valor nominal, para as amostras do Fabricante B, em 100 kV. Método: modelo de Archer

\begin{tabular}{|c|c|c|c|c|c|c|}
\hline Curva & $\begin{array}{l}\text { Dispositivo } \\
\text { de proteção }\end{array}$ & $\begin{array}{c}\text { Equivalência } \\
\text { Nominal (mmPb) }\end{array}$ & $\begin{array}{c}\text { № } \\
\text { Medições }\end{array}$ & $\begin{array}{c}\text { Equivalência } \\
\text { Calculada (mmPb) }\end{array}$ & $\begin{array}{c}\text { Incerteza } \\
(\mathrm{mmPb})\end{array}$ & $\begin{array}{l}\text { Diferença } \\
(\%)\end{array}$ \\
\hline \multirow{3}{*}{2} & \multirow{3}{*}{ AV1 } & \multirow{3}{*}{0,25} & 20 & 0,235 & 0,009 & $-6,4$ \\
\hline & & & 10 & 0,236 & 0,010 & $-5,9$ \\
\hline & & & 5 & 0,236 & 0,009 & $-5,9$ \\
\hline \multirow{3}{*}{2} & \multirow{3}{*}{ AV2 } & \multirow{3}{*}{0,25} & 20 & 0,240 & 0,009 & $-4,2$ \\
\hline & & & 10 & 0,240 & 0,010 & $-4,2$ \\
\hline & & & 5 & 0,240 & 0,009 & $-4,2$ \\
\hline \multirow{3}{*}{2} & \multirow{3}{*}{$\mathrm{A} \vee 3$} & \multirow{3}{*}{0,25} & 20 & 0,272 & 0,010 & 8,1 \\
\hline & & & 10 & 0,273 & 0,010 & 8,4 \\
\hline & & & 5 & 0,272 & 0,010 & 8,1 \\
\hline \multirow{3}{*}{2} & \multirow{3}{*}{ AV4 } & \multirow{3}{*}{0,25} & 20 & 0,242 & 0,009 & $-3,3$ \\
\hline & & & 10 & 0,243 & 0,010 & $-2,9$ \\
\hline & & & 5 & 0,243 & 0,009 & $-2,9$ \\
\hline \multirow{3}{*}{2} & \multirow{3}{*}{ BO1 } & \multirow{3}{*}{0,5} & 20 & 0,467 & 0,012 & $-7,1$ \\
\hline & & & 10 & 0,467 & 0,012 & $-7,1$ \\
\hline & & & 5 & 0,465 & 0,012 & $-7,5$ \\
\hline \multirow{3}{*}{2} & \multirow{3}{*}{ BO2 } & \multirow{3}{*}{0,5} & 20 & 0,488 & 0,012 & $-2,5$ \\
\hline & & & 10 & 0,488 & 0,013 & $-2,5$ \\
\hline & & & 5 & 0,485 & 0,012 & $-3,1$ \\
\hline \multirow{3}{*}{2} & \multirow{3}{*}{ BO3 } & \multirow{3}{*}{0,5} & 20 & 0,461 & 0,012 & $-8,5$ \\
\hline & & & 10 & 0,462 & 0,012 & $-8,2$ \\
\hline & & & 5 & 0,462 & 0,012 & $-8,2$ \\
\hline
\end{tabular}


Tabela 30 - Resultados da determinação da espessura equivalente de atenuação em chumbo, incerteza e diferença percentual entre o valor calculado e o valor nominal, para as amostras do Fabricante B, em 150 kV. Método: modelo de Archer

\begin{tabular}{|c|c|c|c|c|c|c|}
\hline Curva & $\begin{array}{l}\text { Dispositivo } \\
\text { de proteção }\end{array}$ & $\begin{array}{l}\text { Equivalência } \\
\text { Nominal (mmPb) }\end{array}$ & $\begin{array}{c}\text { № } \\
\text { Medições }\end{array}$ & $\begin{array}{l}\text { Equivalência } \\
\text { Calculada } \\
\text { (mmPb) }\end{array}$ & $\begin{array}{c}\text { Incerteza } \\
(\mathrm{mmPb})\end{array}$ & $\begin{array}{c}\text { Diferença } \\
(\%)\end{array}$ \\
\hline \multirow{3}{*}{2} & \multirow{3}{*}{$\mathrm{AV} 1$} & \multirow{3}{*}{0,25} & 20 & 0,239 & 0,011 & $-4,6$ \\
\hline & & & 10 & 0,240 & 0,011 & $-4,2$ \\
\hline & & & 5 & 0,240 & 0,011 & $-4,2$ \\
\hline \multirow{3}{*}{2} & \multirow{3}{*}{ AV2 } & \multirow{3}{*}{0,25} & 20 & 0,247 & 0,011 & $-1,2$ \\
\hline & & & 10 & 0,247 & 0,011 & $-1,2$ \\
\hline & & & 5 & 0,248 & 0,011 & $-0,8$ \\
\hline \multirow{3}{*}{2} & \multirow{3}{*}{ AV3 } & \multirow{3}{*}{0,25} & 20 & 0,275 & 0,011 & 9,1 \\
\hline & & & 10 & 0,275 & 0,011 & 9,1 \\
\hline & & & 5 & 0,275 & 0,011 & 9,1 \\
\hline \multirow{3}{*}{2} & \multirow{3}{*}{ AV4 } & \multirow{3}{*}{0,25} & 20 & 0,251 & 0,011 & 0,4 \\
\hline & & & 10 & 0,252 & 0,011 & 0,8 \\
\hline & & & 5 & 0,252 & 0,011 & 0,8 \\
\hline \multirow{3}{*}{2} & \multirow{3}{*}{ BO1 } & \multirow{3}{*}{0,5} & 20 & 0,489 & 0,015 & $-2,2$ \\
\hline & & & 10 & 0,493 & 0,013 & $-1,4$ \\
\hline & & & 5 & 0,494 & 0,013 & $-1,2$ \\
\hline \multirow{3}{*}{2} & \multirow{3}{*}{$\mathrm{BO} 2$} & \multirow{3}{*}{0,5} & 20 & 0,488 & 0,013 & $-2,5$ \\
\hline & & & 10 & 0,489 & 0,013 & $-2,2$ \\
\hline & & & 5 & 0,488 & 0,013 & $-2,5$ \\
\hline \multirow{3}{*}{2} & \multirow{3}{*}{$\mathrm{BO} 3$} & \multirow{3}{*}{0,5} & 20 & 0,473 & 0,013 & $-5,7$ \\
\hline & & & 10 & 0,474 & 0,013 & $-5,5$ \\
\hline & & & 5 & 0,473 & 0,013 & $-5,7$ \\
\hline
\end{tabular}

Tabela 31 - Resultados da determinação da espessura equivalente de atenuação em chumbo, incerteza e diferença percentual entre o valor calculado e o valor nominal, para as amostras do Fabricante C, em $\mathbf{8 0}$ kV. Método: modelo de Archer

\begin{tabular}{|c|c|c|c|c|c|c|}
\hline Curva & $\begin{array}{l}\text { Dispositivo } \\
\text { de proteção }\end{array}$ & $\begin{array}{c}\text { Equivalência } \\
\text { Nominal (mmPb) }\end{array}$ & $\begin{array}{c}\text { № } \\
\text { Medições }\end{array}$ & $\begin{array}{c}\text { Equivalência } \\
\text { Calculada (mmPb) }\end{array}$ & $\begin{array}{c}\text { Incerteza } \\
(\mathrm{mmPb})\end{array}$ & $\begin{array}{c}\text { Diferença } \\
\text { (\%) }\end{array}$ \\
\hline \multirow{3}{*}{1} & \multirow{3}{*}{ AV1 } & \multirow{3}{*}{0,5} & 20 & 0,519 & 0,014 & 3,7 \\
\hline & & & 10 & 0,517 & 0,052 & 3,3 \\
\hline & & & 5 & 0,518 & 0,013 & 3,5 \\
\hline \multirow{3}{*}{1} & \multirow{3}{*}{ AV2 } & \multirow{3}{*}{0,25} & 20 & 0,281 & 0,009 & 11,0 \\
\hline & & & 10 & 0,281 & 0,039 & 11,0 \\
\hline & & & 5 & 0,279 & 0,010 & 10,4 \\
\hline
\end{tabular}


Tabela 32 - Resultados da determinação da espessura equivalente de atenuação em chumbo, incerteza e diferença percentual entre o valor calculado e o valor nominal, para as amostras do Fabricante C, em $100 \mathrm{kV}$. Método: modelo de Archer

\begin{tabular}{ccccccc}
\hline \hline Curva & $\begin{array}{c}\text { Dispositivo } \\
\text { de proteção }\end{array}$ & $\begin{array}{c}\text { Equivalência } \\
\text { Nominal }(\mathbf{m m P b})\end{array}$ & $\begin{array}{c}\text { No } \\
\text { Medições }\end{array}$ & $\begin{array}{c}\text { Equivalência } \\
\text { Calculada (mmPb) }\end{array}$ & $\begin{array}{c}\text { Incerteza } \\
(\mathbf{m m P b})\end{array}$ & $\begin{array}{c}\text { Diferença } \\
(\%)\end{array}$ \\
\hline \hline \multirow{2}{*}{1} & \multirow{2}{*}{ AV1 } & \multirow{2}{*}{0,5} & 20 & 0,558 & 0,013 & 10,4 \\
& & & 10 & 0,559 & 0,013 & 10,6 \\
\hline \hline \multirow{2}{*}{1} & \multirow{2}{*}{ AV2 } & \multirow{2}{*}{0,25} & 5 & 0,558 & 0,013 & 10,4 \\
\hline & & & 10 & 0,263 & 0,009 & 4,9 \\
\cline { 3 - 7 } & & & 5 & 0,262 & 0,010 & 4,6 \\
\hline \hline
\end{tabular}

Tabela 33 - Resultados da determinação da espessura equivalente de atenuação em chumbo, incerteza e diferença percentual entre o valor calculado e o valor nominal, para as amostras do Fabricante C, em 150 kV. Método: modelo de Archer

\begin{tabular}{ccccccc}
\hline \hline Curva & $\begin{array}{c}\text { Dispositivo } \\
\text { de proteção }\end{array}$ & $\begin{array}{c}\text { Equivalência } \\
\text { Nominal (mmPb) }\end{array}$ & $\begin{array}{c}\text { No } \\
\text { Medições }\end{array}$ & $\begin{array}{c}\text { Equivalência } \\
\text { Calculada (mmPb) }\end{array}$ & $\begin{array}{c}\text { Incerteza } \\
(\mathbf{m m P b})\end{array}$ & $\begin{array}{c}\text { Diferença } \\
(\%)\end{array}$ \\
\hline \hline \multirow{2}{*}{1} & \multirow{2}{*}{ AV1 } & \multirow{2}{*}{0,5} & 20 & 0,563 & 0,013 & 11,2 \\
& & & 10 & 0,562 & 0,014 & 11,0 \\
\hline \hline \multirow{2}{*}{1} & \multirow{2}{*}{ AV2 } & \multirow{2}{*}{0,25} & 5 & 0,559 & 0,017 & 10,6 \\
\hline & & & 10 & 0,273 & 0,011 & 8,4 \\
& & & 5 & 0,273 & 0,011 & 8,4 \\
\hline \hline
\end{tabular}


Tabela 34 - Resultados da determinação da espessura equivalente de atenuação em chumbo, incerteza e diferença percentual entre o valor calculado e o valor nominal, para as amostras do Fabricante D, em $\mathbf{8 0}$ kV. Método: modelo de Archer

\begin{tabular}{|c|c|c|c|c|c|c|}
\hline Curva & $\begin{array}{l}\text { Dispositivo } \\
\text { de proteção }\end{array}$ & $\begin{array}{c}\text { Equivalência } \\
\text { Nominal (mmPb) }\end{array}$ & $\begin{array}{c}\text { № } \\
\text { Medições }\end{array}$ & $\begin{array}{c}\text { Equivalência } \\
\text { Calculada (mmPb) }\end{array}$ & $\begin{array}{c}\text { Incerteza } \\
(\mathrm{mmPb})\end{array}$ & $\begin{array}{c}\text { Diferença } \\
(\%)\end{array}$ \\
\hline \multirow{3}{*}{3} & \multirow{3}{*}{ AV1 } & \multirow{3}{*}{0,25} & 20 & 0,192 & 0,007 & $-30,2$ \\
\hline & & & 10 & 0,191 & 0,007 & $-30,9$ \\
\hline & & & 5 & 0,191 & 0,007 & $-30,9$ \\
\hline \multirow{3}{*}{3} & \multirow{3}{*}{ AV2 } & \multirow{3}{*}{0,5} & 20 & 0,555 & 0,011 & 9,9 \\
\hline & & & 10 & 0,552 & 0,011 & 9,4 \\
\hline & & & 5 & 0,556 & 0,011 & 10,1 \\
\hline \multirow{3}{*}{3} & \multirow{3}{*}{ AV3 } & \multirow{3}{*}{0,25} & 20 & 0,280 & 0,008 & 10,7 \\
\hline & & & 10 & 0,279 & 0,008 & 10,4 \\
\hline & & & 5 & 0,277 & 0,008 & 9,7 \\
\hline \multirow{3}{*}{3} & \multirow{3}{*}{ AV4 } & \multirow{3}{*}{0,25} & 20 & 0,255 & 0,008 & 2,0 \\
\hline & & & 10 & 0,255 & 0,007 & 2,0 \\
\hline & & & 5 & 0,253 & 0,008 & 1,2 \\
\hline \multirow{3}{*}{3} & \multirow{3}{*}{ AV5 } & \multirow{3}{*}{0,25} & 20 & 0,214 & 0,007 & $-16,8$ \\
\hline & & & 10 & 0,214 & 0,007 & $-16,8$ \\
\hline & & & 5 & 0,213 & 0,007 & $-17,4$ \\
\hline \multirow{3}{*}{3} & \multirow{3}{*}{ AV6 } & \multirow{3}{*}{0,5} & 20 & 0,393 & 0,009 & $-27,2$ \\
\hline & & & 10 & 0,394 & 0,009 & $-26,9$ \\
\hline & & & 5 & 0,392 & 0,010 & $-27,6$ \\
\hline \multirow{3}{*}{3} & \multirow{3}{*}{ AV7 } & \multirow{3}{*}{0,5} & 20 & 0,479 & 0,010 & $-4,4$ \\
\hline & & & 10 & 0,480 & 0,010 & $-4,2$ \\
\hline & & & 5 & 0,481 & 0,010 & $-4,0$ \\
\hline \multirow{3}{*}{3} & \multirow{3}{*}{ AV8 } & \multirow{3}{*}{0,25} & 20 & 0,218 & 0,007 & $-14,7$ \\
\hline & & & 10 & 0,218 & 0,007 & $-14,7$ \\
\hline & & & 5 & 0,218 & 0,007 & $-14,7$ \\
\hline & & & 20 & 0,303 & 0,008 & 17,5 \\
\hline 3 & AV9 & 0,25 & 10 & 0,303 & 0,008 & 17,5 \\
\hline & & & 5 & 0,302 & 0,008 & 17,2 \\
\hline & & & 20 & 0,601 & 0,012 & 16,8 \\
\hline 3 & AV10 & 0,5 & 10 & 0,603 & 0,011 & 17,1 \\
\hline & & & 5 & 0,607 & 0,013 & 17,6 \\
\hline & & & 20 & 0,447 & 0,010 & $-11,9$ \\
\hline 3 & AV11 & 0,5 & 10 & 0,446 & 0,010 & $-12,1$ \\
\hline & & & 5 & 0,444 & 0,010 & $-12,6$ \\
\hline & & & 20 & 0,547 & 0,011 & 8,6 \\
\hline 3 & AV12 & 0,5 & 10 & 0,547 & 0,011 & 8,6 \\
\hline & & & 5 & 0,551 & 0,011 & 9,3 \\
\hline & & & 20 & 0,235 & 0,007 & $-6,4$ \\
\hline 3 & $\mathrm{AV} 13$ & 0,25 & 10 & 0,235 & 0,007 & $-6,4$ \\
\hline & & & 5 & 0,234 & 0,007 & $-6,8$ \\
\hline & & & 20 & 0,515 & 0,011 & 2,9 \\
\hline 3 & AV14 & 0,5 & 10 & 0,513 & 0,011 & 2,5 \\
\hline & & & 5 & 0,516 & 0,011 & 3,1 \\
\hline
\end{tabular}


Tabela 35 - Resultados da determinação da espessura equivalente de atenuação em chumbo, incerteza e diferença percentual entre o valor calculado e o valor nominal, para as amostras do Fabricante D, em 100 kV. Método: modelo de Archer

\begin{tabular}{|c|c|c|c|c|c|c|}
\hline Curva & $\begin{array}{l}\text { Dispositivo } \\
\text { de proteção }\end{array}$ & $\begin{array}{c}\text { Equivalência } \\
\text { Nominal (mmPb) }\end{array}$ & $\begin{array}{c}\text { № } \\
\text { Medições }\end{array}$ & $\begin{array}{c}\text { Equivalência } \\
\text { Calculada (mmPb) }\end{array}$ & $\begin{array}{c}\text { Incerteza } \\
(\mathrm{mmPb})\end{array}$ & $\begin{array}{c}\text { Diferença } \\
(\%)\end{array}$ \\
\hline \multirow{3}{*}{3} & \multirow{3}{*}{ AV1 } & \multirow{3}{*}{0,25} & 20 & 0,194 & 0,008 & $-28,9$ \\
\hline & & & 10 & 0,194 & 0,018 & $-28,9$ \\
\hline & & & 5 & 0,193 & 0,008 & $-29,5$ \\
\hline \multirow{3}{*}{3} & \multirow{3}{*}{ AV2 } & \multirow{3}{*}{0,5} & 20 & 0,550 & 0,013 & 9,1 \\
\hline & & & 10 & 0,549 & 0,027 & 8,9 \\
\hline & & & 5 & 0,548 & 0,013 & 8,8 \\
\hline \multirow{3}{*}{3} & \multirow{3}{*}{ AV3 } & \multirow{3}{*}{0,25} & 20 & 0,302 & 0,010 & 17,2 \\
\hline & & & 10 & 0,302 & 0,021 & 17,2 \\
\hline & & & 5 & 0,302 & 0,010 & 17,2 \\
\hline \multirow{3}{*}{3} & \multirow{3}{*}{ AV4 } & \multirow{3}{*}{0,25} & 20 & 0,255 & 0,009 & 2,0 \\
\hline & & & 10 & 0,255 & 0,020 & 2,0 \\
\hline & & & 5 & 0,255 & 0,009 & 2,0 \\
\hline \multirow{3}{*}{3} & \multirow{3}{*}{ AV5 } & \multirow{3}{*}{0,25} & 20 & 0,220 & 0,009 & $-13,6$ \\
\hline & & & 10 & 0,220 & 0,019 & $-13,6$ \\
\hline & & & 5 & 0,219 & 0,009 & $-14,2$ \\
\hline \multirow{3}{*}{3} & \multirow{3}{*}{ AV6 } & \multirow{3}{*}{0,5} & 20 & 0,400 & 0,011 & $-25,0$ \\
\hline & & & 10 & 0,398 & 0,024 & $-25,6$ \\
\hline & & & 5 & 0,397 & 0,011 & $-25,9$ \\
\hline \multirow{3}{*}{3} & \multirow{3}{*}{ AV7 } & \multirow{3}{*}{0,5} & 20 & 0,477 & 0,012 & $-4,8$ \\
\hline & & & 10 & 0,476 & 0,025 & $-5,0$ \\
\hline & & & 5 & 0,475 & 0,012 & $-5,3$ \\
\hline \multirow{3}{*}{3} & \multirow{3}{*}{ AV8 } & \multirow{3}{*}{0,25} & 20 & 0,217 & 0,009 & $-15,2$ \\
\hline & & & 10 & 0,217 & 0,019 & $-15,2$ \\
\hline & & & 5 & 0,217 & 0,009 & $-15,2$ \\
\hline & & & 20 & 0,306 & 0,010 & 18,3 \\
\hline 3 & AV9 & 0,25 & 10 & 0,306 & 0,021 & 18,3 \\
\hline & & & 5 & 0,306 & 0,010 & 18,3 \\
\hline & & & 20 & 0,584 & 0,013 & 14,4 \\
\hline 3 & AV10 & 0,5 & 10 & 0,584 & 0,028 & 14,4 \\
\hline & & & 5 & 0,580 & 0,013 & 13,8 \\
\hline & & & 20 & 0,448 & 0,012 & $-11,6$ \\
\hline 3 & AV11 & 0,5 & 10 & 0,446 & 0,025 & $-12,1$ \\
\hline & & & 5 & 0,446 & 0,012 & $-12,1$ \\
\hline & & & 20 & 0,546 & 0,013 & 8,4 \\
\hline 3 & AV12 & 0,5 & 10 & 0,544 & 0,027 & 8,1 \\
\hline & & & 5 & 0,543 & 0,013 & 7,9 \\
\hline & & & 20 & 0,232 & 0,009 & $-7,8$ \\
\hline 3 & AV13 & 0,25 & 10 & 0,232 & 0,019 & $-7,8$ \\
\hline & & & 5 & 0,231 & 0,009 & $-8,2$ \\
\hline & & & 20 & 0,501 & 0,012 & 0,2 \\
\hline 3 & AV14 & 0,5 & 10 & 0,500 & 0,026 & 0,0 \\
\hline & & & 5 & 0,501 & 0,012 & 0,2 \\
\hline
\end{tabular}


Tabela 36 - Resultados da determinação da espessura equivalente de atenuação em chumbo, incerteza e diferença percentual entre o valor calculado e o valor nominal, para as amostras do Fabricante D, em 150 kV. Método: modelo de Archer

\begin{tabular}{|c|c|c|c|c|c|c|}
\hline Curva & $\begin{array}{l}\text { Dispositivo } \\
\text { de proteção }\end{array}$ & $\begin{array}{c}\text { Equivalência } \\
\text { Nominal (mmPb) }\end{array}$ & $\begin{array}{c}\text { № } \\
\text { Medições }\end{array}$ & $\begin{array}{c}\text { Equivalência } \\
\text { Calculada (mmPb) }\end{array}$ & $\begin{array}{c}\text { Incerteza } \\
(\mathrm{mmPb})\end{array}$ & $\begin{array}{c}\text { Diferença } \\
(\%)\end{array}$ \\
\hline \multirow{3}{*}{3} & \multirow{3}{*}{ AV1 } & \multirow{3}{*}{0,25} & 20 & 0,194 & 0,010 & $-28,9$ \\
\hline & & & 10 & 0,194 & 0,010 & $-28,9$ \\
\hline & & & 5 & 0,194 & 0,011 & $-28,9$ \\
\hline \multirow{3}{*}{3} & \multirow{3}{*}{ AV2 } & \multirow{3}{*}{0,5} & 20 & 0,556 & 0,013 & 10,1 \\
\hline & & & 10 & 0,555 & 0,013 & 9,9 \\
\hline & & & 5 & 0,554 & 0,018 & 9,7 \\
\hline \multirow{3}{*}{3} & \multirow{3}{*}{ AV3 } & \multirow{3}{*}{0,25} & 20 & 0,286 & 0,011 & 12,6 \\
\hline & & & 10 & 0,286 & 0,011 & 12,6 \\
\hline & & & 5 & 0,286 & 0,013 & 12,6 \\
\hline \multirow{3}{*}{3} & \multirow{3}{*}{ AV4 } & \multirow{3}{*}{0,25} & 20 & 0,256 & 0,011 & 2,3 \\
\hline & & & 10 & 0,256 & 0,011 & 2,3 \\
\hline & & & 5 & 0,256 & 0,012 & 2,3 \\
\hline \multirow{3}{*}{3} & \multirow{3}{*}{ AV5 } & \multirow{3}{*}{0,25} & 20 & 0,222 & 0,011 & $-12,6$ \\
\hline & & & 10 & 0,223 & 0,011 & $-12,1$ \\
\hline & & & 5 & 0,223 & 0,012 & $-12,1$ \\
\hline \multirow{3}{*}{3} & \multirow{3}{*}{ AV6 } & \multirow{3}{*}{0,5} & 20 & 0,413 & 0,012 & $-21,1$ \\
\hline & & & 10 & 0,413 & 0,012 & $-21,1$ \\
\hline & & & 5 & 0,413 & 0,015 & $-21,1$ \\
\hline \multirow{3}{*}{3} & \multirow{3}{*}{ AV7 } & \multirow{3}{*}{0,5} & 20 & 0,485 & 0,013 & $-3,1$ \\
\hline & & & 10 & 0,485 & 0,012 & $-3,1$ \\
\hline & & & 5 & 0,485 & 0,017 & $-3,1$ \\
\hline \multirow{3}{*}{3} & \multirow{3}{*}{ AV8 } & \multirow{3}{*}{0,25} & 20 & 0,235 & 0,025 & $-6,4$ \\
\hline & & & 10 & 0,225 & 0,011 & $-11,1$ \\
\hline & & & 5 & 0,224 & 0,012 & $-11,6$ \\
\hline & & & 20 & 0,319 & 0,011 & 21,6 \\
\hline 3 & AV9 & 0,25 & 10 & 0,319 & 0,011 & 21,6 \\
\hline & & & 5 & 0,319 & 0,014 & 21,6 \\
\hline & & & 20 & 0,584 & 0,013 & 14,4 \\
\hline 3 & AV10 & 0,5 & 10 & 0,582 & 0,013 & 14,1 \\
\hline & & & 5 & 0,582 & 0,019 & 14,1 \\
\hline & & & 20 & 0,458 & 0,012 & $-9,2$ \\
\hline 3 & AV11 & 0,5 & 10 & 0,457 & 0,012 & $-9,4$ \\
\hline & & & 5 & 0,456 & 0,016 & $-9,6$ \\
\hline & & & 20 & 0,587 & 0,013 & 14,8 \\
\hline 3 & AV12 & 0,5 & 10 & 0,586 & 0,013 & 14,7 \\
\hline & & & 5 & 0,587 & 0,019 & 14,8 \\
\hline & & & 20 & 0,266 & 0,011 & 6,0 \\
\hline 3 & $\mathrm{AV} 13$ & 0,25 & 10 & 0,266 & 0,011 & 6,0 \\
\hline & & & 5 & 0,265 & 0,013 & 5,7 \\
\hline & & & 20 & 0,511 & 0,013 & 2,2 \\
\hline 3 & AV14 & 0,5 & 10 & 0,510 & 0,013 & 2,0 \\
\hline & & & 5 & 0,508 & 0,017 & 1,6 \\
\hline
\end{tabular}


Tabela 37 - Resultados da determinação da espessura equivalente de atenuação em chumbo, incerteza e diferença percentual entre o valor calculado e o valor nominal, para as amostras do Fabricante E, em 80 kV. Método: modelo de Archer

\begin{tabular}{|c|c|c|c|c|c|c|}
\hline Curva & $\begin{array}{l}\text { Dispositivo } \\
\text { de proteção }\end{array}$ & $\begin{array}{c}\text { Equivalência } \\
\text { Nominal (mmPb) }\end{array}$ & $\begin{array}{c}\text { № } \\
\text { Medições }\end{array}$ & $\begin{array}{c}\text { Equivalência } \\
\text { Calculada (mmPb) }\end{array}$ & $\begin{array}{c}\text { Incerteza } \\
(\mathrm{mmPb})\end{array}$ & $\begin{array}{c}\text { Diferença } \\
(\%)\end{array}$ \\
\hline \multirow{3}{*}{4} & \multirow{3}{*}{1} & \multirow{3}{*}{0,5} & 20 & 0,436 & 0,010 & $-14,7$ \\
\hline & & & 10 & 0,438 & 0,010 & $-14,2$ \\
\hline & & & 5 & 0,441 & 0,010 & $-13,3$ \\
\hline \multirow{3}{*}{4} & \multirow{3}{*}{2} & \multirow{3}{*}{0,5} & 20 & 0,535 & 0,010 & 6,5 \\
\hline & & & 10 & 0,537 & 0,011 & 6,8 \\
\hline & & & 5 & 0,537 & 0,011 & 6,9 \\
\hline \multirow{3}{*}{4} & \multirow{3}{*}{3} & \multirow{3}{*}{0,5} & 20 & 0,483 & 0,010 & $-3,5$ \\
\hline & & & 10 & 0,483 & 0,010 & $-3,4$ \\
\hline & & & 5 & 0,484 & 0,010 & $-3,4$ \\
\hline \multirow{3}{*}{4} & \multirow{3}{*}{4} & \multirow{3}{*}{0,5} & 20 & 0,565 & 0,011 & 11,6 \\
\hline & & & 10 & 0,567 & 0,011 & 11,8 \\
\hline & & & 5 & 0,566 & 0,013 & 11,7 \\
\hline
\end{tabular}

Tabela 38 - Resultados da determinação da espessura equivalente de atenuação em chumbo, incerteza e diferença percentual entre o valor calculado e o valor nominal, para as amostras do Fabricante E, em 100 kV. Método: modelo de Archer

\begin{tabular}{|c|c|c|c|c|c|c|}
\hline Curva & $\begin{array}{l}\text { Dispositivo } \\
\text { de proteção }\end{array}$ & $\begin{array}{c}\text { Equivalência } \\
\text { Nominal }(\mathrm{mmPb})\end{array}$ & $\begin{array}{c}\text { № } \\
\text { Medições }\end{array}$ & $\begin{array}{c}\text { Equivalência } \\
\text { Calculada }(\mathrm{mmPb})\end{array}$ & $\begin{array}{c}\text { Incerteza } \\
(\mathrm{mmPb})\end{array}$ & $\begin{array}{c}\text { Diferença } \\
(\%)\end{array}$ \\
\hline \multirow{3}{*}{4} & \multirow{3}{*}{1} & \multirow{3}{*}{0,5} & 20 & 0,438 & 0,012 & $-14,0$ \\
\hline & & & 10 & 0,439 & 0,012 & $-13,9$ \\
\hline & & & 5 & 0,438 & 0,012 & $-14,1$ \\
\hline \multirow{3}{*}{4} & \multirow{3}{*}{2} & \multirow{3}{*}{0,5} & 20 & 0,571 & 0,013 & 12,5 \\
\hline & & & 10 & 0,571 & 0,013 & 12,4 \\
\hline & & & 5 & 0,571 & 0,013 & 12,5 \\
\hline \multirow{3}{*}{4} & \multirow{3}{*}{3} & \multirow{3}{*}{0,5} & 20 & 0,493 & 0,012 & $-1,4$ \\
\hline & & & 10 & 0,494 & 0,012 & $-1,2$ \\
\hline & & & 5 & 0,495 & 0,012 & $-1,0$ \\
\hline \multirow{3}{*}{4} & \multirow{3}{*}{4} & \multirow{3}{*}{0,5} & 20 & 0,570 & 0,013 & 12,2 \\
\hline & & & 10 & 0,569 & 0,013 & 12,1 \\
\hline & & & 5 & 0,571 & 0,013 & 12,4 \\
\hline
\end{tabular}


Tabela 39 - Resultados da determinação da espessura equivalente de atenuação em chumbo, incerteza e diferença percentual entre o valor calculado e o valor nominal, para as amostras do Fabricante E, em $150 \mathrm{kV}$. Método: modelo de Archer

\begin{tabular}{|c|c|c|c|c|c|c|}
\hline Curva & $\begin{array}{l}\text { Dispositivo } \\
\text { de proteção }\end{array}$ & $\begin{array}{c}\text { Equivalência } \\
\text { Nominal (mmPb) }\end{array}$ & $\begin{array}{c}\text { № } \\
\text { Medições }\end{array}$ & $\begin{array}{c}\text { Equivalência } \\
\text { Calculada (mmPb) }\end{array}$ & $\begin{array}{l}\text { Incerteza } \\
(\mathrm{mmPb})\end{array}$ & $\begin{array}{c}\text { Diferença } \\
(\%)\end{array}$ \\
\hline \multirow{3}{*}{4} & \multirow{3}{*}{1} & \multirow{3}{*}{0,5} & 20 & 0,434 & 0,012 & $-15,2$ \\
\hline & & & 10 & 0,434 & 0,012 & $-15,2$ \\
\hline & & & 5 & 0,434 & 0,013 & $-15,3$ \\
\hline \multirow{3}{*}{4} & \multirow{3}{*}{2} & \multirow{3}{*}{0,5} & 20 & 0,558 & 0,013 & 10,3 \\
\hline & & & 10 & 0,558 & 0,013 & 10,4 \\
\hline & & & 5 & 0,557 & 0,013 & 10,2 \\
\hline \multirow{3}{*}{4} & \multirow{3}{*}{3} & \multirow{3}{*}{0,5} & 20 & 0,499 & 0,013 & $-0,2$ \\
\hline & & & 10 & 0,499 & 0,013 & $-0,2$ \\
\hline & & & 5 & 0,498 & 0,013 & $-0,4$ \\
\hline \multirow{3}{*}{4} & \multirow{3}{*}{4} & \multirow{3}{*}{0,5} & 20 & 0,565 & 0,013 & 11,5 \\
\hline & & & 10 & 0,566 & 0,013 & 11,7 \\
\hline & & & 5 & 0,566 & 0,013 & 11,6 \\
\hline
\end{tabular}

As espessuras equivalentes de atenuação dos dispositivos do Fabricante $A$ apresentaram-se todas abaixo dos valores declarados nas três tensões avaliadas: 80 kV, 100 kV e 150 kV. Foi possível observar diferenças percentuais abaixo dos valores declarados de até $14,5 \%$ para aventais com equivalência nominal de 0,25 mmPb em $80 \mathrm{kV}$ e 15,3\% para aventais com equivalência de 0,50 mmPb em $80 \mathrm{kV}$.

O Fabricante $\mathrm{C}$, como já havia sido observado no método da interpolação linear, apresentou todos os resultados de equivalente de atenuação positivos, ou seja, os valores calculados estavam entre $4,6 \%$ e $11 \%$ para aventais de proteção com equivalência nominal igual a 0,25 mmPb e entre 3,3 \% e 10,6 \% acima dos valores declarados para aventais com equivalência nominal de $0,50 \mathrm{mmPb}$.

Foram obtidos valores de espessura equivalente de atenuação tanto maiores quanto menores que os valores declarados para os fabricantes $\mathrm{B}, \mathrm{D}$ e $\mathrm{E}$.

Como também já havia sido observado no método da interpolação linear, as amostras pertencentes ao Fabricante $D$ foram as menos uniformes, ou seja, a diferença percentual entre os valores declarados e os valores medidos variaram mais que $48 \%$, uma vez que algumas amostras apresentaram uma variação de 30,9 \% abaixo do valor declarado, enquanto que outras apresentaram uma variação de $17,5 \%$ acima do valor declarado, na tensão de $80 \mathrm{kV}$.

Analisando-se os resultados, pôde-se observar que as diferenças percentuais entre os valores do equivalente de atenuação declarados e calculados pelo modelo de 
Archer são praticamente iguais às diferenças obtidas pelo método da interpolação linear.

As incertezas obtidas para este método foram da mesma ordem de grandeza das obtidas para a determinação da espessura equivalente de atenuação utilizando a metodologia da interpolação linear.

\subsubsection{Método do Somatório de Exponenciais}

A terceira metodologia escolhida para a determinação da espessura equivalente de atenuação foi o somatório de exponenciais. A escolha deste método foi motivada pelos resultados apresentados por Guimarães ${ }^{34}$ em 2005 que mostrou, por meio do teste do chi-quadrado $\left(\chi^{2}\right)$, que o somatório de exponenciais, dada pela Equação $24 \mathrm{com} n=2$, é a função que melhor representa a atenuação do feixe de radiação $X$ polienergético, considerando-se o alumínio como material de referência.

$$
\dot{K}=\sum_{i=1}^{n} A_{i} \exp \left(-\frac{x}{t_{i}}\right)
$$

Equação 24

onde $A_{i}$ e $t_{i}$ são os parâmetros de ajuste da função; $\dot{K}$ é a taxa de kerma no ar correspondente à espessura $x$ de um material atenuador.

\subsubsection{Avaliação das Incertezas Associadas à Determinação da Espessura Equivalente de Atenuação pelo Método do Somatório de Exponenciais}

Da mesma forma que a metodologia anterior e pelos mesmos motivos, o processo também foi dividido em duas etapas.

$\mathrm{Na}$ primeira etapa, foi estimada a incerteza nas leituras da taxa de kerma no ar obtidas na obtenção da curva do chumbo padrão. Como fonte de incerteza do Tipo A foi considerado o desvio padrão da média; as incertezas do Tipo B consideradas foram a resolução e a exatidão do monitor da câmara de ionização.

Foi feito o ajuste da Equação 24 considerando-se as espessuras dos filtros de chumbo, as leituras da taxa de kerma no ar correspondente a cada espessura de chumbo e as incertezas combinadas das leituras da taxa de kerma no ar. Os 
parâmetros de ajuste obtidos, neste trabalho chamado de iniciais, e $\circ \chi^{2}$ red para cada tensão e curva estão mostrados nas Tabelas 40 a 42.

A partir desse ajuste prévio, foram determinadas para cada ponto novas incertezas ( $\sigma i)$, de acordo com a Equação 23.

$\mathrm{Na}$ segunda etapa foi feito novamente um ajuste que gerou novos parâmetros de ajuste $\left(A_{1}, t_{1}, A_{2}\right.$ e $\left.t_{2}\right)$. Os parâmetros de ajuste, agora denominados finais, obtidos e o $\chi^{2}$ red para cada tensão e curva estão mostrados nas Tabelas 43 a 45 . Todos os ajustes realizados nesta metodologia também foram feitos utilizando-se o aplicativo GnuPlot versão 4.0.

Como não existe solução analítica para a Equação 24, a espessura equivalente de atenuação dos dispositivos testados teve que ser determinada pelo método numérico, ou seja, os valores da espessura em $\mathrm{mmPb}$ eram substituídos um a um até que se igualassem aos valores de taxa de kerma no ar transmitida pela amostra.

Além disso, para a determinação da incerteza da espessura do equivalente de atenuação, inicialmente foi necessário calcular a incerteza combinada da taxa de kerma no ar, considerando-se as incertezas dos parâmetros de ajuste e coeficientes de correlação.

Sendo a derivada parcial da Equação 24, com $n=2$, no ponto correspondente à espessura equivalente de atenuação igual ao coeficiente angular da reta tangente ao ponto, o coeficiente angular da reta pôde ser determinado segundo a Equação 25, onde $A_{1}, t_{1}, A_{2}$ e $t_{2}$ são os parâmetros de ajuste e $x$ é a espessura equivalente de atenuação.

$$
\frac{\partial \dot{K}}{\partial x}=a=\frac{-A_{1} \cdot \exp \left(\frac{-x}{t_{1}}\right) \cdot t_{2}+A_{2} \cdot \exp \left(\frac{-x}{t_{2}}\right) \cdot t_{1}}{t_{1} \cdot t_{2}}
$$

\section{Equação 25}

A equação da reta foi determinada pela Equação 26. A equação da reta foi derivada com relação a $\dot{K}$ para se determinar o coeficiente de sensibilidade, segundo a Equação 27.

$$
\dot{K}=a \cdot x+b \quad \Rightarrow \quad x=\frac{b-\dot{K}}{a}
$$

onde $a$ é o coeficiente angular e $b$ é a intercepção. 


$$
\frac{\partial \mathrm{x}}{\partial \dot{\mathrm{K}}}=-\frac{1}{\mathrm{a}}
$$

Finalmente, a incerteza combinada $\left(u_{c}\right)$ foi determinada utilizando-se a Equação 28, onde $\sigma_{y}$ é a incerteza da taxa de kerma no ar determinada de acordo com a Equação 23.

$$
u_{C}=\sqrt{\sigma_{y}^{2} \cdot\left(\frac{\partial \mathrm{x}}{\partial \dot{\mathrm{K}}}\right)^{2}} \Rightarrow u_{C}=\sigma_{y} \cdot\left(\frac{\partial \mathrm{x}}{\partial \dot{\mathrm{K}}}\right)
$$

\section{Equação 28}

Do mesmo modo que a metodologia anterior, esse procedimento foi repetido para cada curva de atenuação do chumbo padrão obtida (Curvas 1, 2, 3 e 4), uma vez que as medições para os diferentes fabricantes foram realizadas em dias diferentes. 
Tabela 40 - Parâmetros de ajustes iniciais em $80 \mathrm{kV}\left(A_{1}, t_{1}, A_{2}, t_{2}, \chi_{\text {red }}^{2}\right.$ e $\left.v\right)$ para a função do somatório de exponenciais

\begin{tabular}{|c|c|c|c|c|c|c|c|c|c|c|c|}
\hline \multirow{2}{*}{$\begin{array}{l}\text { Curva Chumbo } \\
\text { Padrão }\end{array}$} & \multirow{2}{*}{$\begin{array}{c}\text { № de } \\
\text { medições }\end{array}$} & \multicolumn{2}{|c|}{$\mathbf{A}_{1}$} & \multicolumn{2}{|c|}{$t_{1}$} & \multicolumn{2}{|c|}{$A_{2}$} & \multicolumn{2}{|c|}{$t_{2}$} & \multirow[b]{2}{*}{$\chi_{\text {red }}^{2}$} & \multirow[b]{2}{*}{$v$} \\
\hline & & Valor & $\begin{array}{c}\text { Incerteza } \\
(+/-)\end{array}$ & Valor & $\begin{array}{c}\text { Incerteza } \\
(+/-)\end{array}$ & Valor & $\begin{array}{c}\text { Incerteza } \\
(+/-)\end{array}$ & Valor & $\begin{array}{c}\text { Incerteza } \\
(+/-)\end{array}$ & & \\
\hline \multirow{3}{*}{1} & 20 & 0,544 & 0,064 & 0,205 & 0,008 & 1,492 & 0,135 & 0,056 & 0,006 & 1,752 & 6 \\
\hline & 10 & 0,549 & 0,057 & 0,204 & 0,007 & 1,490 & 0,117 & 0,055 & 0,006 & 1,282 & 6 \\
\hline & 5 & 0,543 & 0,049 & 0,206 & 0,007 & 1,487 & 0,098 & 0,055 & 0,005 & 0,902 & 6 \\
\hline \multirow{3}{*}{2} & 20 & 0,469 & 0,054 & 0,218 & 0,009 & 1,502 & 0,115 & 0,060 & 0,006 & 1,406 & 6 \\
\hline & 10 & 0,442 & 0,049 & 0,222 & 0,009 & 1,524 & 0,106 & 0,062 & 0,005 & 1,218 & 6 \\
\hline & 5 & 0,432 & 0,053 & 0,223 & 0,009 & 1,528 & 0,107 & 0,063 & 0,005 & 1,231 & 6 \\
\hline \multirow{3}{*}{3} & 20 & 0,458 & 0,038 & 0,218 & 0,006 & 1,520 & 0,058 & 0,061 & 0,004 & 0,266 & 4 \\
\hline & 10 & 0,489 & 0,034 & 0,219 & 0,005 & 1,483 & 0,064 & 0,059 & 0,003 & 0,410 & 4 \\
\hline & 5 & 0,472 & 0,041 & 0,216 & 0,007 & 1,501 & 0,078 & 0,059 & 0,004 & 0,615 & 4 \\
\hline \multirow{3}{*}{4} & 20 & 0,497 & 0,045 & 0,214 & 0,007 & 1,562 & 0,088 & 0,059 & 0,004 & 0,733 & 4 \\
\hline & 10 & 0,504 & 0,045 & 0,213 & 0,007 & 1,556 & 0,087 & 0,059 & 0,004 & 0,685 & 4 \\
\hline & 5 & 0,500 & 0,042 & 0,214 & 0,007 & 1,561 & 0,079 & 0,059 & 0,004 & 0,572 & 4 \\
\hline
\end{tabular}


Tabela 41 - Parâmetros de ajustes iniciais em $100 \mathrm{kV}\left(A_{1}, t_{1}, A_{2}, t_{2}, \chi_{\text {red }}^{2}\right.$ e $\left.v\right)$ para a função do somatório de exponenciais

\begin{tabular}{|c|c|c|c|c|c|c|c|c|c|c|c|}
\hline \multirow{2}{*}{$\begin{array}{l}\text { Curva Chumbo } \\
\text { Padrão }\end{array}$} & \multirow{2}{*}{$\begin{array}{c}\text { № de } \\
\text { medições }\end{array}$} & \multicolumn{2}{|c|}{$A_{1}$} & \multicolumn{2}{|c|}{$t_{1}$} & \multicolumn{2}{|c|}{$A_{2}$} & \multicolumn{2}{|c|}{$t_{2}$} & \multirow[b]{2}{*}{$\chi_{\text {red }}^{2}$} & \multirow[b]{2}{*}{$v$} \\
\hline & & Valor & $\begin{array}{c}\text { Incerteza } \\
(+/-)\end{array}$ & Valor & $\begin{array}{c}\text { Incerteza } \\
(+/-)\end{array}$ & Valor & $\begin{array}{c}\text { Incerteza } \\
(+/-)\end{array}$ & Valor & $\begin{array}{c}\text { Incerteza } \\
(+/-)\end{array}$ & & \\
\hline \multirow{3}{*}{1} & 20 & 0,697 & 0,044 & 0,313 & 0,006 & 1,836 & 0,084 & 0,097 & 0,005 & 0,510 & 9 \\
\hline & 10 & 0,723 & 0,042 & 0,309 & 0,006 & 1,822 & 0,079 & 0,094 & 0,005 & 0,430 & 9 \\
\hline & 5 & 0,743 & 0,042 & 0,305 & 0,006 & 1,810 & 0,076 & 0,093 & 0,005 & 0,385 & 9 \\
\hline \multirow{3}{*}{2} & 20 & 0,669 & 0,040 & 0,319 & 0,006 & 1,811 & 0,076 & 0,098 & 0,005 & 0,443 & 9 \\
\hline & 10 & 0,669 & 0,051 & 0,319 & 0,008 & 1,812 & 0,094 & 0,099 & 0,006 & 0,664 & 9 \\
\hline & 5 & 0,630 & 0,058 & 0,326 & 0,010 & 1,839 & 0,101 & 0,102 & 0,007 & 0,774 & 9 \\
\hline \multirow{3}{*}{3} & 20 & 0,699 & 0,045 & 0,309 & 0,006 & 1,780 & 0,083 & 0,096 & 0,005 & 0,509 & 9 \\
\hline & 10 & 0,670 & 0,050 & 0,314 & 0,008 & 1,800 & 0,089 & 0,099 & 0,006 & 0,599 & 9 \\
\hline & 5 & 0,683 & 0,053 & 0,312 & 0,008 & 1,791 & 0,092 & 0,097 & 0,006 & 0,611 & 9 \\
\hline \multirow{3}{*}{4} & 20 & 0,682 & 0,043 & 0,319 & 0,007 & 1,888 & 0,087 & 0,098 & 0,005 & 0,541 & 9 \\
\hline & 10 & 0,705 & 0,043 & 0,314 & 0,006 & 1,875 & 0,081 & 0,097 & 0,005 & 0,463 & 9 \\
\hline & 5 & 0,724 & 0,042 & 0,312 & 0,006 & 1,865 & 0,076 & 0,095 & 0,005 & 0,386 & 9 \\
\hline
\end{tabular}


Tabela 42 - Parâmetros de ajustes iniciais em $150 \mathrm{kV}\left(A_{1}, t_{1}, A_{2}, t_{2}, \chi_{\text {red }}^{2}\right.$ e $\left.v\right)$ para a função do somatório de exponenciais

\begin{tabular}{|c|c|c|c|c|c|c|c|c|c|c|c|}
\hline \multirow{2}{*}{$\begin{array}{l}\text { Curva Chumbo } \\
\text { Padrão }\end{array}$} & \multirow{2}{*}{$\begin{array}{c}\text { № de } \\
\text { medições }\end{array}$} & \multicolumn{2}{|c|}{$A_{1}$} & \multicolumn{2}{|c|}{$t_{1}$} & \multicolumn{2}{|c|}{$A_{2}$} & \multicolumn{2}{|c|}{$t_{2}$} & \multirow[b]{2}{*}{$\chi_{\text {red }}^{2}$} & \multirow[b]{2}{*}{$v$} \\
\hline & & Valor & $\begin{array}{c}\text { Incerteza } \\
(+/-)\end{array}$ & Valor & $\begin{array}{c}\text { Incerteza } \\
(+/-)\end{array}$ & Valor & $\begin{array}{c}\text { Incerteza } \\
(+/-)\end{array}$ & Valor & $\begin{array}{c}\text { Incerteza } \\
(+/-)\end{array}$ & & \\
\hline \multirow{3}{*}{1} & 20 & 0,941 & 0,079 & 0,366 & 0,008 & 2,006 & 0,073 & 0,167 & 0,006 & 0,098 & 9 \\
\hline & 10 & 0,912 & 0,076 & 0,370 & 0,008 & 2,035 & 0,070 & 0,168 & 0,006 & 0,091 & 9 \\
\hline & 5 & 0,926 & 0,094 & 0,368 & 0,010 & 2,023 & 0,086 & 0,167 & 0,007 & 0,126 & 9 \\
\hline \multirow{3}{*}{2} & 20 & 0,930 & 0,072 & 0,367 & 0,007 & 1,986 & 0,067 & 0,166 & 0,006 & 0,089 & 9 \\
\hline & 10 & 0,939 & 0,077 & 0,366 & 0,008 & 1,979 & 0,071 & 0,166 & 0,006 & 0,093 & 9 \\
\hline & 5 & 0,937 & 0,084 & 0,366 & 0,009 & 1,982 & 0,077 & 0,166 & 0,007 & 0,112 & 9 \\
\hline \multirow{3}{*}{3} & 20 & 1,021 & 0,050 & 0,353 & 0,004 & 1,864 & 0,047 & 0,160 & 0,004 & 0,041 & 9 \\
\hline & 10 & 0,901 & 0,068 & 0,366 & 0,007 & 1,975 & 0,062 & 0,167 & 0,005 & 0,076 & 9 \\
\hline & 5 & 0,907 & 0,060 & 0,366 & 0,006 & 1,973 & 0,055 & 0,167 & 0,005 & 0,057 & 9 \\
\hline \multirow{3}{*}{4} & 20 & 0,991 & 0,054 & 0,363 & 0,005 & 2,021 & 0,050 & 0,163 & 0,004 & 0,048 & 9 \\
\hline & 10 & 1,014 & 0,051 & 0,361 & 0,005 & 2,004 & 0,048 & 0,162 & 0,004 & 0,041 & 9 \\
\hline & 5 & 0,983 & 0,058 & 0,364 & 0,006 & 2,035 & 0,054 & 0,164 & 0,004 & 0,049 & 9 \\
\hline
\end{tabular}


Tabela 43 - Parâmetros de ajustes finais em $80 \mathrm{kV}\left(A_{1}, t_{1}, A_{2}, t_{2}, \chi_{\text {red }}^{2}\right.$ e v) para a função do somatório de exponenciais

\begin{tabular}{|c|c|c|c|c|c|c|c|c|c|c|c|}
\hline \multirow{2}{*}{$\begin{array}{l}\text { Curva Chumbo } \\
\text { Padrão }\end{array}$} & \multirow{2}{*}{$\begin{array}{c}\text { № de } \\
\text { medições }\end{array}$} & \multicolumn{2}{|c|}{$A_{1}$} & \multicolumn{2}{|c|}{$t_{1}$} & \multicolumn{2}{|c|}{$A_{2}$} & \multicolumn{2}{|c|}{$t_{2}$} & \multirow{2}{*}{$\chi^{2}$ red } & \multirow[b]{2}{*}{$v$} \\
\hline & & Valor & $\begin{array}{c}\text { Incerteza } \\
(+/-)\end{array}$ & Valor & $\begin{array}{c}\text { Incerteza } \\
(+/-)\end{array}$ & Valor & $\begin{array}{c}\text { Incerteza } \\
(+/-)\end{array}$ & Valor & $\begin{array}{l}\text { Incerteza } \\
(+/-)\end{array}$ & & \\
\hline \multirow{3}{*}{1} & 20 & 0,503 & 0,029 & 0,211 & 0,004 & 1,534 & 0,047 & 0,058 & 0,003 & 0,173 & 5 \\
\hline & 10 & 0,514 & 0,026 & 0,210 & 0,004 & 1,526 & 0,041 & 0,057 & 0,003 & 0,129 & 5 \\
\hline & 5 & 0,519 & 0,029 & 0,210 & 0,004 & 1,523 & 0,046 & 0,057 & 0,003 & 0,154 & 5 \\
\hline \multirow{3}{*}{2} & 20 & 0,429 & 0,043 & 0,226 & 0,008 & 1,546 & 0,071 & 0,063 & 0,005 & 0,433 & 5 \\
\hline & 10 & 0,423 & 0,051 & 0,226 & 0,009 & 1,553 & 0,084 & 0,064 & 0,005 & 0,598 & 5 \\
\hline & 5 & 0,424 & 0,055 & 0,226 & 0,010 & 1,550 & 0,089 & 0,064 & 0,006 & 0,665 & 5 \\
\hline \multirow{3}{*}{3} & 20 & 0,458 & 0,038 & 0,218 & 0,006 & 1,520 & 0,058 & 0,611 & 0,004 & 0,266 & 4 \\
\hline & 10 & 0,481 & 0,034 & 0,213 & 0,005 & 1,497 & 0,050 & 0,059 & 0,003 & 0,190 & 4 \\
\hline & 5 & 0,460 & 0,041 & 0,218 & 0,007 & 1,519 & 0,063 & 0,060 & 0,004 & 0,302 & 4 \\
\hline \multirow{3}{*}{4} & 20 & 0,491 & 0,045 & 0,215 & 0,007 & 1,576 & 0,068 & 0,060 & 0,004 & 0,330 & 4 \\
\hline & 10 & 0,491 & 0,046 & 0,215 & 0,007 & 1,575 & 0,069 & 0,060 & 0,004 & 0,336 & 4 \\
\hline & 5 & 0,488 & 0,041 & 0,216 & 0,007 & 1,580 & 0,063 & 0,060 & 0,004 & 0,273 & 4 \\
\hline
\end{tabular}


Tabela 44 - Parâmetros de ajustes finais em $100 \mathrm{kV}\left(A_{1}, t_{1}, A_{2}, t_{2}, \chi_{\text {red }}^{2}\right.$ e v) para a função do somatório de exponenciais

\begin{tabular}{|c|c|c|c|c|c|c|c|c|c|c|c|}
\hline \multirow{2}{*}{$\begin{array}{c}\text { Curva Chumbo } \\
\text { Padrão }\end{array}$} & \multirow{2}{*}{$\begin{array}{c}\text { № de } \\
\text { medições }\end{array}$} & \multicolumn{2}{|c|}{$A_{1}$} & \multicolumn{2}{|c|}{$t_{1}$} & \multicolumn{2}{|c|}{$A_{2}$} & \multicolumn{2}{|c|}{$t_{2}$} & \multirow{2}{*}{$\chi_{\text {red }}^{2}$} & \multirow[b]{2}{*}{$v$} \\
\hline & & Valor & $\begin{array}{c}\text { Incerteza } \\
(+/-)\end{array}$ & Valor & $\begin{array}{c}\text { Incerteza } \\
(+/-)\end{array}$ & Valor & $\begin{array}{c}\text { Incerteza } \\
(+/-)\end{array}$ & Valor & $\begin{array}{c}\text { Incerteza } \\
(+/-)\end{array}$ & & \\
\hline \multirow{3}{*}{1} & 20 & 0,699 & 0,042 & 0,313 & 0,006 & 1,868 & 0,069 & 0,095 & 0,005 & 0,275 & 9 \\
\hline & 10 & 0,727 & 0,040 & 0,309 & 0,006 & 1,848 & 0,064 & 0,093 & 0,005 & 0,231 & 9 \\
\hline & 5 & 0,744 & 0,040 & 0,306 & 0,006 & 1,835 & 0,062 & 0,092 & 0,004 & 0,207 & 9 \\
\hline \multirow{3}{*}{2} & 20 & 0,670 & 0,038 & 0,319 & 0,006 & 1,842 & 0,063 & 0,097 & 0,005 & 0,243 & 9 \\
\hline & 10 & 0,664 & 0,050 & 0,320 & 0,008 & 1,848 & 0,810 & 0,098 & 0,006 & 0,397 & 9 \\
\hline & 5 & 0,620 & 0,060 & 0,329 & 0,010 & 1,884 & 0,088 & 0,101 & 0,006 & 0,471 & 9 \\
\hline \multirow{3}{*}{3} & 20 & 0,697 & 0,044 & 0,310 & 0,006 & 1,813 & 0,069 & 0,095 & 0,005 & 0,284 & 9 \\
\hline & 10 & 0,673 & 0,047 & 0,314 & 0,007 & 1,832 & 0,074 & 0,097 & 0,005 & 0,322 & 9 \\
\hline & 5 & 0,677 & 0,052 & 0,313 & 0,008 & 1,827 & 0,079 & 0,097 & 0,006 & 0,352 & 9 \\
\hline \multirow{3}{*}{4} & 20 & 0,681 & 0,042 & 0,319 & 0,006 & 1,925 & 0,071 & 0,097 & 0,005 & 0,296 & 9 \\
\hline & 10 & 0,700 & 0,041 & 0,315 & 0,006 & 1,911 & 0,067 & 0,096 & 0,005 & 0,254 & 9 \\
\hline & 5 & 0,718 & 0,041 & 0,313 & 0,006 & 1,896 & 0,065 & 0,095 & 0,005 & 0,226 & 9 \\
\hline
\end{tabular}


Tabela 45 - Parâmetros de ajustes finais em $150 \mathrm{kV}\left(A_{1}, t_{1}, A_{2}, t_{2}, \chi_{\text {red }}^{2}\right.$ e v) para a função do somatório de exponenciais

\begin{tabular}{|c|c|c|c|c|c|c|c|c|c|c|c|}
\hline \multirow{2}{*}{$\begin{array}{l}\text { Curva Chumbo } \\
\text { Padrão }\end{array}$} & \multirow{2}{*}{$\begin{array}{c}\text { № de } \\
\text { medições }\end{array}$} & \multicolumn{2}{|c|}{$A_{1}$} & \multicolumn{2}{|c|}{$t_{1}$} & \multicolumn{2}{|c|}{$A_{2}$} & \multicolumn{2}{|c|}{$t_{2}$} & \multirow[b]{2}{*}{$\chi_{\text {red }}^{2}$} & \multirow[b]{2}{*}{$v$} \\
\hline & & Valor & $\begin{array}{c}\text { Incerteza } \\
(+/-)\end{array}$ & Valor & $\begin{array}{c}\text { Incerteza } \\
(+/-)\end{array}$ & Valor & $\begin{array}{c}\text { Incerteza } \\
(+/-)\end{array}$ & Valor & $\begin{array}{c}\text { Incerteza } \\
(+/-)\end{array}$ & & \\
\hline \multirow{3}{*}{1} & 20 & 0,963 & 0,077 & 0,364 & 0,008 & 1,997 & 0,073 & 0,164 & 0,006 & 0,054 & 9 \\
\hline & 10 & 0,936 & 0,075 & 0,368 & 0,008 & 2,026 & 0,071 & 0,165 & 0,006 & 0,052 & 9 \\
\hline & 5 & 0,945 & 0,091 & 0,367 & 0,086 & 2,019 & 0,086 & 0,165 & 0,007 & 0,072 & 9 \\
\hline \multirow{3}{*}{2} & 20 & 0,957 & 0,071 & 0,364 & 0,007 & 1,971 & 0,067 & 0,164 & 0,005 & 0,049 & 9 \\
\hline & 10 & 0,968 & 0,074 & 0,363 & 0,007 & 1,964 & 0,070 & 0,163 & 0,006 & 0,052 & 9 \\
\hline & 5 & 0,971 & 0,081 & 0,363 & 0,008 & 1,961 & 0,077 & 0,163 & 0,006 & 0,061 & 9 \\
\hline \multirow{3}{*}{3} & 20 & 1,038 & 0,049 & 0,352 & 0,004 & 1,859 & 0,047 & 0,159 & 0,004 & 0,022 & 9 \\
\hline & 10 & 0,929 & 0,068 & 0,364 & 0,007 & 1,962 & 0,064 & 0,165 & 0,005 & 0,044 & 9 \\
\hline & 5 & 0,934 & 0,060 & 0,363 & 0,006 & 1,958 & 0,057 & 0,164 & 0,004 & 0,033 & 9 \\
\hline \multirow{3}{*}{4} & 20 & 1,014 & 0,053 & 0,361 & 0,005 & 2,010 & 0,050 & 0,161 & 0,004 & 0,027 & 9 \\
\hline & 10 & 1,033 & 0,051 & 0,359 & 0,005 & 1,996 & 0,049 & 0,160 & 0,004 & 0,024 & 9 \\
\hline & 5 & 0,994 & 0,060 & 0,363 & 0,006 & 2,035 & 0,057 & 0,162 & 0,004 & 0,032 & 9 \\
\hline
\end{tabular}




\subsubsection{Resultados das Espessuras Equivalentes de Atenuação e Incertezas Associadas Obtidas pelo Método do Somatório de Exponenciais}

Os resultados das espessuras equivalente de atenuação e as incertezas associadas obtidas pelo método do somatório de exponenciais foram organizados em tabelas. Nessas tabelas também são apresentados os valores declarados da espessura equivalente de atenuação de cada amostra e o desvio percentual entre os valores calculados e os valores declarados. Além disso, está especificada qual foi a curva de chumbo padrão (1, 2, 3 ou 4) utilizada para cada dispositivo de proteção.

Os resultados obtidos do Fabricante A para as tensões de $80 \mathrm{kV}, 100 \mathrm{kV}$ e $150 \mathrm{kV}$ estão mostrados nas Tabelas 46 a 48, respectivamente. Os resultados obtidos referentes ao Fabricante $B$ nas três tensões avaliadas estão apresentados nas Tabelas 49 a 51 , respectivamente.

Nas Tabelas 52 a 54 são apresentados os resultados referentes às amostras do Fabricante $C$, nas Tabelas 55 a 57 os resultados referentes às amostras do Fabricante D, e nas Tabelas 58 a 60 os resultados das amostras do Fabricante E. 
Tabela 46 - Resultados da determinação da espessura equivalente de atenuação em chumbo, incerteza e diferença percentual entre o valor calculado e o valor nominal, para as amostras do Fabricante A, em $\mathbf{8 0 ~ k V}$. Método: somatório de exponenciais

\begin{tabular}{|c|c|c|c|c|c|c|}
\hline Curva & Dispositivo & $\begin{array}{c}\text { Equivalência } \\
\text { Nominal (mmPb) }\end{array}$ & $\begin{array}{c}\text { № } \\
\text { Medições }\end{array}$ & $\begin{array}{c}\text { Equivalência } \\
\text { Calculada (mmPb) }\end{array}$ & $\begin{array}{c}\text { Incerteza } \\
(\mathrm{mmPb})\end{array}$ & $\begin{array}{c}\text { Diferença } \\
\text { (\%) }\end{array}$ \\
\hline \multirow{3}{*}{2} & \multirow{3}{*}{$\mathrm{AV} 1$} & \multirow{3}{*}{0,5} & 20 & 0,456 & 0,006 & $-9,8$ \\
\hline & & & 10 & 0,456 & 0,008 & $-9,8$ \\
\hline & & & 5 & 0,456 & 0,008 & $-9,7$ \\
\hline \multirow{3}{*}{2} & \multirow{3}{*}{ AV1 - costas } & \multirow{3}{*}{0,25} & 20 & 0,215 & 0,005 & $-16,3$ \\
\hline & & & 10 & 0,214 & 0,005 & $-16,6$ \\
\hline & & & 5 & 0,214 & 0,006 & $-16,6$ \\
\hline \multirow{3}{*}{2} & \multirow{3}{*}{ AV2 } & \multirow{3}{*}{0,5} & 20 & 0,436 & 0,006 & $-14,8$ \\
\hline & & & 10 & 0,433 & 0,008 & $-15,5$ \\
\hline & & & 5 & 0,431 & 0,008 & $-16,1$ \\
\hline \multirow{3}{*}{2} & \multirow{3}{*}{ AV2 - costas } & \multirow{3}{*}{0,25} & 20 & 0,218 & 0,005 & $-14,9$ \\
\hline & & & 10 & 0,217 & 0,005 & $-15,5$ \\
\hline & & & 5 & 0,217 & 0,006 & $-15,4$ \\
\hline \multirow{3}{*}{2} & \multirow{3}{*}{ AV3 } & \multirow{3}{*}{0,25} & 20 & 0,214 & 0,005 & $-17,0$ \\
\hline & & & 10 & 0,213 & 0,005 & $-17,3$ \\
\hline & & & 5 & 0,214 & 0,006 & $-17,1$ \\
\hline \multirow{3}{*}{2} & \multirow{3}{*}{ AV4 } & \multirow{3}{*}{0,25} & 20 & 0,216 & 0,005 & $-15,9$ \\
\hline & & & 10 & 0,215 & 0,005 & $-16,2$ \\
\hline & & & 5 & 0,216 & 0,006 & $-16,0$ \\
\hline \multirow{3}{*}{2} & \multirow{3}{*}{ AV5 } & \multirow{3}{*}{0,25} & 20 & 0,218 & 0,005 & $-14,9$ \\
\hline & & & 10 & 0,218 & 0,005 & $-14,8$ \\
\hline & & & 5 & 0,218 & 0,006 & $-14,9$ \\
\hline \multirow{3}{*}{2} & \multirow{3}{*}{ AV6 } & & 20 & 0,442 & 0,006 & $-13,1$ \\
\hline & & 0,5 & 10 & 0,440 & 0,008 & $-13,5$ \\
\hline & & & 5 & 0,439 & 0,008 & $-13,8$ \\
\hline & & & 20 & 0,448 & 0,006 & $-11,7$ \\
\hline 2 & AV7 & 0,5 & 10 & 0,446 & 0,008 & $-12,2$ \\
\hline & & & 5 & 0,448 & 0,008 & $-11,7$ \\
\hline & & & 20 & 0,456 & 0,006 & $-9,6$ \\
\hline 2 & AV8 & 0,5 & 10 & 0,453 & 0,008 & $-10,4$ \\
\hline & & & 5 & 0,453 & 0,008 & $-10,4$ \\
\hline & & & 20 & 0,227 & 0,005 & $-10,4$ \\
\hline 2 & AV9 & 0,25 & 10 & 0,226 & 0,005 & $-10,8$ \\
\hline & & & 5 & 0,225 & 0,006 & $-11,1$ \\
\hline & & & 20 & 0,220 & 0,005 & $-13,7$ \\
\hline 2 & AV10 & 0,25 & 10 & 0,220 & 0,005 & $-13,8$ \\
\hline & & & 5 & 0,219 & 0,006 & $-14,2$ \\
\hline & & & 20 & 0,451 & 0,006 & $-10,8$ \\
\hline 2 & BO1 & 0,5 & 10 & 0,451 & 0,008 & $-10,8$ \\
\hline & & & 5 & 0,451 & 0,008 & $-11,0$ \\
\hline & & & 20 & 0,455 & 0,006 & $-9,8$ \\
\hline 2 & BO2 & 0,5 & 10 & 0,452 & 0,008 & $-10,6$ \\
\hline & & & 5 & 0,453 & 0,008 & $-10,4$ \\
\hline & & & 20 & 0,451 & 0,006 & $-10,9$ \\
\hline 2 & BO3 & 0,5 & 10 & 0,450 & 0,008 & $-11,2$ \\
\hline & & & 5 & 0,449 & 0,008 & $-11,4$ \\
\hline
\end{tabular}


Tabela 47 - Resultados da determinação da espessura equivalente de atenuação em chumbo, incerteza e diferença percentual entre o valor calculado e o valor nominal, para as amostras do Fabricante A, em 100 kV. Método: somatório de exponenciais

\begin{tabular}{|c|c|c|c|c|c|c|}
\hline Curva & $\begin{array}{l}\text { Dispositivo } \\
\text { de proteção }\end{array}$ & $\begin{array}{c}\text { Equivalência } \\
\text { Nominal (mmPb) }\end{array}$ & $\begin{array}{c}\text { № } \\
\text { Medições }\end{array}$ & $\begin{array}{c}\text { Equivalência } \\
\text { Calculada (mmPb) }\end{array}$ & $\begin{array}{l}\text { Incerteza } \\
\text { (mmPb) }\end{array}$ & $\begin{array}{c}\text { Diferença } \\
\text { (\%) }\end{array}$ \\
\hline \multirow{3}{*}{2} & \multirow{3}{*}{$\mathrm{AV} 1$} & \multirow{3}{*}{0,5} & 20 & 0,437 & 0,004 & $-14,4$ \\
\hline & & & 10 & 0,438 & 0,005 & $-14,1$ \\
\hline & & & 5 & 0,436 & 0,006 & $-14,7$ \\
\hline \multirow{3}{*}{2} & \multirow{3}{*}{ AV1 - costas } & \multirow{3}{*}{0,25} & 20 & 0,219 & 0,004 & $-14,1$ \\
\hline & & & 10 & 0,220 & 0,005 & $-13,6$ \\
\hline & & & 5 & 0,221 & 0,005 & $-13,2$ \\
\hline \multirow{3}{*}{2} & \multirow{3}{*}{ AV2 } & \multirow{3}{*}{0,5} & 20 & 0,433 & 0,004 & $-15,4$ \\
\hline & & & 10 & 0,433 & 0,005 & $-15,4$ \\
\hline & & & 5 & 0,431 & 0,006 & $-16,1$ \\
\hline \multirow{3}{*}{2} & \multirow{3}{*}{ AV2 - costas } & \multirow{3}{*}{0,25} & 20 & 0,225 & 0,004 & $-11,3$ \\
\hline & & & 10 & 0,225 & 0,005 & $-11,1$ \\
\hline & & & 5 & 0,226 & 0,005 & $-10,6$ \\
\hline \multirow{3}{*}{2} & \multirow{3}{*}{ AV3 } & \multirow{3}{*}{0,25} & 20 & 0,219 & 0,004 & $-13,9$ \\
\hline & & & 10 & 0,220 & 0,005 & $-13,6$ \\
\hline & & & 5 & 0,221 & 0,005 & $-13,4$ \\
\hline \multirow{3}{*}{2} & \multirow{3}{*}{ AV4 } & \multirow{3}{*}{0,25} & 20 & 0,224 & 0,004 & $-11,5$ \\
\hline & & & 10 & 0,225 & 0,005 & $-11,3$ \\
\hline & & & 5 & 0,226 & 0,005 & $-10,8$ \\
\hline \multirow{3}{*}{2} & \multirow{3}{*}{ AV5 } & \multirow{3}{*}{0,25} & 20 & 0,223 & 0,004 & $-12,2$ \\
\hline & & & 10 & 0,224 & 0,005 & $-11,8$ \\
\hline & & & 5 & 0,224 & 0,005 & $-11,5$ \\
\hline \multirow{3}{*}{2} & \multirow{3}{*}{ AV6 } & & 20 & 0,432 & 0,004 & $-15,8$ \\
\hline & & 0,5 & 10 & 0,432 & 0,005 & $-15,8$ \\
\hline & & & 5 & 0,429 & 0,006 & $-16,6$ \\
\hline & & & 20 & 0,442 & 0,004 & $-13,3$ \\
\hline 2 & AV7 & 0,5 & 10 & 0,456 & 0,005 & $-9,7$ \\
\hline & & & 5 & 0,441 & 0,006 & $-13,4$ \\
\hline & & & 20 & 0,419 & 0,004 & $-19,4$ \\
\hline 2 & AV8 & 0,5 & 10 & 0,425 & 0,005 & $-17,7$ \\
\hline & & & 5 & 0,409 & 0,006 & $-22,2$ \\
\hline & & & 20 & 0,225 & 0,004 & $-11,0$ \\
\hline 2 & AV9 & 0,25 & 10 & 0,226 & 0,005 & $-10,7$ \\
\hline & & & 5 & 0,226 & 0,005 & $-10,7$ \\
\hline & & & 20 & 0,228 & 0,004 & $-9,7$ \\
\hline 2 & AV10 & 0,25 & 10 & 0,228 & 0,005 & $-9,5$ \\
\hline & & & 5 & 0,229 & 0,005 & $-9,3$ \\
\hline & & & 20 & 0,441 & 0,004 & $-13,4$ \\
\hline 2 & BO1 & 0,5 & 10 & 0,441 & 0,005 & $-13,4$ \\
\hline & & & 5 & 0,437 & 0,006 & $-14,5$ \\
\hline & & & 20 & 0,445 & 0,004 & $-12,5$ \\
\hline 2 & BO2 & 0,5 & 10 & 0,444 & 0,005 & $-12,6$ \\
\hline & & & 5 & 0,439 & 0,006 & $-13,8$ \\
\hline & & & 20 & 0,442 & 0,004 & $-13,0$ \\
\hline 2 & BO3 & 0,5 & 10 & 0,442 & 0,005 & $-13,2$ \\
\hline & & & 5 & 0,438 & 0,006 & $-14,1$ \\
\hline
\end{tabular}


Tabela 48 - Resultados da determinação da espessura equivalente de atenuação em chumbo, incerteza e diferença percentual entre o valor calculado e o valor nominal, para as amostras do Fabricante A, em 150 kV. Método: somatório de exponenciais

\begin{tabular}{|c|c|c|c|c|c|c|}
\hline Curva & Dispositivo & $\begin{array}{c}\text { Equivalência } \\
\text { Nominal (mmPb) }\end{array}$ & $\begin{array}{c}\text { № } \\
\text { Medições }\end{array}$ & $\begin{array}{c}\text { Equivalência } \\
\text { Calculada (mmPb) }\end{array}$ & $\begin{array}{c}\text { Incerteza } \\
(\mathrm{mmPb})\end{array}$ & $\begin{array}{c}\text { Diferença } \\
(\%)\end{array}$ \\
\hline \multirow{3}{*}{2} & \multirow{3}{*}{$\mathrm{AV} 1$} & \multirow{3}{*}{ ( } & 20 & 0,447 & 0,002 & $-12,0$ \\
\hline & & & 10 & 0,447 & 0,002 & $-11,9$ \\
\hline & & & 5 & 0,447 & 0,002 & $-11,9$ \\
\hline \multirow{3}{*}{2} & \multirow{3}{*}{ AV1 - costas } & \multirow{3}{*}{0,25} & 20 & 0,225 & 0,002 & $-11,3$ \\
\hline & & & 10 & 0,225 & 0,002 & $-11,3$ \\
\hline & & & 5 & 0,225 & 0,002 & $-11,3$ \\
\hline \multirow{3}{*}{2} & \multirow{3}{*}{ AV2 } & \multirow{3}{*}{0,5} & 20 & 0,447 & 0,002 & $-11,9$ \\
\hline & & & 10 & 0,447 & 0,002 & $-11,9$ \\
\hline & & & 5 & 0,449 & 0,002 & $-11,4$ \\
\hline \multirow{3}{*}{2} & \multirow{3}{*}{ AV2 - costas } & \multirow{3}{*}{0,25} & 20 & 0,225 & 0,002 & $-11,0$ \\
\hline & & & 10 & 0,225 & 0,002 & $-11,1$ \\
\hline & & & 5 & 0,225 & 0,002 & $-11,0$ \\
\hline \multirow{3}{*}{2} & \multirow{3}{*}{ AV3 } & \multirow{3}{*}{0,25} & 20 & 0,225 & 0,002 & $-11,2$ \\
\hline & & & 10 & 0,225 & 0,002 & $-11,3$ \\
\hline & & & 5 & 0,225 & 0,002 & $-11,2$ \\
\hline \multirow{3}{*}{2} & \multirow{3}{*}{ AV4 } & \multirow{3}{*}{0,25} & 20 & 0,230 & 0,002 & $-8,6$ \\
\hline & & & 10 & 0,230 & 0,002 & $-8,6$ \\
\hline & & & 5 & 0,230 & 0,002 & $-8,5$ \\
\hline \multirow{3}{*}{2} & \multirow{3}{*}{ AV5 } & \multirow{3}{*}{0,25} & 20 & 0,231 & 0,002 & $-8,2$ \\
\hline & & & 10 & 0,231 & 0,002 & $-8,3$ \\
\hline & & & 5 & 0,231 & 0,002 & $-8,1$ \\
\hline \multirow{3}{*}{2} & \multirow{3}{*}{ AV6 } & & 20 & 0,448 & 0,002 & $-11,7$ \\
\hline & & 0,5 & 10 & 0,448 & 0,002 & $-11,5$ \\
\hline & & & 5 & 0,448 & 0,002 & $-11,5$ \\
\hline & & & 20 & 0,453 & 0,002 & $-10,3$ \\
\hline 2 & AV7 & 0,5 & 10 & 0,454 & 0,002 & $-10,2$ \\
\hline & & & 5 & 0,454 & 0,002 & $-10,2$ \\
\hline & & & 20 & 0,462 & 0,002 & $-8,2$ \\
\hline 2 & AV8 & 0,5 & 10 & 0,462 & 0,002 & $-8,2$ \\
\hline & & & 5 & 0,463 & 0,002 & $-8,1$ \\
\hline & & & 20 & 0,230 & 0,002 & $-8,5$ \\
\hline 2 & AV9 & 0,25 & 10 & 0,230 & 0,002 & $-8,5$ \\
\hline & & & 5 & 0,231 & 0,002 & $-8,3$ \\
\hline & & & 20 & 0,235 & 0,002 & $-6,6$ \\
\hline 2 & AV10 & 0,25 & 10 & 0,234 & 0,002 & $-6,7$ \\
\hline & & & 5 & 0,235 & 0,002 & $-6,5$ \\
\hline & & & 20 & 0,463 & 0,002 & $-7,9$ \\
\hline 2 & BO1 & 0,5 & 10 & 0,464 & 0,002 & $-7,7$ \\
\hline & & & 5 & 0,465 & 0,002 & $-7,5$ \\
\hline & & & 20 & 0,448 & 0,002 & $-11,7$ \\
\hline 2 & BO2 & 0,5 & 10 & 0,446 & 0,002 & $-12,2$ \\
\hline & & & 5 & 0,447 & 0,002 & $-11,8$ \\
\hline & & & 20 & 0,455 & 0,002 & $-9,9$ \\
\hline 2 & BO3 & 0,5 & 10 & 0,455 & 0,002 & $-9,9$ \\
\hline & & & 5 & 0,455 & 0,002 & $-9,9$ \\
\hline
\end{tabular}


Tabela 49 - Resultados da determinação da espessura equivalente de atenuação em chumbo, incerteza e diferença percentual entre o valor calculado e o valor nominal, para as amostras do Fabricante $\mathrm{B}$, em $\mathbf{8 0}$ kV. Método: somatório de exponenciais

\begin{tabular}{|c|c|c|c|c|c|c|}
\hline Curva & Dispositivo & $\begin{array}{c}\text { Equivalência } \\
\text { Nominal (mmPb) }\end{array}$ & $\begin{array}{c}\text { № } \\
\text { Medições }\end{array}$ & $\begin{array}{c}\text { Equivalência } \\
\text { Calculada (mmPb) }\end{array}$ & $\begin{array}{c}\text { Incerteza } \\
(\mathrm{mmPb})\end{array}$ & $\begin{array}{c}\text { Diferença } \\
(\%)\end{array}$ \\
\hline \multirow{3}{*}{2} & \multirow{3}{*}{$\mathrm{AV} 1$} & \multirow{3}{*}{0,25} & 20 & 0,229 & 0,005 & $-9,1$ \\
\hline & & & 10 & 0,229 & 0,005 & $-9,4$ \\
\hline & & & 5 & 0,229 & 0,006 & $-9,4$ \\
\hline \multirow{3}{*}{2} & \multirow{3}{*}{ AV2 } & \multirow{3}{*}{0,25} & 20 & 0,236 & 0,005 & $-5,8$ \\
\hline & & & 10 & 0,236 & 0,005 & $-6,1$ \\
\hline & & & 5 & 0,236 & 0,006 & $-6,0$ \\
\hline \multirow{3}{*}{2} & \multirow{3}{*}{$\mathrm{AV} 3$} & \multirow{3}{*}{0,25} & 20 & 0,257 & 0,005 & 2,7 \\
\hline & & & 10 & 0,257 & 0,006 & 2,5 \\
\hline & & & 5 & 0,256 & 0,006 & 2,5 \\
\hline \multirow{3}{*}{2} & \multirow{3}{*}{ AV4 } & \multirow{3}{*}{0,25} & 20 & 0,236 & 0,005 & $-5,8$ \\
\hline & & & 10 & 0,236 & 0,005 & $-5,9$ \\
\hline & & & 5 & 0,235 & 0,006 & $-6,4$ \\
\hline \multirow{3}{*}{2} & \multirow{3}{*}{$\mathrm{BO} 1$} & \multirow{3}{*}{0,5} & 20 & 0,470 & 0,006 & $-6,4$ \\
\hline & & & 10 & 0,469 & 0,007 & $-6,6$ \\
\hline & & & 5 & 0,468 & 0,008 & $-6,9$ \\
\hline \multirow{3}{*}{2} & \multirow{3}{*}{ BO2 } & \multirow{3}{*}{0,5} & 20 & 0,498 & 0,006 & $-0,4$ \\
\hline & & & 10 & 0,497 & 0,007 & $-0,6$ \\
\hline & & & 5 & 0,497 & 0,008 & $-0,6$ \\
\hline \multirow{3}{*}{2} & \multirow{3}{*}{$\mathrm{BO} 3$} & \multirow{3}{*}{0,5} & 20 & 0,465 & 0,006 & $-7,5$ \\
\hline & & & 10 & 0,464 & 0,008 & $-7,9$ \\
\hline & & & 5 & 0,463 & 0,008 & $-8,1$ \\
\hline
\end{tabular}

Tabela 50 - Resultados da determinação da espessura equivalente de atenuação em chumbo, incerteza e diferença percentual entre o valor calculado e o valor nominal, para as amostras do Fabricante B, em 100 kV. Método: somatório de exponenciais

\begin{tabular}{|c|c|c|c|c|c|c|}
\hline Curva & Dispositivo & $\begin{array}{c}\text { Equivalência } \\
\text { Nominal (mmPb) }\end{array}$ & $\begin{array}{c}\text { № } \\
\text { Medições }\end{array}$ & $\begin{array}{c}\text { Equivalência } \\
\text { Calculada (mmPb) }\end{array}$ & $\begin{array}{c}\text { Incerteza } \\
(\mathrm{mmPb})\end{array}$ & $\begin{array}{l}\text { Diferença } \\
\text { (\%) }\end{array}$ \\
\hline \multirow{3}{*}{2} & \multirow{3}{*}{$\mathrm{AV} 1$} & \multirow{3}{*}{0,25} & 20 & 0,234 & 0,004 & $-6,8$ \\
\hline & & & 10 & 0,235 & 0,005 & $-6,4$ \\
\hline & & & 5 & 0,236 & 0,005 & $-6,0$ \\
\hline \multirow{3}{*}{2} & \multirow{3}{*}{ AV2 } & \multirow{3}{*}{0,25} & 20 & 0,239 & 0,004 & $-4,8$ \\
\hline & & & 10 & 0,239 & 0,005 & $-4,5$ \\
\hline & & & 5 & 0,240 & 0,005 & $-4,3$ \\
\hline \multirow{3}{*}{2} & \multirow{3}{*}{ AV3 } & \multirow{3}{*}{0,25} & 20 & 0,269 & 0,004 & 6,9 \\
\hline & & & 10 & 0,269 & 0,005 & 7,1 \\
\hline & & & 5 & 0,269 & 0,005 & 7,0 \\
\hline \multirow{3}{*}{2} & \multirow{3}{*}{ AV4 } & \multirow{3}{*}{0,25} & 20 & 0,241 & 0,004 & $-3,9$ \\
\hline & & & 10 & 0,241 & 0,005 & $-3,6$ \\
\hline & & & 5 & 0,242 & 0,005 & $-3,4$ \\
\hline \multirow{3}{*}{2} & \multirow{3}{*}{ BO1 } & \multirow{3}{*}{0,5} & 20 & 0,461 & 0,004 & $-8,5$ \\
\hline & & & 10 & 0,461 & 0,005 & $-8,5$ \\
\hline & & & 5 & 0,479 & 0,006 & $-4,4$ \\
\hline \multirow{3}{*}{2} & \multirow{3}{*}{$\mathrm{BO} 2$} & \multirow{3}{*}{0,5} & 20 & 0,482 & 0,004 & $-3,7$ \\
\hline & & & 10 & 0,482 & 0,006 & $-3,7$ \\
\hline & & & 5 & 0,455 & 0,006 & $-9,8$ \\
\hline \multirow{3}{*}{2} & \multirow{3}{*}{$\mathrm{BO} 3$} & \multirow{3}{*}{0,5} & 20 & 0,455 & 0,004 & $-10,0$ \\
\hline & & & 10 & 0,456 & 0,005 & $-9,8$ \\
\hline & & & 5 & 0,439 & 0,006 & $-13,8$ \\
\hline
\end{tabular}


Tabela 51 - Resultados da determinação da espessura equivalente de atenuação em chumbo, incerteza e diferença percentual entre o valor calculado e o valor nominal, para as amostras do Fabricante B, em 150 kV. Método: somatório de exponenciais

\begin{tabular}{|c|c|c|c|c|c|c|}
\hline Curva & Dispositivo & $\begin{array}{c}\text { Equivalência } \\
\text { Nominal (mmPb) }\end{array}$ & $\begin{array}{c}\text { № } \\
\text { Medições }\end{array}$ & $\begin{array}{c}\text { Equivalência } \\
\text { Calculada (mmPb) }\end{array}$ & $\begin{array}{c}\text { Incerteza } \\
(\mathrm{mmPb})\end{array}$ & $\begin{array}{c}\text { Diferença } \\
\text { (\%) }\end{array}$ \\
\hline \multirow{3}{*}{2} & \multirow{3}{*}{$\mathrm{AV} 1$} & \multirow{3}{*}{0,25} & 20 & 0,241 & 0,002 & $-3,9$ \\
\hline & & & 10 & 0,241 & 0,002 & $-3,7$ \\
\hline & & & 5 & 0,241 & 0,002 & $-3,6$ \\
\hline \multirow{3}{*}{2} & \multirow{3}{*}{ AV2 } & \multirow{3}{*}{0,25} & 20 & 0,249 & 0,002 & $-0,6$ \\
\hline & & & 10 & 0,249 & 0,002 & $-0,6$ \\
\hline & & & 5 & 0,249 & 0,002 & $-0,4$ \\
\hline \multirow{3}{*}{2} & \multirow{3}{*}{ AV3 } & \multirow{3}{*}{0,25} & 20 & 0,276 & 0,002 & 9,3 \\
\hline & & & 10 & 0,276 & 0,002 & 9,3 \\
\hline & & & 5 & 0,276 & 0,002 & 9,4 \\
\hline \multirow{3}{*}{2} & \multirow{3}{*}{ AV4 } & \multirow{3}{*}{0,25} & 20 & 0,253 & 0,002 & 1,1 \\
\hline & & & 10 & 0,253 & 0,002 & 1,1 \\
\hline & & & 5 & 0,253 & 0,002 & 1,3 \\
\hline \multirow{3}{*}{2} & \multirow{3}{*}{ BO1 } & \multirow{3}{*}{0,5} & 20 & 0,487 & 0,002 & $-2,8$ \\
\hline & & & 10 & 0,491 & 0,002 & $-1,8$ \\
\hline & & & 5 & 0,492 & 0,002 & $-1,6$ \\
\hline \multirow{3}{*}{2} & \multirow{3}{*}{$\mathrm{BO} 2$} & \multirow{3}{*}{0,5} & 20 & 0,486 & 0,002 & $-2,8$ \\
\hline & & & 10 & 0,486 & 0,002 & $-2,9$ \\
\hline & & & 5 & 0,487 & 0,002 & $-2,7$ \\
\hline \multirow{3}{*}{2} & \multirow{3}{*}{$\mathrm{BO} 3$} & \multirow{3}{*}{0,5} & 20 & 0,472 & 0,002 & $-6,0$ \\
\hline & & & 10 & 0,472 & 0,002 & $-6,0$ \\
\hline & & & 5 & 0,471 & 0,002 & $-6,1$ \\
\hline
\end{tabular}

Tabela 52 - Resultados da determinação da espessura equivalente de atenuação em chumbo, incerteza e diferença percentual entre o valor calculado e o valor nominal, para as amostras do Fabricante $\mathrm{C}$, em $80 \mathrm{kV}$. Método: somatório de exponenciais

\begin{tabular}{|c|c|c|c|c|c|c|}
\hline Curva & Dispositivo & $\begin{array}{c}\text { Equivalência } \\
\text { Nominal (mmPb) }\end{array}$ & $\begin{array}{c}\text { № } \\
\text { Medições }\end{array}$ & $\begin{array}{c}\text { Equivalência } \\
\text { Calculada (mmPb) }\end{array}$ & $\begin{array}{c}\text { Incerteza } \\
(\mathrm{mmPb})\end{array}$ & $\begin{array}{c}\text { Diferença } \\
(\%)\end{array}$ \\
\hline \multirow{3}{*}{1} & \multirow{3}{*}{$\mathrm{AV} 1$} & \multirow{3}{*}{0,5} & 20 & 0,521 & 0,003 & 4,1 \\
\hline & & & 10 & 0,520 & 0,003 & 3,9 \\
\hline & & & 5 & 0,522 & 0,003 & 4,1 \\
\hline \multirow{3}{*}{1} & \multirow{3}{*}{ AV2 } & \multirow{3}{*}{0,25} & 20 & 0,272 & 0,003 & 8,0 \\
\hline & & & 10 & 0,272 & 0,003 & 8,1 \\
\hline & & & 5 & 0,272 & 0,003 & 8,0 \\
\hline
\end{tabular}


Tabela 53 - Resultados da determinação da espessura equivalente de atenuação em chumbo, incerteza e diferença percentual entre o valor calculado e o valor nominal, para as amostras do Fabricante $\mathrm{C}$, em $100 \mathrm{kV}$. Método: somatório de exponenciais

\begin{tabular}{ccccccc}
\hline \hline Curva & Dispositivo & $\begin{array}{c}\text { Equivalência } \\
\text { Nominal (mmPb) }\end{array}$ & $\begin{array}{c}\text { No } \\
\text { Medições }\end{array}$ & $\begin{array}{c}\text { Equivalência } \\
\text { Calculada (mmPb) }\end{array}$ & $\begin{array}{c}\text { Incerteza } \\
(\mathbf{m m P b})\end{array}$ & $\begin{array}{c}\text { Diferença } \\
(\%)\end{array}$ \\
\hline \hline \multirow{2}{*}{1} & \multirow{2}{*}{ AV1 } & \multirow{2}{*}{0,5} & 20 & 0,556 & 0,005 & 10,1 \\
& & & 10 & 0,557 & 0,005 & 10,2 \\
\hline \hline \multirow{2}{*}{1} & \multirow{2}{*}{ AV2 } & \multirow{2}{*}{0,25} & 5 & 0,557 & 0,004 & 10,3 \\
\hline & & & 20 & 0,260 & 0,004 & 3,7 \\
\hline \hline
\end{tabular}

Tabela 54 - Resultados da determinação da espessura equivalente de atenuação em chumbo, incerteza e diferença percentual entre o valor calculado e o valor nominal, para as amostras do Fabricante C, em $150 \mathrm{kV}$. Método: somatório de exponenciais

\begin{tabular}{|c|c|c|c|c|c|c|}
\hline Curva & Dispositivo & $\begin{array}{c}\text { Equivalência } \\
\text { Nominal (mmPb) }\end{array}$ & $\begin{array}{c}\text { № } \\
\text { Medições }\end{array}$ & $\begin{array}{c}\text { Equivalência } \\
\text { Calculada (mmPb) }\end{array}$ & $\begin{array}{c}\text { Incerteza } \\
(\mathrm{mmPb})\end{array}$ & $\begin{array}{c}\text { Diferença } \\
(\%)\end{array}$ \\
\hline \multirow{3}{*}{1} & \multirow{3}{*}{$\mathrm{AV} 1$} & \multirow{3}{*}{0,5} & 20 & 0,561 & 0,002 & 10,9 \\
\hline & & & 10 & 0,560 & 0,002 & 10,6 \\
\hline & & & 5 & 0,556 & 0,002 & 10,1 \\
\hline \multirow{3}{*}{1} & \multirow{3}{*}{ AV2 } & \multirow{3}{*}{0,25} & 20 & 0,274 & 0,002 & 8,7 \\
\hline & & & 10 & 0,274 & 0,002 & 8,6 \\
\hline & & & 5 & 0,274 & 0,002 & 8,7 \\
\hline
\end{tabular}


Tabela 55 - Resultados da determinação da espessura equivalente de atenuação em chumbo, incerteza e diferença percentual entre o valor calculado e o valor nominal, para as amostras do Fabricante $\mathrm{D}$, em $\mathbf{8 0}$ kV. Método: somatório de exponenciais

\begin{tabular}{|c|c|c|c|c|c|c|}
\hline Curva & Dispositivo & $\begin{array}{c}\text { Equivalência } \\
\text { Nominal (mmPb) }\end{array}$ & $\begin{array}{c}\text { № } \\
\text { Medições }\end{array}$ & $\begin{array}{c}\text { Equivalência } \\
\text { Calculada (mmPb) }\end{array}$ & $\begin{array}{c}\text { Incerteza } \\
\text { (mmPb) }\end{array}$ & $\begin{array}{c}\text { Diferença } \\
(\%)\end{array}$ \\
\hline \multirow{3}{*}{3} & \multirow{3}{*}{ AV1 } & \multirow{3}{*}{0,25} & 20 & 0,189 & 0,004 & $-32,4$ \\
\hline & & & 10 & 0,188 & 0,003 & $-33,2$ \\
\hline & & & 5 & 0,187 & 0,004 & $-33,4$ \\
\hline \multirow{3}{*}{3} & \multirow{3}{*}{ AV2 } & \multirow{3}{*}{0,5} & 20 & 0,561 & 0,004 & 10,9 \\
\hline & & & 10 & 0,558 & 0,004 & 10,4 \\
\hline & & & 5 & 0,563 & 0,005 & 11,1 \\
\hline \multirow{3}{*}{3} & \multirow{3}{*}{ AV3 } & \multirow{3}{*}{0,25} & 20 & 0,274 & 0,004 & 8,7 \\
\hline & & & 10 & 0,275 & 0,003 & 8,9 \\
\hline & & & 5 & 0,272 & 0,004 & 8,2 \\
\hline \multirow{3}{*}{3} & \multirow{3}{*}{ AV4 } & \multirow{3}{*}{0,25} & 20 & 0,250 & 0,004 & $-0,1$ \\
\hline & & & 10 & 0,250 & 0,003 & $-0,1$ \\
\hline & & & 5 & 0,248 & 0,004 & $-0,9$ \\
\hline \multirow{3}{*}{3} & \multirow{3}{*}{ AV5 } & \multirow{3}{*}{0,25} & 20 & 0,210 & 0,004 & $-19,3$ \\
\hline & & & 10 & 0,210 & 0,003 & $-19,2$ \\
\hline & & & 5 & 0,208 & 0,004 & $-20,0$ \\
\hline \multirow{3}{*}{3} & \multirow{3}{*}{ AV6 } & \multirow{3}{*}{0,5} & 20 & 0,393 & 0,005 & $-27,3$ \\
\hline & & & 10 & 0,395 & 0,004 & $-26,7$ \\
\hline & & & 5 & 0,393 & 0,005 & $-27,3$ \\
\hline \multirow{3}{*}{3} & \multirow{3}{*}{ AV7 } & \multirow{3}{*}{0,5} & 20 & 0,484 & 0,005 & $-3,3$ \\
\hline & & & 10 & 0,485 & 0,004 & $-3,1$ \\
\hline & & & 5 & 0,486 & 0,005 & $-2,9$ \\
\hline \multirow{3}{*}{3} & \multirow{3}{*}{ AV8 } & \multirow{3}{*}{0,25} & 20 & 0,213 & 0,004 & $-17,3$ \\
\hline & & & 10 & 0,214 & 0,003 & $-17,1$ \\
\hline & & & 5 & 0,214 & 0,004 & $-17,1$ \\
\hline & & & 20 & 0,298 & 0,004 & 16,2 \\
\hline 3 & AV9 & 0,25 & 10 & 0,299 & 0,004 & 16,5 \\
\hline & & & 5 & 0,297 & 0,005 & 15,8 \\
\hline & & & 20 & 0,607 & 0,004 & 17,6 \\
\hline 3 & AV10 & 0,5 & 10 & 0,608 & 0,004 & 17,8 \\
\hline & & & 5 & 0,613 & 0,005 & 18,4 \\
\hline & & & 20 & 0,450 & 0,005 & $-11,0$ \\
\hline 3 & AV11 & 0,5 & 10 & 0,449 & 0,004 & $-11,3$ \\
\hline & & & 5 & 0,448 & 0,005 & $-11,7$ \\
\hline & & & 20 & 0,553 & 0,004 & 9,6 \\
\hline 3 & AV12 & 0,5 & 10 & 0,553 & 0,004 & 9,6 \\
\hline & & & 5 & 0,558 & 0,005 & 10,3 \\
\hline & & & 20 & 0,229 & 0,004 & $-9,0$ \\
\hline 3 & AV13 & 0,25 & 10 & 0,230 & 0,003 & $-8,9$ \\
\hline & & & 5 & 0,228 & 0,004 & $-9,5$ \\
\hline & & & 20 & 0,521 & 0,005 & 4,0 \\
\hline 3 & AV14 & 0,5 & 10 & 0,518 & 0,004 & 3,5 \\
\hline & & & 5 & 0,522 & 0,005 & 4,3 \\
\hline
\end{tabular}


Tabela 56 - Resultados da determinação da espessura equivalente de atenuação em chumbo, incerteza e diferença percentual entre o valor calculado e o valor nominal, para as amostras do Fabricante D, em 100 kV. Método: somatório de exponenciais

\begin{tabular}{|c|c|c|c|c|c|c|}
\hline Curva & Dispositivo & $\begin{array}{c}\text { Equivalência } \\
\text { Nominal (mmPb) }\end{array}$ & $\begin{array}{c}\text { № } \\
\text { Medições }\end{array}$ & $\begin{array}{c}\text { Equivalência } \\
\text { Calculada }(\mathrm{mmPb})\end{array}$ & $\begin{array}{c}\text { Incerteza } \\
(\mathrm{mmPb})\end{array}$ & $\begin{array}{c}\text { Diferença } \\
(\%)\end{array}$ \\
\hline \multirow{3}{*}{3} & \multirow{3}{*}{$\mathrm{AV} 1$} & \multirow{3}{*}{0,25} & 20 & 0,195 & 0,004 & $-28,0$ \\
\hline & & & 10 & 0,195 & 0,004 & $-27,9$ \\
\hline & & & 5 & 0,195 & 0,004 & $-28,4$ \\
\hline \multirow{3}{*}{3} & \multirow{3}{*}{ AV2 } & \multirow{3}{*}{0,5} & 20 & 0,549 & 0,005 & 8,9 \\
\hline & & & 10 & 0,546 & 0,005 & 8,5 \\
\hline & & & 5 & 0,546 & 0,006 & 8,5 \\
\hline \multirow{3}{*}{3} & \multirow{3}{*}{ AV3 } & \multirow{3}{*}{0,25} & 20 & 0,297 & 0,004 & 15,8 \\
\hline & & & 10 & 0,297 & 0,004 & 15,8 \\
\hline & & & 5 & 0,297 & 0,005 & 15,7 \\
\hline \multirow{3}{*}{3} & \multirow{3}{*}{ AV4 } & \multirow{3}{*}{0,25} & 20 & 0,253 & 0,004 & 1,0 \\
\hline & & & 10 & 0,253 & 0,004 & 1,1 \\
\hline & & & 5 & 0,252 & 0,005 & 1,0 \\
\hline \multirow{3}{*}{3} & \multirow{3}{*}{ AV5 } & \multirow{3}{*}{0,25} & 20 & 0,219 & 0,004 & $-13,9$ \\
\hline & & & 10 & 0,220 & 0,004 & $-13,9$ \\
\hline & & & 5 & 0,219 & 0,005 & $-14,3$ \\
\hline \multirow{3}{*}{3} & \multirow{3}{*}{ AV6 } & \multirow{3}{*}{0,5} & 20 & 0,393 & 0,004 & $-27,2$ \\
\hline & & & 10 & 0,391 & 0,005 & $-27,8$ \\
\hline & & & 5 & 0,390 & 0,005 & $-28,1$ \\
\hline \multirow{3}{*}{3} & \multirow{3}{*}{ AV7 } & \multirow{3}{*}{0,5} & 20 & 0,472 & 0,005 & $-5,9$ \\
\hline & & & 10 & 0,471 & 0,005 & $-6,2$ \\
\hline & & & 5 & 0,470 & 0,005 & $-6,4$ \\
\hline \multirow{3}{*}{3} & \multirow{3}{*}{ AV8 } & \multirow{3}{*}{0,25} & 20 & 0,217 & 0,004 & $-15,5$ \\
\hline & & & 10 & 0,217 & 0,004 & $-15,2$ \\
\hline & & & 5 & 0,216 & 0,005 & $-15,6$ \\
\hline & & & 20 & 0,301 & 0,004 & 16,9 \\
\hline 3 & AV9 & 0,25 & 10 & 0,301 & 0,004 & 16,9 \\
\hline & & & 5 & 0,301 & 0,005 & 16,8 \\
\hline & & & 20 & 0,584 & 0,005 & 14,3 \\
\hline 3 & AV10 & 0,5 & 10 & 0,583 & 0,006 & 14,3 \\
\hline & & & 5 & 0,580 & 0,006 & 13,8 \\
\hline & & & 20 & 0,442 & 0,004 & $-13,2$ \\
\hline 3 & AV11 & 0,5 & 10 & 0,440 & 0,005 & $-13,6$ \\
\hline & & & 5 & 0,440 & 0,005 & $-13,6$ \\
\hline & & & 20 & 0,544 & 0,005 & 8,1 \\
\hline 3 & AV12 & 0,5 & 10 & 0,542 & 0,005 & 7,7 \\
\hline & & & 5 & 0,541 & 0,006 & 7,6 \\
\hline & & & 20 & 0,230 & 0,004 & $-8,5$ \\
\hline 3 & AV13 & 0,25 & 10 & 0,231 & 0,004 & $-8,4$ \\
\hline & & & 5 & 0,229 & 0,005 & $-9,0$ \\
\hline & & & 20 & 0,497 & 0,005 & $-0,7$ \\
\hline 3 & AV14 & 0,5 & 10 & 0,496 & 0,005 & $-0,8$ \\
\hline & & & 5 & 0,497 & 0,006 & $-0,6$ \\
\hline
\end{tabular}


Tabela 57 - Resultados da determinação da espessura equivalente de atenuação em chumbo, incerteza e diferença percentual entre o valor calculado e o valor nominal, para as amostras do Fabricante D, em $150 \mathrm{kV}$. Método: somatório de exponenciais

\begin{tabular}{|c|c|c|c|c|c|c|}
\hline Curva & Dispositivo & $\begin{array}{c}\text { Equivalência } \\
\text { Nominal (mmPb) }\end{array}$ & $\begin{array}{c}\text { № } \\
\text { Medições }\end{array}$ & $\begin{array}{c}\text { Equivalência } \\
\text { Calculada (mmPb) }\end{array}$ & $\begin{array}{l}\text { Incerteza } \\
\text { (mmPb) }\end{array}$ & $\begin{array}{c}\text { Diferença } \\
(\%)\end{array}$ \\
\hline \multirow{3}{*}{3} & \multirow{3}{*}{$\mathrm{AV} 1$} & \multirow{3}{*}{0,25} & 20 & 0,195 & 0,001 & $-27,9$ \\
\hline & & & 10 & 0,194 & 0,001 & $-29,2$ \\
\hline & & & 5 & 0,196 & 0,001 & $-27,7$ \\
\hline \multirow{3}{*}{3} & \multirow{3}{*}{ AV2 } & \multirow{3}{*}{0,5} & 20 & 0,554 & 0,001 & 9,7 \\
\hline & & & 10 & 0,551 & 0,002 & 9,2 \\
\hline & & & 5 & 0,552 & 0,002 & 9,4 \\
\hline \multirow{3}{*}{3} & \multirow{3}{*}{ AV3 } & \multirow{3}{*}{0,25} & 20 & 0,286 & 0,001 & 12,7 \\
\hline & & & 10 & 0,285 & 0,002 & 12,2 \\
\hline & & & 5 & 0,286 & 0,002 & 12,7 \\
\hline \multirow{3}{*}{3} & \multirow{3}{*}{ AV4 } & \multirow{3}{*}{0,25} & 20 & 0,257 & 0,001 & 2,6 \\
\hline & & & 10 & 0,255 & 0,002 & 2,0 \\
\hline & & & 5 & 0,257 & 0,001 & 2,8 \\
\hline \multirow{3}{*}{3} & \multirow{3}{*}{ AV5 } & \multirow{3}{*}{0,25} & 20 & 0,224 & 0,001 & $-11,8$ \\
\hline & & & 10 & 0,222 & 0,002 & $-12,7$ \\
\hline & & & 5 & 0,224 & 0,001 & $-11,5$ \\
\hline \multirow{3}{*}{3} & \multirow{3}{*}{ AV6 } & \multirow{3}{*}{0,5} & 20 & 0,411 & 0,001 & $-21,6$ \\
\hline & & & 10 & 0,409 & 0,002 & $-22,1$ \\
\hline & & & 5 & 0,412 & 0,002 & $-21,5$ \\
\hline \multirow{3}{*}{3} & \multirow{3}{*}{ AV7 } & \multirow{3}{*}{0,5} & 20 & 0,483 & 0,001 & $-3,6$ \\
\hline & & & 10 & 0,481 & 0,002 & $-4,0$ \\
\hline & & & 5 & 0,483 & 0,002 & $-3,6$ \\
\hline \multirow{3}{*}{3} & \multirow{3}{*}{ AV8 } & \multirow{3}{*}{0,25} & 20 & 0,226 & 0,001 & $-10,7$ \\
\hline & & & 10 & 0,224 & 0,002 & $-11,6$ \\
\hline & & & 5 & 0,226 & 0,001 & $-10,6$ \\
\hline & & & 20 & 0,319 & 0,001 & 21,7 \\
\hline 3 & AV9 & 0,25 & 10 & 0,318 & 0,002 & 21,3 \\
\hline & & & 5 & 0,319 & 0,002 & 21,6 \\
\hline & & & 20 & 0,582 & 0,001 & 14,0 \\
\hline 3 & AV10 & 0,5 & 10 & 0,579 & 0,002 & 13,6 \\
\hline & & & 5 & 0,579 & 0,002 & 13,7 \\
\hline & & & 20 & 0,456 & 0,001 & $-9,6$ \\
\hline 3 & AV11 & 0,5 & 10 & 0,454 & 0,002 & $-10,2$ \\
\hline & & & 5 & 0,455 & 0,002 & $-9,9$ \\
\hline & & & 20 & 0,585 & 0,001 & 14,5 \\
\hline 3 & AV12 & 0,5 & 10 & 0,583 & 0,002 & 14,2 \\
\hline & & & 5 & 0,584 & 0,002 & 14,4 \\
\hline & & & 20 & 0,267 & 0,001 & 6,4 \\
\hline 3 & AV13 & 0,25 & 10 & 0,265 & 0,002 & 5,6 \\
\hline & & & 5 & 0,267 & 0,001 & 6,2 \\
\hline & & & 20 & 0,509 & 0,001 & 1,7 \\
\hline 3 & AV14 & 0,5 & 10 & 0,506 & 0,002 & 1,2 \\
\hline & & & 5 & 0,498 & 0,002 & $-0,5$ \\
\hline
\end{tabular}


Tabela 58 - Resultados da determinação da espessura equivalente de atenuação em chumbo, incerteza e diferença percentual entre o valor calculado e o valor nominal, para as amostras do Fabricante $\mathrm{E}$, em $\mathbf{8 0 ~ k V}$. Método: somatório de exponenciais

\begin{tabular}{|c|c|c|c|c|c|c|}
\hline Curva & Dispositivo & $\begin{array}{c}\text { Equivalência } \\
\text { Nominal (mmPb) }\end{array}$ & $\begin{array}{c}\text { № } \\
\text { Medições }\end{array}$ & $\begin{array}{c}\text { Equivalência } \\
\text { Calculada (mmPb) }\end{array}$ & $\begin{array}{l}\text { Incerteza } \\
(\mathrm{mmPb})\end{array}$ & $\begin{array}{c}\text { Diferença } \\
(\%)\end{array}$ \\
\hline \multirow{3}{*}{4} & \multirow{3}{*}{1} & \multirow{3}{*}{0,5} & 20 & 0,440 & 0,005 & $-13,8$ \\
\hline & & & 10 & 0,441 & 0,005 & $-13,3$ \\
\hline & & & 5 & 0,445 & 0,005 & $-12,4$ \\
\hline \multirow{3}{*}{4} & \multirow{3}{*}{2} & \multirow{3}{*}{0,5} & 20 & 0,541 & 0,005 & 7,6 \\
\hline & & & 10 & 0,543 & 0,005 & 7,9 \\
\hline & & & 5 & 0,544 & 0,005 & 8,0 \\
\hline \multirow{3}{*}{4} & \multirow{3}{*}{3} & \multirow{3}{*}{0,5} & 20 & 0,489 & 0,005 & $-2,4$ \\
\hline & & & 10 & 0,489 & 0,005 & $-2,3$ \\
\hline & & & 5 & 0,489 & 0,005 & $-2,2$ \\
\hline \multirow{3}{*}{4} & \multirow{3}{*}{4} & \multirow{3}{*}{0,5} & 20 & 0,572 & 0,005 & 12,5 \\
\hline & & & 10 & 0,573 & 0,005 & 12,7 \\
\hline & & & 5 & 0,573 & 0,005 & 12,7 \\
\hline
\end{tabular}

Tabela 59 - Resultados da determinação da espessura equivalente de atenuação em chumbo, incerteza e diferença percentual entre o valor calculado e o valor nominal, para as amostras do Fabricante E, em 100 kV. Método: somatório de exponenciais

\begin{tabular}{|c|c|c|c|c|c|c|}
\hline Curva & Dispositivo & $\begin{array}{c}\text { Equivalência } \\
\text { Nominal (mmPb) }\end{array}$ & $\begin{array}{c}№ \\
\text { Medições }\end{array}$ & $\begin{array}{c}\text { Equivalência } \\
\text { Calculada (mmPb) }\end{array}$ & $\begin{array}{c}\text { Incerteza } \\
(\mathrm{mmPb})\end{array}$ & $\begin{array}{c}\text { Diferença } \\
(\%)\end{array}$ \\
\hline \multirow{3}{*}{4} & \multirow{3}{*}{1} & \multirow{3}{*}{0,5} & 20 & 0,431 & 0,004 & $-16,1$ \\
\hline & & & 10 & 0,432 & 0,004 & $-15,8$ \\
\hline & & & 5 & 0,432 & 0,004 & $-15,8$ \\
\hline \multirow{3}{*}{4} & \multirow{3}{*}{2} & \multirow{3}{*}{0,5} & 20 & 0,569 & 0,005 & 12,1 \\
\hline & & & 10 & 0,569 & 0,005 & 12,2 \\
\hline & & & 5 & 0,571 & 0,005 & 12,4 \\
\hline \multirow{3}{*}{4} & \multirow{3}{*}{3} & \multirow{3}{*}{0,5} & 20 & 0,487 & 0,005 & $-2,6$ \\
\hline & & & 10 & 0,489 & 0,005 & $-2,3$ \\
\hline & & & 5 & 0,490 & 0,004 & $-2,0$ \\
\hline \multirow{3}{*}{4} & \multirow{3}{*}{4} & \multirow{3}{*}{0,5} & 20 & 0,567 & 0,005 & 11,8 \\
\hline & & & 10 & 0,567 & 0,005 & 11,8 \\
\hline & & & 5 & 0,570 & 0,005 & 12,3 \\
\hline
\end{tabular}


Tabela 60 - Resultados da determinação da espessura equivalente de atenuação em chumbo, incerteza e diferença percentual entre o valor calculado e o valor nominal, para as amostras do Fabricante E, em $150 \mathrm{kV}$. Método: somatório de exponenciais

\begin{tabular}{|c|c|c|c|c|c|c|}
\hline Curva & Dispositivo & $\begin{array}{l}\text { Equivalência } \\
\text { Nominal (mmPb) }\end{array}$ & $\begin{array}{c}\text { № } \\
\text { Medições }\end{array}$ & $\begin{array}{c}\text { Equivalência } \\
\text { Calculada } \\
\text { (mmPb) }\end{array}$ & $\begin{array}{c}\text { Incerteza } \\
(\mathrm{mmPb})\end{array}$ & $\begin{array}{c}\text { Diferença } \\
(\%)\end{array}$ \\
\hline \multirow{3}{*}{4} & \multirow{3}{*}{1} & \multirow{3}{*}{0,5} & 20 & 0,432 & 0,001 & $-15,6$ \\
\hline & & & 10 & 0,432 & 0,001 & $-15,6$ \\
\hline & & & 5 & 0,432 & 0,001 & $-15,7$ \\
\hline \multirow{3}{*}{4} & \multirow{3}{*}{2} & \multirow{3}{*}{0,5} & 20 & 0,555 & 0,001 & 9,9 \\
\hline & & & 10 & 0,556 & 0,001 & 10,1 \\
\hline & & & 5 & 0,554 & 0,001 & 9,8 \\
\hline \multirow{3}{*}{4} & \multirow{3}{*}{3} & \multirow{3}{*}{0,5} & 20 & 0,497 & 0,001 & $-0,7$ \\
\hline & & & 10 & 0,497 & 0,001 & $-0,6$ \\
\hline & & & 5 & 0,496 & 0,001 & $-0,8$ \\
\hline \multirow{3}{*}{4} & \multirow{3}{*}{4} & \multirow{3}{*}{0,5} & 20 & 0,563 & 0,001 & 11,2 \\
\hline & & & 10 & 0,564 & 0,001 & 11,3 \\
\hline & & & 5 & 0,564 & 0,001 & 11,3 \\
\hline
\end{tabular}

Analisando-se os resultados pode-se observar que as diferenças percentuais entre os valores do equivalente de atenuação declarados e calculados pelo modelo do somatório de exponenciais são praticamente iguais às diferenças obtidas pelo método da interpolação e pelo modelo de Archer.

Como nos outros dois métodos, as espessuras equivalentes de atenuação dos dispositivos do Fabricante A estavam todas abaixo dos valores declarados, apresentando diferenças percentuais até $17,2 \%$ para aventais com equivalência nominal de $0,25 \mathrm{mmPb}$ em $80 \mathrm{kV}$ e $19,8 \%$ para aventais com equivalência de 0,50 $\mathrm{mmPb}$ em 80kV.

Novamente o Fabricante $\mathrm{C}$ apresentou todos os resultados de equivalente de atenuação positivos, ou seja, os valores calculados estavam entre 4,0 e 10,5\% para aventais de proteção com equivalência nominal igual a $0,50 \mathrm{mmPb}$.

Foram obtidos valores de espessura equivalente de atenuação tanto maiores quanto menores que os valores declarados para os fabricantes $\mathrm{B}, \mathrm{D}$ e $\mathrm{E}$.

Os resultados encontrados para os dispositivos do Fabricante $D$ foram os menos uniformes, ou seja, a diferença percentual entre os valores declarados e os valores medidos variaram aproximadamente 50\%: algumas amostras com equivalência nominal de $0,25 \mathrm{mmPb}$ apresentaram variação de 21,5\% para menos, enquanto que outras apresentaram uma variação de $28,3 \%$ para mais.

As incertezas obtidas para este método foram menores que as obtidas no método da interpolação linear e no modelo de Archer e novamente o número de medições não influenciou significativamente a incerteza associada ao método. 


\subsubsection{Re-avaliação da Espessura Equivalente de Atenuação dos Aventais Modificados pelo Fabricante $D$}

Todos os fabricantes receberam um relatório com os resultados da determinação das espessuras equivalente de atenuação e avaliação das características de confecção de cada amostra enviada.

O Fabricante $D$ foi alertado sobre as grandes diferenças entre os valores medidos e declarados para a espessura equivalente de atenuação de suas amostras. O Fabricante $D$ então investigou a borracha plumbífera que utilizava na confecção de seus dispositivos de proteção e percebeu que havia diferenças na espessura da borracha ao longo de sua extensão.

O Fabricante $\mathrm{D}$ trocou de fornecedor de borracha plumbífera e enviou 12 novas amostras para serem avaliadas. Dessas 12 amostras seis eram do tipo odontológico e, portanto, não aplicáveis à norma NRB / IEC 61331-3 ${ }^{15}$.

A determinação da espessura equivalente de atenuação para estas amostras foi realizada utilizando-se 5 medições da taxa de kerma no ar em cada ponto da curva do chumbo padrão.

Os resultados obtidos estão mostrados nas Tabelas 61 a 63. A identificação dos dispositivos, como por exemplo AV1R e AV2R, não tem nenhuma correlação com a identificação dos aventais de proteção que haviam sido testados anteriormente.

Analisando-se os resultados, foi possível perceber uma diminuição da variação da diferença percentual entre os valores de espessura equivalente declarados e os valores medidos.

Antes da mudança de fornecedor de borracha plumbífera, a diferença percentual do equivalente de atenuação entre os valores declarados e os valores medidos para as amostras de $0,25 \mathrm{mmPb}$ variava entre $-19,8 \%$ e $20,6 \%$, e para as amostras com equivalente nominal de $0,50 \mathrm{mmPb}$ variava entre $-25,7 \%$ e $17,7 \%$.

No re-teste, ou seja, após a mudança de fornecedor de borracha plumbífera, estas diferenças percentuais passaram a variar entre -3,6\% e 9,5\% para dispositivos de proteção com equivalência nominal de $0,25 \mathrm{mmPb}$ e entre 0 e $-11,7 \%$ para os dispositivos com equivalência nominal de $0,50 \mathrm{mmPb}$.

Estes resultados poderão ser confirmados no item 5.2.6, onde serão apresentados os resultados da reprodutibilidade da espessura equivalente de atenuação para os diferentes fabricantes. 
Tabela 61 - Resultados da re-avaliação dos aventais de proteção do Fabricante D. Método: interpolação linear

\begin{tabular}{|c|c|c|c|c|c|}
\hline $\begin{array}{c}\text { Tensão } \\
\text { (kV) }\end{array}$ & Dispositivo & $\begin{array}{c}\text { Equivalência } \\
\text { Nominal (mmPb) }\end{array}$ & $\begin{array}{c}\text { Equivalência } \\
\text { Calculada (mmPb) }\end{array}$ & $\begin{array}{c}\text { Incerteza } \\
(\mathrm{mmPb})\end{array}$ & $\begin{array}{c}\text { Diferença } \\
(\%)\end{array}$ \\
\hline \multirow{12}{*}{80} & AV1R & 0,25 & 0,250 & 0,018 & 0,0 \\
\hline & AV2R & 0,25 & 0,241 & 0,011 & $-3,6$ \\
\hline & $A \vee 3 R$ & 0,5 & 0,449 & 0,016 & $-11,4$ \\
\hline & AV4R & 0,25 & 0,276 & 0,016 & 9,5 \\
\hline & AV5R & 0,25 & 0,246 & 0,011 & $-1,7$ \\
\hline & AV6R & 0,5 & 0,482 & 0,019 & $-3,8$ \\
\hline & AV7R & 0,5 & 0,497 & 0,031 & $-0,7$ \\
\hline & AV8R & 0,25 & 0,262 & 0,017 & 4,5 \\
\hline & AV9R & 0,5 & 0,448 & 0,018 & $-11,7$ \\
\hline & $A V 10 R$ & 0,5 & 0,500 & 0,029 & 0,0 \\
\hline & AV11R & 0,25 & 0,243 & 0,011 & $-2,9$ \\
\hline & $A V 12 R$ & 0,5 & 0,468 & 0,018 & $-6,9$ \\
\hline \multirow{12}{*}{100} & AV1R & 0,25 & 0,257 & 0,020 & 2,9 \\
\hline & AV2R & 0,25 & 0,242 & 0,012 & $-3,4$ \\
\hline & AV3R & 0,5 & 0,454 & 0,017 & $-10,2$ \\
\hline & AV4R & 0,25 & 0,273 & 0,018 & 8,5 \\
\hline & AV5R & 0,25 & 0,274 & 0,018 & 8,8 \\
\hline & AV6R & 0,5 & 0,498 & 0,025 & $-0,4$ \\
\hline & AV7R & 0,5 & 0,484 & 0,018 & $-3,4$ \\
\hline & AV8R & 0,25 & 0,268 & 0,018 & 6,6 \\
\hline & AV9R & 0,5 & 0,449 & 0,018 & $-11,4$ \\
\hline & AV10R & 0,5 & 0,506 & 0,025 & 1,2 \\
\hline & AV11R & 0,25 & 0,238 & 0,012 & $-5,2$ \\
\hline & AV12R & 0,5 & 0,473 & 0,018 & $-5,7$ \\
\hline \multirow{12}{*}{150} & AV1R & 0,25 & 0,262 & 0,021 & 4,5 \\
\hline & AV2R & 0,25 & 0,249 & 0,022 & $-0,5$ \\
\hline & AV3R & 0,5 & 0,460 & 0,018 & $-8,7$ \\
\hline & AV4R & 0,25 & 0,280 & 0,019 & 10,7 \\
\hline & AV5R & 0,25 & 0,278 & 0,019 & 10,1 \\
\hline & AV6R & 0,5 & 0,484 & 0,019 & $-3,3$ \\
\hline & AV7R & 0,5 & 0,490 & 0,019 & $-2,0$ \\
\hline & AV8R & 0,25 & 0,267 & 0,020 & 6,5 \\
\hline & AV9R & 0,5 & 0,457 & 0,017 & $-9,5$ \\
\hline & AV10R & 0,5 & 0,509 & 0,026 & 1,8 \\
\hline & AV11R & 0,25 & 0,241 & 0,014 & $-3,9$ \\
\hline & AV12R & 0,5 & 0,474 & 0,018 & $-5,5$ \\
\hline
\end{tabular}


Tabela 62 - Resultados da re-avaliação dos aventais de proteção do Fabricante D. Método: modelo de Archer

\begin{tabular}{|c|c|c|c|c|c|}
\hline $\begin{array}{l}\text { Tensão } \\
\text { (kV) }\end{array}$ & Dispositivo & $\begin{array}{c}\text { Equivalência } \\
\text { Nominal (mmPb) }\end{array}$ & $\begin{array}{c}\text { Equivalência } \\
\text { Calculada }(\mathrm{mmPb})\end{array}$ & $\begin{array}{l}\text { Incerteza } \\
(\mathrm{mmPb})\end{array}$ & $\begin{array}{c}\text { Diferença } \\
(\%)\end{array}$ \\
\hline \multirow{12}{*}{80} & AV1R & 0,25 & 0,247 & 0,007 & $-1,1$ \\
\hline & AV2R & 0,25 & 0,236 & 0,007 & $-5,8$ \\
\hline & AV3R & 0,5 & 0,439 & 0,010 & $-14,0$ \\
\hline & AV4R & 0,25 & 0,266 & 0,008 & 6,1 \\
\hline & AV5R & 0,25 & 0,245 & 0,007 & $-2,2$ \\
\hline & AV6R & 0,5 & 0,480 & 0,011 & $-4,2$ \\
\hline & AV7R & 0,5 & 0,498 & 0,011 & $-0,4$ \\
\hline & AV8R & 0,25 & 0,256 & 0,007 & 2,2 \\
\hline & AV9R & 0,5 & 0,437 & 0,011 & $-14,3$ \\
\hline & AV10R & 0,5 & 0,500 & 0,010 & 0,1 \\
\hline & AV11R & 0,25 & 0,239 & 0,007 & $-4,6$ \\
\hline & $A \vee 12 R$ & 0,5 & 0,461 & 0,011 & $-8,4$ \\
\hline \multirow{12}{*}{100} & AV1R & 0,25 & 0,253 & 0,009 & 1,2 \\
\hline & AV2R & 0,25 & 0,238 & 0,009 & $-4,9$ \\
\hline & AV3R & 0,5 & 0,444 & 0,012 & $-12,7$ \\
\hline & AV4R & 0,25 & 0,265 & 0,010 & 5,8 \\
\hline & AV5R & 0,25 & 0,266 & 0,010 & 6,0 \\
\hline & AV6R & 0,5 & 0,495 & 0,012 & $-1,0$ \\
\hline & AV7R & 0,5 & 0,479 & 0,012 & $-4,4$ \\
\hline & AV8R & 0,25 & 0,261 & 0,009 & 4,2 \\
\hline & AV9R & 0,5 & 0,439 & 0,012 & $-14,0$ \\
\hline & AV10R & 0,5 & 0,501 & 0,013 & 0,3 \\
\hline & AV11R & 0,25 & 0,232 & 0,009 & $-7,7$ \\
\hline & $A \vee 12 R$ & 0,5 & 0,466 & 0,012 & $-7,4$ \\
\hline \multirow{12}{*}{150} & AV1R & 0,25 & 0,258 & 0,011 & 3,1 \\
\hline & AV2R & 0,25 & 0,248 & 0,011 & $-0,8$ \\
\hline & AV3R & 0,5 & 0,452 & 0,013 & $-10,6$ \\
\hline & AV4R & 0,25 & 0,273 & 0,011 & 8,5 \\
\hline & AV5R & 0,25 & 0,272 & 0,011 & 8,0 \\
\hline & AV6R & 0,5 & 0,481 & 0,013 & $-4,0$ \\
\hline & AV7R & 0,5 & 0,489 & 0,013 & $-2,3$ \\
\hline & AV8R & 0,25 & 0,263 & 0,011 & 4,8 \\
\hline & AV9R & 0,5 & 0,449 & 0,012 & $-11,5$ \\
\hline & AV10R & 0,5 & 0,505 & 0,013 & 1,0 \\
\hline & AV11R & 0,25 & 0,238 & 0,011 & $-4,8$ \\
\hline & AV12R & 0,5 & 0,468 & 0,012 & $-6,8$ \\
\hline
\end{tabular}


Tabela 63 - Resultados da re-avaliação dos aventais de proteção do Fabricante D. Método: somatório de exponenciais

\begin{tabular}{|c|c|c|c|c|c|}
\hline $\begin{array}{c}\text { Tensão } \\
\text { (kV) }\end{array}$ & Dispositivo & $\begin{array}{c}\text { Equivalência } \\
\text { Nominal (mmPb) }\end{array}$ & $\begin{array}{c}\text { Equivalência } \\
\text { Calculada (mmPb) }\end{array}$ & $\begin{array}{c}\text { Incerteza } \\
(\mathrm{mmPb})\end{array}$ & $\begin{array}{c}\text { Diferença } \\
(\%)\end{array}$ \\
\hline \multirow{12}{*}{80} & AV1R & 0,25 & 0,242 & 0,004 & $-3,2$ \\
\hline & AV2R & 0,25 & 0,231 & 0,004 & $-8,1$ \\
\hline & AV3R & 0,5 & 0,442 & 0,005 & $-13,0$ \\
\hline & AV4R & 0,25 & 0,261 & 0,004 & 4,3 \\
\hline & AV5R & 0,25 & 0,239 & 0,004 & $-4,4$ \\
\hline & AV6R & 0,5 & 0,485 & 0,005 & $-3,1$ \\
\hline & AV7R & 0,5 & 0,504 & 0,005 & 0,7 \\
\hline & AV8R & 0,25 & 0,250 & 0,004 & 0,1 \\
\hline & AV9R & 0,5 & 0,441 & 0,005 & $-13,4$ \\
\hline & AV10R & 0,5 & 0,506 & 0,005 & 1,2 \\
\hline & AV11R & 0,25 & 0,234 & 0,004 & $-6,8$ \\
\hline & $A \vee 12 R$ & 0,5 & 0,466 & 0,005 & $-7,4$ \\
\hline \multirow{12}{*}{100} & AV1R & 0,25 & 0,250 & 0,004 & 0,2 \\
\hline & AV2R & 0,25 & 0,237 & 0,004 & $-5,7$ \\
\hline & AV3R & 0,5 & 0,437 & 0,004 & $-14,4$ \\
\hline & AV4R & 0,25 & 0,262 & 0,004 & 4,5 \\
\hline & AV5R & 0,25 & 0,262 & 0,004 & 4,7 \\
\hline & AV6R & 0,5 & 0,490 & 0,004 & $-2,0$ \\
\hline & AV7R & 0,5 & 0,474 & 0,004 & $-5,5$ \\
\hline & AV8R & 0,25 & 0,258 & 0,004 & 3,0 \\
\hline & AV9R & 0,5 & 0,432 & 0,004 & $-15,7$ \\
\hline & AV10R & 0,5 & 0,497 & 0,004 & $-0,5$ \\
\hline & AV11R & 0,25 & 0,231 & 0,004 & $-8,3$ \\
\hline & AV12R & 0,5 & 0,460 & 0,004 & $-8,7$ \\
\hline \multirow{12}{*}{150} & AV1R & 0,25 & 0,259 & 0,001 & 3,6 \\
\hline & AV2R & 0,25 & 0,249 & 0,001 & $-0,3$ \\
\hline & AV3R & 0,5 & 0,450 & 0,001 & $-11,0$ \\
\hline & AV4R & 0,25 & 0,274 & 0,001 & 8,8 \\
\hline & AV5R & 0,25 & 0,273 & 0,001 & 8,3 \\
\hline & AV6R & 0,5 & 0,479 & 0,001 & $-4,5$ \\
\hline & AV7R & 0,5 & 0,487 & 0,001 & $-2,7$ \\
\hline & AV8R & 0,25 & 0,264 & 0,001 & 5,2 \\
\hline & AV9R & 0,5 & 0,447 & 0,001 & $-11,9$ \\
\hline & AV10R & 0,5 & 0,503 & 0,001 & 0,6 \\
\hline & AV11R & 0,25 & 0,240 & 0,001 & $-4,2$ \\
\hline & $\mathrm{AV} 12 \mathrm{R}$ & 0,5 & 0,466 & 0,001 & $-7,2$ \\
\hline
\end{tabular}




\subsubsection{Comparação entre as três Metodologias Avaliadas para Determinação da Espessura Equivalente de Atenuação}

Comparando-se as três metodologias avaliadas para a determinação da espessura equivalente de atenuação pode-se perceber que o resultado final é praticamente o mesmo.

A Tabela 64 apresenta a comparação dos três métodos utilizados. Para compor esta tabela, foram escolhidos dois aventais de cada fabricante: um com o equivalente de atenuação nominal igual a $0,25 \mathrm{mmPb}$ e o outro com o equivalente de atenuação igual nominal a $0,50 \mathrm{mmPb}$, exceto para o Fabricante $\mathrm{E}$ que eram todas equivalentes a $0,50 \mathrm{mmPb}$. Além disso, para a composição desta tabela foram selecionados os resultados referentes a cinco medições na tensão de $100 \mathrm{kV}$.

O método da interpolação linear é apresentado como método 1 , o modelo de Archer como método 2 e o método do somatório de exponenciais como método 3.

Analisando-se os dados, é possível observar que os resultados das espessuras equivalentes de atenuação nas três metodologias avaliadas apresentam uma diferença máxima de 5,9 \% entre uma metodologia e outra. Além disso, as incertezas associadas a cada método apresentaram pouca variação.

Para se obter os resultados referentes à metodologia da interpolação linear, foi necessário apenas uma planilha do Excel; alguns resultados foram trabalhados utilizando-se o software Mathcad $\AA$ para a monitoração dos resultados, pois neste aplicativo a visualização dos resultados pode ser acompanhada passo a passo.

Nas metodologias do somatório de exponenciais e modelo de Archer foi necessária a utilização do software GnuPlot que ajustava as funções e apresentava os valores dos parâmetros, as incertezas dos parâmetros e a matriz de correlação; a partir daí, estes valores podiam ser trabalhados a fim de se obter o equivalente de atenuação. Além disso, como foi necessário transferir as incertezas das espessuras dos filtros de chumbo para os valores da taxa de kerma no ar em cada ponto, o ajuste teve que ser feito duas vezes em cada metodologia, para cada tensão e para cada número de medições realizado.

Assim, levando-se em consideração a praticidade do método, juntamente com os resultados de incertezas apresentados, é possível dizer que dentre as três metodologias a que mais se adequaria às condições do laboratório para a determinação da espessura equivalente de atenuação é a metodologia da interpolação linear. 
Tabela 64 - Comparação dos resultados utilizando as três metodologias avaliadas na tensão de $100 \mathrm{kV}$ entre todos os fabricantes

\begin{tabular}{|c|c|c|c|c|c|c|}
\hline Fabricante & Dispositivo & $\begin{array}{c}\text { Equivalência } \\
\text { Nominal (mmPb) }\end{array}$ & Método & $\begin{array}{c}\text { Equivalência } \\
\text { Calculada }(\mathrm{mmPb})\end{array}$ & $\begin{array}{c}\text { Incerteza } \\
\text { (mmPb) }\end{array}$ & $\begin{array}{c}\text { Diferença } \\
(\%)\end{array}$ \\
\hline \multirow{6}{*}{$A$} & \multirow{3}{*}{ AV3 } & \multirow{3}{*}{0,25} & 1 & 0,228 & 0,012 & $-9,6$ \\
\hline & & & 2 & 0,220 & 0,009 & $-13,6$ \\
\hline & & & 3 & 0,221 & 0,005 & $-13,4$ \\
\hline & \multirow{3}{*}{ AV6 } & \multirow{3}{*}{0,5} & 1 & 0,448 & 0,016 & $-11,5$ \\
\hline & & & 2 & 0,436 & 0,012 & $-14,7$ \\
\hline & & & 3 & 0,429 & 0,006 & $-16,6$ \\
\hline \multirow{6}{*}{$B$} & \multirow{3}{*}{ AV1 } & \multirow{3}{*}{0,25} & 1 & 0,240 & 0,012 & $-4,1$ \\
\hline & & & 2 & 0,236 & 0,009 & $-5,9$ \\
\hline & & & 3 & 0,236 & 0,005 & $-6,0$ \\
\hline & \multirow{3}{*}{ BO1 } & \multirow{3}{*}{0,5} & 1 & 0,473 & 0,017 & $-5,8$ \\
\hline & & & 2 & 0,465 & 0,012 & $-7,5$ \\
\hline & & & 3 & 0,479 & 0,006 & $-4,4$ \\
\hline \multirow{6}{*}{ C } & \multirow{3}{*}{ AV2 } & \multirow{3}{*}{0,25} & 1 & 0,269 & 0,018 & 7,1 \\
\hline & & & 2 & 0,262 & 0,009 & 4,6 \\
\hline & & & 3 & 0,258 & 0,004 & 3,3 \\
\hline & \multirow{3}{*}{ AV1 } & \multirow{3}{*}{0,5} & 1 & 0,565 & 0,018 & 11,5 \\
\hline & & & 2 & 0,558 & 0,013 & 10,4 \\
\hline & & & 3 & 0,557 & 0,004 & 10,3 \\
\hline \multirow{6}{*}{$\mathrm{D}$} & \multirow{3}{*}{ AV3 } & \multirow{3}{*}{0,25} & 1 & 0,315 & 0,015 & 20,7 \\
\hline & & & 2 & 0,302 & 0,010 & 17,2 \\
\hline & & & 3 & 0,297 & 0,005 & 15,7 \\
\hline & \multirow{3}{*}{$\mathrm{A} \vee 7$} & \multirow{3}{*}{0,5} & 1 & 0,481 & 0,020 & $-4,0$ \\
\hline & & & 2 & 0,475 & 0,012 & $-5,3$ \\
\hline & & & 3 & 0,470 & 0,005 & $-6,4$ \\
\hline \multirow{6}{*}{$E$} & \multirow{3}{*}{$\mathrm{AV} 1$} & \multirow{3}{*}{0,5} & 1 & 0,448 & 0,017 & $-11,5$ \\
\hline & & & 2 & 0,438 & 0,012 & $-14,1$ \\
\hline & & & 3 & 0,432 & 0,004 & $-15,8$ \\
\hline & \multirow{3}{*}{ AV2 } & \multirow{3}{*}{0,5} & 1 & 0,578 & 0,019 & 13,5 \\
\hline & & & 2 & 0,571 & 0,013 & 12,5 \\
\hline & & & 3 & 0,571 & 0,005 & 12,4 \\
\hline \multirow{6}{*}{$\mathrm{D}$ (re-teste) } & \multirow{3}{*}{$A \vee 1 R$} & & 1 & 0,257 & 0,020 & 2,9 \\
\hline & & 0,25 & 2 & 0,253 & 0,009 & 1,2 \\
\hline & & & 3 & 0,250 & 0,004 & 0,2 \\
\hline & & & 1 & 0,449 & 0,018 & $-11,4$ \\
\hline & AV9R & 0,5 & 2 & 0,439 & 0,012 & $-14,0$ \\
\hline & & & 3 & 0,432 & 0,004 & $-15,7$ \\
\hline
\end{tabular}

\subsubsection{Avaliação da Reprodutibilidade da Espessura Equivalente de Atenuação}

Em geral, o fabricante dos dispositivos de proteção radiológica seleciona um único fornecedor de borracha plumbífera e confecciona todos os seus produtos utilizando a mesma borracha. Assim, a espessura equivalente de atenuação em 
chumbo de todos os dispositivos confeccionados deveria, a princípio, apresentar praticamente a mesma variação entre o valor nominal e o valor medido.

Porém, durante a determinação da espessura equivalente de atenuação das amostras avaliadas, percebeu-se que havia uma grande variação entre os valores calculados para amostras com o mesmo valor nominal de espessura equivalente de atenuação de um mesmo fabricante.

Desta forma, foi feita a avaliação da reprodutibilidade da espessura equivalente de atenuação (calculada) de cada fabricante. Neste estudo, os dispositivos de proteção pertencentes a cada fabricante foram divididos por equivalência nominal.

A reprodutibilidade $(R)$ foi determinada utilizando-se a Equação 29:

$$
R(\%)=\frac{E \max -E \min }{(E \max +E \min ) / 2} \cdot 100
$$

\section{Equação 29}

onde $E$ max é a espessura de equivalente de atenuação calculada máxima para os dispositivos de proteção com a mesma equivalência nominal

$E$ min é a espessura de equivalente de atenuação calculada mínima para os dispositivos de proteção com a mesma equivalência nominal

Este estudo não pôde ser realizado para os dispositivos de proteção enviados pelo Fabricante C, uma vez que foi ensaiado apenas um avental de proteção de cada espessura.

Os resultados obtidos para as tensões de $80 \mathrm{kV}, 100 \mathrm{kV}$ e $150 \mathrm{kV}$, mostrados na Figura 23, mostram que as espessuras equivalentes de atenuação dos dispositivos de proteção confeccionados pelo Fabricante A são mais reprodutíveis, ou seja, a espessura equivalente de atenuação para diferentes dispositivos com a mesma equivalência nominal é praticamente a mesma nas três tensões avaliadas.

O contrário acontece com os dispositivos de proteção confeccionados pelo Fabricante D, visto que a reprodutibilidade calculada foi de $53 \%$ para os dispositivos com equivalência nominal igual a $0,25 \mathrm{mmPb}$ e de $36 \%$ para os dispositivos com equivalência nominal de $0,5 \mathrm{mmPb}$ na tensão de $100 \mathrm{kV}$, chegando a $57 \%$ para os dispositivos com equivalência nominal igual a 0,25 mmPb na tensão de $150 \mathrm{kV}$.

Os resultados obtidos no re-teste dos aventais de proteção do Fabricante D mostraram que houve diminuição dos valores percentuais obtidos. Desta forma, podese dizer que após a troca do material atenuador as espessuras equivalentes de 
atenuação dos aventais confeccionados pelo Fabricante $D$ são mais reprodutíveis que os valores obtidos inicialmente.
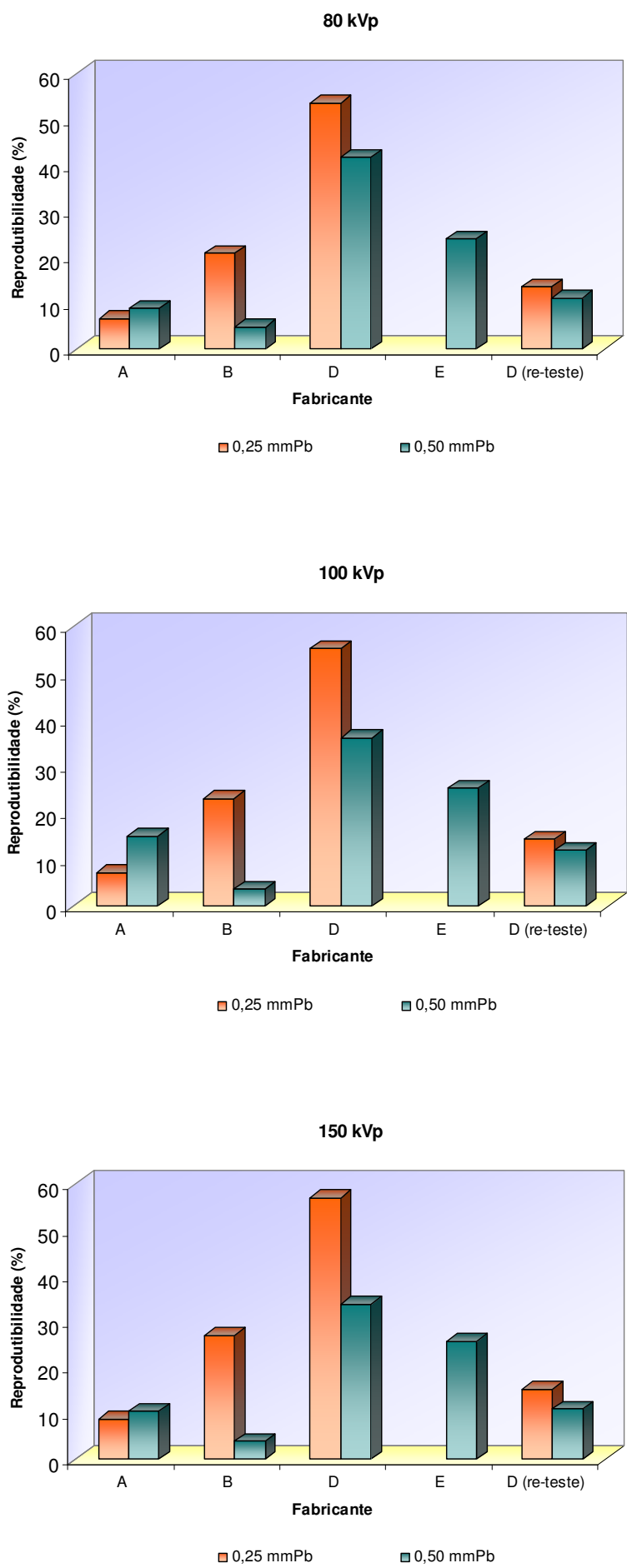

Figura 23 - Verificação da reprodutibilidade do equivalente de atenuação dos dispositivos com equivalência nominal igual a $0,25 \mathrm{mmPb}$ e $0,50 \mathrm{mmPb}$, para as tensões de $80 \mathrm{kV}, 100 \mathrm{kV}$ e $150 \mathrm{kV}$ 


\subsubsection{Avaliação do Percentual de Transmissão Para os Dispositivos de Proteção Radiológica dos Diferentes Fabricantes}

Considerando-se dois dispositivos de proteção com a mesma equivalência nominal e confeccionados por fabricantes diferentes, o percentual de transmissão, a princípio, deveria ser o mesmo.

Observando-se os resultados obtidos para as espessuras equivalentes de atenuação para os dispositivos de proteção, percebeu-se que havia variações entre os valores calculados para os diferentes fabricantes.

Com o objetivo de quantificar quanto estas diferenças influenciam na eficiência destes dispositivos com relação à atenuação, foi feita a avaliação do percentual de transmissão dos dispositivos de proteção para os diferentes fabricantes.

Para cada fabricante, calculou-se a média de todos os dispositivos enviados (avental de proteção e blindagem de ovário) com o mesmo equivalente de atenuação nas tensões de $80 \mathrm{kV}, 100 \mathrm{kV}$ e $150 \mathrm{kV}$, com o objetivo de se verificar a transmissão percentual na faixa de tensão utilizada em radiodiagnóstico.

Os resultados obtidos para os dispositivos com equivalência igual a 0,25 $\mathrm{mmPb}$ e $0,50 \mathrm{mmPb}$ estão apresentados na Figura 24. Comparando-se os diferentes fabricantes, é possível verificar diferenças de até 5,6\% em $150 \mathrm{kV}$ para os dispositivos equivalentes a $0,25 \mathrm{mmPb}$ e $4,2 \%$ em $150 \mathrm{kV}$ para dispositivos de $0,50 \mathrm{mmPb}$.
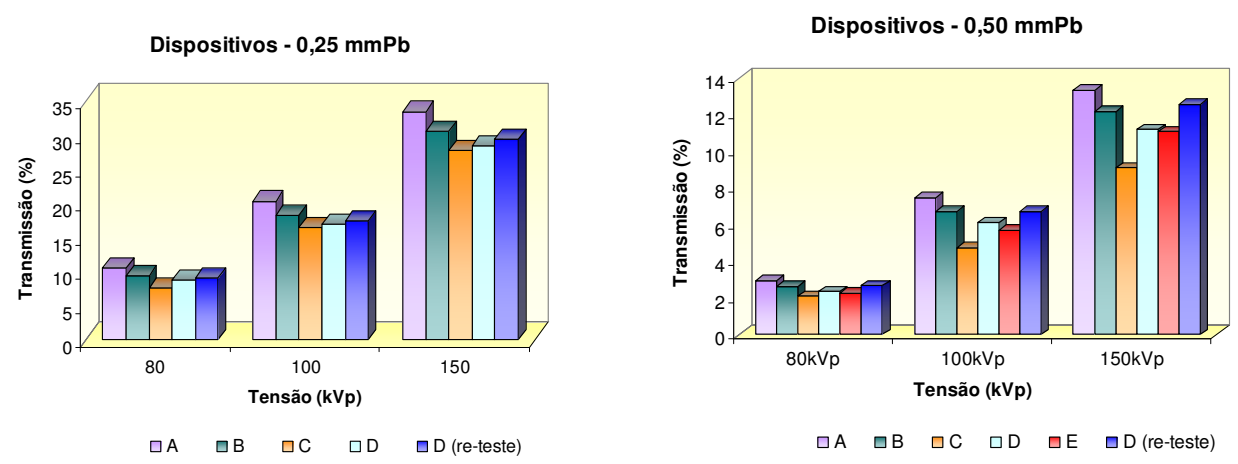

Figura 24 - Avaliação do percentual de transmissão dos dispositivos com equivalência igual a $0,25 \mathrm{mmPb}$ e $0,50 \mathrm{mmPb}$ pertencentes aos diferentes fabricantes (A, B, C, D, E e $D$ re-teste) na faixa de tensão utilizada em radiodiagnóstico

Christodoulou et $\mathrm{al}^{7}$ fizeram um estudo para avaliar o percentual de transmissão de 40 aventais de proteção do Departamento de Radiologia da University of Michigan, provenientes de oito diferentes fabricantes dos Estados Unidos. Comparando-se os resultados obtidos no presente trabalho com os resultados 
apresentados por Christodoulou et $\mathrm{al}^{7}$, mostrados na Tabela 65, pode-se observar a grande semelhança no percentual de transmissão dos dispositivos de proteção de $0,25 \mathrm{mmPb}$ e de $0,50 \mathrm{mmPb}$ dos fabricantes brasileiros e dos fabricantes americanos.

Tabela 65 - Intervalo de variação do percentual de transmissão dos dispositivos de proteção com equivalência igual a $0,25 \mathrm{mmPb}$ e $0,50 \mathrm{mmPb}$, em $100 \mathrm{kV}$

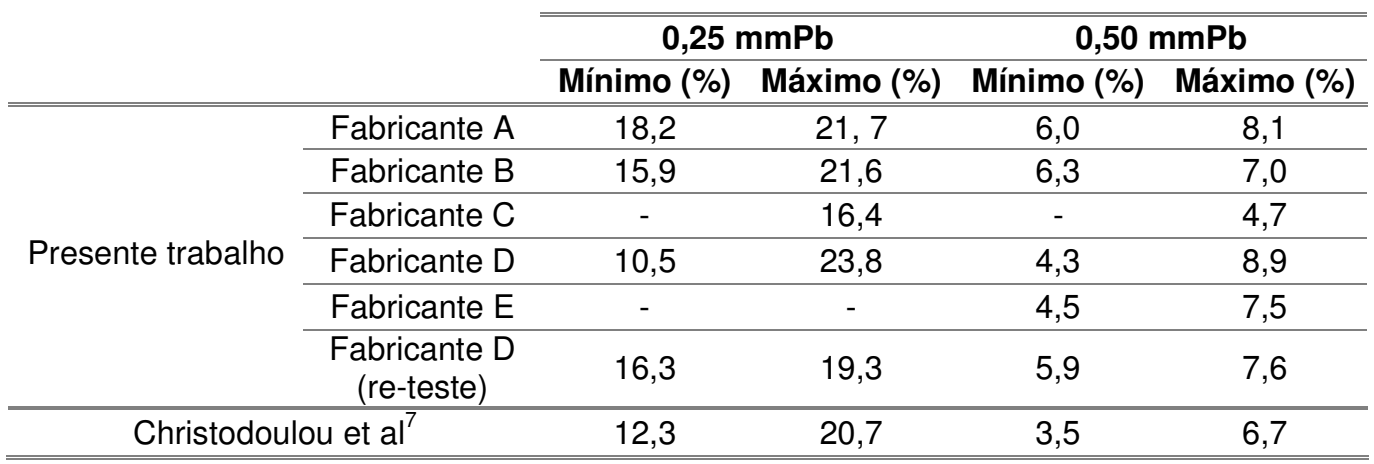

\subsubsection{Cálculo da Inomogeneidade}

Segundo a norma NBR / IEC 61331-1 ${ }^{13}$, a inomogeneidade do material atenuador deve ser indicada junto com a espessura equivalente de atenuação como tolerância, nas mesmas unidades.

Com o objetivo de otimizar os cálculos, a inomogeneidade foi determinada utilizando-se a metodologia da interpolação linear para cinco medições da taxa de kerma no ar em cada ponto.

A Tabela 66 apresenta os valores obtidos da inomogeneidade dos dispositivos de proteção avaliados em $100 \mathrm{kV}$

De acordo com os resultados obtidos, os fabricantes $D$ e $E$ apresentaram os valores maiores de inomogeneidade. A explicação para este fato, no caso do Fabricante $D$, deve-se, provavelmente, às diferenças na espessura ao longo da borracha plumbífera, uma vez que após a troca do fornecedor de borracha, o valor máximo da inomogeneidade passou de $0,030 \mathrm{mmPb}$ para $0,018 \mathrm{mmPb}$. 
Tabela 66 - Inomogeneidade do material atenuador dos dispositivos de proteção em $100 \mathrm{kV}$

\begin{tabular}{|c|c|c|c|c|}
\hline Fabricante & Dispositivo & $\begin{array}{l}\text { Equivalência Nominal } \\
(\mathrm{mmPb})\end{array}$ & $\begin{array}{c}\text { Equivalência } \\
\text { Calculada ( }(\mathrm{mmPb})\end{array}$ & $\begin{array}{c}\text { Inomogeneidade } \\
\text { (mmPb) }\end{array}$ \\
\hline \multirow{15}{*}{ A } & AV1 & 0,5 & 0,455 & 0,010 \\
\hline & $\mathrm{AV} 1$ - costa & 0,25 & 0,229 & 0,008 \\
\hline & AV2 & 0,5 & 0,450 & 0,004 \\
\hline & AV2 - costa & 0,25 & 0,233 & 0,002 \\
\hline & AV3 & 0,25 & 0,228 & 0,002 \\
\hline & AV4 & 0,25 & 0,232 & 0,004 \\
\hline & AV5 & 0,25 & 0,231 & 0,003 \\
\hline & AV6 & 0,5 & 0,448 & 0,002 \\
\hline & AV7 & 0,5 & 0,459 & 0,008 \\
\hline & AV8 & 0,5 & 0,430 & 0,005 \\
\hline & AV9 & 0,25 & 0,233 & 0,002 \\
\hline & AV10 & 0,25 & 0,235 & 0,004 \\
\hline & BO1 & 0,5 & 0,455 & 0,010 \\
\hline & $\mathrm{BO} 2$ & 0,5 & 0,458 & 0,006 \\
\hline & $\mathrm{BO} 3$ & 0,5 & 0,457 & 0,006 \\
\hline \multirow{7}{*}{ B } & AV1 & 0,25 & 0,240 & 0,010 \\
\hline & AV2 & 0,25 & 0,243 & 0,009 \\
\hline & $\mathrm{AV} 3$ & 0,25 & 0,282 & 0,011 \\
\hline & AV4 & 0,25 & 0,244 & 0,005 \\
\hline & BO1 & 0,5 & 0,473 & 0,017 \\
\hline & $\mathrm{BO} 2$ & 0,5 & 0,488 & 0,011 \\
\hline & $\mathrm{BO} 3$ & 0,5 & 0,471 & 0,012 \\
\hline \multirow{2}{*}{ C } & AV1 & 0,5 & 0,565 & 0,022 \\
\hline & AV2 & 0,25 & 0,269 & 0,011 \\
\hline \multirow{14}{*}{ D } & AV1 & 0,25 & 0,206 & 0,011 \\
\hline & AV2 & 0,5 & 0,558 & 0,003 \\
\hline & $\mathrm{AV} 3$ & 0,25 & 0,315 & 0,014 \\
\hline & AV4 & 0,25 & 0,260 & 0,008 \\
\hline & AV5 & 0,25 & 0,228 & 0,005 \\
\hline & AV6 & 0,5 & 0,408 & 0,017 \\
\hline & AV7 & 0,5 & 0,481 & 0,030 \\
\hline & AV8 & 0,25 & 0,226 & 0,009 \\
\hline & AV9 & 0,25 & 0,319 & 0,009 \\
\hline & AV10 & 0,5 & 0,588 & 0,012 \\
\hline & AV11 & 0,5 & 0,457 & 0,006 \\
\hline & AV12 & 0,5 & 0,554 & 0,024 \\
\hline & $A V 13$ & 0,25 & 0,236 & 0,021 \\
\hline & AV14 & 0,5 & 0,506 & 0,014 \\
\hline \multirow{4}{*}{$E$} & $\mathrm{AV} 1$ & 0,5 & 0,448 & 0,019 \\
\hline & AV2 & 0,5 & 0,578 & 0,035 \\
\hline & $\mathrm{AV} 3$ & 0,5 & 0,498 & 0,030 \\
\hline & AV4 & 0,5 & 0,578 & 0,044 \\
\hline \multirow{6}{*}{ D (re-teste) } & AV1 & 0,25 & 0,257 & 0,012 \\
\hline & AV2 & 0,25 & 0,242 & 0,018 \\
\hline & $\mathrm{AV} 3$ & 0,5 & 0,454 & 0,003 \\
\hline & AV9 & 0,5 & 0,449 & 0,005 \\
\hline & AV11 & 0,25 & 0,238 & 0,006 \\
\hline & AV12 & 0,5 & 0,473 & 0,009 \\
\hline
\end{tabular}




\subsection{Características de Confecção}

As características de confecção dos aventais de proteção e das blindagens de ovário avaliadas foram divididas em documentos acompanhantes, prescrições gerais na marcação, projeto e materiais e particularidades dos aventais de proteção e das blindagens de ovário.

Todos os itens que foram avaliados, mostrados no Anexo 1, são requisitos da norma NBR / IEC $61331-3^{15}$.

\subsubsection{Documentos Acompanhantes}

Foram avaliados os documentos acompanhantes dos aventais de proteção e das blindagens de ovário em conjunto, uma vez que este item faz parte do capítulo de generalidades da norma.

As exigências da norma foram colocadas em forma de questões. Desta forma, os documentos acompanhantes foram analisados por meio de 10 itens:

1. Possui documento acompanhante?

2. O documento acompanhante possui identidade dos itens de dispositivos de proteção aos quais se aplicam?

3. O documento acompanhante possui descrição de todas as marcações nos itens, com explanação de seus significados?

4. O documento acompanhante possui instruções para utilização com recomendações para armazenamento quando não em uso?

5. O documento acompanhante possui instruções para utilização com recomendações para métodos e materiais a serem utilizados para limpeza e desinfecção?

6. O documento acompanhante possui método recomendado e freqüência da inspeção periódica pelo usuário, a fim de verificar a manutenção das propriedades de atenuação?

7. O documento acompanhante possui detalhes de conformidade com a norma NBR / IEC 61331-3 ${ }^{15}$ ?

8. Se o documento possui alguma informação destinada ao paciente, ela está separada das outras informações?

9. Qual é o idioma no qual o documento acompanhante foi originalmente redigido, aprovado ou fornecido pelo fabricante? 
10. Se o documento acompanhante foi escrito em um idioma diferente do idioma que foi redigido originalmente: possui pelo menos uma referência à versão original?

Dentre os cinco fabricantes, apenas os Fabricantes $A, D$ e $E$ possuíam documentos acompanhantes para os seus modelos de aventais de proteção.

Nenhum dos documentos acompanhantes, apresentados pelos 3 fabricantes, atendiam a todos os itens exigidos pela norma, como pode ser observado na Figura 25. O documento acompanhante que menos apresentou não-conformidades foi o enviado pelo Fabricante A, e os Fabricantes D e E apresentaram a mesma quantidade de conformidades.

Além disso, das blindagens de ovário analisadas, nenhuma possuía documento acompanhante. As blindagens de ovário pertenciam aos Fabricantes A e B.

$O$ item relativo ao idioma em que o documento acompanhante foi originalmente escrito, foi considerado não aplicável, uma vez que todos os documentos acompanhantes avaliados pertenciam a dispositivos nacionais.

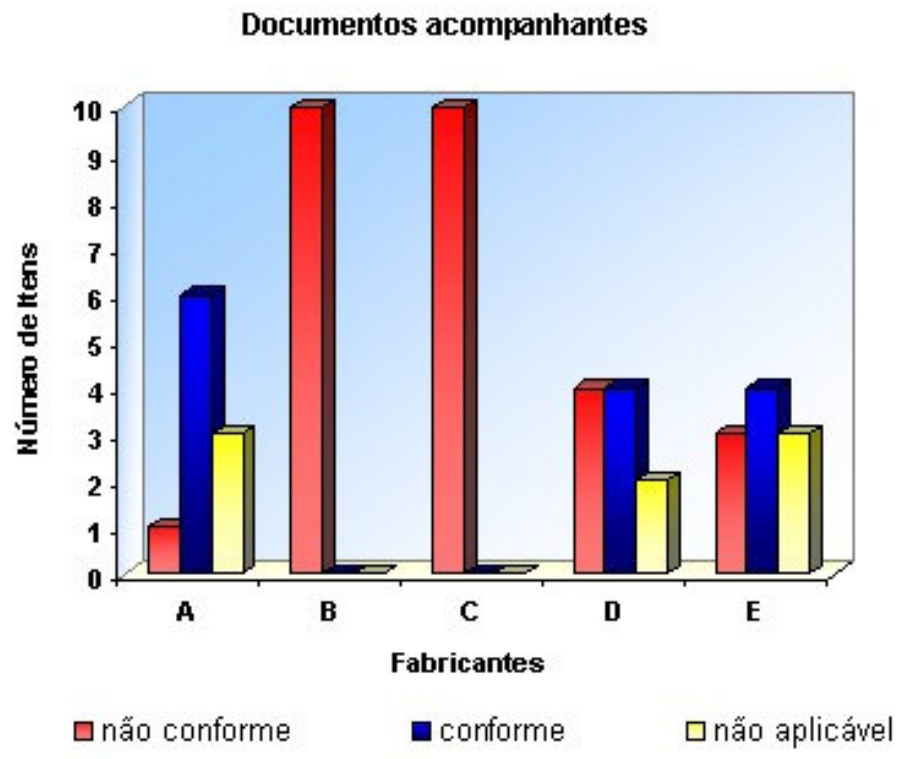

Figura 25 - Resultado da avaliação dos documentos acompanhantes dos aventais de proteção e das blindagens de ovário 


\subsubsection{Prescrições Gerais na Marcação, Projeto e Materiais}

Da mesma forma que os documentos acompanhantes, as prescrições gerais na marcação, projeto e materiais dos aventais de proteção e das blindagens de ovário também foram analisadas em conjunto, visto que este item também faz parte do capítulo de generalidades da norma.

Assim, as prescrições gerais na marcação, projeto e materiais foram analisados por meio de 05 itens:

1. O avental de proteção está marcado de forma que seja garantida sua correlação com o documento acompanhante?

2. É possível colocar e retirar o avental de proteção sem ajuda?

3. O material atenuador possui certificado segundo a norma NBR / IEC 61331-1 ${ }^{13}$ ?

4. Todas as superfícies acessíveis internas e externas do avental de proteção são adequadas para limpeza e desinfecção?

5. É possível tocar alguma superfície do material atenuador?

Pode-se observar que dos 05 itens avaliados, nenhum dos fabricantes atenderam ao item 1, mesmo aqueles fabricantes que possuíam documentos acompanhantes para os aventais de proteção. Dentre os cinco Fabricantes, somente o Fabricante A possuía o material atenuador certificado pela norma NBR / IEC 61331-1 ${ }^{13}$ de 2004.

Os demais itens foram atendidos por todos os Fabricantes.

\subsubsection{Aventais de Proteção}

Os aventais de proteção foram avaliados basicamente por meio de um questionário de 16 perguntas, formuladas a partir dos itens requeridos pela norma em questão. Dessas 16 perguntas, 09 estavam relacionadas com as características de confecção e 6 eram relativas à marcação dos aventais de proteção.

Os resultados obtidos foram divididos em características de confecção e verificação da marcação e estão mostrados a seguir. 


\subsubsection{Características de confecção}

As características de confecção foram analisadas por meio das seguintes perguntas:

1. Como a norma NBR / IEC 61331-3 ${ }^{15}$ classifica este avental de proteção? O avental está classificado de acordo com a Norma?

2. O avental de proteção consiste em uma ou mais camadas de material protetor?

3. O avental protetor cobre a parte anterior do corpo, a garganta, todo o esterno, os ombros e desce pelo menos até a metade dos joelhos?

4. Há furos de costura (para fixação das partes) desprotegidos na parte anterior do avental de proteção?

5. O avental de proteção está classificado por tamanho de acordo com a Tabela 67? Qual é a sua classificação?

6. A largura do material protetor em cada ombro é maior que $11 \mathrm{~cm}$ ?

7. O material protetor na parte posterior dos ombros possui pelo menos $15 \mathrm{~cm}$ ?

8. Se o avental de proteção for do tipo fechado: ele cobre as laterais do corpo (10 cm ou menos abaixo da axila) até pelo menos a metade da coxa e as costas até o joelho?

9. De acordo com as medições e com as informações da Tabela 63, qual é a sua classificação? 
Tabela 67 - Tamanhos padronizados de aventais de proteção segundo a NBR / IEC $61331-3^{15}$ de 2004

\begin{tabular}{|c|c|c|c|c|c|}
\hline \multirow{2}{*}{\multicolumn{2}{|c|}{ Tamanho padronizado }} & \multirow{3}{*}{$\begin{array}{c}\text { Símbolos } \\
\text { literais }\end{array}$} & \multicolumn{3}{|c|}{ Dimensões (cm) } \\
\hline & & & D1 & D2 & D3 \\
\hline \multirow{5}{*}{ Pequeno } & Muito curto & & 90 & \multirow{5}{*}{60} & \multirow{5}{*}{100} \\
\hline & Curto & PC & 100 & & \\
\hline & Médio & PM & 110 & & \\
\hline & Longo & $\mathrm{PL}$ & 120 & & \\
\hline & Extralongo & PEL & 130 & & \\
\hline \multirow{5}{*}{ Médio } & Muito curto & MMC & 90 & \multirow{5}{*}{60} & \multirow{5}{*}{110} \\
\hline & Curto & MC & 100 & & \\
\hline & Médio & MM & 110 & & \\
\hline & Longo & $M L$ & 120 & & \\
\hline & Extralongo & MEL & 130 & & \\
\hline \multirow{4}{*}{ Grande } & Curto & GC & 100 & \multirow{4}{*}{75} & \multirow{4}{*}{120} \\
\hline & Médio & GM & 110 & & \\
\hline & Longo & $\mathrm{GL}$ & 120 & & \\
\hline & Extralongo & GEL & 130 & & \\
\hline
\end{tabular}

Onde: D1 é o comprimento do meio do ombro até a borda inferior;

D2 é a largura da parte anterior e a largura da parte posterior dos aventais de proteção fechados com presilhas na lateral;

D3 é a medição da cintura dos aventais de proteção fechados com presilhas no meio da parte anterior ou posterior;

Dimensões D1, D2 e D3 são dimensões mínimas.

A Norma NBR / IEC $61331-3^{15}$ descreve 04 categorias de aventais de proteção. São elas: avental de proteção leve; avental de proteção fechado; avental de proteção fechado leve e avental de proteção fechado pesado. De acordo com a análise da classificação por categoria, 35 \% dos aventais de proteção não estavam classificados segundo a norma, os quais pertencem aos Fabricantes B, C e E. Somente os aventais de proteção dos Fabricantes $A$ e $D$ apresentaram classificação por categoria, porém $60 \%$ dos aventais do Fabricante A e $43 \%$ do Fabricante D estavam classificados de maneira incorreta, como mostra a Figura 26. 


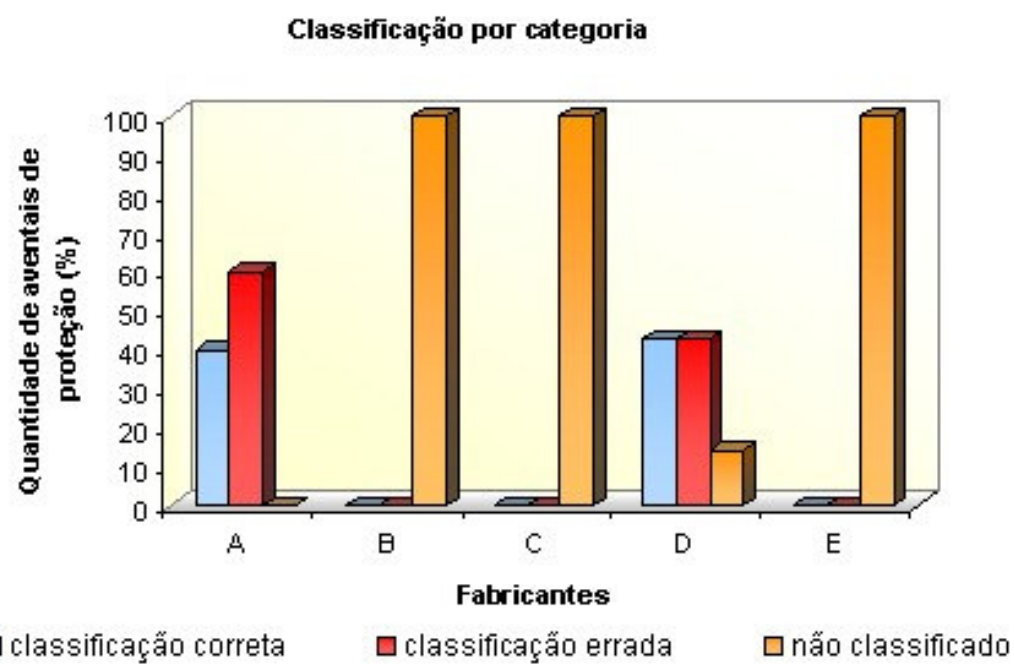

Figura 26 - Resultado da classificação por categoria dos aventais de proteção avaliados

Dentre as características de projeto dos aventais de proteção, a norma em questão descreve que estes devem ser projetados de maneira a cobrir a parte anterior do corpo, da garganta, todo o esterno e os ombros, descendo pelo menos até o joelho. Segundo a avaliação feita, os aventais de proteção dos Fabricantes A, C e E atendiam a essa exigência, porém $25 \%$ dos aventais do Fabricante B e $79 \%$ do Fabricante D não estavam de acordo com este item, como ilustra a Figura 27.

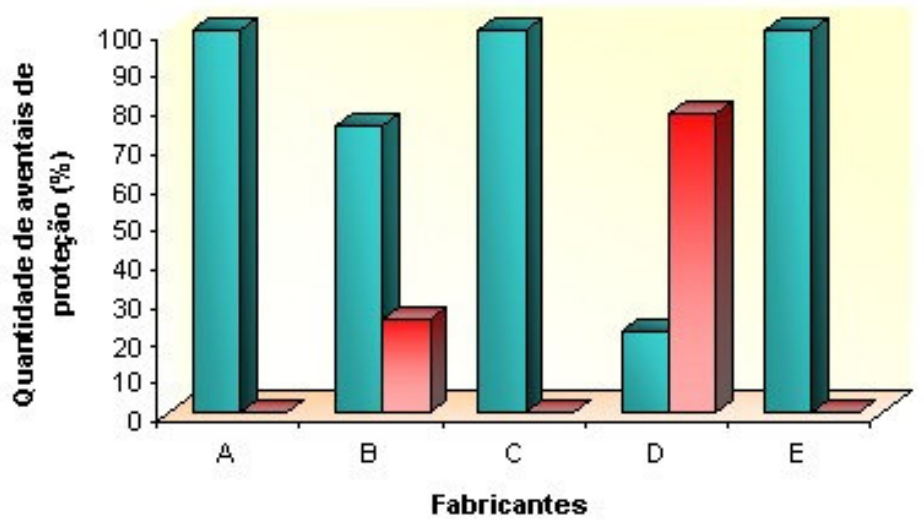

$\square$ conforme

ロ nẫo conforme

Figura 27 - Resultado da verificação se os aventais de proteção cobrem a parte anterior do corpo, da garganta, todo o esterno e os ombros, descendo pelo menos até o joelho

$\mathrm{Na}$ avaliação feita para verificar se os aventais de proteção estavam classificados segundo a Tabela 67, foi possível observar que somente o Fabricante D possuía esta classificação, porém dos 14 aventais de proteção cedidos, 02 não 
estavam classificados, 02 estavam classificados errados e o restante, 10 aventais, não se enquadravam na classificação.

Foram feitas as medições do comprimento (Figura 28-a), largura (Figura 28-b) e medição da cintura dos aventais de proteção. Com essas medições, procurava-se na Tabela 67 uma classificação por tamanho padronizado. Nem sempre era possível classificar o avental, uma vez que grande parte dos aventais possuía valores inferiores aos valores de comprimento e largura mínimos exigidos pela norma, como mostra a Figura 29.

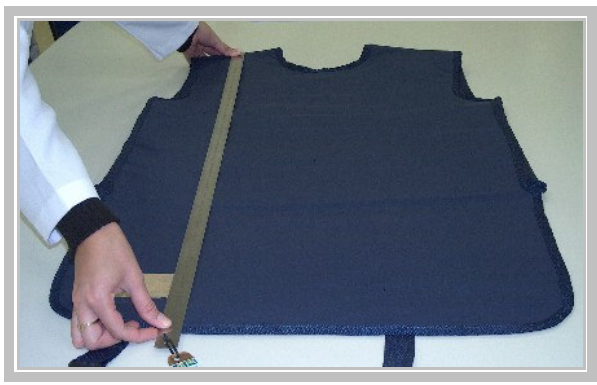

(a)

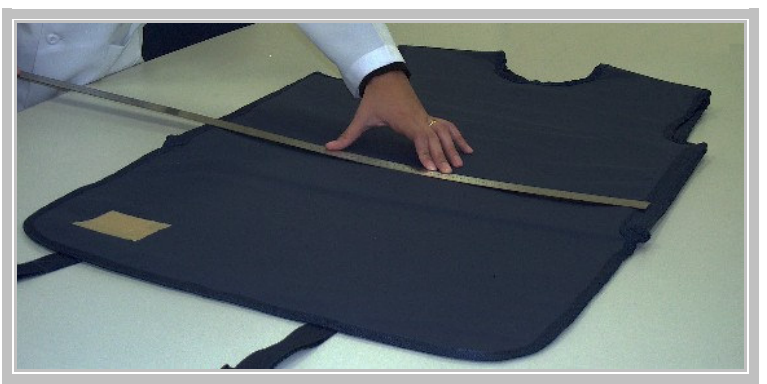

(b)

Figura 28 - (a) Medição do comprimento e (b) da largura dos aventais de proteção

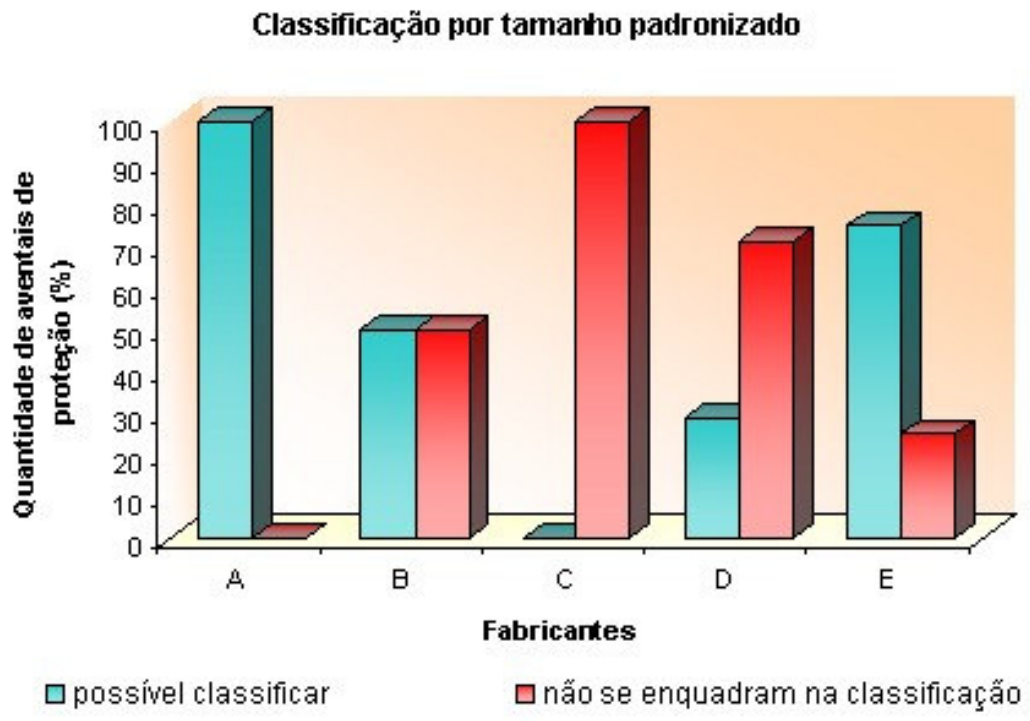

Figura 29 - Resultados da classificação dos aventais de proteção por tamanho padronizado

Com relação ao item que exige que a largura do material atenuador no ombro do avental de proteção seja maior que $11 \mathrm{~cm}$ (como é apresentado na Figura 30-a), 
somente 01 modelo do Fabricante B não estava em conformidade. Os demais modelos avaliados dos 05 Fabricantes estavam conforme.

Além disso, a norma exige que todo avental de proteção possua pelo menos $15 \mathrm{~cm}$ de material atenuador na região posterior dos ombros, mostrado na Figura 30. Mais de 50 \% dos aventais de proteção não estavam em conformidade com este item. A Figura 31 mostra a distribuição por Fabricante da quantidade de aventais de proteção conforme ou não conforme com este item.

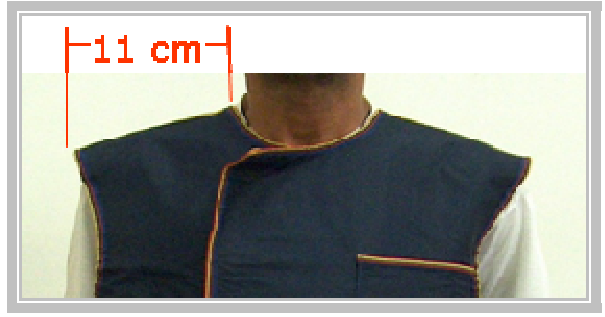

(a)

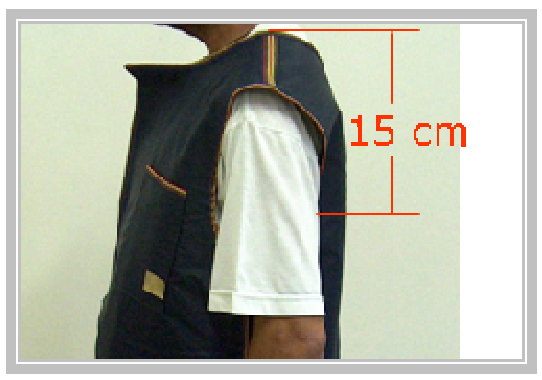

(b)

Figura 30 - Requisitos de confecção dos aventais de confecção: (a) a largura do material atenuador nos ombros deve ser maior que $11 \mathrm{~cm}$; (b) deve haver pelo menos $15 \mathrm{~cm}$ de material atenuador na região posterior dos ombros

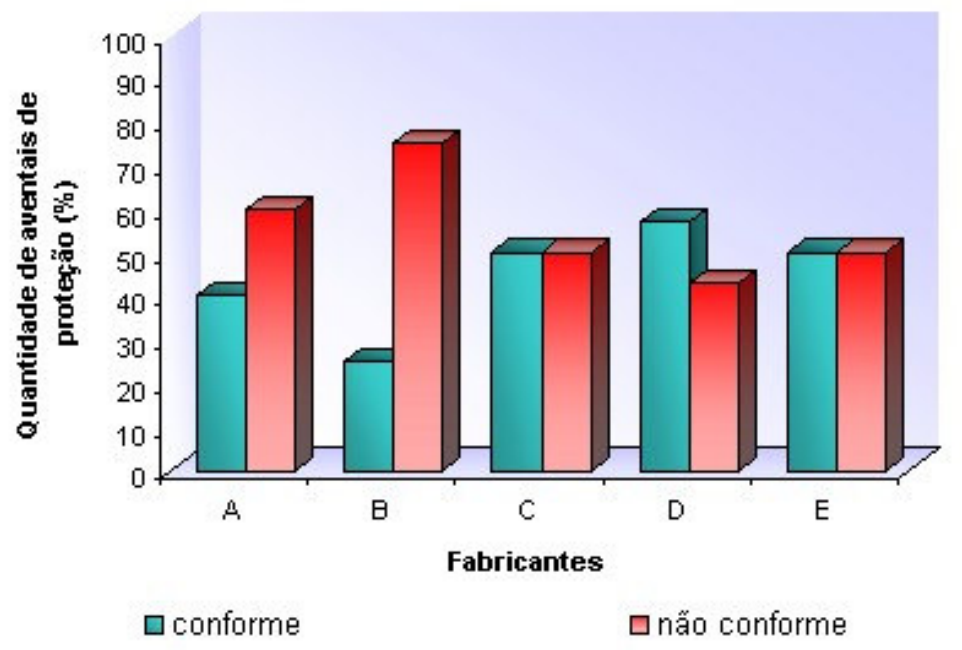

Figura 31 - Resultado da avaliação dos aventais de proteção com relação à presença de material atenuador na região posterior dos ombros.

Dos 34 aventais de proteção pesquisados, somente 6 eram do tipo fechado. A norma exige que esses aventais cubram as laterais do corpo $(10 \mathrm{~cm}$ ou menos abaixo da axila) até pelo menos a metade da coxa e as costas até o joelho. O grande 
problema encontrado foi com relação aos "10 cm ou menos abaixo da axila" uma vez que esta medição pode ser relativa. Dos 6 aventais, 02 não estavam em conformidade com este item.

\subsubsection{Verificação da marcação}

Segundo a norma, os aventais de proteção devem apresentar uma marcação de forma clara e permanente das seguintes informações:

1. Nome ou marca do fabricante ou fornecedor;

2. Letra designando o tipo de avental de proteção;

3. Valor da espessura equivalente de atenuação em espessura de chumbo, expresso com o símbolo $\mathrm{Pb}$ seguido pela espessura em milímetros;

4. Tensão do tubo de raios $X$ utilizada para a determinação do valor da espessura equivalente de atenuação, anexada à marcação dada do valor da espessura equivalente de atenuação, pela adição de um traço oblíquo seguido pelo valor da tensão do tubo de raios $\mathrm{X}$, em quilovolts;

5. Símbolos literais correspondentes ao tamanho do avental;

6. Referência à norma: ABNT NBR / IEC 61331-3: $2004^{15}$.

A verificação desses itens resultou nos seguintes dados:

Todos os aventais de proteção apresentaram de forma clara o nome do fabricante.

Somente o Fabricante A apresentava a letra designando o tipo do avental, porém $60 \%$ dos aventais de proteção estavam classificados de forma incorreta. Os demais Fabricantes apresentaram não conformidade com este item.

A marcação do valor da espessura equivalente de atenuação em chumbo foi detectada em todos os 34 aventais de proteção analisados, porém nos aventais de proteção do Fabricante $\mathrm{D}$ a espessura equivalente de atenuação estava sem a unidade de medição (mmPb). Já a marcação da tensão do tubo utilizada para a determinação desta espessura equivalente de atenuação estava presente somente nas etiquetas dos Fabricantes A e D. O Fabricante D indicava a tensão do tubo com a unidade errada: $\mathrm{KV}$, onde o correto é kV (quilovolts).

Entre os 05 Fabricantes, somente o Fabricante D apresentava na etiqueta de seus aventais de proteção símbolos literais correspondentes ao tamanho dos aventais, 
porém segundo as medições de comprimento e largura realizadas, os aventais não se enquadravam na classificação.

Finalmente, somente $\mathrm{O}$ Fabricante $\mathrm{A}$ fazia referência à norma NBR / IEC 61331-3 de $2004{ }^{15}$ nas etiquetas dos seus aventais de proteção.

\subsubsection{Re-avaliação da Espessura Equivalente de Atenuação dos Aventais Modificados pelo Fabricante $D$}

O Fabricante D, como informado no item 5.2.4, enviou novas amostras dos aventais de proteção para serem avaliadas. Além da troca do fornecedor de borracha plumbífera, o Fabricante D modificou algumas características de confecção.

Foi feita novamente uma avaliação das características de confecção, documentos acompanhantes, características de projeto e marcação nas novas amostras.

O documento acompanhante das amostras iniciais não atendia a quatro itens da norma e o material atenuador (borracha plumbífera) dos aventais não possuía certificado segundo a NBR / IEC 61331-1 ${ }^{13}$. Após as modificações, todos os requisitos com relação aos documentos acompanhantes e projeto foram atendidos.

Todos os aventais de proteção avaliados apresentaram marcação de acordo com todos os requisitos da parte 3 da norma. $O$ único problema que ainda não foi solucionado foi a unidade de tensão que continua KV, onde o correto é kV (quilovolts).

Outro problema encontrado foi com relação à classificação por tamanho padronizado. Dos seis aventais de proteção avaliados, somente um estava classificado de forma correta. Este problema aconteceu porque os valores da largura e comprimento estavam de um a dois centímetros menores que os tamanhos nominais. Se a largura e o comprimento medidos fossem iguais aos valores nominais, todas as classificações estariam corretas. 


\section{DISCUSSÃO}

Dos resultados obtidos, pode-se observar que há uma grande variação dos valores declarados pelos diversos fabricantes em relação aos valores medidos. A maior parte das amostras analisadas apresentou uma diferença percentual negativa, ou seja, o nível de proteção radiológica para o usuário é menor que o esperado. Por outro lado, as diferenças percentuais entre os valores declarados e medidos muito altas podem levar ao aumento no peso desses aventais, desestimulando o seu uso. Neste trabalho, não foi possível avaliar a contribuição do aumento da espessura equivalente de atenuação para o peso do avental.

A comparação entre as três metodologias utilizadas na determinação da espessura equivalente de atenuação mostrou que os resultados apresentam diferença máxima de 5,9\% entre as metodologias.

Além disso, foi possível observar que as incertezas combinadas não variam significativamente entre as três metodologias. Foi possível verificar também que a fonte de incerteza do Tipo A, que leva em consideração o número de medições da taxa de kerma no ar, não contribui significativamente para o aumento da incerteza.

A fonte de incerteza do Tipo $B$, que maior contribui para incerteza combinada, é a exatidão do monitor da câmara de ionização. Deve-se levar em consideração que a exatidão do monitor da câmara de ionização considerada nos cálculos foi de 4 \%, valor máximo apresentado pelo fabricante do instrumento.

Não foi possível calcular o número de graus de liberdade efetivo no caso do método do somatório de exponenciais e do método do modelo de Archer, uma vez que são funções ajustadas. Desta forma, as estimativas das incertezas dos três métodos avaliados foram apresentadas no nível de confiança de $68 \%$ para que pudessem ser comparados.

A análise da reprodutibilidade da espessura equivalente de atenuação apresentada pelos diferentes fabricantes mostrou que o Fabricante D apresenta a maior faixa de variação entre os valores declarados e medidos, ou seja, as amostras do Fabricante D, quando comparadas às amostras dos outros quatro fabricantes, mostraram-se menos uniformes. Os resultados obtidos no re-teste do Fabricante D mostraram que, após a troca da borracha plumbífera, as espessuras equivalentes de atenuação estão mais reprodutíveis.

$\mathrm{Na}$ avaliação do percentual de transmissão foram obtidas diferenças na transmissão entre os aventais de mesma equivalência nominal, porém pertencentes a 
diferentes fabricantes. As amostras do Fabricante A, por exemplo, foram as menos eficientes; esta diminuição da atenuação diminui a proteção ao usuário.

A determinação da inomogeneidade dos dispositivos de proteção mostrou que os materiais atenuadores dos dispositivos de proteção dos Fabricantes $D$ e E são os menos homogêneos. Pôde-se perceber uma diminuição dos valores da inomogeneidade apresentados pelas amostras do Fabricante D após a troca do fornecedor de borracha plumbífera.

Os ensaios relacionados com as características de confecção dos aventais de proteção mostraram que a principal confusão na classificação foi com relação à categoria fechada, uma vez que os fabricantes confundiam a classificação fechada com proteção nas costas. Todos os aventais deveriam ter pelo menos $15 \mathrm{~cm}$ de proteção nas costas e na maior parte das vezes, se o avental tinha proteção nas costas, ele era classificado como avental de proteção fechado. Além disso, os aventais do tipo fechado eram confundidos com aventais pesados.

Os tamanhos medidos do comprimento e largura dos aventais, por exemplo, estavam, na maioria dos casos, menores que os valores declarados. Com isso, uma região menor do corpo é protegida da radiação-X. Outro problema é que como os aventais estavam com dimensões abaixo dos valores mínimos, não era possível classificá-los em nenhum dos tamanhos previstos na Tabela 67.

Inicialmente, nenhum avental de proteção analisado estava em conformidade com todos os requisitos da norma. O Fabricante $D$ fez algumas modificações nos aventais de proteção. Estas modificações diminuíram a diferença entre a espessura equivalente de atenuação declarada e a calculada. Além disso, um modelo do Fabricante $\mathrm{D}$ apresentou conformidade com todos os requisitos da norma. 


\section{CONCLUSÕES}

Este trabalho contribui diretamente para as atividades da Seção Técnica de Desenvolvimento de Tecnologia em Saúde, uma vez que este laboratório poderá optar por uma das três metodologias estudadas na rotina dos ensaios para verificação das propriedades de atenuação dos dispositivos de proteção radiológica. Além disso, neste trabalho foi desenvolvido um procedimento para avaliação das características de confecção dos aventais de proteção que já está sendo utilizado na rotina do laboratório.

O método do somatório de exponenciais, apesar de ser o que apresentou menores incertezas nos resultados, é o mais trabalhoso, dificultando a rotina do laboratório, pois além de se ter que gerar duas vezes os parâmetros de ajuste como no modelo de Archer, os valores da espessura têm que ser substituídos um a um até que a taxa de kerma no ar calculada seja igual à taxa de kerma no ar transmitida pelo dispositivo de proteção.

Dos três métodos analisados, o método da interpolação linear foi o método mais prático, uma vez que por meio de funções do aplicativo Excel é possível se obter facilmente os parâmetros necessários para o cálculo.

Cada fabricante recebeu um relatório detalhando as suas não-conformidades com cada requisito da norma NBR / IEC 61331-3 ${ }^{15}$. Neste relatório também foi apresentado o valor da espessura equivalente de atenuação em 100 kV obtido pelo método da interpolação linear. Este relatório serve como um guia para os fabricantes que têm interesse em certificar seus dispositivos.

Os resultados da determinação da espessura equivalente de atenuação dos aventais de proteção do Fabricante $D$ foram os que apresentaram a maior variação entre os valores declarados e medidos. Além disso, observou-se uma grande variação entre os valores da espessura equivalente de atenuação calculada para aventais de proteção com o mesmo valor declarado. Observou-se melhoria nos resultados do re-teste após a troca do fornecedor do material atenuador utilizado na confecção dos dispositivos.

A discrepância entre os resultados apresentados neste trabalho e as exigências das normas estudadas mostra a necessidade de tornar compulsória a certificação dos dispositivos de proteção, contribuindo assim para o aumento da proteção radiológica do usuário. 


\section{REFERÊNCIAS BIBLIOGRÁFICAS}

1 KUON, E., SCHMITT, M., DAHM, J. B. Significant reduction of radiation exposure to operator and staff during cardiac interventions by analysis of radiation leakage and improved lead shielding. The American Journal of Cardiology, v. 89, n. 1, p. 44-49, 2002.

2 HUBBERT, T. E., VUCICH, J. J., ARMSTRONG, M. R. Lightweight aprons for protection against scattered radiation during fluoroscopy. American Journal of Roentgenology, v. 161 , p. $1079-1081,1993$.

3 MURPHY, P. H.; WU, Y.; GLAZE, S. A. Attenuation properties of lead composite aprons. Radiology, v. 186, p. 269-272, 1993.

4 MUIR, S., McLEOD, R., DOVE, R. Light-weight lead aprons - light on weight, protection or labelling accuracy?. Australasian Physical \& Engineering Sciences in Medicine, v. 28, n. 2, p. 1-3, 2005.

5 GLAZE, S.; LE BLANC, A. D.; BUSHONG, S. C. Defects in new aprons. Radiology, v. 152, 217-218, 1984.

6 LAMBERT, K.; McKEON, T. Inspection of lead aprons: criteria for rejection. Health Physics, v. 80, S67-69, 2001.

7 CHRISTODOULOU, E. G.; GOODSITT, M. M.; LARSON, S. C.; DARNER, K. L.; SATTI, J.; $\mathrm{CHAN}, \mathrm{H}$. P. Evaluation of the transmitted exposure through lead equivalent aprons used in a radiology department, including the contribution from backscatter. Medical Physics, v. 30, n. 6, p. 1033-1038, 2003.

8 FINNERTY, M. BRENNAM, P. C. Protective aprons in imaging departments: manufacturer stated lead equivalence values require validation. European Radiology, v. 15, p.1477-1484, 2005.

9 ARCHER, B. R.; FEWELL, T. R.; CONWAY, B. J.; QUINN, P. W. Attenuation properties of diagnostic x-ray shielding materials. Medical Physics, v. 21, n. 9, p. 1499-1507, 1994.

10 ROSSI, R. P.; RITENOUR R.; CHRISTODOULOU, E. Broad beam transmission properties of some common shielding materials for use in diagnostic radiology. Health Physics, v. 61, n. 5, p. 601-608, 1991.

11 DIXON, R.L.; SIMPKIN, D. J. Primary shielding barriers for diagnostic x-ray facilities: a new model. Health Physics, v. 74, n. 2, p. 181-189, 1998.

12 COSTA, P. R.; CALDAS, L. V. E. Evaluation of protective shielding thickness for diagnostic radiology rooms: Theory and computer simulation. Medical Physics, v. 29, n. 1, p. 73-85, 2002.

13 ASSOCIAÇÃO BRASILEIRA DE NORMAS TÉCNICAS. Dispositivos de proteção contra radiação-x para fins de diagnóstico médico. Parte 1: Determinação das propriedades de atenuação de materiais. Rio de Janeiro: ABNT, 2004. (ABNT NBR / IEC 61331-1). 
14 ASSOCIAÇÃO BRASILEIRA DE NORMAS TÉCNICAS. Dispositivos de proteção contra radiação-x para fins de diagnóstico médico. Parte 2: Placas de vidro para proteção radiológica. Rio de Janeiro: ABNT, 2004. (ABNT NBR / IEC 61331-2).

15 ASSOCIAÇÃO BRASILEIRA DE NORMAS TÉCNICAS. Dispositivos de proteção contra radiação-x para fins de diagnóstico médico. Parte 3: Vestimentas de proteção e dispositivos de proteção para gônadas. Rio de Janeiro: ABNT, 2004. (ABNT NBR / IEC 61331-3).

16 ASSOCIAÇÃO BRASILEIRA DE NORMAS TÉCNICAS. Segurança e desempenho de equipamento elétrico para radiologia médica - Terminologia. Rio de Janeiro: ABNT, 1995.

17 SPRAWLS, P. Jr. Physical Principles of Medical Imaging. 2. ed. Gaithersburg: Aspen Publishers, 1993.

18 DOWN, S. B., TILSON, E. R. Pratical radiation protection and applied radiobiology. 2. ed. Philadelphia: W. B. Saunders Company, 1999.

19 SHERER, M. A. S., VISCONTI, P. J., RITENOUR, E. R. Radiation Protection in Medical Radiography. 4. ed. St. Louis: Mosby, 2002.

20 INTERNATIONAL COMMISSION ON RADIATION UNITS AND MEASUREMENTS. Fundamental quantities and units for ionizing radiation.

21 MINISTÉRIO DA SAÚDE. Portaria SVS MS 453: Diretrizes de proteção radiológica em radiodiagnóstico médico e odontológico do Ministério da Saúde. Diário Oficial da União. Brasília, de 02 de junho de 1998.

22 THEOCHAROPOULOS, N., PERSINAKIS, K., DAMILAKIS, J., PAPADOKOSTAKIS, G., HADJIPAVLOU, A., GOURTSOYIANNIS, N. Occupational exposure from common fluoroscopic projections used in orthopaedic surgery. The Journal of Bone and Joint Surgery. v. 85, p. 1698-1703, 2003.

23 MINISTER OF SUPLY AND SERVICES CANADA. Radiation protection in veterinary medicine: recommended safety procedures for installation and use of veterinary X-ray equipment. Safety Code 28. Canada, 1991.

24 RADIATION SAFETY PROGRAM - DEPARTMENT OF HUMAN SERVICES. Information for veterinary surgeons using $X$-ray equipment. Victoria. Disponível em <www.health.vic.gov.au/environment/downloads/vetxray.pdf>. Acesso em 31/08/2006.

25 ASSOCIAÇÃO BRASILEIRA DE NORMAS TÉCNICAS; INSTITUTO NACIONAL DE METROLOGIA, NORMALIZAÇÃO E QUALIDADE INDUSTRIAL. Guia para a expressão da incerteza de medição. 3.ed. Rio de Janeiro: ABNT, INMETRO, 2003.

26 FUNDAÇÃO CERTI. Apostila do curso: Incerteza de medição. São Paulo, junho / 2004.

27 NERSISSIAN, D. Y. Determinação das dimensões do ponto focal de tubos de raios $\mathbf{X}$ utilizando um sensor CCD e o método das funções de transferência. 2004. Tese (Doutorado) - Instituto de Pesquisas Energéticas e Nucleares, Universidade de São Paulo, São Paulo. 
28 RADCAL CORPORATION. Model 9015 radiation monitor controller - manual. Monrovia, CA, 2005.

29 GREGORY, K. J., PATTISON, H. E., BIBBO, G. Uncertainties of exposure-related quantities in mammographic x-ray unit quality control. Medical Physics, v. 33, n. 3, p. 687-698, 2006.

$30 \mathrm{FRIMAIO}, \mathrm{A}$. Desenvolvimento de um material cerâmico para utilização em proteção radiológica diagnóstica. 2006. Dissertação (Mestrado) - Instituto de Pesquisas Energéticas e Nucleares, Universidade de São Paulo, São Paulo.

31 TSALAFOUTAS, A., YAKOUMAKIS, E., MANETOU, A., FLIONI-VYZA, A. The diagnostic $X$-ray protection characteristics of Ytong, an aerated concrete based building material. The British Journal of Radiology, v.71, p. 994-949, 1998.

32 NATIONAL COUNCIL ON RADIATION PROTECTION AND MEASUREMENTS. Structural Shielding design for medical X-ray facilities. Bethesda, 2004 (NCRP Report ํㅜ 147).

33 HELENE, O. A. M., VANIN, V. R. Tratamento estatístico de dados em física experimental. São Paulo: Ed. Edgard Blücher Ltda, 1981.

34 GUIMARÃES, C. C. Monitoração individual externa: experimentos e simulações com o método de Monte Carlo. 2005. Tese (Doutorado) - Instituto de Física, Universidade de São Paulo, São Paulo. 